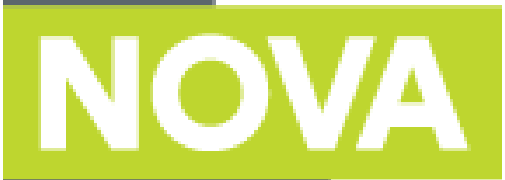

IMS

Information

Management

School
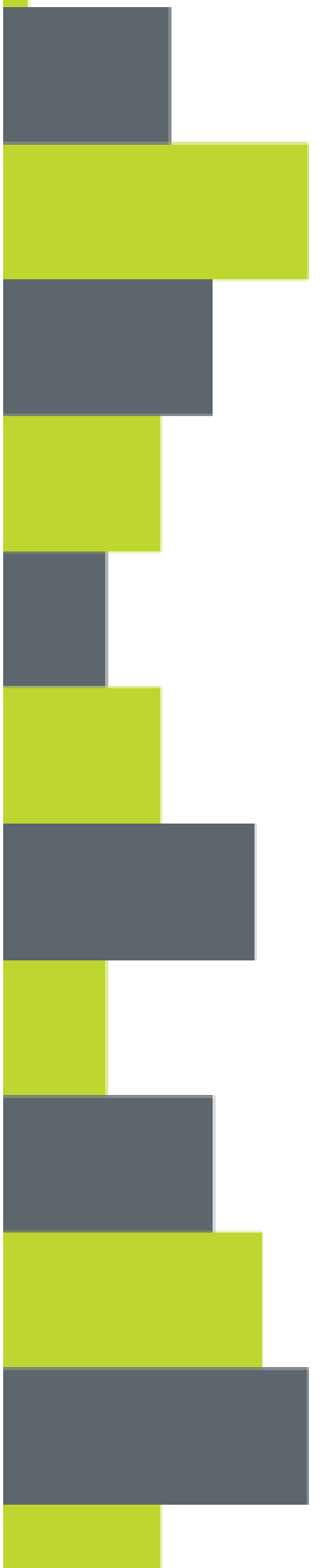

\section{Information Management \\ Specialization in Geographic Information Systems}

Determinants of information and communication technologies for the online citizen participation adoption in urban contexts

Mijail Juanovich Naranjo Zolotov, MSc

A thesis submitted in partial fulfillment of the requirements for the degree of Doctor in Information Management

August 2018

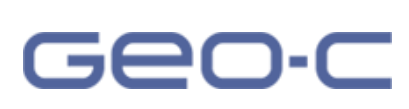

Joint Doctorate in Geoinformatics: Enabling Open Cities

NOVA Information Management School (IMS)

Universidade Nova de Lisboa 


\title{
Determinants of information and communication technologies for the online citizen participation adoption in urban contexts
}

\author{
Supervised by: \\ Professor Doctor Tiago André Gonçalves Félix de Oliveira \\ Co-supervised by: \\ Professor Doctor Christian Kray \\ Professor Doctor Sven Casteleyn
}

2018 
Copyright (C) by

Mijail Juanovich Naranjo Zolotov

All rights reserved

III | P a g e 


\begin{abstract}
The electronic citizen participation (e-participation) is considered a branch of e-government with a focus on citizen involvement in information, consultation, and decision-making processes along with local governments. E-participation is considered an important pillar to support an inclusive and participative democracy. Governments all around the world, mainly local governments, are implementing different e-participation tools, for instance, online participatory budgeting, e-petitions, online incident reporting systems, online forums, etc. The potential benefits for the society of citizens engagement in the use of e-participation is widely agreed in the literature. However, the drivers of the e-participation adoption by the citizens are still on an exploratory stage in existing research. The understanding of the e-participation adoption factors is of a crucial importance for defining governmental strategies that pursue the citizen participatory engagement.
\end{abstract}

This thesis contributes to a better understanding of the determinants of e-participation adoption in the urban contexts at individual level. The dissertation first carries out a review of the existing literature following a quantitative approach. Second, we developed three research models grounded in theories as unified theory of acceptance and use of technology (UTAUT), psychological empowerment, social capital, and sense of virtual community. Each model was evaluated in a cross-sectional experiment in two Portuguese cities that have implemented eparticipation tools. The analysis of each model and its results are analysed in detail in each of the sections of this dissertation. And finally, we propose two lines for future research, one focused on the citizens satisfaction with e-participation, and the other explores the inclusion of components from social geography. Furthermore, the findings from this dissertation also provide insights for local governments that implement e-participation tools.

The literature review of sixty quantitative studies published from the year 2000 to year 2017 revealed that the factors with stronger effect on the intention to use e-participation were the perceived usefulness, attitude, trust, trust in government, effort expectancy, and social influence. However, the most of these studies used a single theory of information systems to investigate e-participation, which may not uncover specific factors of the e-participation phenomenon. Moreover, the success of e-participation tools relies on the continuous usage over time. Understanding solely the drivers of intention to use in the short time does not guarantee the success in the long-term adoption. 
From the three research models presented in this dissertation, the first model focus on the study of the intention to use, usage, and intention to recommend e-participation. The last two focus on the continued intention to use e-participation. The first study develops a model that integrates the psychological empowerment, as second-order construct, and UTAUT to explain the intention to use and intention to recommend e-participation. We found that performance expectancy and empowerment were the stronger motivators of intention to use, and empowerment was the stronger driver for the citizens recommend the e-participation technologies. The second study evaluates the effect of each of the dimensions of empowerment plus habit on the continued intention to use e-participation. Results show that competence, meaning, and habit have a significant effect on the continuous intention. Multigroup analysis in this study revealed that the use of e-participation has stronger meaning for older participants. The third cross-sectional study integrates the sense of virtual community theory with constructs of UTAUT that have a direct effect on the usage behaviour, namely facilitating conditions and habit. We found that habit is a good predictor of use behaviour and continued intention, nevertheless, sense of virtual community resulted a good predictor of e-participation usage in the short term, but not significant on the continued intention to use over time.

Keywords: E-participation, E-government, PLS-SEM, UTAUT, Social capital, Empowerment, Sense of virtual community. 


\section{Graphical abstract}

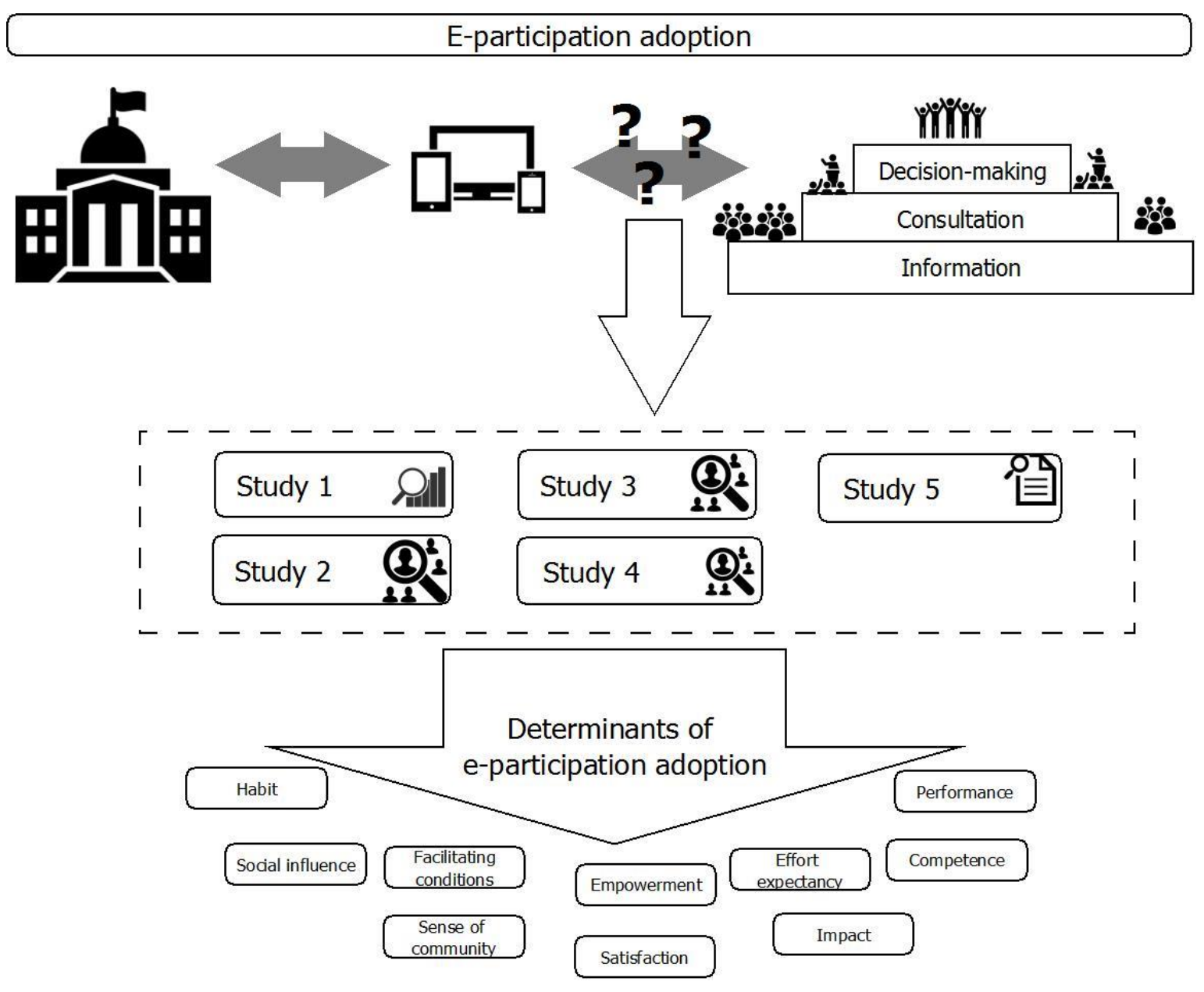




\section{Publications}

\section{Journal articles}

Naranjo Zolotov, M., Oliveira, T., \& Casteleyn, S. (2018). E-participation adoption models research in the last 17 years: A weight and meta-analytical review. Computers in Human Behavior, 81, 350-365. http://doi.org/10.1016/j.chb.2017.12.031

Naranjo-Zolotov, M., Oliveira, T., \& Casteleyn, S. (2018). Citizens' intention to use and recommend e-participation: Drawing upon UTAUT and citizen empowerment. Information Technology \& People. Accepted for publication. (Awarded as the Best Research Paper in the conference)

Naranjo-Zolotov, M., Oliveira, T., \& Casteleyn, S. (2018). Continuous usage of e-participation in the long term: The role of the sense of virtual community. (Submitted to a top journal in the area of information systems).

Acedo, A.; Oliveira, T.; Naranjo-Zolotov, M.; Painho, M. Place and city: Towards a geography of engagement. (Submitted to a top journal in the area of Geographical Information Science)

\section{Conference papers (Scopus indexed)}

Zolotov, M. N., Oliveira, T., \& Casteleyn, S. (2018). Continued intention to use online participatory budgeting: The effect of empowerment and habit. Proceedings of the 11th International Conference on Theory and Practice of Electronic Governance - ICEGOV'18, 209-216. http://doi.org/10.1145/3209415.3209461

Zolotov M.N., Oliveira T., Cruz-Jesus F., Martins J. (2018) Satisfaction with e-participation: A Model from the Citizen's Perspective, Expectations, and Affective Ties to the Place. In: Rocha Á., Adeli H., Reis L.P., Costanzo S. (eds) Trends and Advances in Information Systems and Technologies. WorldCIST'18 2018. Advances in Intelligent Systems and Computing, vol 745. Springer, Cham. 


\section{Acknowledgements}

To my lovely family, Mónica, my wife, and Nuno, my little child, for their everlasting patience and support for this journey, in which, much of time dedicated to this dissertation was a priceless time missed with my beloved ones.

To my parents, who encouraged me from the beginning to pursue a PhD degree. Even from abroad, always proud of me.

To Prof. Tiago Oliveira, main supervisor of this thesis, for all the guidance and good advice from the beginning and throughout the whole project.

To Prof. Sven Casteleyn, a co-supervisor of this thesis, for all the help and good advice to improve the quality of the articles that were published.

To Prof. Christian Kray, a co-supervisor of this thesis, for all his help during the external semester in the city of Muenster, Germany.

To the Municipality of Lisbon, for supporting me in my one-month internship where I could have a closer look at the participatory budgeting project.

We acknowledge the support of the "Geoinformatics: Enabling Open Cities (GEO-C)", the project funded by the European Commission within the Marie Skłodowska-Curie Actions, International Training Networks (ITN), and European Joint Doctorates (EJD). Grant Agreement number 642332 - GEO-C - H2020-MSCA-ITN-2014.

To all my sincere thanks. 


\section{Table of Contents}

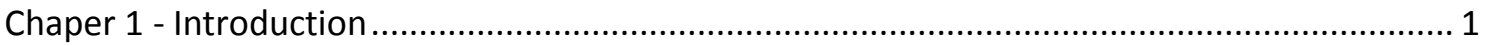

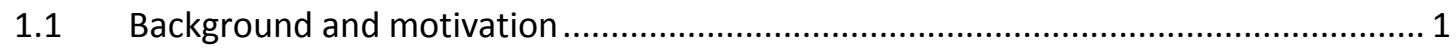

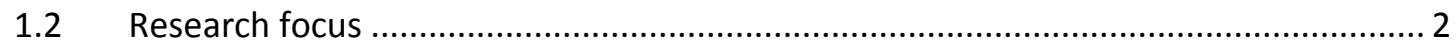

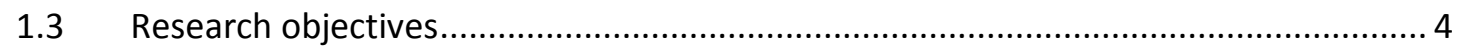

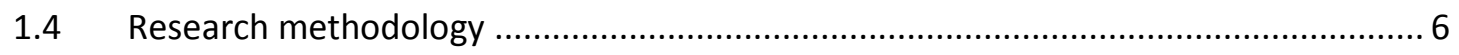

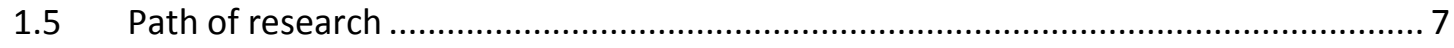

Chaper 2 - E-participation adoption models research in the last 17 years: A weight and

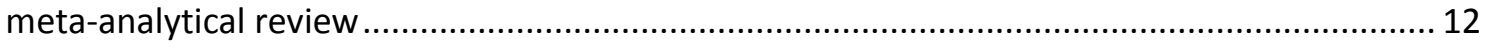

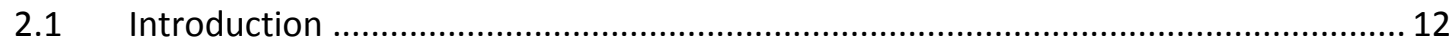

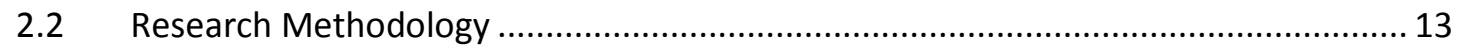

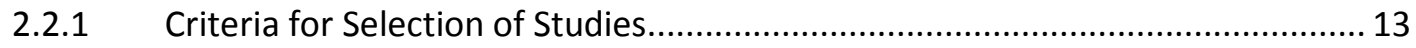

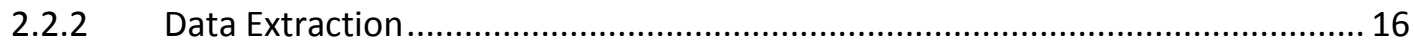

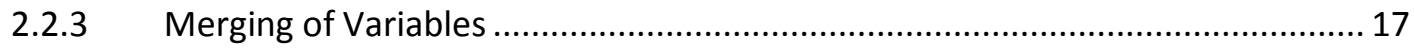

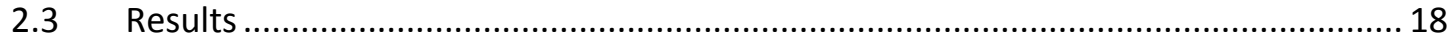

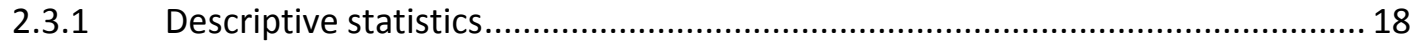

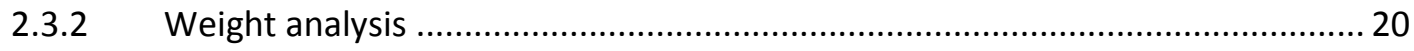

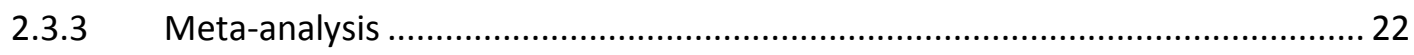

2.3.4 Evaluation of publication bias and normality................................................... 26

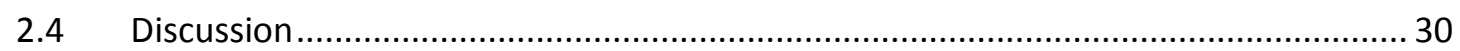

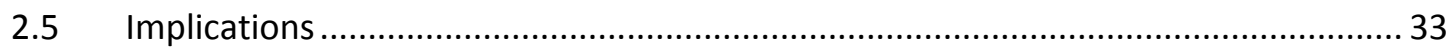

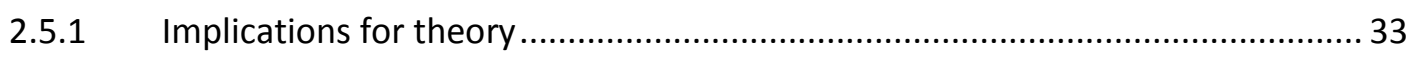

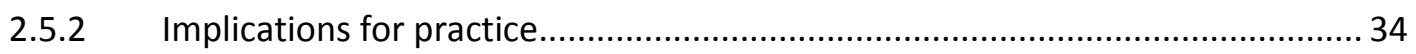

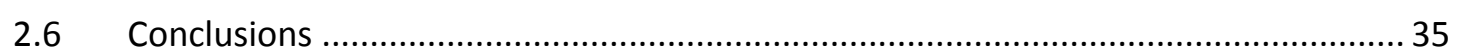

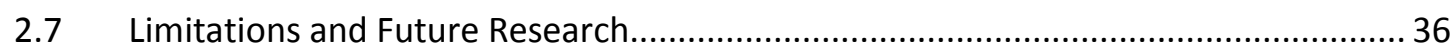

Chaper 3 - Citizen's intention to use and recommend e-participation: Drawing upon

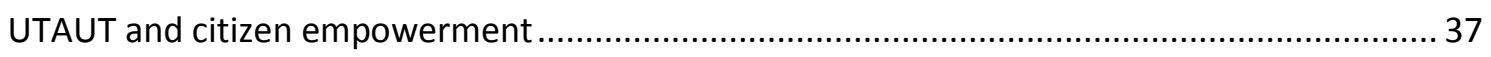

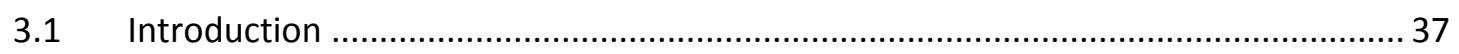

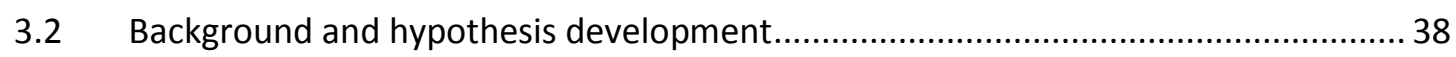

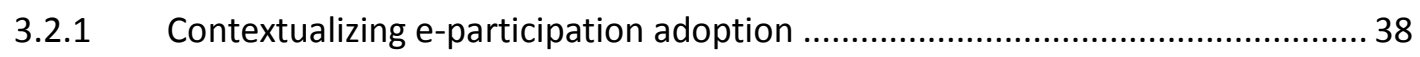

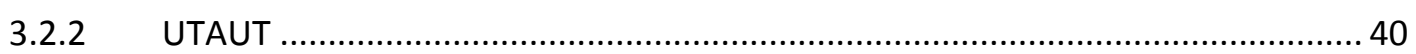

3.2.3 Recommending the use of e-participation...................................................... 42

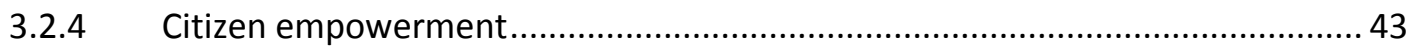

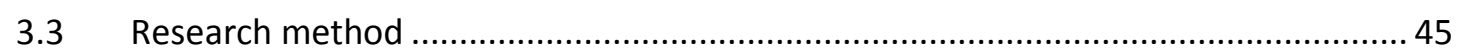




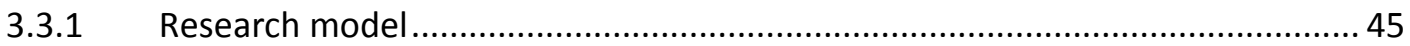

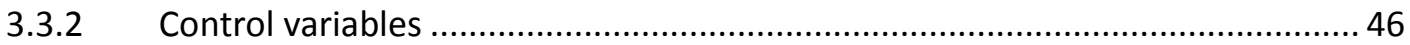

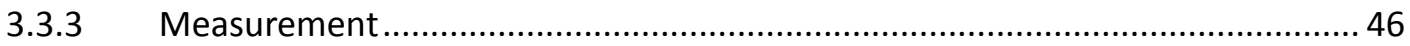

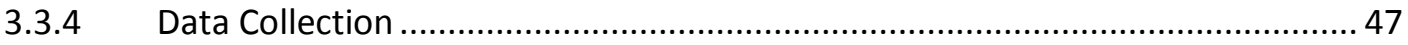

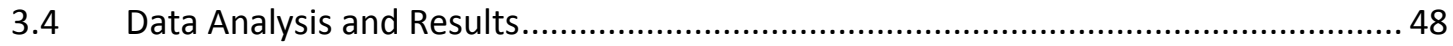

3.4.1 Exploratory factor analysis and model fit ........................................................ 49

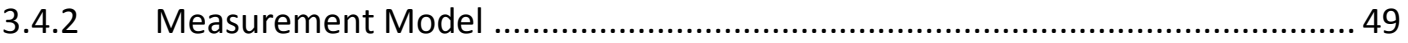

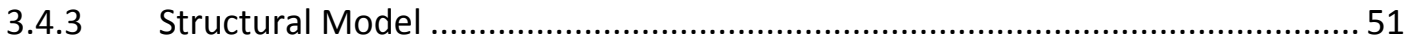

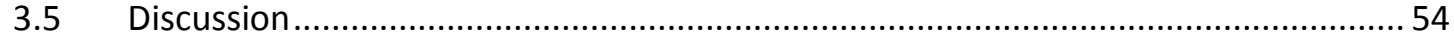

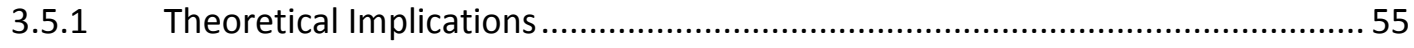

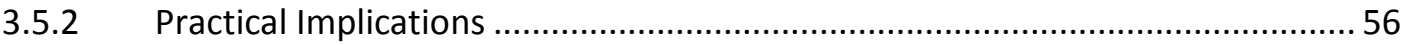

3.5.3 Limitations and Future Research.................................................................... 57

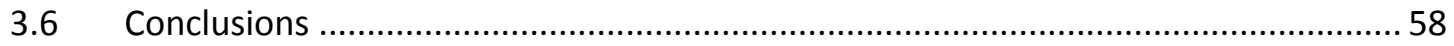

Chaper 4 - Continuous usage of e-participation in the long term: The role of the sense of

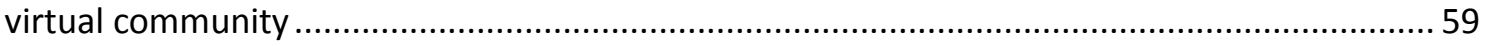

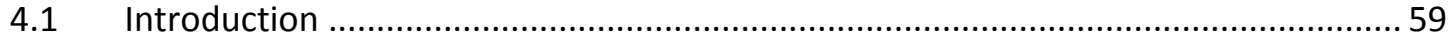

4.2 An overview of e-participation in the post-adoption stage .........................................6 60

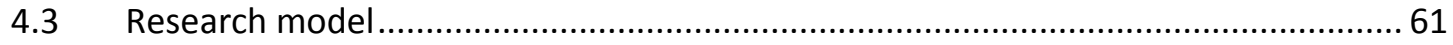

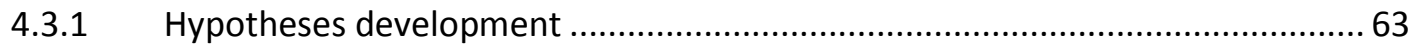

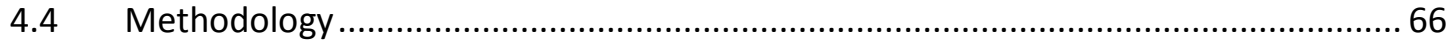

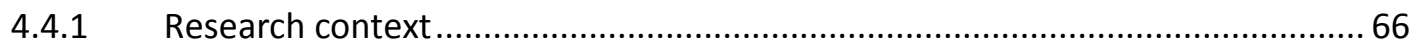

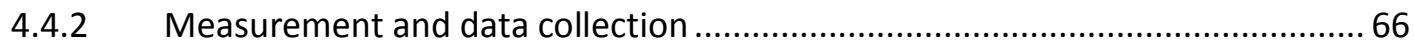

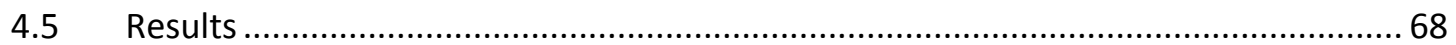

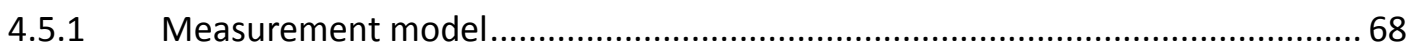

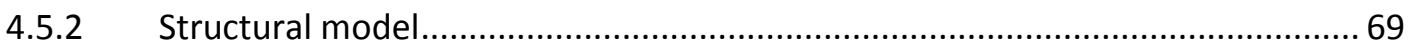

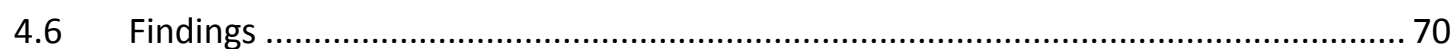

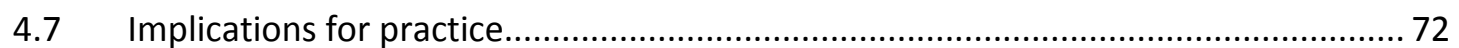

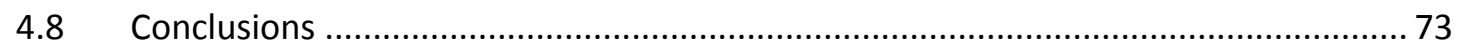

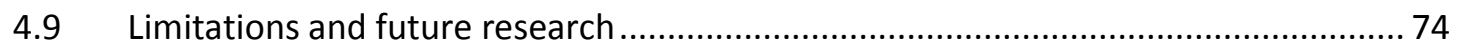

Chaper 5 - Continued intention to use online participatory budgeting: The effect of

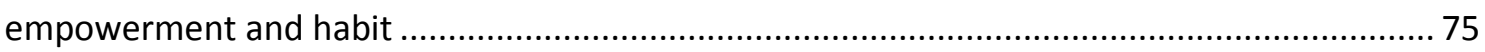

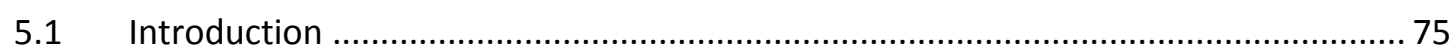

5.2 Online participatory budgeting in the city of Lisbon.................................................. 76

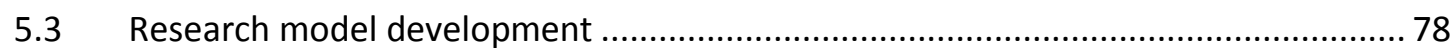

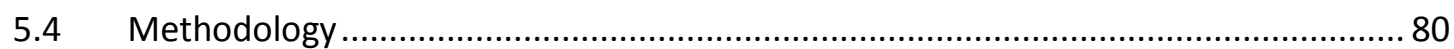




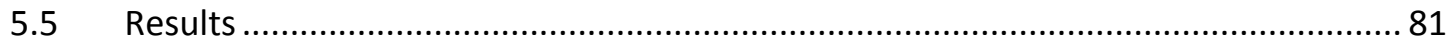

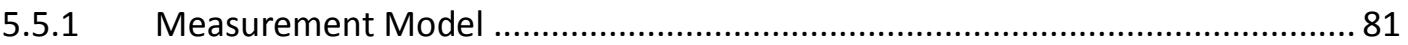

5.5.2 Structural Model and Multi-Group Analysis .................................................... 82

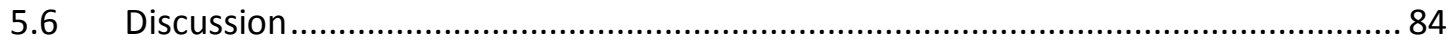

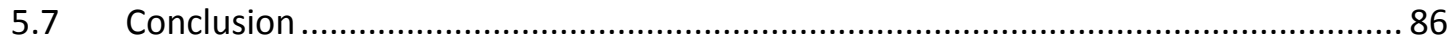

Chaper 6 - Satisfaction with e-participation: A model from the citizen's perspective,

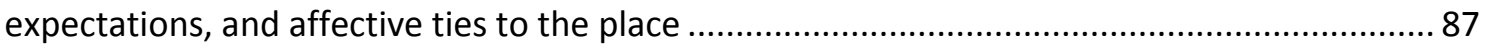

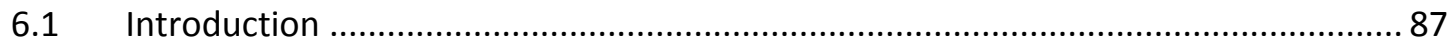

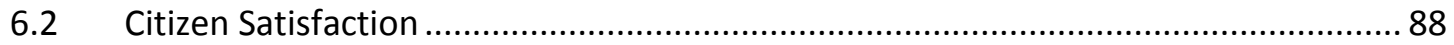

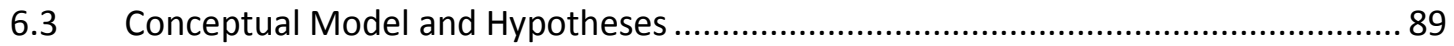

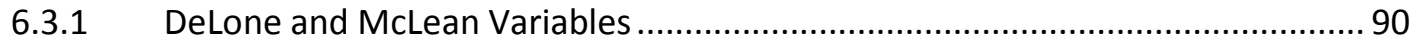

6.3.2 Expectation-Confirmation Variables ……........................................................ 92

6.3.3 Moderator Role of Sense of Place (SOP) ........................................................ 93

6.4 Implications and Future Research................................................................................ 94

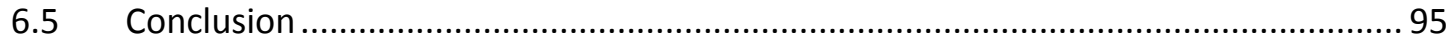

Chaper 7 - Place and City: Towards a geography of engagement ....................................... 97

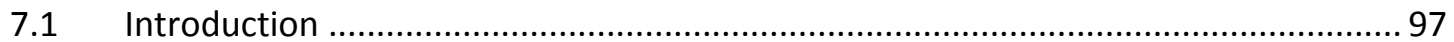

7.2 Theoretical background and hypotheses .................................................................... 99

7.2.1 Relating sense of place, social capital, and civic engagement .......................... 100

7.2.2 Relating sense of place, social capital, and civic engagement spatial dimensions 102

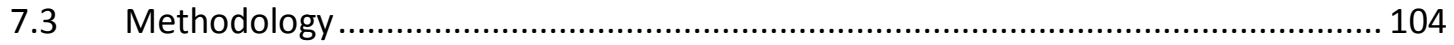

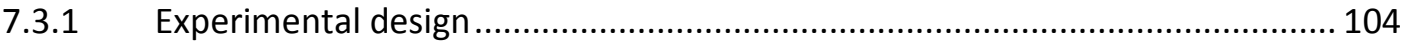

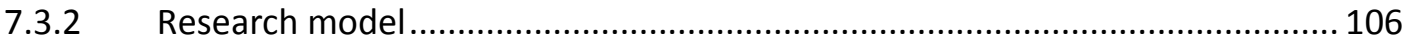

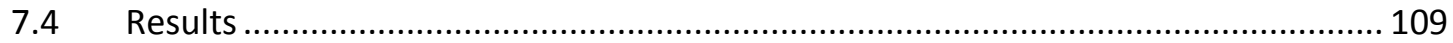

7.4.1 Data collection and measurement model ...................................................... 109

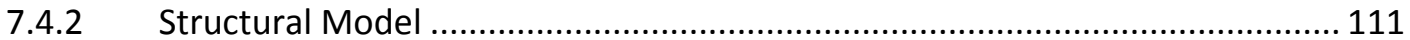

7.4.3 A geographical evaluation of the structural model........................................ 112

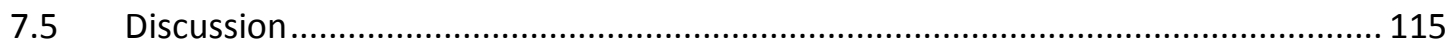

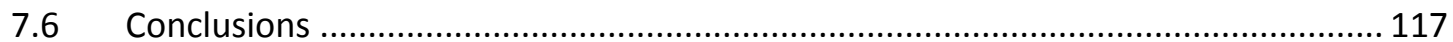

7.6.1 Notes to advance in the acquisition of the socio-spatial concepts................... 118

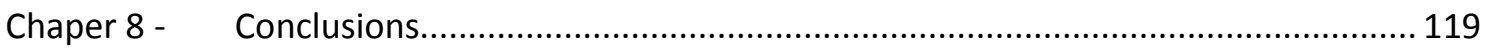

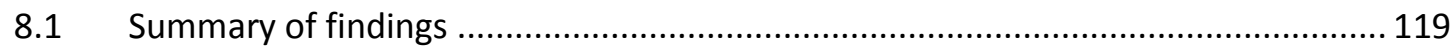

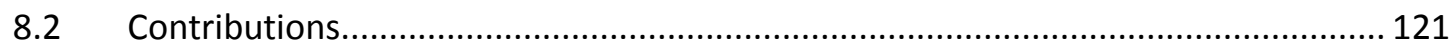

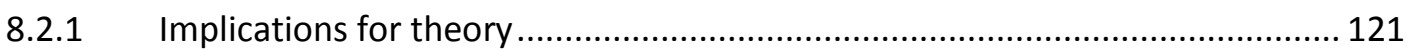




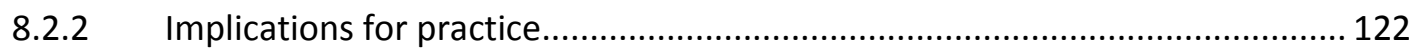

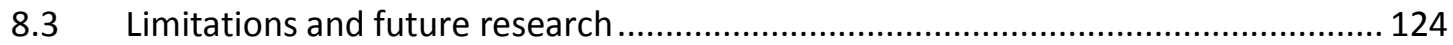

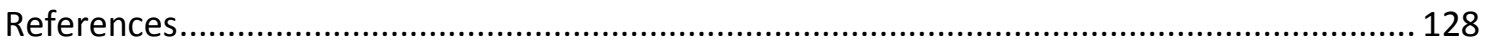

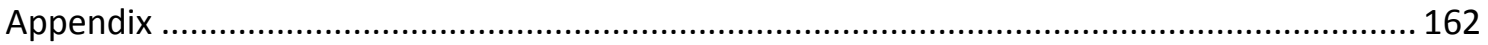

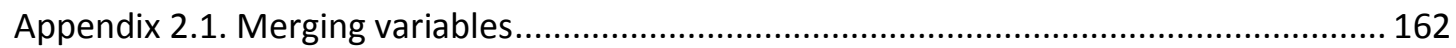

Appendix 3.1. Measurement Items and Factor's Loadings ................................................. 164

Appendix 3.2. Exploratory factor analysis results ............................................................... 165

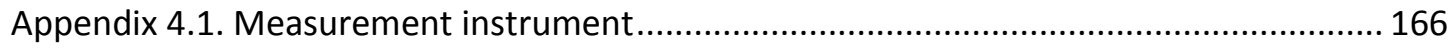

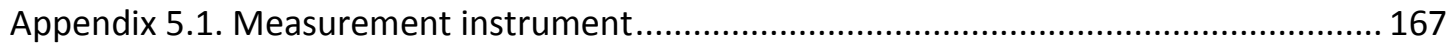

Appendix 7.1. Theoretical support for relationship between numbers in Figure 7.1........... 168

Appendix 7.2. Questions from the web map-based application ........................................... 169 


\section{List of Tables}

Table 1.1. Methodological approach summary 7

Table 1.2. Match chapter - research article 8

Table 2.1. Sets of keywords to query databases 14

Table 2.2. List of useful datasets in studies (ordered by publication year, author) 16

Table 2.3. Distribution of respondents by type (ordered by percentage) 18

Table 2.4. Respondents by country and year (ordered by country name) 19

Table 2.5. Weight analysis results (ordered by Frequency of use) 21

Table 2.6. Meta-analysis results (ordered by frequency) 24

Table 2.7. List of 17 articles that examined the relationship [perceived usefulness - intention to use] (ordered by year) 27

Table 2.8. Egger Regression for asymmetry 28

Table 2.9. Subgroup analysis of studies that examined [perceived usefulness - intention to use] 29

Table 3.1. Sample demographic characteristics (ordered by number of observations) 48

Table 3.2. Quality criteria 50

Table 3.3. Hetrotrait-Monotrait Ratio 50

Table 3.4. Measurement model evaluation for higher-order formative constructs 51

Table 3.5. Comparison of results 53

Table 3.6. Summary of hypotheses testing 54

Table 4.1. Demographic profile 67

Table 4.2. Assessment of measurement model 68

Table 4.3. Heterotrait-Monotrait Ratio (HTMT) 69

Table 4.4. Multicollinearity valuation for higher-order formative constructs 69

Table 5.1. Demographic profile 81

Table 5.2. Loadings and cross-loadings 82

Table 5.3. Correlation matrix and the square root of AVE (in bold) 82

Table 5.4. Multi-group analysis 84

Table 7.1. Research hypotheses 102

Table 7.2. Spatial hypotheses 104

Table 7.3. Demographics of the sample for this study 110

Table 7.4. Quality assessment (square root of AVE in bold) 111

Table 7.5. Higher-order formative constructs. Inner VIF values ( $N=119)$ 111 
Table 7.6. Structural model evaluation ( $\beta$ values) for the sample and related subsets 114

Table 7.7. R2 values for the sample and related subsets 114

Table 7.8. Summary about supported (y) and rejected $(n)$ hypothesis 114

Table 8.1. Relationships analysed in the quantitative studies 119 


\section{List of Figures}

Figure 1.1. Research focus___ 3

Figure 1.2. Research objectives by studies __ 5

Figure 2.1. Selection of studies _ـ 15

Figure 2.2. World distribution of the respondents analysed in the articles considered for this study _ 20

Figure 2.3. Resulting model based on TAM and UTAUT. Values represent weights, and the average $\beta$ -

values are in parentheses. Bold arrows represent the 'best' predictors__ 22

Figure 2.4. Forrest plot of Table 2.6 (Meta-analysis). Ordered by $\Sigma$ sample size descending __ 25

Figure 2.5. Model resulting from meta-analysis___ 26

Figure 2.6. Funnel plot of studies that examined [perceived usefulness - intention to use] __ 28

Figure 2.7. Forest plot of the 17 articles that examined [perceived usefulness - intention to use]. Ordered by sample size descending

Figure 2.8. Normal quantile plot for the studies that examine [perceived usefulness - intention to use] 30

Figure 3.1.Research model 45

Figure 3.2. Structural model results 52

Figure 4.1. Research model and hypotheses __ 62

Figure 4.2. Structural model results _ـ 70

Figure 4.3. Moderating effect of SOVC between technology use and continuous intention to use __ 72

Figure 5.1. Voting in the Lisbon participatory budgeting. (Data from: www.lisboaparticipa.pt) ___ 77

Figure 5.2. Research model and hypotheses __ 79

Figure 5.3. Structural model results by groups___ 83

Figure 6.1. Conceptual model __ 90

Figure 7.1. Relationships between sense of place and social capital dimensions toward civic engagement

Figure 7.2. Schema of the application flow___ 106

Figure 7.3. Research model __ 107

Figure 7.4. Spatial relationships between the three constructors: sense of place, social capital, and civic engagement. 108

Figure 7.5. Structural model results __ 112

Figure 7.6. Spatial relationships results. Discontinuous lines mean statistically not significant. ___ 113 


\section{List of abbreviations and acronyms}

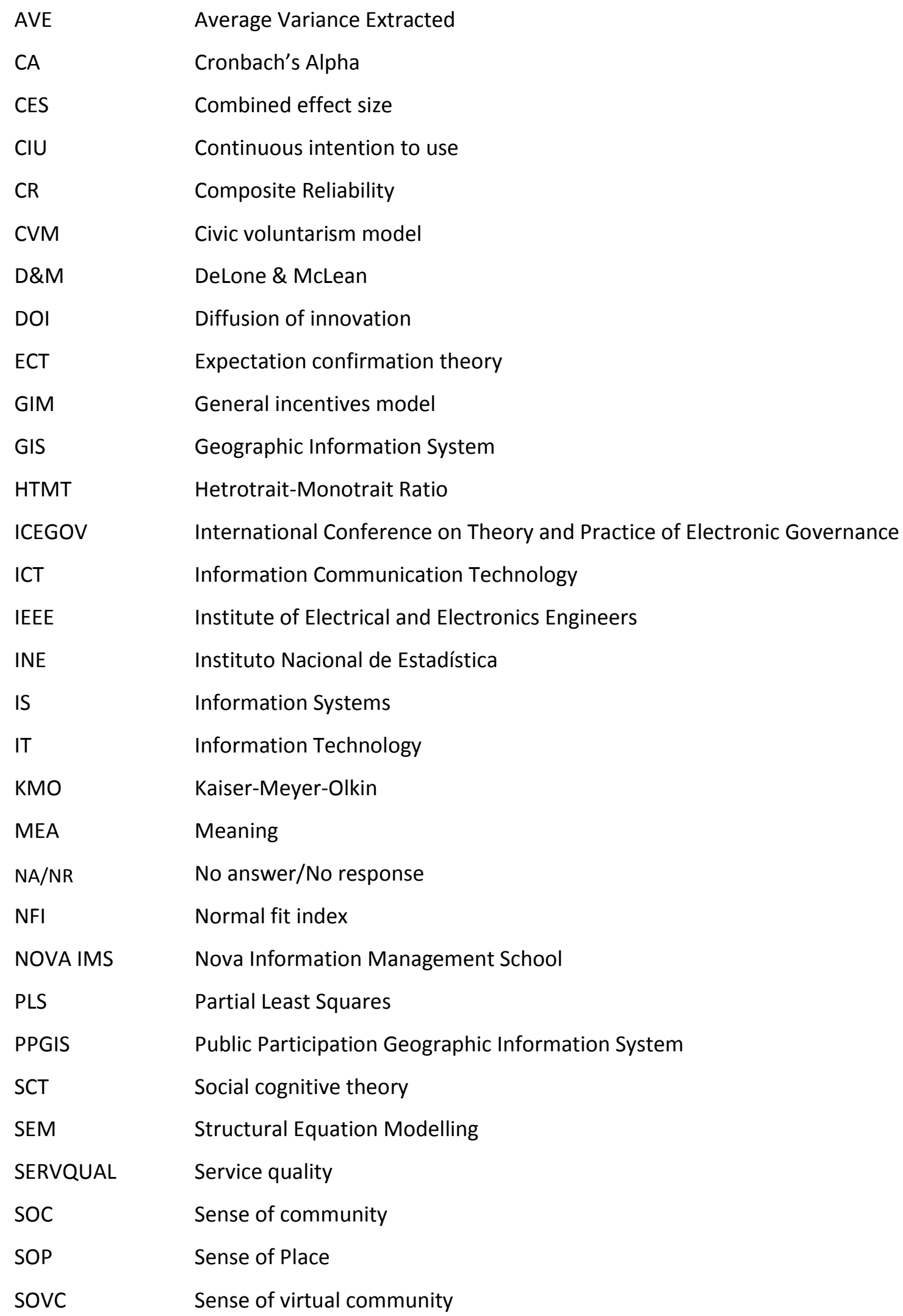


SRMR

TAM

TPB

TRA

UTAUT

VIF
Root mean square residual

Technology Acceptance Model

Theory of Planned Behaviour

Theory of Reasoned Action

Unified Theory of Acceptance and Use of Technology

Variance inflation factor 


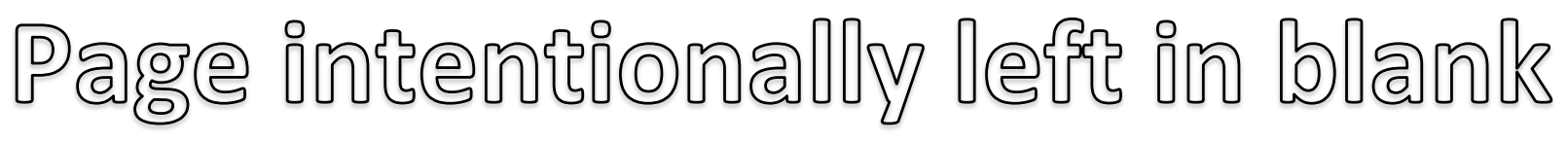




\section{Chaper 1 - Introduction}

\subsection{Background and motivation}

E-participation has received different definitions in the literature. United Nations (2014) define e-participation as "the process of engaging citizens through ICTs [Information and Communication Technologies] in policy and decision-making in order to make public administration participatory, inclusive, collaborative and deliberative for intrinsic and instrumental ends". Welch (2012) defines e-participation as a branch of e-government with special focus on citizen engagement for deliberation and decision orientation and (Macintosh \& Whyte, 2008) describes e-participation as the use of Information and Communication Technologies to support "top-down" engagement and empower citizens and civil society organizations. The successful engagement of citizens in the use of e-participation in the long term scenario may bring important benefits for the society, as increasing the levels of inclusiveness, transparency, efficiency, quality of public services, and even the reduction of costs in consultation and decision-making processes (Royo \& Yetano, 2015; Sæb $\varnothing$, Rose, \& Skiftenes Flak, 2008; Vragov \& Kumar, 2013).

E-participation is described in three-level model: e-information, e-consultation, and edecision-making (United Nations, 2014). Thus moving from "passive" to "active" engagement with citizens (Kassen, 2017). The implementation of e-participation towards consultation and decision-making is continuously growing in all regions of the world. As evidenced in the United Nations report (2018), the number of countries that reached a very-high e-participation index (EPI) have doubled from 31 to 62 in the last 2 years. In Europe, the number of countries with portals with e-tools for public consultation and deliberation increased from 28 in 2016 to 39 in 2018 , and in Africa, the number of countries that had no online engagement tools dropped from 21 in 2016 to 2 in 2018. However, despite the progress made in the terms of development of eparticipation tools, there are two serious challenges that remain unsolved: (1) even though the implementation of e-consultation tools (second level of e-participation) have made progress in the last years, the progress in e-decision-making (third level of e-participation) is rather limited. And (2) as e-participation is oriented to a long term usage, it is still very vulnerable to failure due to the risk of low adoption rates by the citizens (Kersting, 2016; Omar, Weerakkody, \& Sivarajah, 2017). Therefore, a better understanding of the drivers that affect the adoption of e- 
participation by the citizens is crucial for the governments that implement e-participation tools. The literature does not provide a strong theoretical basis to support successful implementations and adoption of e-participation.

Existing literature presents several research gaps that this dissertation contributes filling out. First, there is a lack of comparative studies analysing e-participation; instead, the body of research mainly consists of isolated case studies (Kubicek \& Aichholzer, 2016). Second, the most of studies that examined the drivers of the e-participation adoption have used research models in the context of information technology (Naranjo Zolotov, Oliveira, \& Casteleyn, 2018). Using single models of information technology adoption may not provide a strong theoretical basis of the general factors that drive the adoption of an interdisciplinary and highly dynamic phenomenon as is the e-participation (Medaglia, 2012; Susha \& Grönlund, 2012). For instance, Wang \& Shih (2009) analysed the adoption of information kiosks using UTAUT, Choi \& Kim (2012) studied the intention to use e-voting using the technology acceptance model (TAM) (Davis, 1989). The single-theory model's approach provides little insights into the information technology exogenous and individual elements that may help to explain e-participation usage. Using technology adoption models alone may not be enough if we wish to analyse the specific characteristics of e-participation. In this regard, Venkatesh et al. (2016) suggest that "it is necessary to draw on other theoretical perspectives to identify and examine specific characteristics" of e-participation. And third, the successful adoption and usage of eparticipation in the short term does not guarantee the success in the long term, which is the desired scenario for implementations of e-participation. This dissertation also examines the factors for both the intention to use and the continuous intention to use e-participation.

\subsection{Research focus}

E-participation tools are usually implemented and host by governments, mainly local, and oriented to be adopted by the citizenry. The exploration and understanding of the factors, technological and non-technological, that impact on the acceptance and post-acceptance stage of e-participation is the focus of the dissertation. Specifically, we study the potential factors, at individual level, that may help to explain the behavioural intention to use and use at the acceptance stage, and the intention to recommend and continuous intention to use at the postacceptance stage. See Figure 1.1. This dissertation contributes to answer the question of what are the main determinants factors of information and communication technologies (ICT) of the e-participation adoption? 


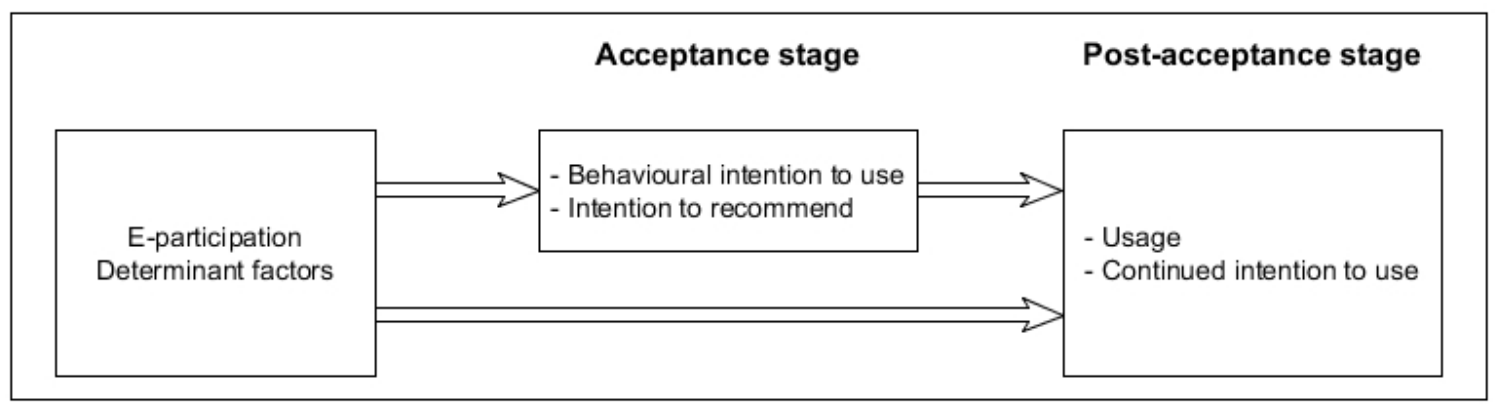

Figure 1.1. Research focus

The phenomenon of e-participation has unique characteristics that differentiate it from other e-government systems, (i) the highest level of e-participation is the involvement of a significant number of citizens in the decision-making process along with authorities (United Nations, 2014), (ii) the usage of e-participation is oriented to produce an impact on the community (Talò, Mannarini, \& Rochira, 2014), and (iii) is designed to be used in the long term scenario to produce the desired outcomes for the community (Zhao, Lu, Wang, Chau, \& Zhang, 2012). Consequently, in order to provide better insights on the e-participation adoption drivers, this phenomenon should be studied from different theoretical perspectives (Venkatesh et al., 2016), different contexts, and different samples. In this regard, we used theories from the information systems field, as is the unified theory of acceptance and use of technology - UTAUT (Venkatesh, Morris, Davis, \& Davis, 2003), in combination with theories from the cognitive psychology field, as the psychological empowerment (Zimmerman, 1995) and sense of virtual community (Koh \& Kim, 2003), and differences at individual level as age and gender to understand better the adoption of e-participation.

UTAUT is a theoretical model that has been widely used in the study of technology acceptance and adoption. UTAUT is an appropriate theory to study e-participation adoption for three main reasons: first, according to Venkatesh et al. (2003), UTAUT is suitable to study complex organizational technologies. E-participation can be considered a complex technological context due to the number of different tools available (Sæbø et al., 2008), different types and amounts of data generated by the citizens, stakeholders with diverse interests, and two-way government-citizen interactions in which citizens usually expect to receive feedback for their actions. These factors make a complex research scenario in which UTAUT can be appropriate to 
examine the behavioural intention to use the e-participation, which has been suggested as the main predictor of human behaviour (JinKyu Lee \& Rao, 2009).

Empowerment has been described as the highest expression of participation (Macintosh, 2004). Earlier studies have found that several activities such as consulting, exchange of opinions, and involving citizens in decision-making processes increase the intention to participate in e-government initiatives (Bataineh \& Abu-Shanab, 2016; Phang \& Kankanhalli, 2008). Furthermore, Kang (2014) found empowerment to be a key dimension for public engagement, which may lead to positive recommendations. These findings suggest that the psychological empowerment theory may contribute to theoretical knowledge in the field of eparticipation, specifically, to understand its pre- and post-adoption behaviour.

One of the goals of using e-participation is to involve citizens in consultation and decision-making process that have an impact on the community they belong to or to which they have some affective ties. Existing literature provides evidence to support the belief that citizens who are involved in different forms of civic engagement and community activities also show high levels of sense of community (Peterson, Speer, \& McMillan, 2008; Talò et al., 2014).

The implementation of e-participation systems by local governments has been proven to increase the level of citizen satisfaction (Ahn \& Bretschneider, 2011), and in turn, citizen satisfaction positively impacts the level of trust in government (Christensen \& Lægreid, 2005; Welch, Hinnant, \& Moon, 2005). In the case of e-participation, which is used voluntarily (Medaglia, 2012), the perception of satisfaction may differ from other systems because the final perceived outcomes and benefits for the community are influenced directly by the interactions of the citizens with the e-participation.

\subsection{Research objectives}

The main objective of our research is to explore and understand better the factors that drive the adoption of e-participation technologies in the urban contexts. In order to achieve that main objective, we divided our research in five different sub-objectives that are developed each one in a separate study, each study is presented in this dissertation as a separate chapter. Error! $\mathbf{R}$ eference source not found.Figure 1.2 depicts how the five studies contribute to the understanding of the e-participation adoption factors. 


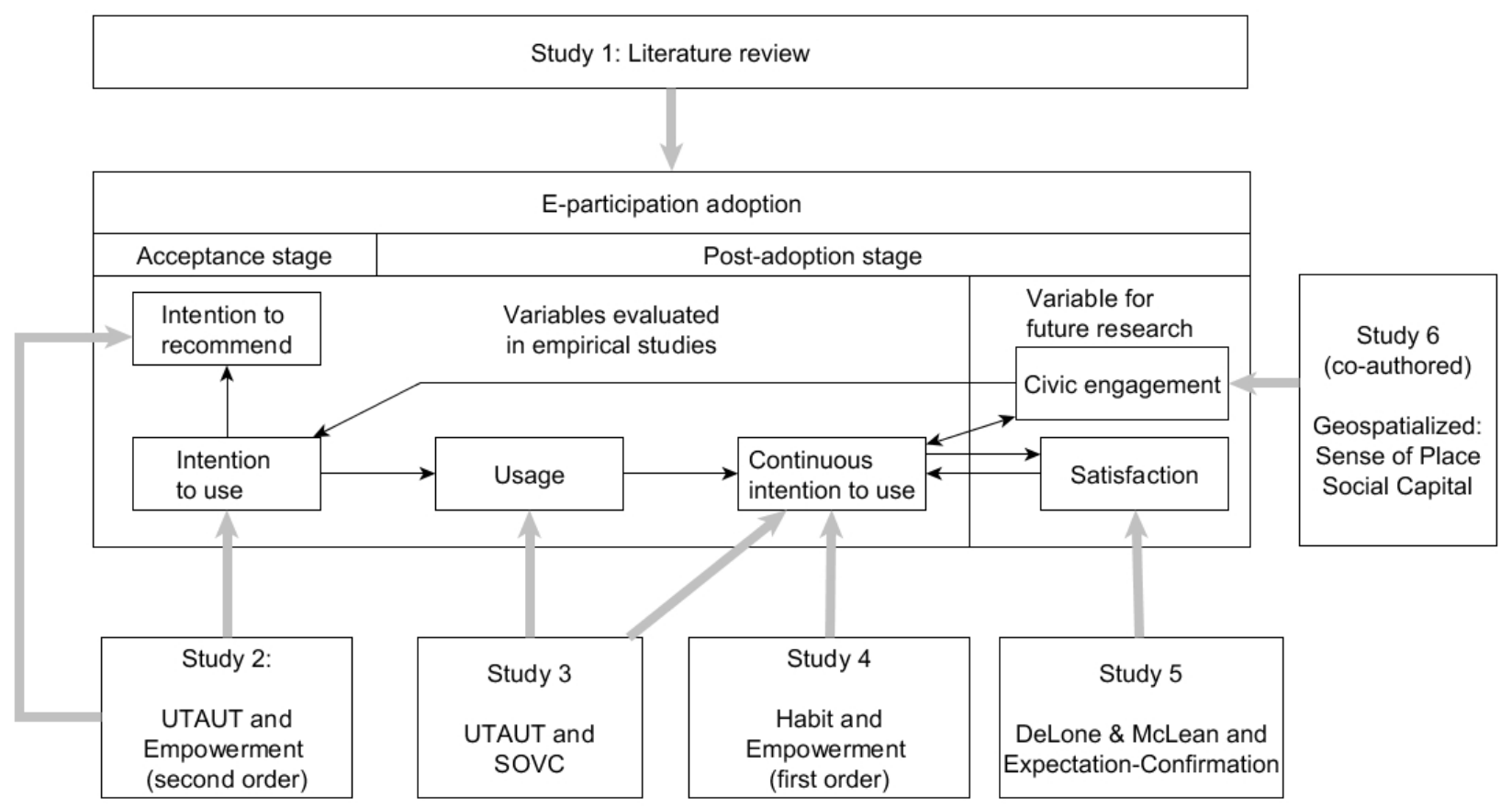

Figure 1.2. Research objectives by studies

\section{List of objectives:}

1. To identify the trends and synthesize the findings from existing research in the context of e-participation adoption.

2. To explore the effect of psychological empowerment on the intention to use and recommend e-participation.

3. To explore the effect of sense of virtual community (SOVC) (Koh \& Kim, 2003) on the usage and continued intention to use e-participation in the post-adoption stage.

4. To explore the effect of each of the components of empowerment and the effect of habit over the continued intention to use e-participation.

5. To propose a theoretical model to evaluate the citizen satisfaction with e-participation.

6. To evaluate the impact of sense of place and sense of community on civic engagement considering the geographic component. 


\subsection{Research methodology}

Epistemologically, the core of our research methodology of the e-participation adoption phenomenon follows a positivist approach which assumes that a set of variables related to the phenomenon and the causal relationships between those variables actually exist and can explain the e-participation adoption (Heeks \& Bailur, 2007). The positivist approach requires the deduction of research hypothesis on the theoretical grounds and quantifiable measures through empirical work to validate those hypotheses (Orlikowski \& Baroudi, 1991). In order to address our research objectives, this dissertation is composed for five studies. The first study is a literature review that follows a quantitative approach to develop a weight and meta-analysis of the existing cross-sectional studies in the e-participation adoption context. From the second to the forth study we developed three research models to evaluate our research hypotheses. The research models are evaluated using partial least squares structural equation modelling method (PLS-SEM) (J. Hair, Hult, Ringle, \& Sarstedt, 2017) based on data collected through an electronic questionnaire. And the fifth study follows a theoretical approach to propose a research model.

We used an electronic questionnaire for the data collection. The questions were derived from previously validated scales for all the constructs in the three research models and adjusted to the context of e-participation. The research was carried out in two Portuguese cities where their municipalities have implemented a set of e-participation tools in the last few years to promote the involvement of citizens in consultation and decision-making processes, these cities are Lisbon and Cascais. Both cities have implemented the online participatory budgeting (Sintomer, Herzberg, Allegretti, Röcke, \& Alves, 2013), which is considered as e-participation platform where citizens can submit project initiatives through a web portal, and then vote by means of SMS messages or through the web portal to choose which project(s) should be funded and implemented by the local government of each city.

We assess the research model using the partial least squares structural equation modelling method (PLS-SEM) (Hair et al., 2017). PLS is a variance-based technique, which is data driven and suitable for predictive analysis to test the causal relationships that were theoretically derived as hypotheses and using empirical data (J. F. Hair, Ringle, \& Sarstedt, 2011). The PLSSEM method is appropriate when the model complies with the following considerations: the objective is to predict the key drivers of an information technology adoption, the research model is considered complex, and the sample size is at least ten times the highest number of paths directed to a construct in the model. The three models evaluated complied with those 
considerations. We first assessed the measurement model for reliability and validity of the survey instrument, and then the structural model for the hypotheses testing. Error! Reference $\mathbf{s}$ ource not found. summarizes the research methods used for each study in this dissertation.

Table 1.1. Methodological approach summary

\begin{tabular}{|c|c|c|c|c|c|}
\hline Objective & Method & Theories & $\begin{array}{l}\text { Sample } \\
\text { size }\end{array}$ & City & Instrument \\
\hline $\begin{array}{l}\text { Identify the trends and synthesize } \\
\text { the findings from existing literature }\end{array}$ & $\begin{array}{l}\text { Quantitative } \\
\text { literature } \\
\text { review }\end{array}$ & N/A & N/A & N/A & $\begin{array}{l}\text { Existing } \\
\text { literature }\end{array}$ \\
\hline $\begin{array}{l}\text { Explore the effect of psychological } \\
\text { empowerment on the intention to } \\
\text { use and recommend }\end{array}$ & PLS-SEM & $\begin{array}{c}\text { UTAUT + } \\
\text { Empowerment }\end{array}$ & 210 & Cascais & $\begin{array}{c}\text { Electronic } \\
\text { survey }\end{array}$ \\
\hline $\begin{array}{l}\text { Explore the effect of SOVC on the } \\
\text { usage and continued intention to } \\
\text { use }\end{array}$ & PLS-SEM & UTAUT + SOVC & 370 & Lisbon & $\begin{array}{l}\text { Electronic } \\
\text { survey }\end{array}$ \\
\hline $\begin{array}{l}\text { Explore the effect of } \\
\text { empowerment dimensions and } \\
\text { habit over the continued intention } \\
\text { to use }\end{array}$ & PLS-SEM & $\begin{array}{c}\text { Empowerment } \\
+ \text { habit }\end{array}$ & 370 & Lisbon & $\begin{array}{l}\text { Electronic } \\
\text { survey }\end{array}$ \\
\hline $\begin{array}{l}\text { Develop a theoretical model to } \\
\text { evaluate the citizen satisfaction }\end{array}$ & $\begin{array}{l}\text { Theoretical } \\
\text { discussion }\end{array}$ & $\begin{array}{c}\text { DeLone \& } \\
\text { McLean + } \\
\text { Expectation- } \\
\text { Confirmation }\end{array}$ & N/A & N/A & $\begin{array}{l}\text { Existing } \\
\text { literature }\end{array}$ \\
\hline $\begin{array}{l}\text { Evaluate the impact of sense of } \\
\text { place and sense of community on } \\
\text { civic engagement considering the } \\
\text { geographic component }\end{array}$ & PLS-SEM & $\begin{array}{l}\text { Sense of Place } \\
+ \text { Social capital } \\
\text { + Sense of } \\
\text { community }\end{array}$ & 119 & Lisbon & GIS survey \\
\hline
\end{tabular}

Note: GIS = Geographic information system

\subsection{Path of research}

This dissertation encompasses a collection of five articles, each article corresponds to one of the chapters from 2 to 6 . Four of the five articles went through a peer-review process and are already published either in journals or conference proceedings. One of the articles is under review status. The peer-review process contributes to increase the quality of the articles. These articles focus on the exploration and evaluation of different drivers that may affect the adoption of the e-participation. Table 1.2 list each of the articles and the corresponding chapter in the dissertation. 
Table 1.2. Match chapter - research article

\begin{tabular}{|c|c|c|c|c|c|}
\hline Chapter & Publication & Authors & Contribution of each author & Status & Year \\
\hline 2 & $\begin{array}{l}\text { E-participation adoption } \\
\text { models research in the } \\
\text { last } 17 \text { years: A weight } \\
\text { and meta-analytical } \\
\text { review }\end{array}$ & \multirow{2}{*}{$\begin{array}{l}\text { Naranjo-Zolotov, } \\
\text { M. (MN), } \\
\text { Oliveira, T. (TO), } \\
\text { Casteleyn, S. (SC) }\end{array}$} & $\begin{array}{l}\text { Conceptualization, MN, TO; Data } \\
\text { search, MN; Data collection, MN; } \\
\text { Merging analysis, MN; Meta- } \\
\text { analysis, MN; Weight-analysis, MN; } \\
\text { Draft writing, MN; Reviewing and } \\
\text { editing, MN, TO, SC. }\end{array}$ & $\begin{array}{l}\text { Published in } \\
\text { Computers in } \\
\text { Human } \\
\text { Behavior }\end{array}$ & 2018 \\
\hline 3 & $\begin{array}{l}\text { Citizens' intention to } \\
\text { use and recommend e- } \\
\text { participation: Drawing } \\
\text { upon UTAUT and citizen } \\
\text { empowerment }\end{array}$ & & $\begin{array}{l}\text { Conceptualization, MN, TO; } \\
\text { Research model development, } \\
\text { MN; Survey instrument, MN, TO, } \\
\text { Data collection, MN; SEM-PLS } \\
\text { results, MN; Draft writing, MN; } \\
\text { Reviewing and editing, MN, TO, SC. }\end{array}$ & $\begin{array}{l}\text { Published in } \\
\text { Information } \\
\text { Technology } \\
\text { \& People }\end{array}$ & 2018 \\
\hline 4 & $\begin{array}{l}\text { Continuous usage of e- } \\
\text { participation in the long } \\
\text { term: The role of the } \\
\text { sense of virtual } \\
\text { community }\end{array}$ & $\begin{array}{l}\text { Naranjo-Zolotov, } \\
\text { M. (MN), } \\
\text { Oliveira, T. (TO), } \\
\text { Casteleyn, S. } \\
\text { (SC), Zahir Irani } \\
\text { (ZI) }\end{array}$ & $\begin{array}{l}\text { Conceptualization, MN, TO; } \\
\text { Research model development, } \\
\text { MN; Survey instrument, MN, TO, } \\
\text { Data collection, MN; SEM-PLS } \\
\text { results, MN; Draft writing, MN; } \\
\text { Reviewing and editing, MN, TO, SC, } \\
\text { Zl. }\end{array}$ & $\begin{array}{l}\text { Under } \\
\text { review }\end{array}$ & N/A \\
\hline 5 & $\begin{array}{l}\text { Continued intention to } \\
\text { use online participatory } \\
\text { budgeting: The effect of } \\
\text { empowerment and } \\
\text { habit }\end{array}$ & $\begin{array}{l}\text { Naranjo-Zolotov, } \\
\qquad \text { M. (MN), } \\
\text { Oliveira, T. (TO), } \\
\text { Casteleyn, S. (SC) }\end{array}$ & $\begin{array}{l}\text { Conceptualization, MN, TO; } \\
\text { Research model development, } \\
\text { MN; Survey instrument, MN, TO, } \\
\text { Data collection, MN; SEM-PLS } \\
\text { results, MN; Draft writing, MN; } \\
\text { Reviewing and editing, MN, TO, SC. }\end{array}$ & $\begin{array}{l}\text { Published in } \\
\text { the } \\
\text { Proceedings } \\
\text { of ICEGOV'18 }\end{array}$ & 2018 \\
\hline 6 & $\begin{array}{l}\text { Satisfaction with e- } \\
\text { participation: A model } \\
\text { from the citizen's } \\
\text { perspective, } \\
\text { expectations, and } \\
\text { affective ties to the } \\
\text { place }\end{array}$ & $\begin{array}{l}\text { Naranjo-Zolotov, } \\
\text { M. (MN), } \\
\text { Oliveira, T. (TO), } \\
\text { Cruz-Jesus, F. } \\
\text { (CJ) } \\
\text { Martins, J (JM). }\end{array}$ & $\begin{array}{l}\text { Conceptualization, MN, TO; } \\
\text { Research model development, } \\
\text { MN; Draft writing, MN; Reviewing } \\
\text { and editing, MN, TO, CJ, JM. }\end{array}$ & $\begin{array}{l}\text { Published in } \\
\text { Proceedings } \\
\text { of the } \\
\text { WorldCIST'18 } \\
2018 .\end{array}$ & 2018 \\
\hline 7 & $\begin{array}{l}\text { Place and city: Towards } \\
\text { a geography of } \\
\text { engagement }\end{array}$ & $\begin{array}{c}\text { Acedo, A.; } \\
\text { Oliveira, T.; } \\
\text { Naranjo-Zolotov, } \\
\text { M.; Painho, M. }\end{array}$ & $\begin{array}{l}\text { Conceptualization, AA, MP; Data } \\
\text { curation, AA; Formal analysis, AA, } \\
\text { MP, MN, TO; Funding acquisition, } \\
\text { MP; Investigation, AA; } \\
\text { Methodology, AA, MN; SEM-PLS } \\
\text { results, MN; Project } \\
\text { administration, MP, TO; Resources, } \\
\text { MP; Software, AA, MN; } \\
\text { Visualization, AA, MN; Writing - } \\
\text { original draft, AA, MN; Writing - } \\
\text { review \& editing, MP, TO. }\end{array}$ & $\begin{array}{l}\text { Under } \\
\text { review }\end{array}$ & N/A \\
\hline
\end{tabular}

One of the ongoing research lines derived from this project is the combination of the qualitative and quantitative methods to explore further the drivers of e-participation adoption. We follow the approach used by Zhang \& Venkatesh (2017), which first carried out a qualitative 
study with the employees of a company about the usage of knowledge management systems and then, using the insights obtained from the qualitative study they built a research model and conducted a quantitative study to evaluate the model. Additionally, during May and July we were honoured with the visit of two renowned scientists in the field of information systems to collaborate with us for this future line of research: Prof. Dr. Christy Cheung and Prof. Dr. Viswanath Venkatesh.

In most of scientific research projects, establishing a theoretical background is the first logical step to follow. In chapter 2 we present a literature review in a form of a weight and metaanalysis study of the existing quantitative articles of e-participation adoption from the year 2000 to year 2017. We identify the most used theories and variables used in the study of eparticipation adoption.

The engagement of citizens in consultation and decision-making processes may create a feeling of empowerment in those citizens (Gonçalves et al., 2014), so empowerment can play an important role as motivator of e-participation adoption. In chapter 3 we design and evaluate a research model that integrates UTAUT (Venkatesh et al., 2003) and psychological empowerment (Zimmerman, 1995) to measure the effect of the constructs from these theories on the intention to use and intention to recommend e-participation, the acceptance stage.

The usage of e-participation is more likely to have a significant impact on the community if used in the long term. The feeling of being part of a community may encourage the citizens to use e-participation. In chapter 4 we present a cross-sectional study that analyses the effect of SOVC as motivator for the continued intention to use e-participation in the post-adoption stage.

In chapter 5 we go back to the analysis of the empowerment and combine it with habit. This study is carried out in a different context and focused on the continued intention to use. In the post-adoption stage, citizens may develop an habit regarding the use of the information technology (Venkatesh, Thong, \& Xu, 2012). We discuss how both empowerment and habit can have an effect on the continued intention to use e-participation.

In chapter 6 we propose a theoretical model to assess the citizens satisfaction with the use of e-participation in the post-adoption stage. As citizen's satisfaction is an indicator of successful continuous usage of e-participation (Kipenis \& Askounis, 2016), we develop a theoretical model aimed for future research as next step of this project. 
In chapter 7 we include the findings of an additional article which was co-authored by the author of this dissertation. The article title is "Place and city: Towards a geography of engagement" and uses PLS-SEM to evaluate the impact of geographical ties as drivers of sense of belonging to a community and for civic engagement.

In chapter 8 we provide the conclusions of the major findings and implications for theory and practice of the six articles included from chapter 2 to 7 . Place and city: Furthermore, we provide the limitations and suggestions for future research in the field of e-participation adoption. 


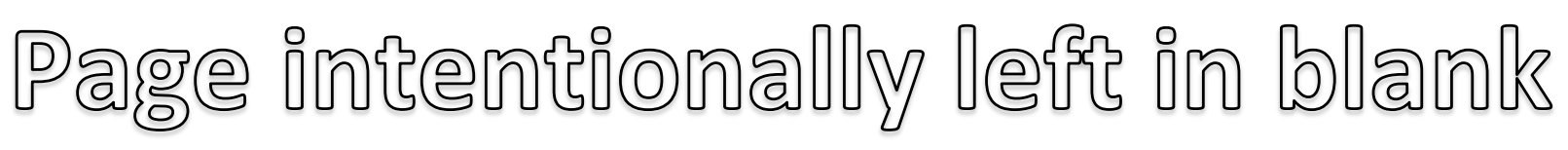




\section{Chaper 2 - E-participation adoption models research in the last 17 years: A weight and meta-analytical review}

\subsection{Introduction}

E-participation is defined as "the process of engaging citizens through ICTs [Information and Communication Technologies] in policy and decision-making in order to make public administration participatory, inclusive, collaborative and deliberative for intrinsic and instrumental ends" (United Nations, 2014, p. 61). The definition provided by United Nations emphasizes the importance of citizen engagement and e-participation for sustainable development and for facing the current global challenges such as climate change, inequality, poverty, and the collaboration between governmental and non-governmental actors. Eparticipation is a strategic factor to improve citizen participation in digital governance (Sanford \& Rose, 2007) and to promote a more efficient society (Sæbø et al., 2008).

In recent years the availability of e-participation technologies has increased around the globe. For instance, by 2010 there was an estimate of 795 to 1469 implementations of participatory budgeting around the world (Sintomer, Herzberg, Allegretti, \& Röcke, 2010), whereas by 2013 the estimate was updated to nearly 2700 implementations worldwide (Sintomer et al., 2013). Recently United Nations (2016) reported on the current situation of forms of e-participation worldwide. Of the 193 members states: 183 have implemented einformation by posting online information about education, health, finance, environment, social protection, and labour; 62 provide the option for citizens to subscribe to updates via SMS and e-mail about labour information; 152 use e-consultation through social network features; however, in only 38 of these 152 countries e-consultation resulted in new policies or regulations; and 120 countries have developed e-decision-making tools.

E-participation is considered a field of interdisciplinary nature (Macintosh, Coleman, \& Schneeberger, 2009; Medaglia, 2012; Susha \& Grönlund, 2012). Comparative and review studies on e-participation may help considerably to form a better picture of the research progress in this field. From the qualitative perspective, review studies such as Medaglia (2012), Sæbø et al. (2008), Sanford \& Rose (2007), have contributed to the characterization of the field. However, Kubicek \& Aichholzer (2016) identified that there is a lack of comparative studies analysing eparticipation; instead, the body of research mainly consists of isolated case studies. They contributed by reviewing the major types of conceptual frameworks and evaluation criteria in 
the e-participation context. On the quantitative side, very few review and comparative studies address e-participation directly. This article fills the gap of quantitative review in the eparticipation domain.

The main objective of this study is to perform a weight analysis (Jeyaraj, Rottman, \& Lacity, 2006) and meta-analysis (King \& He, 2006), which are strong alternatives to the narrative methods of literature review to synthetize findings presented in primary quantitative articles on e-participation technology adoption. Specifically, we analyse the performance of the constructs obtained from the assessment of the research models found in 60 articles published in the last 17 years. This article makes two contributions. First, according to Webster \& Watson (2002) an effective review can serve as a strong basis for advancement of knowledge, facilitating the path for theoretical development and revealing gaps where more research is needed. Second, we offer a better understanding of the existing trends and patterns in the use of theoretical models and constructs, especially for the most widely used research models: the technology acceptance model - TAM (Davis, 1989) and the unified theory of acceptance and use of technology - UTAUT (Venkatesh et al., 2003). The most frequently used constructs are identified as 'best' and 'promising' predictors (Jeyaraj et al., 2006). Besides the weight and meta-analysis, the article also examines trends on technologies used for e-participation and the type of sample population, with its distribution by country and by year.

The paper is organized as follows. The next section describes the research methodology, this is, the definition of the problem, the criteria for selection or rejection of studies, the data extraction process, and merging the names of variables. Section 3 provide the results: (3.1) descriptive statistics, (3.2) weight analysis, (3.3) meta-analysis, and (3.4) analysis of publication bias. Then, a discussion of the findings with their implications for theory and practice is presented; and finally, the conclusions, and limitations and future research.

\subsection{Research Methodology}

\subsubsection{Criteria for Selection of Studies}

The first step in a meta-analysis investigation is formulating the problem (Cooper, 2010). In our case, we are interested in analysing the overall performance of the relationships between independent and dependent variables, measured in theoretical models for adoption of eparticipation over the last 17 years or research. We included all available electronic databases 
relevant to the topic: Science Direct, ISI Web of Science, ACM Digital Library, and Google Scholar. The search engines of the databases provide options to perform advance search using keywords and logical operators (AND/OR), within a specific timeframe.

The keywords for the queries are defined in four sets: (i) the keywords oriented to find articles where research models were evaluated, thus, 'model', 'survey', and 'questionnaire'; (ii) the context of the studies, thus, 'e-participation' and 'e-government' (with and without hyphen) (United Nations, 2016); (iii) the keywords about the most used methods used to assess the models, 'regression', 'PLS', and 'structural equation modelling'; and finally, (iv) the activities and levels of e-participation. We adopted the e-participation activities 'e-voting', 'e-democracy', and 'e-petition' from Medaglia (2012), and 'e-empowering'(Macintosh, 2004). To frame the levels of e-participation we adopt 'e-information', 'e-consultation', 'policy-making', and 'decisionmaking' from United Nations (2016). Please, see Table 2.1. Logical operators 'AND' and 'OR' connect the keywords for the query. The general conditions: articles published from year 2000 to present in journal and conferences. The studies must report the correlation coefficients, sample size, and be written in English language.

Table 2.1. Sets of keywords to query databases

\begin{tabular}{llll}
\hline $\begin{array}{l}\text { Theoretical model } \\
\text { and evaluation }\end{array}$ & Context & $\begin{array}{l}\text { Quantitative } \\
\text { methods }\end{array}$ & $\begin{array}{l}\text { Activities/Levels } \\
\text { of e-participation }\end{array}$ \\
\hline & & e-democracy \\
& & e-voting \\
model & structural equation modelling & policy-making \\
survey & e-government & PLS & e-petition \\
questionnaire & e-participation & regression & e-informing \\
& & coefficient & e-consulting \\
& & decision-making \\
& & e-empowering \\
\hline
\end{tabular}

Initially, 779 publications were found ranging from year 2003 to 2017 across the databases used in the search. Some articles retrieved from the different databases were duplicates, which were excluded from the list. Even though the timeframe was set to [20002017], no articles were found between years 2000 and 2002. Most of the 779 initial publications had a qualitative approach, that is, they did not conduct any statistical evaluation from which a sample size and correlation coefficients could be calculated. Consequently, qualitative articles were excluded from the list, leaving 76 quantitative studies. Those 76 articles received three independent reviews to verify whether the technological tools and activities studied comply 
with the conditions of our study and the list of predefined activities. As a result, 12 articles were excluded as not fitting our list of e-participation activities and levels (Table 2.1). Remaining 64 studies.

In these 64 studies, four were excluded for using the same dataset of respondents, because of the same dataset in more than one publication may bias the aggregate effects in meta-analysis (Wood, 2007). If two or more studies used the same dataset, we selected the one that contained the highest number of variables. On the other hand, the article of Seo \& Bernsen (2016) contained four independent datasets, from which we consider only the one with biggest sample size for weight and meta-analysis. Finally, this article includes 60 studies and 63 useful datasets. Figure 2.1 describes the workflow and conditions of the search.

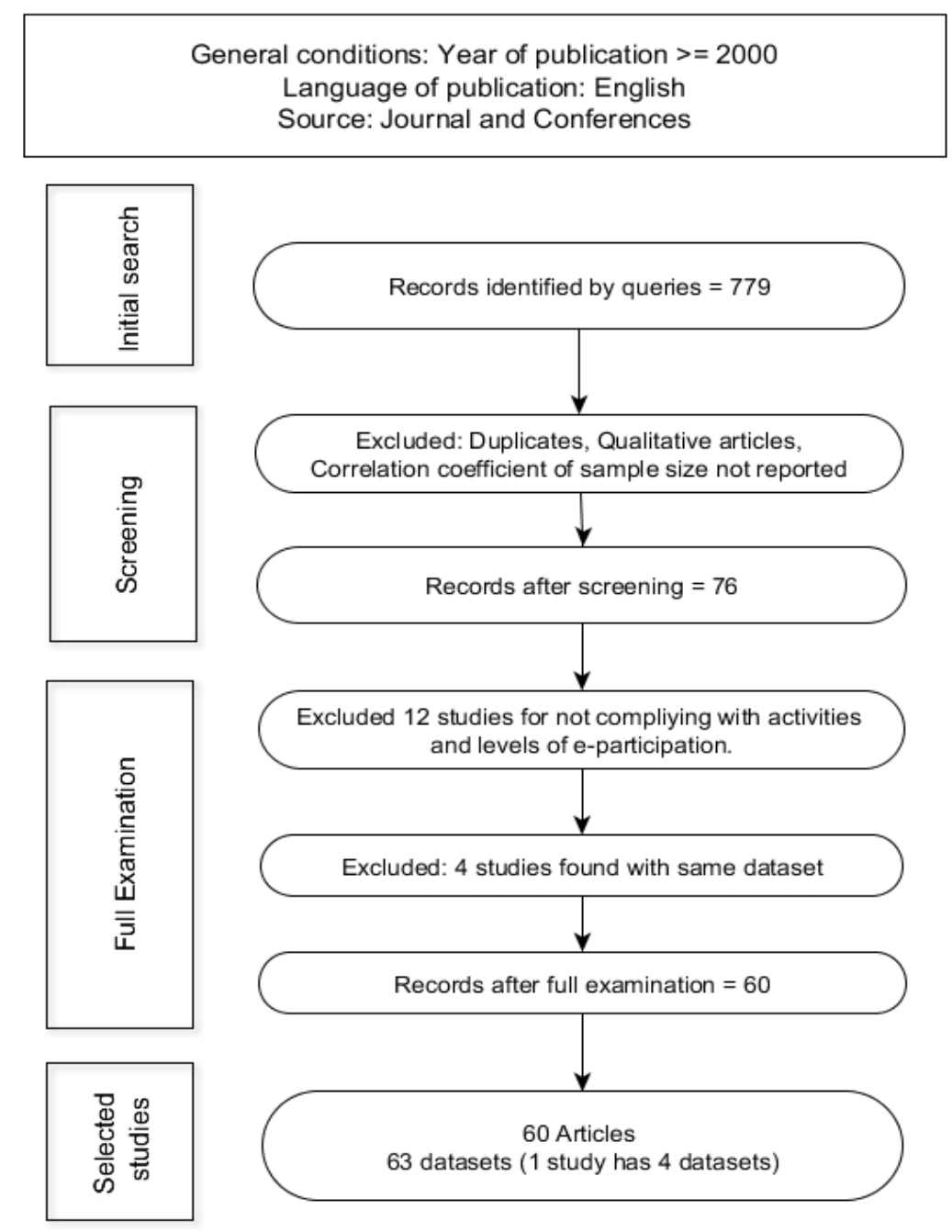

Figure 2.1. Selection of studies 


\subsubsection{Data Extraction}

Each article was examined and the following items were extracted: year of publication, source, theory, independent variable, dependent variable, correlation coefficient from relationships between constructs (independent variables moderating the relationship were not included), significance (yes or not), quantitative method, keywords, type of e-participation technologies (e.g., e-voting, online discussion forum, online services), type of survey, sample size, type of population, and nationality of the sample. The list of all useful datasets in individual studies is in

Table 2.2.

Table 2.2. List of useful datasets in studies (ordered by publication year, author)

\begin{tabular}{|c|c|c|c|c|c|}
\hline No. & Author & Model & Technologies & $\begin{array}{l}\text { Sample } \\
\text { size }\end{array}$ & Country \\
\hline 1 & Lee, Braynov, \& Rao (2003) & TAM & Online services & 158 & United States \\
\hline 2 & Carter \& Bélanger (2004) & TAM, DOI & Online services & 136 & United States \\
\hline 3 & Carter \& Bélanger (2005) & TAM, DOI & Online services & 105 & United States \\
\hline 4 & Schaupp \& Carter (2005) & $\begin{array}{l}\text { TAM, DOI, and web } \\
\text { trust }\end{array}$ & e-voting & 208 & United States \\
\hline 5 & Phang \& Kankanhalli (2006) & CVM, GIM & Online discussion forum & 121 & Singapore \\
\hline 6 & Yang, Li, Tan, \& Teo (2007) & TRA & Online discussion forum & 183 & Singapore \\
\hline 7 & Yao \& Murphy (2007) & TAM, UTAUT & e-voting & 453 & United States \\
\hline 8 & Bélanger \& Carter (2008) & $\begin{array}{l}\text { Trust of the Internet, } \\
\text { Trust of government }\end{array}$ & Online services & 214 & United States \\
\hline 9 & Colesca \& Dobrica (2008) & TAM & Web portal & 481 & Romania \\
\hline 10 & Tan, Bembasat, \& Cenfetelli (2008) & SERVQUAL, TAM, Trust & Online services & 647 & United States \\
\hline 11 & Van Dijk, Peters, \& Ebbers (2008) & UTAUT & Online services & 1225 & Netherlands \\
\hline 12 & Wang \& Liao (2008) & DeLone and McLean & Online services & 119 & Taiwan \\
\hline 13 & $\begin{array}{l}\text { Wangpipatwong, Chutimaskul, \& } \\
\text { Papasratorn (2008) }\end{array}$ & TAM & Web portal & 614 & Thailand \\
\hline 14 & Chiang (2009) & TAM & e-voting & 281 & Taiwan \\
\hline 15 & $\begin{array}{l}\text { Lean, Zailani, Ramayah, \& Fernando } \\
\text { (2009) }\end{array}$ & TAM, DOI & Online services & 150 & Malaysia \\
\hline 16 & Tang, Chung, \& Se (2009) & TAM, TRA & Online services & 385 & China \\
\hline 17 & Teo, Srivastava, \& Jiang (2009) & $\begin{array}{l}\text { DeLone and McLean, } \\
\text { Trust }\end{array}$ & Online services & 214 & Singapore \\
\hline 18 & Wang \& Shih (2009) & UTAUT & Information Kiosks & 244 & Taiwan \\
\hline 19 & Kollmann \& Kayser (2010) & UTAUT, CVM & E-democracy & 232 & Germany \\
\hline 20 & Alathur, Ilavarasan, \& Gupta (2011) & Empowerment & Online discussion forum & 360 & India \\
\hline 21 & $\begin{array}{l}\text { Al-Hujran, Al-dalahmeh, \& Aloudat } \\
\text { (2011) }\end{array}$ & TAM, Hofstede & Online services & 197 & Jordan \\
\hline 22 & $\begin{array}{l}\text { Al-Sobhi, Weerakkody, \& El- } \\
\text { Haddadeh (2011) }\end{array}$ & UTAUT & Online services & 624 & Saudi Arabia \\
\hline 23 & Lin, Fofanah, \& Liang (2011) & TAM & Online services & 167 & Gambia \\
\hline 24 & Rokhman (2011) & DOI & Online services & 751 & Indonesia \\
\hline 25 & Shyu \& Huang (2011) & TAM & Online services & 307 & Taiwan \\
\hline 26 & Styvén \& Wallström (2011) & Trust & Online services & 422 & Sweden \\
\hline 27 & Alomari, Woods, \& Kuldeep (2012) & DOI, TAM & Online services & 400 & Jordan \\
\hline 28 & $\begin{array}{l}\text { Alshehri, Drew, Alhussain, \& } \\
\text { Alghamdi (2012) }\end{array}$ & UTAUT, Web quality, & Online services & 400 & Saudi Arabia \\
\hline 29 & Belanche, Casaló, \& Flavián (2012) & TAM & Online services & 416 & Spain \\
\hline
\end{tabular}




\begin{tabular}{|c|c|c|c|c|c|}
\hline No. & Author & Model & Technologies & $\begin{array}{l}\text { Sample } \\
\text { size }\end{array}$ & Country \\
\hline 30 & Carter \& Bélanger (2012) & $\begin{array}{l}\text { TAM, DOI, Political } \\
\text { Factors }\end{array}$ & e-voting & 372 & United States \\
\hline 31 & Choi \& Kim (2012) & TAM & e-voting & 228 & United States \\
\hline 32 & Lee \& Kim (2012) & TAM, Social Networks & Online discussion forum & 1076 & South Korea \\
\hline 33 & Khan, Moon, Swar, Zo, \& Rho (2012) & Self-developed & Online services & 360 & Afghanistan \\
\hline 34 & Rehman, Esichaikul, \& Kamal (2012) & TAM, DOI & E-informing & 138 & Pakistan \\
\hline 35 & Wang \& Lo (2012) & TAM, TBP & Online services & 200 & Taiwan \\
\hline 36 & $\begin{array}{l}\text { Winkler, Hirsch, Trouvilliez, \& } \\
\text { Günther (2012) }\end{array}$ & TAM & Mobile Reporting Service & 200 & Germany \\
\hline 37 & Alawneh, Al-Refai, \& Batiha (2013) & Customer satisfaction & Web portal & 206 & Jordan \\
\hline 38 & Hung, Chang, \& Kuo (2013) & TPB & Mobile government & 331 & Taiwan \\
\hline 39 & Mou, Atkin, Fu, Lin, \& Lau (2013) & Self-developed & Online discussion forum & 181 & China \\
\hline 40 & Persaud \& Persaud (2013) & Self-developed & Web portal & 437 & Canada \\
\hline 41 & Abu-Shanab (2014) & $\begin{array}{l}\text { TRA, Trust } \\
\text { Antecedents Model }\end{array}$ & Online services & 759 & Jordan \\
\hline 42 & Al-Hujran, Al-Debei, \& Al-Lozi (2014) & TAM, TPB & E-democracy & 189 & Jordan \\
\hline 43 & $\begin{array}{l}\text { Aloudat, Michael, Chen, \& Al-Debei } \\
\text { (2014) }\end{array}$ & TAM & Mobile government & 290 & Australia \\
\hline 44 & $\begin{array}{l}\text { Cegarra-Navarro, Garcia-Perez, \& } \\
\text { Moreno-Cegarra (2014) }\end{array}$ & TAM & E-informing & 307 & Spain \\
\hline 45 & Liu et al. (2014) & TAM & Mobile government & 409 & China \\
\hline 46 & Park, Choi, \& Rho (2014) & Self-developed & Online social networks & 491 & South Korea \\
\hline 47 & Abu-Shanab (2015) & Self-developed & Open government data & 869 & Jordan \\
\hline 48 & Al-Quraan \& Abu-Shanab (2015) & Self-developed & Web portal & 248 & Jordan \\
\hline 49 & $\begin{array}{l}\text { Alharbi, Kang, \& Hawryszkiewycz } \\
\text { (2015) }\end{array}$ & TBP, Trust & Web portal & 770 & Saudi Arabia \\
\hline 50 & Alrashedi, Persaud, \& Kindra (2015) & Self-developed & E-informing & 200 & Saudi Arabia \\
\hline 51 & Dahi \& Ezziane (2015) & TAM & Online services & 845 & Abu Dhabi \\
\hline 52 & Rabaa'i (2015) & TAM & Online services & 853 & Jordan \\
\hline 53 & Rana \& Dwivedi (2015) & SCT & $\begin{array}{l}\text { Online public grievance } \\
\text { redressal system }\end{array}$ & 419 & India \\
\hline 54 & $\begin{array}{l}\text { Zuiderwijk, Janssen, \& Dwivedi } \\
\text { (2015) }\end{array}$ & UTAUT & Open government data & 111 & $\begin{array}{l}\text { Several } \\
\text { countries }\end{array}$ \\
\hline 55 & Cai Shuqin, Mastoi, Gul, \& Gul (2016) & Self-developed & Online services & 200 & Pakistan \\
\hline 56 & Piehler, Wirtz, \& Daiser (2016) & ECT & Web portal & 477 & Germany \\
\hline 57 & $\begin{array}{l}\text { Rodrigues, Sarabdeen, } \\
\text { Balasubramanian (2016) }\end{array}$ & UTAUT & Online services & 380 & $\begin{array}{l}\text { United Arab } \\
\text { Emirates }\end{array}$ \\
\hline & & & Municipality e-services & 111 & \\
\hline 58 & Seo \& Bernsen (2016) & SCT, UTAUT, Trust & Municipality e-services & 73 & Netherlands \\
\hline & & & $\begin{array}{l}\text { Municipality e-services } \\
\text { Municipality e-services }\end{array}$ & $\begin{array}{l}70 \\
83\end{array}$ & \\
\hline 59 & Oni, Oni, Mbarika, \& Ayo (2017) & CMV, TRA & E-democracy & 327 & Nigeria \\
\hline 60 & $\begin{array}{l}\text { Schmidthuber, } \quad \text { Hilgers, } \\
\text { Gegenhuber (2017) }\end{array}$ & TAM & Open government & 466 & Austria \\
\hline
\end{tabular}

Notes: CVM - civic voluntarism model, DOI - diffusion of innovation, GIM - general incentives model, SCT - social cognitive theory, SERVQUAL - service quality, TAM - technology acceptance model, TPB - theory of planned behaviour, TRA - theory of reasoned action, UTAUT - unified theory of acceptance and use of technology, ECT Expectation confirmation theory

\subsubsection{Merging of Variables}

When data were extracted, the names of independent and dependent variables were collected as defined by their original authors. Among the plethora of variables, we faced the problem that 
many of those variables had different names, but likely stand for similar meanings. We identified two main scenarios: (i) some constructs were identified as synonyms (i.e.: Internet Trust, Trust of the Internet, and Trust in Internet were considered jointly as a single construct Trust in Internet); (ii) several constructs presented longer names (i.e.: Intention to use online function, and Attitude toward using e-voting system were reduced to Intention to use and Attitude, respectively). When the names of the constructs were of these forms: Intention to use... [Studied technology], Attitude towards... [Studied technology], or Trust in... [Studied technology], we considered them as Intention to use, Attitude, and Trust, respectively. For further details see the Appendix 2.1. After the merging process, we identified 24 relationships that have been used at least three or more times. This threshold has been used also in Baptista \& Oliveira (2016) and Rana et al. (2015). Those relationships are used for the weight and meta-analysis in the next section.

\subsection{Results}

\subsubsection{Descriptive statistics}

In these 60 articles, 483 relationships [independent-dependent variable] were identified to be useful for the weight analysis. For the meta-analysis 11 relationships were dropped because the articles did not report the correlation coefficient values when they were not significant. They only reported whether significant or not; therefore, 472 useful relationships were identified for the meta-analysis. The total number of individuals from the 63 datasets is 22,890 . Based on the description provided in each article, we categorized the type of respondents to obtain a summarized view. General public in urban areas and University students were the most common description of the population in the articles (see Table 2.3).

Table 2.3. Distribution of respondents by type (ordered by percentage)

\begin{tabular}{lll}
\hline Population type & Respondents & Percentage (\%) \\
\hline General public - urban area & 15,972 & 69.78 \\
University students & 3,904 & 17.05 \\
Employed people & 1,666 & 7.28 \\
E-business consumers & 647 & 2.83 \\
General public - rural area & 590 & 2.58 \\
Public in scientific conferences & 111 & 0.48 \\
TOTAL & 22,890 & 100 \\
\hline
\end{tabular}


In the analysis of distribution of respondents by country and year we take into account a total of 22,779 respondents, the dataset presented in the article of Zuiderwijk et al. (2015) is dropped for this particular analysis, because it reports individuals from various nationalities with a sample size of 111 (public in conferences). Few articles were found until year 2007, but from year 2008 to 2016 we observe a more regular number of publications per year (Table 2.4), 4.2 on average. The United States and Jordan are the countries that have contributed with the highest number of articles and respondents. Two thirds of all respondents belong to Asia and the Middle East. Given the limited number of datasets (63) for a global context study, there is not enough evidence to identify trends at such a scale. Figure 2.2 represents the world distribution of the respondents.

Table 2.4. Respondents by country and year (ordered by country name)

\begin{tabular}{|c|c|c|c|c|c|c|c|c|c|c|c|c|c|c|c|}
\hline Country & Year & & & & & & & & & & & & & & Total \\
\hline & 2003 & 2004 & 2005 & 2007 & 2008 & 2009 & 2010 & 2011 & 2012 & 2013 & 2014 & 2015 & 2016 & 2017 & \\
\hline Afghanistan & & & & & & & & & 360 & & & & & & 360 \\
\hline Australia & & & & & & & & & & & 290 & & & & 290 \\
\hline Austria & & & & & & & & & & & & & & 466 & 466 \\
\hline Canada & & & & & & & & & & 437 & & & & & 437 \\
\hline China & & & & & & & & & & 181 & 409 & & & & 590 \\
\hline Gambia & & & & & & & & 167 & & & & & & & 167 \\
\hline Germany & & & & & & & 232 & & 200 & & & & 477 & & 909 \\
\hline India & & & & & & & & 360 & & & & 419 & & & 779 \\
\hline Indonesia & & & & & & & & 751 & & & & & & & 751 \\
\hline Jordan & & & & & & & & 197 & 400 & 206 & 948 & 1970 & & & 3721 \\
\hline Macao & & & & & & 385 & & & & & & & & & 385 \\
\hline Malaysia & & & & & & 150 & & & & & & & & & 150 \\
\hline Netherlands & & & & & 1225 & & & & & & & & 337 & & 1562 \\
\hline Nigeria & & & & & & & & & & & & & & 327 & 327 \\
\hline Pakistan & & & & & & & & & 138 & & & & 200 & & 338 \\
\hline Romania & & & & & 481 & & & & & & & & & & 481 \\
\hline Saudi & & & & & & & & 624 & 400 & & & 970 & & & 1994 \\
\hline Arabia & & & & & & & & & & & & & & & \\
\hline Singapore & & & 121 & 183 & 214 & & & & & & & & & & 518 \\
\hline South Korea & & & & & & & & & 1076 & & 491 & & & & 1567 \\
\hline Spain & & & & & & & & & 416 & & 307 & & & & 723 \\
\hline Sweden & & & & & & & & 422 & & & & & & & 422 \\
\hline Taiwan & & & & & 119 & 525 & & 307 & & 531 & & & & & 1482 \\
\hline Thailand & & & & & 614 & & & & & & & & & & 614 \\
\hline United Arab & & & & & & & & & & & & 845 & 380 & & 1225 \\
\hline Emirates & & & & & & & & & & & & 040 & 300 & & $12 \angle J$ \\
\hline $\begin{array}{l}\text { United } \\
\text { States }\end{array}$ & 158 & 136 & 313 & 453 & 861 & & & & 600 & & & & & & 2521 \\
\hline $\begin{array}{l}\text { Total by } \\
\text { Year }\end{array}$ & 158 & 136 & 434 & 636 & 3514 & 1060 & 232 & 2828 & 3590 & 1355 & 2445 & 4204 & 1394 & 793 & 22779 \\
\hline
\end{tabular}

Notes: As an exception, Zuiderwijk et al. (2015) were not accounted for in this table, the respondents (111) of that study were selected in an international conference, and therefore no particular country was reported. 


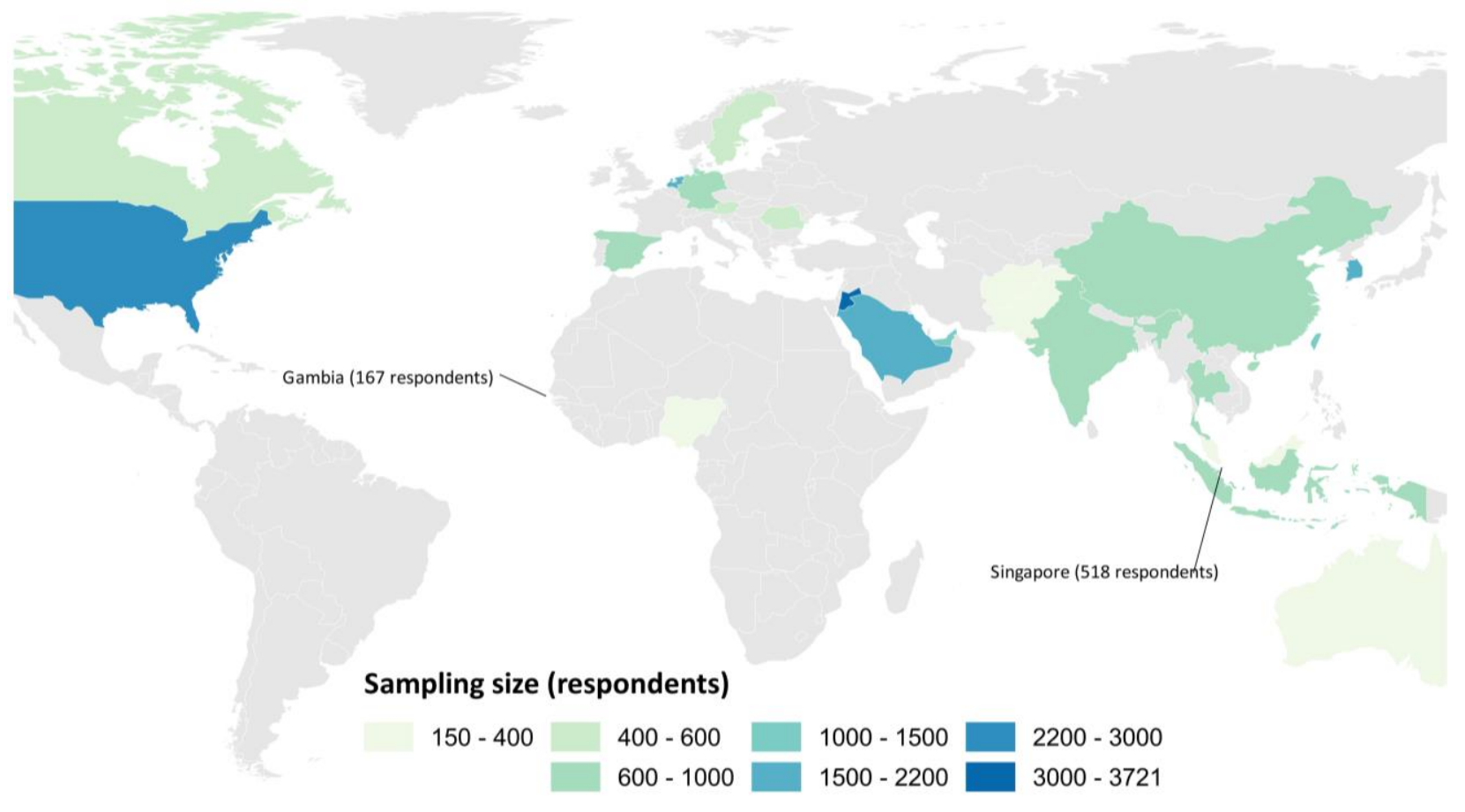

Figure 2.2. World distribution of the respondents analysed in the articles considered for this study

\subsubsection{Weight analysis}

Weight is an indicator of the predictive power of independent variables (Jeyaraj et al., 2006). The weight for a variable is calculated by dividing the number of times an independent variable was reported to be significant by the total number of times the independent variable was examined. In our case, we analyse the influence of an independent variable over a dependent variable; that is, a constructs' relationship strength. Following the approach implemented in Baptista \& Oliveira (2016) and Rana et al. (2015), we included in our analysis all relationships that were examined three or more times, counting 24 relationships that comply with this condition (see Table 2.5). 
Table 2.5. Weight analysis results (ordered by Frequency of use)

\begin{tabular}{|c|c|c|c|c|c|c|}
\hline Independent variable & Dependent variable & $\begin{array}{c}\text { Non- } \\
\text { significant }\end{array}$ & Significant & $\begin{array}{c}\text { Frequency } \\
\text { of use }\end{array}$ & $\begin{array}{c}\text { Weight = } \\
\text { Significant / } \\
\text { Frequency }\end{array}$ & TAM/UTAUT \\
\hline Perceived usefulness & Intention to use & 1 & 16 & 17 & 0.94 & TAM \\
\hline Perceived ease of use & Perceived usefulness & 1 & 13 & 14 & 0.93 & TAM \\
\hline Perceived ease of use & Intention to use & 5 & 8 & 13 & 0.62 & TAM derived \\
\hline Attitude & Intention to use & 1 & 10 & 11 & 0.91 & TAM \\
\hline Perceived ease of use & Attitude & 2 & 7 & 9 & 0.78 & TAM \\
\hline Perceived usefulness & Attitude & 1 & 8 & 9 & 0.89 & TAM \\
\hline Social influence & Intention to use & 1 & 6 & 7 & 0.86 & UTAUT \\
\hline Trust & Intention to use & 0 & 7 & 7 & 1.00 & \\
\hline Trust in Internet & Intention to use & 2 & 5 & 7 & 0.71 & \\
\hline Subjective norm & Intention to use & 2 & 4 & 6 & 0.67 & \\
\hline Image & Intention to use & 5 & 1 & 6 & 0.17 & \\
\hline Relative advantage & Intention to use & 2 & 4 & 6 & 0.67 & \\
\hline Intention to use & Use & 1 & 5 & 6 & 0.83 & TAM, UTAUT \\
\hline Effort expectancy & Intention to use & 0 & 5 & 5 & 1.00 & UTAUT \\
\hline Performance expectancy & Intention to use & 2 & 3 & 5 & 0.60 & UTAUT \\
\hline Trust in government & Intention to use & 1 & 4 & 5 & 0.80 & \\
\hline Compatibility & Intention to use & 0 & 4 & 4 & 1.00 & \\
\hline Facilitating conditions & Use & 0 & 4 & 4 & 1.00 & UTAUT \\
\hline Perceived quality & Satisfaction & 0 & 4 & 4 & 1.00 & \\
\hline Trust & Perceived usefulness & 0 & 4 & 4 & 1.00 & \\
\hline Perceived behavioural control & Intention to use & 0 & 3 & 3 & 1.00 & \\
\hline Perceived risk & Intention to use & 0 & 3 & 3 & 1.00 & \\
\hline Computer Self-Efficacy & Perceived ease of use & 1 & 2 & 3 & 0.67 & \\
\hline Trust in government & Trust (in the technological tool) & 0 & 3 & 3 & 1.00 & \\
\hline
\end{tabular}

According to Jeyaraj et al. (2006), in the context of individual IT adoption, independent variables can be considered "well-utilized" if tested at least five times; if tested fewer than five times, with a weight equal to 1 , independent constructs can be considered as 'promising' predictors. For an independent variable to be labelled as 'best' predictor, it must have a weight greater or equal than 0.80 and have been examined at least five times (Jeyaraj et al., 2006). When weight $=1$ it indicates that the relationship was significant in all articles. Weight $=0$ indicates that the relationship is non-significant in all studies (Jeyaraj et al., 2006). In our case, the relationships that fall into the 'best' predictors for e-participation are: trust and effort expectancy on intention to use with a perfect weight of 1 ; perceived usefulness on intention to use and perceived ease of use on perceived usefulness with weights 0.94 and 0.93 respectively; perceived usefulness on attitude (0.89), attitude and social influence on intention to use (0.91 and 0.86 respectively); intention to use on use (0.83); and finally trust in government on intention to use (0.80). Figure 2.3 shows variables of the two most used research models found in our list of articles, TAM and UTAUT, and includes two variables that are not part of those models, although obtained high weight values. 


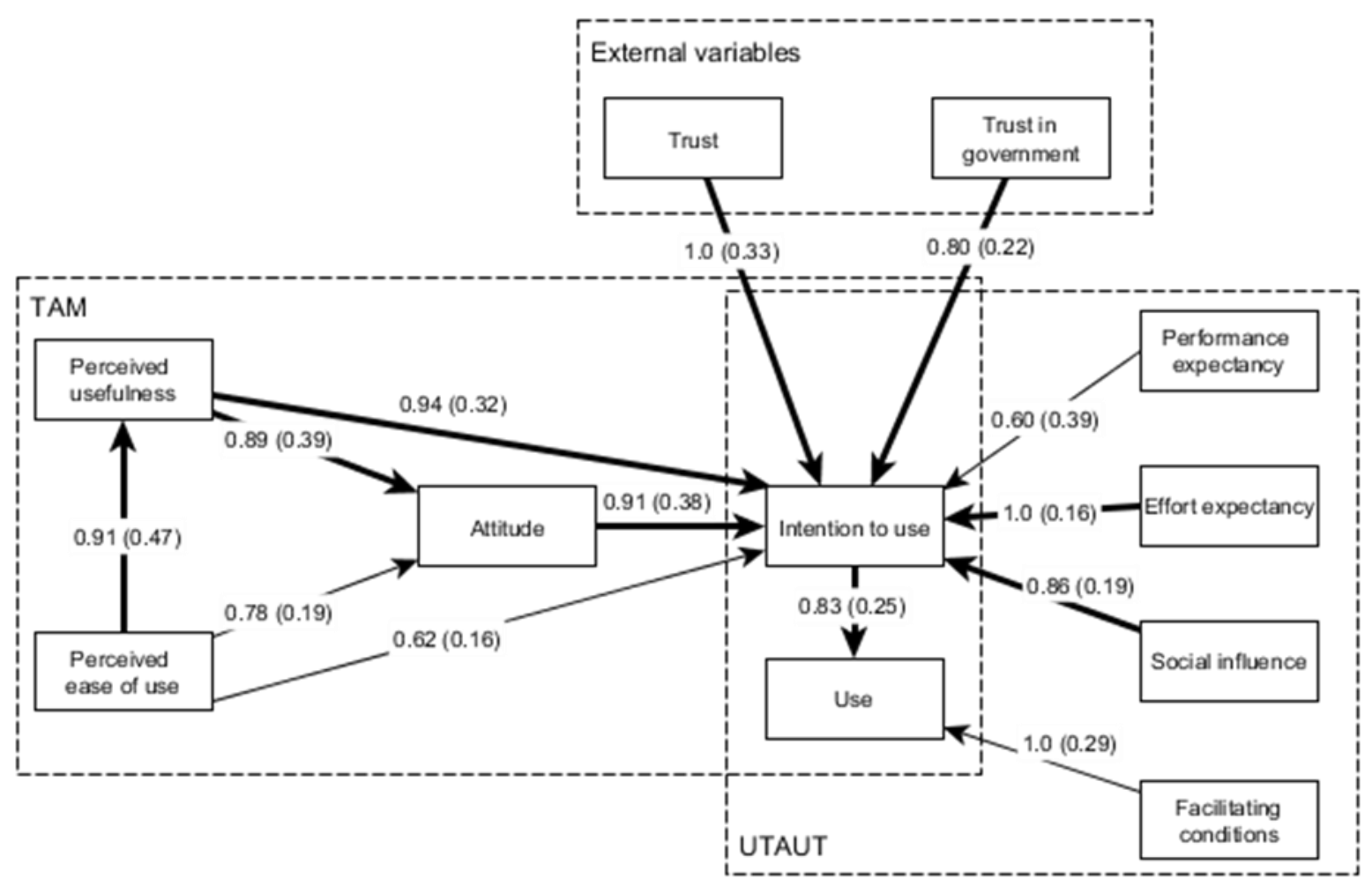

Figure 2.3. Resulting model based on TAM and UTAUT. Values represent weights, and the average $\beta$-values are in parentheses. Bold arrows represent the 'best' predictors

The relationships that fall into the category of 'promising' predictors (Jeyaraj et al., 2006) of e-participation (examined fewer than five times and weight 1 are: compatibility, perceived behavioural control and perceived risk on intention to use, facilitating conditions on use, perceived quality on satisfaction, trust on perceived usefulness, and trust in government on trust (in the technological tool).

\subsubsection{Meta-analysis}

One of the main reasons to use meta-analysis is the capacity of this quantitative technique to compare size of effect across studies, in this case, across relationships between constructs. It therefore requires a metric to measure those effects (Bowman, 2012). As metrics of effect sizes that can be used we have: correlation coefficient, regression coefficient, and standardized regression coefficient (Cooper, 2010). Furthermore, Bowman (2012), claimed that standardized regression coefficients $(\beta)$ and correlation coefficients are highly correlated and able to be substituted one for the other in a quantitative meta-analysis. The input required to perform our 
meta-analysis is the effect size and the sample size of each relationship that has been identified three or more times in the articles.

We use the random effect models of error to calculate the variability in the effect size estimated across studies (Cooper, 2010). As discussed in Cooper (2010), the fixed effect models consider only variation within studies due to sampling of participations. Random effect models take into consideration both the variance within a study and the variance between studies methods. Several meta-analysis articles have adopted the random effect model for their analysis, including for instance: Talò et al. (2014), random effect model was chosen because the studies were heterogeneous from each other; Šumak, Heričko, \& Pušnik (2011), conducted on random effect basis, assuming that every population is likely to have a different effect size; King \& He (2006), adopted random effect model under the assumption that samples in individual studies are taken from populations that had varying effect sizes; and finally, Dwivedi et al. (2011), used the random effect model assuming that is more realistic in accordance with the articles they examined. The 24 most often evaluated relationships are shown in Table 2.6. We used the free tool software Meta-Essentials (Van Rhee, Suurmond, \& Hak, 2015) for calculations and graphics. The average of $\beta$-values (correlation coefficient between independent and dependent variable) and the total sample size is previously calculated in a spreadsheet and then provided as input for the meta-analytic software.

A forest plot (Hak, van Rhee, \& Suurmond, 2016) is the graphical representation of the meta-analysis. Figure 2.4 presents the forest plot of the meta-analysis of the set of studies in Table 2.6. The $X$-axis represent the effect size (average $\beta$ ), the blue bullets represent the effect size for each individual relationship and the line across the blue dot is the confidence interval for that relationship at 95\%. To generate the forest plot, the relationships are arranged from the biggest to the smallest in terms of cumulative sample size. When the confidence interval lines are entirely on the positive side $(>0)$ the relationships are considered statistically significant; when the confidence interval includes zero, the relationship is not statistically significant. The plot shows that all the relationships, but trust in government on trust, are statistically significant. We also test for heterogeneity in the dataset, which is assessed by the statistic $\mathrm{I}^{2}$ (Higgins \& Thompson, 2002). $I^{2}$ indicate the percentage of variance between studies produced by heterogeneity rather than by chance. The results show a high level of heterogeneity for the list of variables in Table $2.6\left(I^{2}=0.97\right)$. 
Table 2.6. Meta-analysis results (ordered by frequency)

\begin{tabular}{|c|c|c|c|c|c|c|c|c|}
\hline \multirow{2}{*}{$\begin{array}{l}\text { Independent variable } \\
\text { Perceived usefulness }\end{array}$} & \multirow{2}{*}{$\begin{array}{l}\text { Dependent variable } \\
\text { Intention to use }\end{array}$} & \multirow{2}{*}{$\begin{array}{c}\text { Frequency } \\
17\end{array}$} & \multirow{2}{*}{$\begin{array}{c}\text { Average } \\
\beta \\
0.32\end{array}$} & \multirow{2}{*}{$\begin{array}{c}\begin{array}{c}\sum \text { sample } \\
\text { size }\end{array} \\
4895\end{array}$} & \multirow{2}{*}{$\begin{array}{c}\begin{array}{c}p- \\
\text { value }\end{array} \\
0.00\end{array}$} & \multirow{2}{*}{$\begin{array}{l}\text { z-value } \\
23.33\end{array}$} & \multicolumn{2}{|c|}{$\begin{array}{c}\text { Confidence } \\
\text { interval }(95 \%) \\
\text { Low - High }\end{array}$} \\
\hline & & & & & & & 0.30 & 0.35 \\
\hline Perceived ease of use & Perceived usefulness & 14 & 0.47 & 5091 & 0.00 & 36.37 & 0.45 & 0.49 \\
\hline Perceived ease of use & Intention to use & 13 & 0.16 & 4475 & 0.00 & 10.81 & 0.13 & 0.19 \\
\hline Attitude & Intention to use & 10 & 0.38 & 3277 & 0.00 & 22.82 & 0.35 & 0.41 \\
\hline Perceived ease of use & Attitude & 9 & 0.19 & 3057 & 0.00 & 10.76 & 0.16 & 0.23 \\
\hline Perceived usefulness & Attitude & 9 & 0.39 & 3048 & 0.00 & 22.90 & 0.36 & 0.42 \\
\hline Social influence & Intention to use & 7 & 0.19 & 2798 & 0.00 & 10.28 & 0.16 & 0.23 \\
\hline Trust & Intention to use & 7 & 0.33 & 2963 & 0.00 & 18.44 & 0.29 & 0.36 \\
\hline Trust in Internet & Intention to use & 7 & 0.14 & 2106 & 0.00 & 6.60 & 0.10 & 0.18 \\
\hline Intention to use & Use & 6 & 0.25 & 2959 & 0.00 & 14.07 & 0.22 & 0.29 \\
\hline Relative advantage & Intention to use & 6 & 0.30 & 1722 & 0.00 & 12.94 & 0.26 & 0.34 \\
\hline Subjective norm & Intention to use & 6 & 0.28 & 2003 & 0.00 & 12.83 & 0.24 & 0.32 \\
\hline Image & Intention to use & 5 & 0.07 & 1350 & 0.00 & 2.65 & 0.02 & 0.13 \\
\hline Effort expectancy & Intention to use & 5 & 0.16 & 2436 & 0.00 & 7.98 & 0.12 & 0.20 \\
\hline Trust in government & Intention to use & 5 & 0.22 & 1110 & 0.00 & 7.39 & 0.16 & 0.27 \\
\hline $\begin{array}{l}\text { Performance } \\
\text { expectancy }\end{array}$ & Intention to use & 4 & 0.39 & 1211 & 0.00 & 14.31 & 0.34 & 0.44 \\
\hline Compatibility & Intention to use & 4 & 0.35 & 1200 & 0.00 & 12.55 & 0.30 & 0.40 \\
\hline Facilitating conditions & Use & 4 & 0.29 & 1500 & 0.00 & 11.68 & 0.25 & 0.34 \\
\hline Perceived quality & Satisfaction & 4 & 0.39 & 1014 & 0.00 & 13.21 & 0.34 & 0.44 \\
\hline Trust & Perceived usefulness & 4 & 0.36 & 1834 & 0.00 & 15.88 & 0.31 & 0.39 \\
\hline $\begin{array}{l}\text { Computer Self- } \\
\text { Efficacy }\end{array}$ & Perceived ease of use & 3 & 0.23 & 2312 & 0.00 & 11.10 & 0.19 & 0.27 \\
\hline $\begin{array}{l}\text { Perceived behavioural } \\
\text { control }\end{array}$ & Intention to use & 3 & 0.22 & 631 & 0.00 & 5.54 & 0.14 & 0.29 \\
\hline Perceived risk & Intention to use & 3 & 0.03 & 463 & 0.27 & 0.60 & -0.06 & 0.12 \\
\hline Trust in government & $\begin{array}{l}\text { Trust (technological } \\
\text { tool) }\end{array}$ & 3 & 0.30 & 1743 & 0.00 & 12.83 & 0.25 & 0.34 \\
\hline
\end{tabular}




\begin{tabular}{|c|c|c|c|c|}
\hline \multirow{2}{*}{$\frac{\text { No }}{1}$} & \multicolumn{2}{|c|}{ Independent-dependent variable } & \multirow{2}{*}{$\begin{array}{c}\text { Average } \\
(\beta) \\
0.47\end{array}$} & \multirow{2}{*}{$\begin{array}{c}\sum \begin{array}{c}\sum \text { sample } \\
\text { size }\end{array} \\
5091\end{array}$} \\
\hline & Perceived ease of use & Perceived usefulness & & \\
\hline 2 & Perceived usefulness & Intention to use & 0.32 & 4895 \\
\hline 3 & Perceived ease of use & Intention to use & 0.16 & 4475 \\
\hline 4 & Attitude & Intention to use & 0.38 & 3277 \\
\hline 5 & Perceived ease of use & Attitude & 0.19 & 3057 \\
\hline 6 & Perceived usefulness & Attitude & 0.39 & 3048 \\
\hline 7 & Trust & Intention to use & 0.33 & 2963 \\
\hline 8 & Intention to use & Use & 0.25 & 2959 \\
\hline 9 & Social influence & Intention to use & 0.19 & 2798 \\
\hline 10 & Effort expectancy & Intention to use & 0.16 & 2436 \\
\hline 11 & Computer Self-Efficacy & Perceived ease of use & 0.23 & 2312 \\
\hline 12 & Trust in Internet & Intention to use & 0.14 & 2106 \\
\hline 13 & Subjective norm & Intention to use & 0.28 & 2003 \\
\hline 14 & Trust & Perceived usefulness & 0.36 & 1834 \\
\hline 15 & Trust in government & Trust (technological tool) & 0.30 & 1743 \\
\hline 16 & Relative advantage & Intention to use & 0.30 & 1722 \\
\hline 17 & Facilitating conditions & Use & 0.29 & 1500 \\
\hline 18 & Image & Intention to use & 0.07 & 1350 \\
\hline 19 & Performance expectancy & Intention to use & 0.39 & 1211 \\
\hline 20 & Compatibility & Intention to use & 0.35 & 1200 \\
\hline 21 & Trust in government & Intention to use & 0.22 & 1110 \\
\hline 22 & Perceived quality & Satisfaction & 0.39 & 1014 \\
\hline 23 & Perceived behavioural control & Intention to use & 0.22 & 631 \\
\hline 24 & Perceived risk & Intention to use & 0.03 & 463 \\
\hline
\end{tabular}

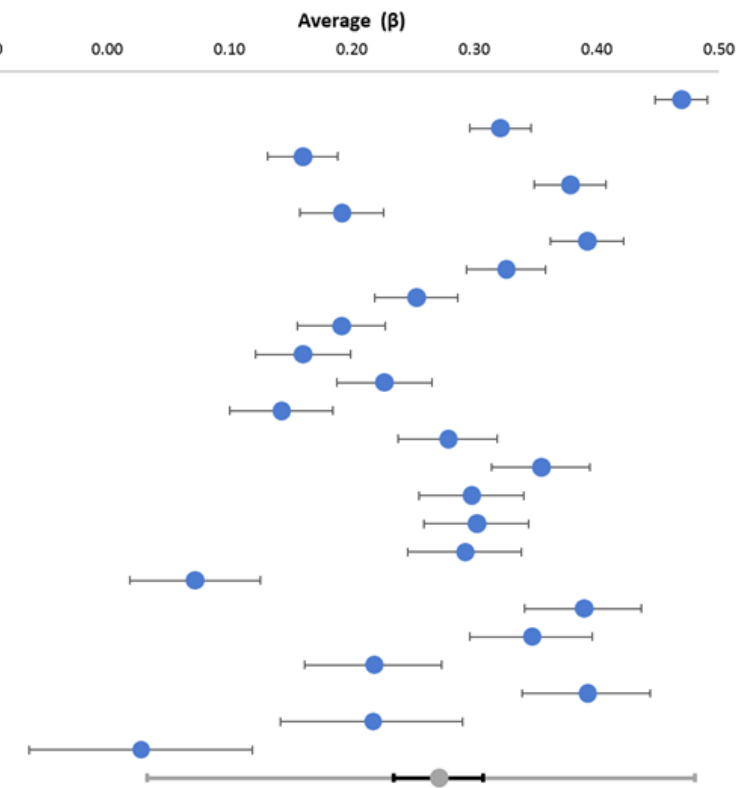

Figure 2.4. Forrest plot of Table 2.6 (Meta-analysis). Ordered by $\Sigma$ sample size descending

Following the approach of King \& He (2006) and Rana et al. (2015), p-value, standard normal deviations (Z-value), and the upper and lower confidence interval (95\%) are calculated. Based on $p$-value, the effect of the relationship strength was found to be non-significant $(p>0.05)$ for perceived risk ( $p$-value $=0.27$ ) on intention to use. The remaining relationships in the list were found significant. The average $\beta$ indicates the strength of the influence of the independent variable over the dependent variable; thus, perceived ease of use on perceived usefulness (0.47), perceived usefulness on attitude (0.39), attitude on intention use (0.38), and perceived usefulness on intention to use (0.32) were found to be the strongest ones. By using all the relationships that have been examined five or more times, we build the resulting model (see Figure 2.5). Jeyaraj et al. (2006) suggest that variables that have been tested five or more times can be considered "well-utilized". Variables that have been used less than five times, even though having high values for weight and $\beta$, under the same approach, are still considered 'promising' predictors (Jeyaraj et al., 2006). 


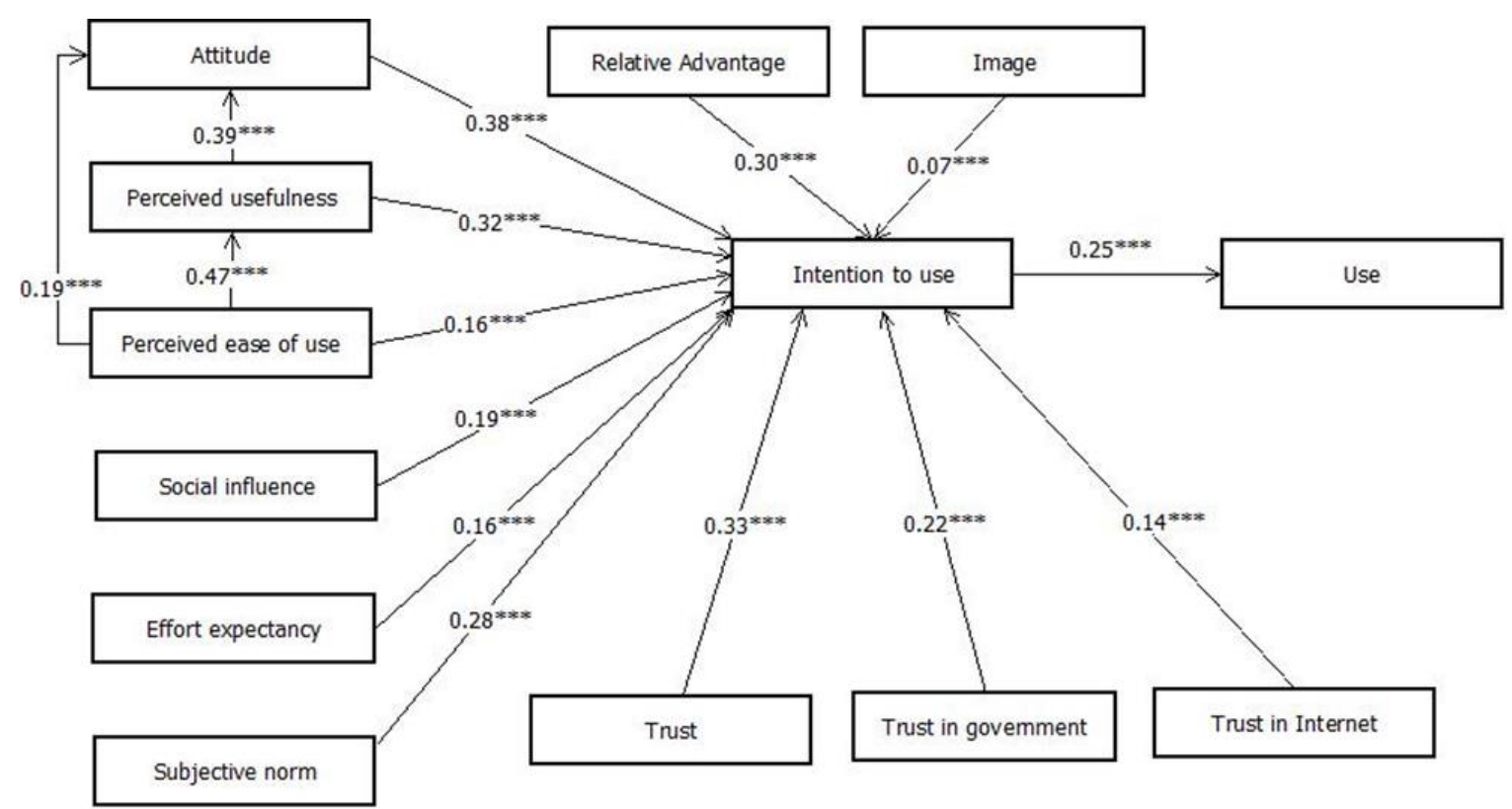

Figure 2.5. Model resulting from meta-analysis

Note: Numerical values represent the average $\beta ;{ }^{* * *} p<0.05$

\subsubsection{Evaluation of publication bias and normality}

Publication bias (Borenstein, Hedges, Higgins, \& Rothstein, 2009), refers to the higher probability for studies with significant and positive results to get published over the studies that report not statistical significant or negative results. If the articles included in the meta-analysis are a biased sample of the e-participation literature, then it is likely that the results computed by the meta-analysis may reflect this bias. Harrison, Banks, Pollack, O'Boyle, \& Short (2017) notes that publication bias can occur for different reasons: (i) researchers may adjust their research models until supportive results are obtained; (ii) researchers may prefer to publish the results that have bigger effect size and statistically significant; and, (iii) reviewers and editors may give priority to studies with statistically significant results over the not statistically significant ones. Following the approach of Harrison et al. (2017), that focusing on a single criterion offers a more sensitive and appropriate test for publication bias, we focus our analysis of the publications bias on one of the most widely examined variables of e-participation, intention to use. We derive a dataset from our list of selected articles to perform a publication bias test. The dataset contains the studies that have reported the $\beta$ values, which are the effect size for the relationship perceived usefulness on intention to use [independent - dependent variable] (Table 2.7). This relationship is the most examined in our list of studies (17 times). 
Table 2.7. List of 17 articles that examined the relationship [perceived usefulness - intention to use] (ordered by year)

\begin{tabular}{|c|c|c|c|c|c|c|c|}
\hline \multirow{2}{*}{$\begin{array}{l}\text { Study } \\
\text { Lee et al. (2003) }\end{array}$} & \multirow{2}{*}{$\begin{array}{c}\operatorname{Beta}(\beta) \\
0.360\end{array}$} & \multirow{2}{*}{$\begin{array}{c}\begin{array}{c}\text { Sample } \\
\text { size }\end{array} \\
158\end{array}$} & \multirow{2}{*}{$\begin{array}{c}\text { Correlation } \\
\text { (z) } \\
0.38\end{array}$} & \multirow{2}{*}{$\begin{array}{c}\text { Standard } \\
\text { error (z) }\end{array}$} & \multicolumn{2}{|c|}{$\begin{array}{c}\text { Confidence } \\
\text { interval (95\%) } \\
\text { Low - High }\end{array}$} & \multirow[t]{2}{*}{ Subgroup } \\
\hline & & & & & 0.21 & 0.49 & \\
\hline Carter \& Bélanger (2004) & 0.192 & 136 & 0.19 & 0.09 & 0.02 & 0.35 & \multirow{7}{*}{$\begin{array}{c}\text { Year 2003- } \\
2011\end{array}$} \\
\hline Schaupp \& Carter (2005) & 0.357 & 208 & 0.37 & 0.07 & 0.23 & 0.47 & \\
\hline Tang et al. (2009) & 0.069 & 385 & 0.07 & 0.05 & -0.03 & 0.17 & \\
\hline Lean el al. (2009) & 0.580 & 150 & 0.66 & 0.08 & 0.46 & 0.68 & \\
\hline Lin et al. (2011) & 0.210 & 167 & 0.21 & 0.08 & 0.06 & 0.35 & \\
\hline Shyu \& Huang (2011) & 0.405 & 307 & 0.43 & 0.06 & 0.31 & 0.49 & \\
\hline Al-Hujran et al. (2011) & 0.236 & 197 & 0.24 & 0.07 & 0.10 & 0.36 & \\
\hline Belanche et al. (2012) & 0.356 & 416 & 0.37 & 0.05 & 0.27 & 0.44 & \multirow{9}{*}{$\begin{array}{c}\text { Year 2012- } \\
2017\end{array}$} \\
\hline Winkler et al. (2012) & 0.290 & 200 & 0.30 & 0.07 & 0.16 & 0.41 & \\
\hline Rehman et al. (2012) & 0.105 & 138 & 0.11 & 0.09 & -0.06 & 0.27 & \\
\hline Choi \& Kim (2012) & 0.360 & 228 & 0.38 & 0.07 & 0.24 & 0.47 & \\
\hline Wang \& Lo (2012) & 0.360 & 200 & 0.38 & 0.07 & 0.23 & 0.48 & \\
\hline Aloudat el al. (2014) & 0.444 & 290 & 0.48 & 0.06 & 0.35 & 0.53 & \\
\hline Abu-Shanab (2014) & 0.428 & 759 & 0.46 & 0.04 & 0.37 & 0.48 & \\
\hline Dahi \& Ezziane (2015) & 0.549 & 845 & 0.62 & 0.03 & 0.50 & 0.59 & \\
\hline Seo \& Bernsen, (2016) & 0.169 & 111 & 0.17 & 0.10 & -0.02 & 0.35 & \\
\hline
\end{tabular}

The funnel plot (Torgerson, 2006), is a graphical method commonly used to detect publication bias. As explained in Sterne et al. (2011), the plot will be similar to a symmetrical and inverted funnel if there is no bias and between-study heterogeneity. The asymmetry in the funnel plot, which can be caused by the missing studies, may indicate publication bias. We follow the suggestion of Borenstein et al. (2009), that the use of the standard error in the $Y$ axis instead of the traditional sample size makes the identification of asymmetry easier. Torgerson (2006) cautions that the asymmetry in the funnel plot should be considered just 'suggestive' of publication bias. Sterne, Gavaghan, \& Egger (2000) describe three other possible reasons for asymmetry in the funnel plot: (i) true heterogeneity, (ii) data irregularities, and (iii) chance. Publication bias is evaluated assuming a random effect model with a $95 \%$ confidence level. Random effect model (Cooper, 2010) considers the variance within study and the variance between studies methods. The funnel plot (Figure 2.6), heterogeneity $\left(I^{2}\right)$, and the Egger regression (Egger, Smith, Schneider, \& Minder, 1997) (Table 2.8) to assess for asymmetry are calculated using a free tool software, Meta-Essentials (Van Rhee et al., 2015). 


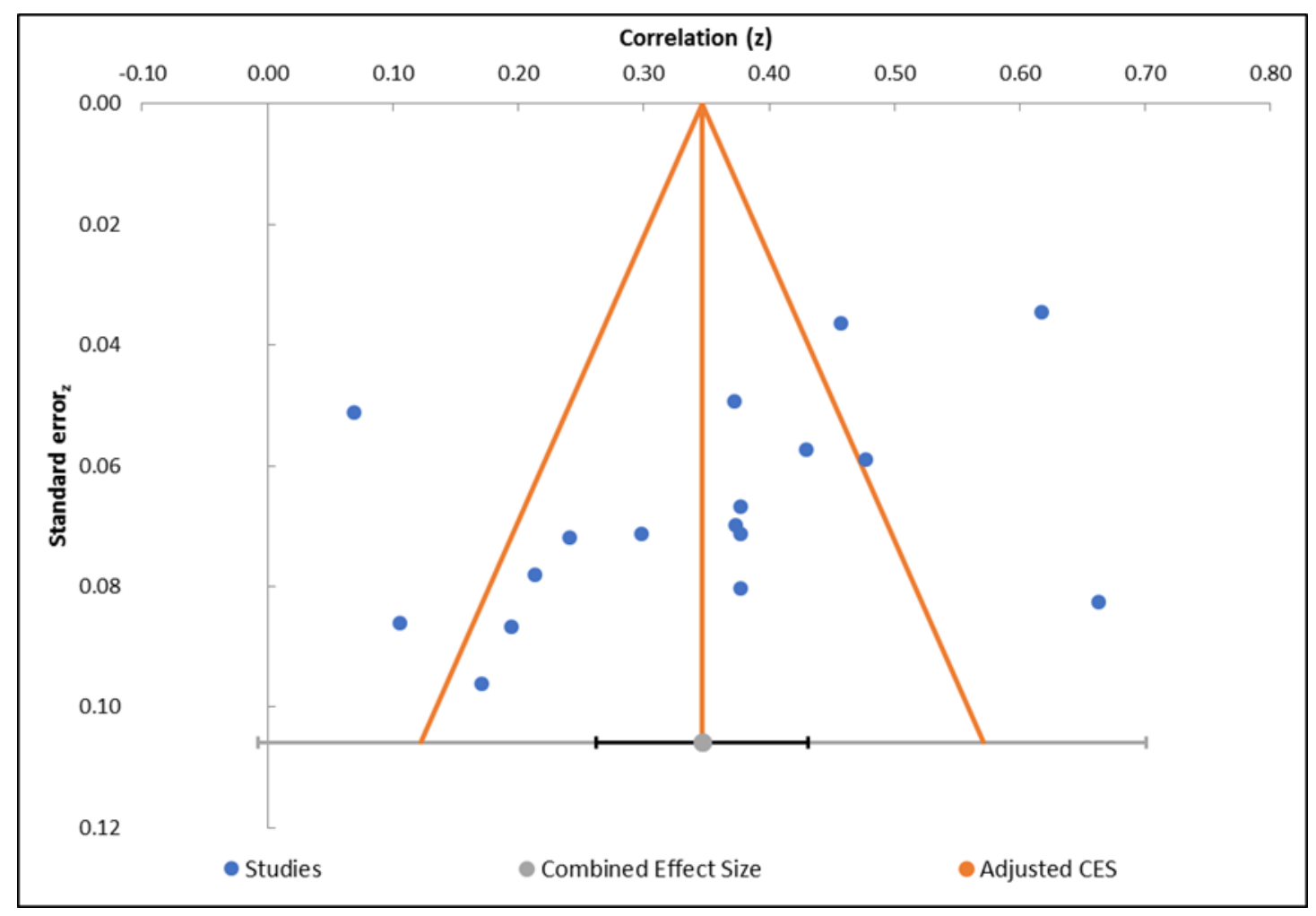

Figure 2.6. Funnel plot of studies that examined [perceived usefulness - intention to use] Note: Between sample heterogeneity $12=87.91 \%$. CES $=$ Combined effect size

Table 2.8. Egger Regression for asymmetry

\begin{tabular}{lllll}
\hline & Estimate & SE & CI LL & CI UL \\
\hline Intercept & -10.64 & 6.01 & -23.39 & 2.10 \\
Slope & 2.22 & 1.06 & -0.03 & 4.47 \\
\hline
\end{tabular}

Note: $\mathrm{t}$ test $=-1.77 ; \mathrm{p}$-value $=0.10 . \mathrm{SE}=$ Standard error. $\mathrm{Cl} \mathrm{LL}=$ Confidence interval lower level. $\mathrm{Cl}$ UL=Confidence interval upper level.

Heterogeneity is assessed by the statistic $I^{2}$ (Higgins \& Thompson, 2002). The results show a high level of heterogeneity $(87.91 \%)$ in the data set of studies. Even though having a high level of heterogeneity may not produce a funnel shape in the plot (Terrin, Schmid, \& Lau, 2005), Sterne et al. (2011) suggest that the "funnel plot will be symmetrical but with additional horizontal scatter". To provide a more accurate assessment of the asymmetry, rather than the visual evaluation of the funnel plot, Egger regression is also presented in the results, which resulted not significant for asymmetry ( $p$-value $=0.10$ ). In summary, there is no evidence to suggest that there is a publication bias in the selected data set of e-participation adoption studies. Nevertheless, there is a high level of heterogeneity. High level of heterogeneity in our 
study coincides with studies like Harrison et al.(2017), that evaluated a set of meta-analysis articles in the field of strategic management research, and $\mathrm{I}^{2}$ was found above $60 \%$ for most of the meta-analysis studies.

Given the high level of heterogeneity of the dataset (Table 2.7), we perform a subgroup analysis to examine if the level of heterogeneity decreases, the first group are the studies from 2003 to 2011 ( 8 articles) and the second group are the studies from 2012 to 2017 (9 articles). Results of the subgroup analysis are shown in Table 2.9 , heterogeneity $I^{2}$ remains very high $(0.86)$ for each of the subgroups.

The forest plot of the 17 articles that examined the relationship perceived usefulness on intention to use is presented in Figure 2.7. The plot shows three not significant studies in the meta-analysis of this dataset (studies No. 1, 15, and 17). We can notice a small drift to the left when the studies of smaller sample size are added. The drift can be an indicator of publication bias (Harrison et al., 2017) produced by the inclusion of studies with small sample size.

Table 2.9. Subgroup analysis of studies that examined [perceived usefulness - intention to use]

\begin{tabular}{lllll}
\hline Subgroup name & Correlation & Cl Lower limit & Cl Upper limit & $\mathrm{I}^{2}$ \\
\hline Studies year 2003-2011 & 0.31 & 0.16 & 0.44 & 0.86 \\
Studies year 2012-2017 & 0.36 & 0.25 & 0.46 & 0.86 \\
\hline
\end{tabular}

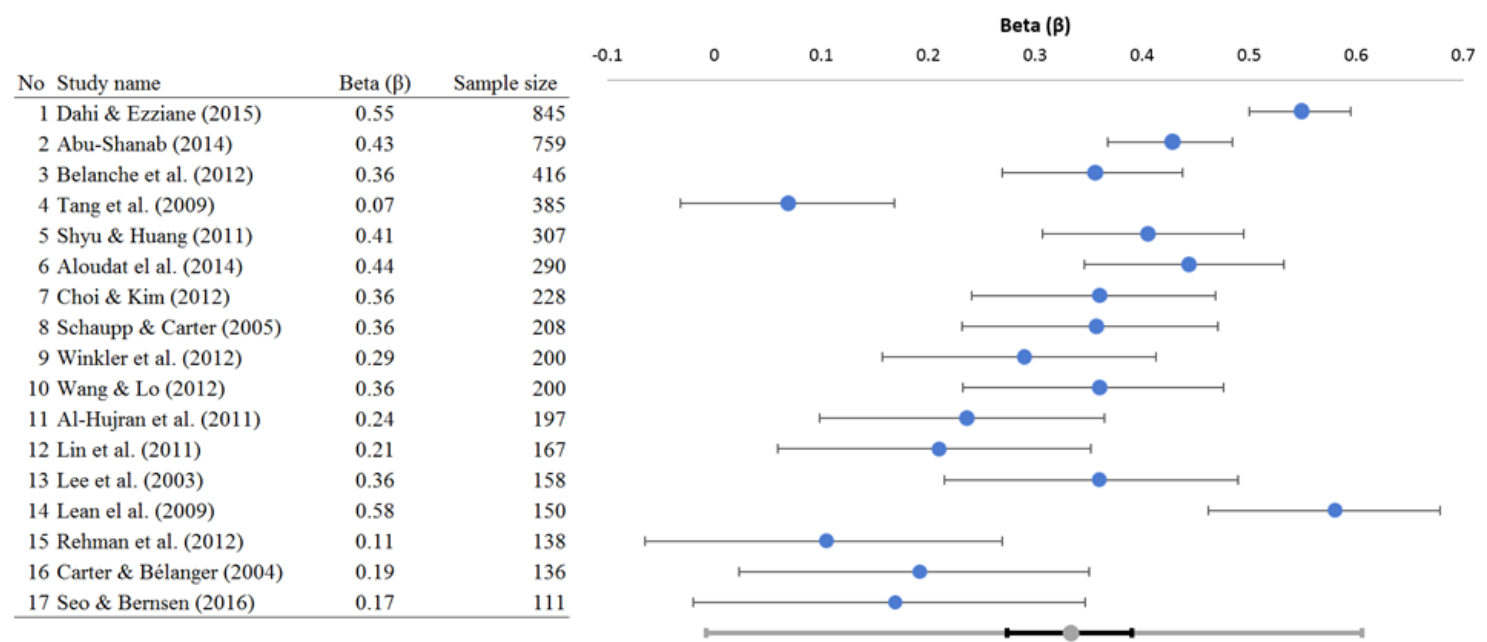

Figure 2.7. Forest plot of the 17 articles that examined [perceived usefulness - intention to use]. Ordered by sample size descending 
This study uses the random effect model for the meta-analysis. Nevertheless, Chen, Zhang, \& Li (2015) caution that the selected model may result in misleading results if the model does not fit the data. They suggest that "normality tests can be used to check the goodness-offit for random model". The normal quantile plot (M. C. Wang \& Bushman, 1998), also known as the Q-Q plot, has been proven to be useful in checking normality in meta-analytic datasets. The normal quantile plot is used to evaluate normality on the dataset of studies that examined the relationship between perceived usefulness and intention to use e-participation. All data points fall approximately on a straight line (Slope $=1$ ), which suggests that the data follow a standard normal distribution (see Figure 2.8).

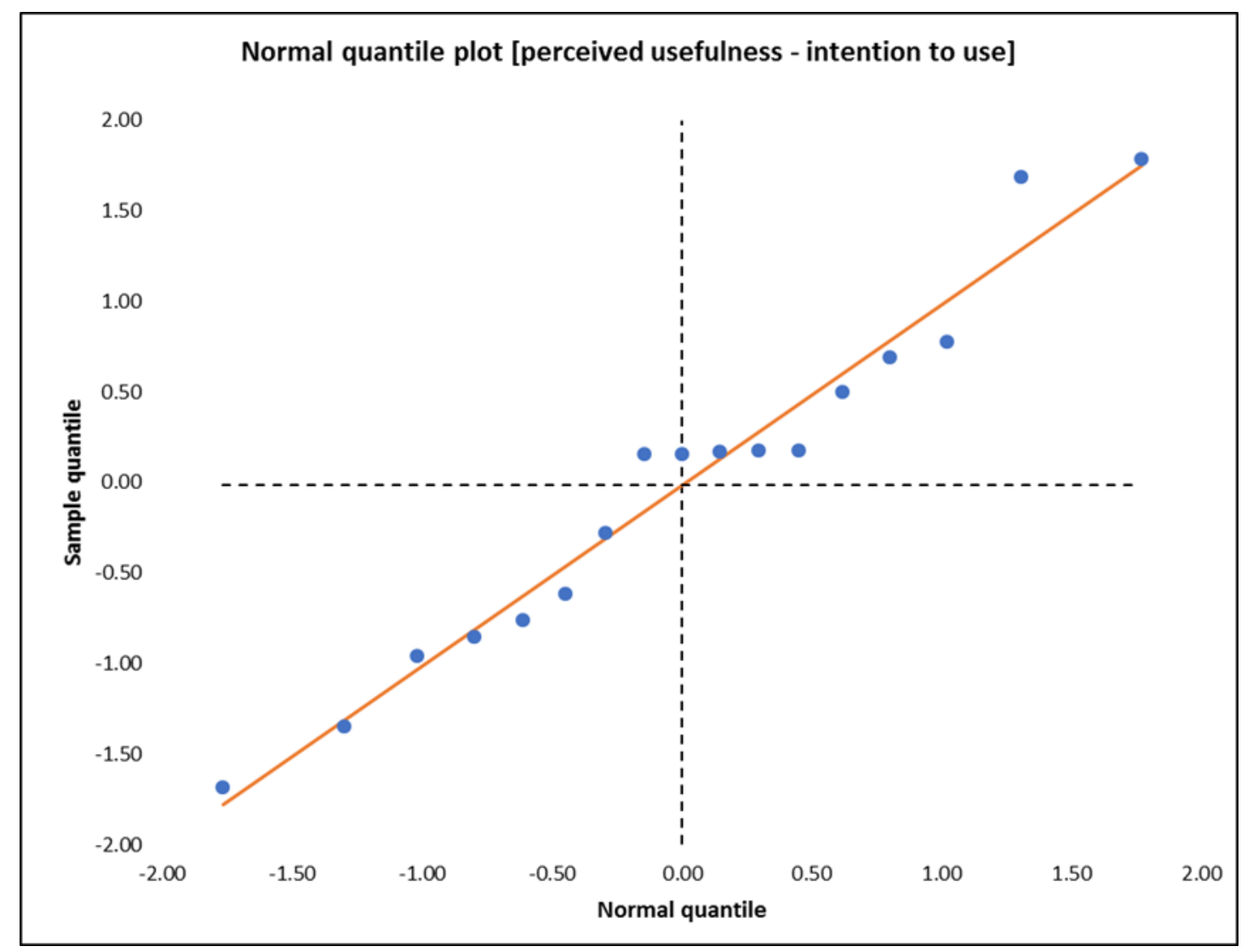

Figure 2.8. Normal quantile plot for the studies that examine [perceived usefulness - intention to use]

\subsection{Discussion}

A substantial variety of theories, theoretical models, and constructs were evaluated in the 60 articles considered in our paper. This led to a respectable number of 483 relationships [independent-dependent variable] and provides a comprehensive picture of all variables 
analysed in e-participation adoption research in the last 17 years, which may lay the foundations for future research (Webster \& Watson, 2002). The analysis of the correlations in those 483 relationships through weight analysis revealed the 'best' and 'promising' predictors (Jeyaraj et al., 2006) in the analysis of e-participation. Meta-analysis complemented these findings by providing the significance level, the level of heterogeneity $\mathrm{I}^{2}$ of the dataset, and an analysis of publication bias using the forest plot and funnel plot.

'Best' predictors include perceived usefulness, attitude, social influence, trust, effort expectancy, and trust in government on intention to use, perceived ease of use on perceived usefulness, perceived usefulness on attitude, and intention to use on use. All those relationships identified as best predictors in the weight analysis were also found to be statistically significant in the meta-analysis, coinciding with the claim of Baptista \& Oliveira (2016) and Rana et al. (2015) about the predictors, that is, the higher its weight, the higher the probability that it achieves significance in the meta-analysis. All of these predictors, except trust and trust in government, are part of either TAM (Davis, 1989) and UTAUT (Venkatesh et al., 2003). Trust on intention to use (weight 1 ) was also identified as a strong predictor in other contexts: Mobile banking (Goncalo Baptista \& Oliveira, 2016), e-government (Rana et al., 2015), mobile commerce (L. Zhang, Zhu, \& Liu, 2012), social network services (Shin, 2010), and health informatics services (Shin, Lee, \& Hwang, 2017). The importance of trust for e-participation was also highlighted by Panopoulou, Tambouris, \& Tarabanis (2014), as one of the success factors for e-participation. Building trust is a challenging matter, however. The increase of citizen's trust can lead to satisfaction and continuance intention to use over time (Shin et al., 2017).

Relationships in the weight analysis that were examined three or four times and obtained weight $=1$ are considered 'promising' predictors (Jeyaraj et al., 2006): compatibility, perceived behavioural control, and perceived risk on intention to use, facilitating conditions on use, perceived quality on satisfaction, trust on perceived usefulness, and trust in government on trust. The promising predictors need further analysis before being considered as best predictors (Jeyaraj et al., 2006). However, results in meta-analysis and low value of average $\beta$ for perceived risk on intention to use suggest that perceived risk is a weak predictor of e-participation adoption. An interesting relationship from the set of promising predictors is trust in government as predictor trust on the e-participation system, that showed satisfactory results in terms of weight, significance and average $\beta$. This finding may suggest that when the citizens have a higher level of trust in their governments, are also more willing to trust, and indeed use, the eparticipation systems available from that government. 
Publication bias (Borenstein et al., 2009) was not conclusive by the analysis of the funnel plot (Figure 2.6) because the high level of heterogeneity $\left(I^{2}=0.879\right)$ in the dataset (Table 2.7). As suggested by Hak et al. (2016), when exist a high level of heterogeneity, results in the funnel plot are not very clear for interpretation. The high level of heterogeneity can be due to the use of different research models, different variables, different populations, and different study protocols to evaluate e-participation adoption. We also used a second approach to test for publication bias, the forest plot (Figure 2.7) of the 17 studies that analysed the relationship [perceived usefulness - intention to use]. In the forest plot we can observe a slight drift toward the left when studies with smaller sample are added to the list, which may indicate a publication bias (Harrison et al., 2017). However, we consider that there is not enough evidence to conclude that there is publication bias in the set of studies. As suggested by Harrison et al. (2017) in the context of management research, at least a sample of 20 studies should be analysed to obtain clear results about the publication bias. In other scientific fields, as the medicine, publication bias can be assessed with smaller datasets of studies, as few as 10 studies (Sterne et al., 2011). In the case of e-participation research would be more appropriate to evaluate a sample of at least 20 studies that analyse the same variable.

Research on e-participation adoption has used TAM, UTAUT, combinations of TAM and UTAUT with other theories, and self-developed research models (see Table 2.2). Therefore, it is not a surprise that the most frequently evaluated constructs across the studies also belong to TAM and UTAUT or are adapted from them. Although, not all constructs from these well-known theories resulted always significant or demonstrated to be strong predictors of e-participation (see Figure 2.3). This is the case of perceived ease of use on attitude (TAM), and perceived ease of use on intention to use (adaptation of TAM), which did not show a good performance in weight analysis and obtained low average $\beta$ values ( 0.19 and 0.16 respectively). On the other side, perceived ease of use has the strongest average $\beta(0.47)$ on perceived usefulness, which in turn is a strong predictor of attitude and intention to use. The explanation for these seemingly opposite results may be due to the fact that the solely perception that the e-participation system is easy to use is not enough motivation to trigger the intention to use the system in the citizen. Maybe there are other factors inherent to the participation itself -and not to the technological tool- that can produce stronger motivation in the citizen to use e-participation, for instance, trust in the public institutions, sense of community (Talò et al., 2014), or the perception of the citizen that is truly making a contribution to a given community by using e-participation (empowerment). Perceived usefulness may encompass, at least partially, those above- 
mentioned factors, thus demonstrating to be a strong motivator for intention to use and attitude.

Interestingly, effort expectancy on intention to use, a relationship of the UTAUT model (Venkatesh et al., 2003) that was originally derived from perceived ease of use from TAM (Davis, 1989), has been found significant and examined five times in the studies. Due to the low number of times that perceived ease of use has been examined in the articles, there is not enough evidence to claim that effort expectancy performs better than its predecessor perceived ease of use in the study of e-participation adoption.

Other relationships evaluated five or more times were found to be significant in the meta-analysis but obtained a weight slightly below 0.80 . This is the case for perceived ease of use on attitude (weight $=0.78)$, relative advantage on intention to use (weight $=0.67$ ), and trust in Internet on intention to use (weight $=0.67$ ). For those variables, further research is needed to assess the impact in the prediction of e-participation adoption. Variables such as performance expectancy (weight $=0.60)$, perceived ease of use $($ weight $=0.62)$ and image $($ weight $=0.17)$ on intention to use ranked considerably lower from the threshold of 0.80. Even though they show statistical significance in the meta-analysis, their low weight values may discourage their continued use in future studies.

\subsection{Implications}

\subsubsection{Implications for theory}

First, the synthesis of cumulative influence of an independent variable on a dependent variable in the form of weight analysis, and the evaluation of significance in the meta-analysis, allowed us to derive a model of best predictors of intention to use and actual use of e-participation. Results presented in this paper confirm the high performance of all TAM and UTAUT constructs for research on e-participation adoption, except for perceived ease of use on intention to use, which resulted in low performance. Trust and trust in government, without being part of UTAUT or TAM, are also part of the best predictors of intention to use e-participation. These findings suggest continuing the use of trust and trust in government on intention to use in future research of e-participation adoption.

Second, weight and meta-analysis provide the performance of a wide-ranging view of the relationships [independent-dependent variable] used in models to study e-participation 
adoption at individual level, consequently allowing researchers to identify trends, and highlighting issues in the use of some constructs. For instance, even though perceived ease of use and image were found to be significant and frequently used in literature, their weight is noticeably low. Researchers can use the findings of this study as a starting point for a more accurate and effective selection of constructs in the analysis of e-participation adoption, providing additional criteria whether to include or not a variable in the research model. For example, on one hand, variables that showed high frequency of use, low weight, and nonsignificance, may be excluded from further use; on the other hand, promising predictors require further analysis to become best predictors, and their continued use may therefore be appropriate.

\subsubsection{Implications for practice}

Findings in this study raise important implications for governments and institutions aiming to implement e-participation platforms. Perceived usefulness, attitude, social influence, trust, and effort expectancy on intention to use e-participation technologies resulted strong predictors in the weight analysis. The meta-analysis confirms the significance. This suggest that governments should put special attention on strategies that help to preserve positive attitude, the perception that the platform is useful, and trust of citizens in the long-term. The implementation of eparticipation should not only lie on the use of cutting edge technology and innovative interface design, solid back office processes are also recommended for e-participation platforms. For instance, when users give opinions on forums or vote electronically, feedback should be provided in a reasonable timeframe; this may contribute to improve the perception of usefulness and preserve trust of citizens.

The high weight value of perceived usefulness on intention to use, but low weight value of perceived ease of use on intention to use may suggest that citizens do not really find difficulties in the use of e-participation, rather, citizens probably are more focused on the contributions that they can make to a given community through e-participation, for instance, submitting a project proposal to a government agency or giving an electronic vote for a project to be implemented. The action to vote electronically, for instance, by SMS message may not be a technical challenge for citizens (perceived ease of use) but is the final impact of the given vote (perceived usefulness) that really motivates the intention to use e-participation. This implies that governments that implement e-participation systems should make sure that the citizens have a clear understanding about the impact of using e-participation to contribute for the community. 
Due to voluntary nature of e-participation, ease and simplicity for general public users is strongly advised to promote the diffusion of this technological platform amongst the citizens. Even though, implementation and promotion of e-participation can lead to a better governance in the long term, Andersen, Henriksen, Secher, \& Medaglia (2007) highlight the importance for public agencies to be aware of the significant administrative costs to support e-participation. Furthermore, citizen participation involves a sense of community (Chavis \& Wandersman, 1990), thus social influence resulted an important predictor of the intention to use e-participation. This suggest that governments should actively promote and socialize its e-participation tools among the citizens.

\subsection{Conclusions}

We carried out a weight and meta-analysis of the constructs utilized in the evaluation of theoretical models of e-participation adoption amongst 60 articles published in the last 17 years. This study presents an extensive vision of the predictors and their cumulative synthesis through weight and meta-analysis, serving as the foundation for future research and providing additional criteria for researchers to accurately select the constructs to be included in research models to analyse e-participation adoption. The article identifies 'best' and 'promising' predictors (Jeyaraj et al., 2006) of e-participation adoption. The constructs: perceived usefulness, attitude, social influence, trust, effort expectancy, and trust in government on intention to use; perceived ease of use on perceived usefulness; perceived usefulness on attitude; and intention to use on use are considered the best predictors. This suggests that public agencies, authorities, and governments that plan to implement e-participation platforms should endeavour to preserve the positive attitude, perception of usefulness, and trust of citizens in the long-term participative processes. Moreover, best predictors achieved statistically significant results in most of the studies in which they were used, and therefore represent a safe side for future research in e-participation intention to use and use. The constructs identified as 'promising' predictors: compatibility and perceived behavioural control on intention to use, facilitating conditions on use, perceived quality on satisfaction, trust on perceived usefulness, and trust in government on trust (in the technological tool), reached a perfect weight of 1 , however, due to low frequency of usage in research models, still more research is needed for the promising predictors may be considered 'best' predictors. 


\subsection{Limitations and Future Research}

The 60 articles used for the weight and meta-analysis in this study are a small portion of the existing literature on e-participation adoption. There are two main factors in the literature search that limit the results: (i) The language of the articles is limited to English, which excludes all the significant research conducted in other languages; and (ii) as for the calculations, the beta coefficients and sample size are needed, the type of selected articles was of quantitative type, excluding all the qualitative articles that are the majority retrieved from the database search. Due to the relatively limited sample size, conclusions regarding the trends and patterns should be interpreted with caution.

Since most of the studies did not report the items used in their surveys, it is not possible to fully identify whether a construct is already used in other articles. Hence, the merging process has its limitations. Not all variables with similar names, apparently standing for analogous meanings, could be merged due to the lack of details in the articles that allow us to determine their equivalence (see Appendix 2.1). For instance, trust, in some articles is not entirely clear whether it refers to the technological tool, to the authorities, or to the whole process.

More than the half of the articles analysed do not describe the technologies evaluated in sufficient detail, nor their specific interaction with citizens. For example, of the 60 studies, 25 described them only as online services and seven described them as web portals. Lack of detailed description prevents us from deepening the research of more tailored adoption models for different levels of e-participation. The use of moderator variables (e.g., cultural dimensions or demographics, and second-order constructs) was scarce in the quantitative articles. As a result, moderator analysis and second-order constructs analysis were not incorporated in this study.

Hoftede, Hofstede, \& Minkov (2010) have stated that culture is for humans what software is for computers. Culture varies from country to country. The inclusion of new or barely explored variables such as cultural dimensions in primary studies is suggested for future research on e-participation adoption. We note that e-participation has several levels of citizen involvement, from simply being informed to expressing opinion and voting. Therefore, a comparative meta-analysis between incremental levels of e-participation is recommended. This may provide interesting insights about whether the factors that influence e-participation have the same impact across the different levels. 


\section{Chaper 3 - Citizen's intention to use and recommend e-participation: Drawing upon UTAUT and citizen empowerment}

\subsection{Introduction}

E-participation is defined as a branch of e-government with special focus on citizen engagement for deliberation and decision orientation (Welch, 2012). For instance, the online participatory budgeting platforms (Sintomer et al., 2013) allow citizens to decide on how to spend a part of the public budget managed by local governments. Engaging citizens in consultation and decision-making has a prominent importance to promote a more efficient and inclusive society (Sæbø et al., 2008), citizen participation in digital governance (Sanford \& Rose, 2007), transparency, efficiency, and quality of public services (Royo \& Yetano, 2015). Electronic consultation and decision-making tools are considered the highest level of e-participation from the perspective of empowering citizens. However, the implementation of e-participation is still very challenging and vulnerable to failure due to the risk of low adoption rates on the part of citizens (Kersting, 2016; Omar et al., 2017). The literature does not provide a strong theoretical basis to support successful implementations and adoption of e-participation.

Beyond the potential benefits of involving citizens in consultation and decision-making, e-participation also has the potential of reducing the costs for democratic and decision-making processes (Vragov \& Kumar, 2013). Traditional paper balloting for the same purpose would demand many more resources from both the citizens (time) and the local governments (money). Despite the latest growing number of implementations of the e-participation tools; significant adoption and tangible positive outcomes from citizen interaction with e-participation remain at low levels. For instance, comparing the levels of e-participation within the top 25 countries ranked by the United Nations in 2014 and 2016, the utilization level rose from 36\% (United Nations, 2014) to $62 \%$ (United Nations, 2016), but only $20 \%$ of the United Nations member states report that "e-consultation outcomes have resulted in new policy decisions, regulation or service" (United Nations, 2016).

Previous studies of the factors that drive the adoption of e-participation have used theoretical models in the context of technology adoption (Naranjo Zolotov et al., 2018). Using only theoretical models of technology adoption may not provide a strong theoretical basis of the general factors that drive the adoption of e-participation. For example, Chiang (2009) used TAM (technology acceptance model) (Davis, 1989) to examine trust in the e-voting system; and 
Wang \& Shih (2009) studied the use of information kiosks by using UTAUT (Venkatesh et al., 2003). Building theory on e-participation adoption is still challenging for researchers due to its interdisciplinary and highly dynamic nature (Medaglia, 2012; Susha \& Grönlund, 2012). Using technology adoption models alone may not be enough if we wish to analyse the specific characteristics of e-participation. Venkatesh et al. (2016) suggest that "it is necessary to draw on other theoretical perspectives to identify and examine specific characteristics" of e-participation. Even though citizen empowerment has been identified as a key factor for public participation and engagement (Kang, 2014), little research has analysed the perspective of empowerment in the adoption of e-participation for public consultation and decision-making. Consequently, the integration of UTAUT and empowerment in a research model may bring valuable insights on eparticipation adoption drivers.

Our work makes three main contributions to the enrichment of the theoretical body of literature in the e-participation context. First, we develop a research model that integrates UTAUT and empowerment theory. The research model allows us to identify that the feeling of empowerment in citizens is indeed a strong motivator of intention to use and intention to recommend e-participation. Second, we analyse how the integration of empowerment with UTAUT increases the intention to use and to recommend e-participation. And third, we contribute to the construct clarity of second-order multidimensional constructs in the context of e-participation. Moreover, this study yields insights for local governments seeking to implement or extend the scope of e-participation.

The rest of the paper is organized as follows: Section 2 provides a literature review of the e-participation context and the description of the theories employed in the research model. Section 3 contains the research model and hypotheses development. Section 4 describes the methods used and the data collected. Section 5 presents the data analysis and results. Then, Section 6 discusses the findings along with theoretical and practical implications, limitations, and future research. Finally, a conclusion presents final thoughts.

\subsection{Background and hypothesis development}

\subsubsection{Contextualizing e-participation adoption}

The United Nations E-Government Survey 2014 report (United Nations, 2014) includes eparticipation as one of e-government's core components and describes a three-level e- 
participation model: e-information, e-consultation, and e-decision-making, thus moving from "passive" to "active" engagement with citizens (Kassen, 2017). The highest level in the eparticipation model, the decision-making, requires an active engagement and involvement of the citizens in the long-term scenario for its success, which means that citizens should be highly motivated to devote their time to activities such as deliberation, decision-making, and voting using information and communication technologies (ICT). Today, most governments have adopted one or more participation technologies to interact with citizens, for instance, open data technologies (Zuiderwijk et al., 2015), information kiosks (Y.-S. Wang \& Shih, 2009), and e-voting (Chiang, 2009). Research shows that the adoption of participative technologies facilitates interaction and collaboration between government and citizens (Welch, 2012). However, interaction does not necessarily mean achieving consulting and decision-making levels. Those levels of e-participation may require citizen empowerment.

Previous studies discussed important factors that can influence the process of eparticipation adoption, although they did not address the issue of what it is that would attain consulting and decision-making levels. For instance, Oliveira \& Welch (2013) studied the use of social media in government for improving public service and engagement and found that the organizational factors, such as innovativeness, technological capacity, and external influence, predict the use of social media for different tasks; citizen satisfaction, trust in government, and the use of e-participation were found to be interrelated (Welch et al., 2005); Schaupp et al. (2010) found evidence that once trust is lost, adoption of e-government and e-participation becomes very challenging; digital divide (Cruz-Jesus, Oliveira, \& Bacao, 2012), such as lack of computer literacy or limited access to infrastructure and internet connection, and accessibility (J. Martins, Gonçalves, \& Branco, 2017) can represent important barriers to adoption (Janssen, Charalabidis, \& Zuiderwijk, 2012); political factors (Oni et al., 2017) such as political awareness, political efficacy, and political culture have been found to play an important role in eparticipation usage.

The literature suggests that citizen empowerment is one of the key ingredients for successful citizen participation over time in consulting and decision-making processes (Kang, 2014; Macintosh, 2004; Omar et al., 2017). Empowering citizens implies allowing them to influence the decisions made by the government. Nevertheless, it is not entirely clear how the perception of empowerment affects the behavioural intention to use and recommend eparticipation technologies. Most studies rely on single theories from information technology, which does not allow analysing specific effects from e-participation, such as citizen 
empowerment. On the other hand, UTAUT allows the analysis of the drivers of technology adoption in complex scenarios and can shed light on both the information technology factors and social factors (Zuiderwijk et al., 2015). Analysing the drivers of the behavioural intention to use and intention to recommend e-participation from both the empowerment perspective and UTAUT can provide insights for governments to achieve higher levels of citizen involvement in consulting and decision processes and exploit the potential benefits of citizen electronic participation. In this study we address these issues by integrating UTAUT constructs with empowerment theory to investigate the effect of these factors on the intention to use and recommend e-participation.

\subsubsection{UTAUT}

The unified theory of acceptance and use of technology - UTAUT (Venkatesh et al., 2003) is a theoretical model that has been widely used in the study of technology acceptance and adoption. UTAUT is an appropriate theory to study e-participation adoption for three main reasons: first, according to Venkatesh et al. (2003), UTAUT is suitable to study complex organizational technologies. E-participation can be considered a complex technological context due to the number of different tools available (Sæbø et al., 2008), different types and amounts of data generated by the citizens, stakeholders with diverse interests, and two-way governmentcitizen interactions in which citizens usually expect to receive feedback for their actions. These factors make a complex research scenario in which UTAUT can be appropriate to examine the behavioural intention to use the e-participation, which has been suggested as the main predictor of human behaviour (JinKyu Lee \& Rao, 2009). Second, UTAUT has the potential to provide valuable insights in the investigation of e-participation because it takes into account both the information technology factors and social factors (Zuiderwijk et al., 2015).

UTAUT has been used in a broad range of research fields to understand the factors that drive the technology adoption, obtaining diverse results in terms of significance of the constructs - for instance: (i) internet banking (Tarhini, El-Masri, Ali, \& Serrano, 2016), in which performance expectancy, effort expectancy, social influence, perceived credibility, and task technology fit (Goodhue \& Thompson, 1995) were found significant on intention to use; (ii) egovernment services (N. Alharbi, Papadaki, \& Dowland, 2017), in which three of the four UTAUT constructs are significant on intention to use (not effort expectancy); and, (iii) e-learning (Oh \& Yoon, 2014), in which performance expectancy, effort expectancy, and social influence have a significant effect on intention to use. For the application of the UTAUT model, the hypotheses 
are usually adapted to the context of the study (Venkatesh, Thong, Chan, Hu, \& Brown, 2011). In the case of our study, we have adapted the original UTAUT hypotheses to the context of eparticipation. We use four constructs from UTAUT to determine the behavioural intention to use: performance expectancy, effort expectancy, social influence, and facilitating conditions.

(1) Performance expectancy (Venkatesh et al., 2003, 2012) has been found, in most cases, to be the strongest predictor of intention to use an information technology, regardless of the environment (X. Luo, Li, Zhang, \& Shim, 2010). Herein it is defined as the degree to which the individual considers that using e-participation will help to obtain gains or provide benefits for the community. Performance expectancy implies that the citizen notices that she/he can increase productivity in the participation processes. The existing ICT tools for e-participation, such us e-petition, online incident reporting apps, and online participatory budgeting, allow the citizens to express their ideas, opinions, and petitions using online resources such as text, pictures, and videos. Thus, the use of e-participation may increase the citizen's expectation of performing better when giving their contributions to the community.

H1. Performance expectancy positively impacts the intention to use e-participation.

(2) Effort expectancy is defined as the degree of ease associated with the use of a given technology, which influences the intention to use that technology (Venkatesh et al., 2003, 2012). E-participation is designed for and oriented toward the citizenry. As e-participation is voluntary and users devote their time for benefits that are not reflected at the individual level, but at the community level, the perception of the effort required to use e-participation may play a critical role in the citizen's intention to use it. One of the main barriers to e-participation use are the digital skills of citizens (van Deursen \& van Dijk, 2009). We believe that citizens will expect that e-participation tools are extremely easy to use. Consequently, if they find some level of difficulty to use e-participation, they would probably not adopt the technology.

H2. Effort expectancy positively influences the intention to use e-participation.

(3) Social influence is defined as the extent to which an individual perceives that others who are important to her/him, such as family and friends, consider that she or he should use the system (Venkatesh et al., 2003, 2012). The important others are usually members of the same community in which an online participation takes place. In the case of e-participation, the social influence may also come from the media and politically active individuals (Oni et al., 2017). The positive opinions of those members may encourage other citizens to contribute through eparticipation, thus, increasing their intention to use the system. 
H3. Social influence positively impacts the intention to use e-participation.

(4) Facilitating conditions are the degree to which the individual perceives the existence of resources and support to use a certain technology whenever necessary (Venkatesh et al., $2003,2012)$. E-participation is mainly provided and supported by local government agencies. A citizen who has easy access to resources like computers, smartphones, internet connection, support chat rooms, phone line, or other favourable conditions will increase his or her intention to use e-participation. In the e-participation context the facilitation environment (Venkatesh et al., 2012) can vary across citizens because of different technological devices and different eparticipation tools available according to the goal and level of participation. For instance, when reporting an incident through a mobile app, the resources needed to carry out this task are less demanding than the resources needed to participate in deliberation forums or ideas and online project proposals.

H4. Facilitating conditions positively influence the intention to use e-participation.

\subsubsection{Recommending the use of e-participation}

Recommendation is considered a form of post-adoption behaviour (M. M. Luo, Chea, \& Bui, 2016), which makes the intention to recommend a key factor for the successful diffusion of eparticipation. In the marketing context a positive recommendation has been shown to be very persuasive and effective to influence the behaviour and attitude of other customers (P.-Y. Chen, Wu, \& Yoon, 2004; Hsiao \& Chuang, 2009). Hong \& Yang (2009) found that the customercompany identification mediates the intention of positive recommendation. Intention to recommend has also been found to be mediated by trust (Vlachos, Tsamakos, Vrechopoulos, \& Avramidis, 2009). In the context of e-participation the satisfaction and trust in government (Welch et al., 2005) may mediate the effect of intention to use and empowerment over the intention to recommend e-participation. In the field of mobile government, Liu et al. (2014) suggest that after a positive recommendation, the likelihood of adoption may also increase.

Recommending a technology has not been widely studied due to a much greater focus on the use behaviour construct. Miltgen et al. (2013); Oliveira et al. (2016) and Lee et al. (2011) provide evidence that citizens with high levels of intention to use an information technology are more likely to recommend the technology to others. The rationale to hypothesize an effect of intention to use over intention to recommend is that when a citizen has the intention to use eparticipation, she/he may also have an interest in other citizens supporting the same goals and 
getting involved in e-participation. The behaviour of recommending the technology may play a critical role in supporting the diffusion of e-participation. Since the use of e-participation implies that the citizen already has access to Internet, providing recommendations online is just one more step ahead. The existing technologies such as online social networks (e.g. Facebook, Twitter) allow the rapid dissemination of positive recommendations regarding the eparticipation technologies. When a citizen has the intention to use e-participation, she/he may also have an interest in other citizens supporting the same goals and getting involved in eparticipation. For instance, when there is an e-voting process to choose some projects to be implemented in the city amongst several candidate projects, the citizens interested in the execution of a given project may recommend the technological platform to others to promote the projects. It is also important to keep in mind that e-participation processes will be successful in the long term only if a sufficient number of citizens contribute to them.

H5. Intention to use e-participation positively influences the intention to recommend the technology to others.

\subsubsection{Citizen empowerment}

Psychological empowerment theory (Rappaport, 1987; Zimmerman, 1995; Zimmerman \& Rappaport, 1988), is described as "the connection between a sense of personal competence, a desire for, and a willingness to take action in the public domain" (Zimmerman \& Rappaport, 1988). This theory has been mainly applied in efforts to understand motivations in the work environment. Spreitzer (1995) developed a multidimensional measure of psychological empowerment in the work context that has been widely used and adjusted in many studies. For instance, (i) Ergeneli, Ari, \& Metin (2007) examined the relationship between psychological empowerment and bank managers' cognition-based trust in immediate managers; and (ii) Hochwälder \& Brucefors (2005) studied the relationship between psychological empowerment in the workplace and aspects of ill health. Despite the extensive use of psychological empowerment in the work context, to the best of our knowledge, it has not yet been applied in the context of e-participation adoption. Empowerment has been approached as a set of dimensions, rather than as a singular concept (Peterson, 2014; Spreitzer, 1995; Thomas \& Velthouse, 1990). We measure the effect of citizen empowerment as a second-order construct on the intention to use and intention to recommend e-participation. Empowerment is defined by its first-order dimensions: impact, competence, meaning, and self-determination. 
(1) Competence (Thomas \& Velthouse, 1990), or self-efficacy (Bandura, 1986), is defined as the degree to which a citizen can perform an e-participation activity with sufficient required skills, for example, complete a search for a candidate project on e-participation and send an SMS to vote for that project.

(2) Meaning refers to the individual judgment of the value of an e-participation action or purpose, seen according to the citizen's own ideas or standards (Thomas \& Velthouse, 1990). For instance, if there is a participative online discussion about a project that has a value for the citizen, it is more likely that he or she will join the online discussion.

(3) Impact refers to the degree to which a behaviour or action on the e-participation is seen as producing the effects or influence intended by the citizen (Sjoberg, Mellon, \& Peixoto, 2017; Thomas \& Velthouse, 1990), as for instance, an electronic vote for a project that later is implemented in the community.

(4) Self-determination (Deci \& Ryan, 1985), also known as choice, is the perception of causal responsibility for an outcome of e-participation derived from an activity of the citizen (Thomas \& Velthouse, 1990). When a citizen submits a proposal for a project through eparticipation, he or she becomes the origin of that project's existence, which is evaluated by the local government and other citizens, thereby causing empowerment in the citizen.

Psychological empowerment has been described as the highest expression of participation (Macintosh, 2004). Earlier studies have found that several activities such as consulting, exchange of opinions, and involving citizens in decision-making processes increase the intention to participate in e-government initiatives (Bataineh \& Abu-Shanab, 2016; Phang \& Kankanhalli, 2008). Furthermore, Kang (2014) found empowerment to be a key dimension for public engagement, which may lead to positive recommendations. These findings suggest that the psychological empowerment theory may contribute to theoretical knowledge in the field of e-participation, specifically, to understand its pre- and post-adoption behaviour. We posit that a citizen who has the perception of being empowered by the actions performed on eparticipation will experience a greater intention to use, and later recommend, this technology.

H6. Empowerment positively influences the intention to use e-participation.

H7. Empowerment positively impacts the intention to recommend e-participation. 


\subsection{Research method}

\subsubsection{Research model}

The integration of UTAUT with empowerment fills a gap in the analysis of e-participation adoption. UTAUT has been widely used in the study of technology adoption, yet the use of psychological empowerment has been rather marginal in the context of e-participation adoption. Given the unique characteristics of e-participation (Sæbø et al., 2008; Medaglia, 2012), we explore the inner motivations that may trigger the citizen's desire to be involved in the public participatory process using ICT and contribute to its diffusion. In other words, we consider intention to use and intention to recommend as a first and second dependent variable respectively. Even though intention to recommend has received very little attention in the literature of technology adoption, due to the massive focus on use (Miltgen et al., 2013), intention to recommend may be of great interest for government agencies that implement eparticipation, as it can help to identify insights for dissemination and diffusion of e-participation initiatives. The research model is shown in Figure 3.1.

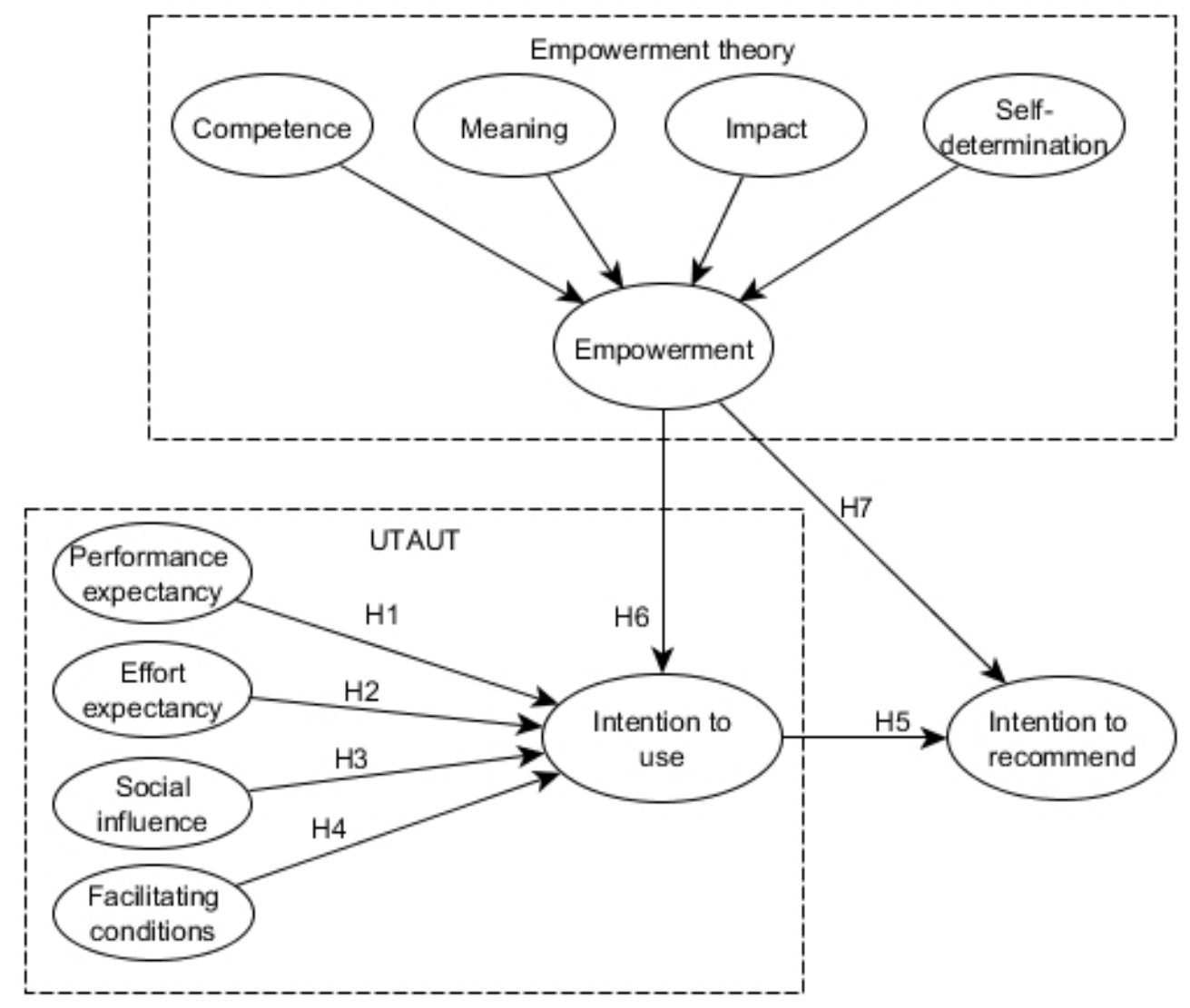

Figure 3.1. Research model 


\subsubsection{Control variables}

We include age, gender, and level of education as control variables on the intention to use and recommend e-participation. Control variables are external to the theories being tested. Individual differences such as age, gender, and level of education may affect the way users perceive technology (Venkatesh, Morris, \& Ackerman, 2000; White Baker, Al-Gahtani, \& Geoffrey S. Hubona, 2007). Nevertheless, results from earlier studies differ in the conclusions about the preference for technology adoption regarding age and gender. For instance, Venkatesh et al. (2016) found that age had significant impact on a citizen's intention to use egovernment, although gender was not significant; AI-Somali, Gholami, \& Clegg (2009) found that age and gender had no effect on attitude toward use of online banking; Vicente \& Novo (2014) found that age was not significant while gender was significant for citizen online engagement with e-participation, where men are more likely than women to express opinions about political issues or sign online petitions; Choi \& Kim (2014) analysed the effect of word-of-mouth on online social networks and found that men are more likely than women to share online brand-related content and product information. In the case of education, earlier research reports evidence that citizens with higher levels of education are more likely to adopt e-participation (Lindner \& Riehm, 2011).

\subsubsection{Measurement}

We use previously validated scales for all the constructs in our research model, adjusted to the context of e-participation (see Appendix 3.1). We use reflective measures for all first-order constructs in the model. All the variables pertaining to the main constructs were measured by multiple-type close-ended questions on a seven-point Likert scale ranging from 1 (totally disagree) to 7 (totally agree). The items for performance expectancy, effort expectancy, social influence, facilitating conditions, and intention to use are adapted from Venkatesh et al. (2012). For intention to recommend, two of their items were adapted from Oliveira, Thomas, Baptista, \& Campos (2016), and another from Hoehle \& Venkatesh (2015). Gender was coded as a 0 or 1 dummy variable where 1 represents men. Age was measured in years. Level of education is a categorical variable for which the categories correspond to the Portuguese education system from primary school to the PhD level. When evaluated in the model, level of education was translated into years of schooling. Following the suggestion of Peterson (2014), we consider empowerment as a second-order reflective-formative type construct represented by its firstorder dimensions: competence, meaning, impact, and self-determination. Their items were 
adapted from Kim \& Gupta (2014). The hierarchical model is of a reflective-formative type (Becker, Klein, \& Wetzels, 2012; Ringle, 2012).

The questions were originally written in English and reviewed for content validity by a group of university researchers. The questionnaire was translated from English to Portuguese by a professional translator, and then back to English by a different professional to check for equivalence. Wording of the translated questions in Portuguese were discussed and polished with local colleagues in academia and public officials of the municipality, who also provided us with their database of contacts for the electronic survey. Previously, we carried out a pilot study with 27 complete answers to test the questionnaire and correct possible errors. The data from the pilot test were not used in the next phase of data analysis.

\subsubsection{Data Collection}

This study takes place in Portugal, where municipalities in several cities across the country have implemented e-participation tools for the direct involvement of and contribution from citizens. The so called online participatory budget (Allegretti \& Antunes, 2014) is amongst the most popular ones. The electronic participative budget allows citizens to submit project initiatives through a web portal, and to vote for the available projects on the platform. Most of the citizens vote by means of an SMS message from their mobile phone. These platforms stand out in the eparticipation context as they facilitate the inclusion of a larger number of citizens that are willing to contribute with project proposals and/or by voting for the available projects to be implemented by the municipality.

In Portugal, 74\% of families had access to Internet at home by 2016 (INE - Instituto Nacional de Estadística, 2016). The access to Internet at home is higher in the urban areas and big cities (e.g., $82 \%$ in the metropolitan area of Lisbon). Regarding the political attitudes and political action, Magalhães (2005) found that citizens are increasingly dissatisfied with the democratic performance. This may be due to a negative perception of political responsiveness of representative institutions (Torcal, 2014) and the economic crisis in Portugal one decade ago that negatively influenced the political attitude (Brito Vieira, Carreira da Silva, \& Pereira, 2017) and the political trust (van der Meer \& Hakhverdian, 2017). The e-participation tools oriented for decision-making may open an interesting opportunity to allow the citizens themselves to propose and decide on local issues, which could help to recover the trust and satisfaction in representative institutions. 
Data were collected through an electronic survey. An invitation email containing a hyperlink to the questionnaire was sent to a database of registered users in the municipality systems of a Portuguese city; the hyperlinks could be used only once. At the beginning of the questionnaire the respondents were presented an explanatory introduction of the goal of the survey, including electronic participative budget as one example of e-participation tool. Participation in the survey was voluntary. We offered prizes as incentives to participants. The questionnaire was available from September $6^{\text {th }}$ to October $30^{\text {th }}$ of 2016 . A total of 210 valid responses were collected. Details of respondents' demographic characteristic are in Table 3.1.

Table 3.1. Sample demographic characteristics (ordered by number of observations)

\begin{tabular}{|c|c|c|}
\hline Characteristics $(n=210)$ & Obs. & $\%$ \\
\hline \multicolumn{3}{|l|}{ Gender } \\
\hline Feminine & 112 & 53.33 \\
\hline Masculine & 98 & 46.67 \\
\hline \multicolumn{3}{|l|}{ Age } \\
\hline From 40 to 55 & 123 & 58.57 \\
\hline From 26 to 39 & 47 & 22.38 \\
\hline 56 or more & 35 & 16.67 \\
\hline 25 or less & 5 & 2.38 \\
\hline \multicolumn{3}{|l|}{ Level of education } \\
\hline Bachelor's degree & 92 & 43.81 \\
\hline High school & 59 & 28.10 \\
\hline Master's degree & 29 & 13.81 \\
\hline Post-graduation & 19 & 9.05 \\
\hline NA/NR & 4 & 1.90 \\
\hline Doctorate & 4 & 1.90 \\
\hline Primary school & 3 & 1.43 \\
\hline \multicolumn{3}{|l|}{ Profession } \\
\hline Worker for third parties & 121 & 57.62 \\
\hline Self-employed & 35 & 16.67 \\
\hline Retired & 13 & 6.19 \\
\hline Unemployed & 13 & 6.19 \\
\hline Freelancer & 11 & 5.24 \\
\hline Other & 10 & 4.76 \\
\hline Student & 7 & 3.33 \\
\hline
\end{tabular}

\subsection{Data Analysis and Results}

We assess the research model using the partial least squares structural equation modelling (PLSSEM) method (Hair, Hult, Ringle, \& Sarstedt, 2014). We use SmartPLS 3.0 software (Ringle, Wende, \& Becker, 2015). PLS is a variance-based technique, which is data driven and suitable 
for predictive analysis to test the causal relationships that were theoretically derived as hypotheses and using empirical data (Hair et al., 2011). Although the study does not use longitudinal data, the participants that answered the electronic questionnaire have previously experienced the online participatory budgeting platform (Hibberts, Johnson, \& Hudson, 2012). Our model complies with several considerations stated in Hair et al. (2014) for choosing the PLS

method: (i) the goal is to predict key drivers of e-participation adoption; (ii) the structural model is complex, comprising 11 constructs (empowerment as second-order construct) and its 31 indicators; and, (iii) the sample size $(n=210)$ fulfils the rule of being at least 10 times more than the largest number of paths directed to a construct in the model; in this case the largest number of structural paths is five.

\subsubsection{Exploratory factor analysis and model fit}

We conduct exploratory factor analysis with varimax rotation to check whether the measurement items are adequately related to their constructs. The Kaiser-Meyer-Olkin (KMO) test resulted in 0.9, which is considered "marvellous" (Sharma, 1996), indicating that the data are appropriate for factor analysis. All the items loaded above 0.5 (Costello \& Osborne, 2005) except for FC4. We eliminated FC4 from the model, please see Appendix 3.2. The adequacy of measurements items is confirmed.

For a tenable model fit, Hair et al. (2014) suggest 0.08 or smaller cut-off value for standardized root mean square residual (SRMR). Ziggers \& Henseler (2016) reported a good model fit based on a normal fit index (NFI) of 0.865 or higher using PLS-SEM. Results for SRMR (0.04) and NFI (0.87) support a good model fit.

\subsubsection{Measurement Model}

We have reflective and formative constructs in our model. For reflective constructs we analysed the internal consistency, convergent validity, and discriminant validity (Hair et al., 2014). Cronbach's alpha and composite reliability are the two criteria used for internal consistency. As reported in Table 3.2, both have values above 0.7 for all latent variables, which suggests internal consistency (Hair et al., 2014; Mackenzie, Podsakoff, \& Podsakoff, 2011). Convergent validity is also assessed by two criteria, the average variance extracted (AVE) and the indicator reliability. The AVE and the loadings are above 0.5 and 0.7 respectively (Table 3.2 ), in almost all cases, showing a good convergent validity (Hair et al., 2014). Loadings below 0.4 should be dropped 
(Henseler, Ringle, \& Sinkovics, 2009), which was not necessary for any item in the measurement model.

We use two criteria to test discriminant validity. (i) Fornell \& Larcker (1981), which states that the square root of AVE should be greater than its correlation with any other construct (see Table 3.2), and (ii) the Hetrotrait-Monotrait Ratio (HTMT) (Henseler, Ringle, \& Sarstedt, 2015), which requires the HTMT ratios to be below the threshold of 0.9 (see Table 3.3). Therefore, the model presents a good discriminant validity.

Table 3.2. Quality criteria

\begin{tabular}{|c|c|c|c|c|c|c|c|c|c|c|c|c|c|}
\hline Constructs & CA & CR & AVE & 1 & 2 & 3 & 4 & 5 & 6 & 7 & 8 & 9 & 10 \\
\hline 1. Performance expectancy & 0.85 & 0.91 & 0.77 & 0.88 & & & & & & & & & \\
\hline 2. Effort Expectancy & 0.91 & 0.93 & 0.78 & 0.52 & 0.88 & & & & & & & & \\
\hline 3. Social influence & 0.95 & 0.97 & 0.91 & 0.39 & 0.20 & 0.95 & & & & & & & \\
\hline 4. Facilitating conditions & 0.83 & 0.90 & 0.75 & 0.37 & 0.58 & 0.17 & 0.87 & & & & & & \\
\hline 5. Behavioural intention & 0.91 & 0.94 & 0.85 & 0.50 & 0.48 & 0.24 & 0.51 & 0.92 & & & & & \\
\hline 6. Recommendation & 0.90 & 0.94 & 0.84 & 0.47 & 0.45 & 0.24 & 0.45 & 0.49 & 0.91 & & & & \\
\hline 7. Competence & 0.97 & 0.98 & 0.95 & 0.37 & 0.62 & 0.19 & 0.66 & 0.42 & 0.49 & 0.97 & & & \\
\hline 8. Meaning & 0.96 & 0.98 & 0.93 & 0.43 & 0.32 & 0.33 & 0.48 & 0.52 & 0.49 & 0.53 & 0.96 & & \\
\hline 9. Impact & 0.94 & 0.96 & 0.89 & 0.32 & 0.21 & 0.31 & 0.16 & 0.27 & 0.45 & 0.31 & 0.32 & 0.94 & \\
\hline 10. Self-determination & 0.95 & 0.96 & 0.90 & 0.37 & 0.50 & 0.11 & 0.52 & 0.47 & 0.52 & 0.58 & 0.39 & 0.34 & 0.95 \\
\hline
\end{tabular}

Notes: CA = Cronbach's Alpha, CR = Composite Reliability, AVE = Average Variance Extracted.

Square root of AVE in bold.

Table 3.3. Hetrotrait-Monotrait Ratio

\begin{tabular}{lcccccccccc}
\hline Constructs & 1 & 2 & 3 & 4 & 5 & 6 & 7 & 8 & 9 & 10 \\
\hline 1. Performance expectancy & & & & & & & & & & \\
2. Effort Expectancy & 0.59 & & & & & & & & & \\
3. Social influence & 0.44 & 0.21 & & & & & & & & \\
4. Facilitating conditions & 0.44 & 0.66 & 0.19 & & & & & & & \\
5. Behavioural intention & 0.57 & 0.53 & 0.26 & 0.58 & & & & & & \\
6. Recommendation & 0.54 & 0.50 & 0.26 & 0.52 & 0.53 & & & & & \\
7. Competence & 0.41 & 0.66 & 0.20 & 0.74 & 0.45 & 0.52 & & & & \\
8. Meaning & 0.48 & 0.34 & 0.35 & 0.54 & 0.56 & 0.53 & 0.55 & & & \\
9. Impact & 0.35 & 0.22 & 0.33 & 0.18 & 0.29 & 0.49 & 0.32 & 0.33 & & \\
10. Self-determination & 0.40 & 0.55 & 0.11 & 0.59 & 0.51 & 0.56 & 0.60 & 0.41 & 0.36 & \\
\hline
\end{tabular}

For formative constructs we assessed the multicollinearity, statistical significance, and sign of the weights. Psychological empowerment is modelled as a higher-order construct of a reflective-formative type (Becker et al., 2012; Ringle, 2012). Multicollinearity is evaluated by the 
variance inflation factor (VIF). The VIF ranges from 1.191 to 1.804 , which is below 5 , indicating no collinearity issues (Hair et al., 2014). All the weights are statistically significant $(p<0.01)$ and positive. See Table 3.4 .

Table 3.4. Measurement model evaluation for higher-order formative constructs

\begin{tabular}{llll}
\hline Higher-order formative construct & First-order reflective constructs & VIF & Weight \\
\hline \multirow{3}{*}{ Empowerment } & Competence & 1.804 & $0.363^{* * *}$ \\
& Meaning & 1.462 & $0.355^{* * *}$ \\
& Impact & 1.191 & $0.257^{* * *}$ \\
& Self-determination & 1.585 & $0.346^{* * *}$ \\
\hline
\end{tabular}

Note: ${ }^{*} p<0.10 ;{ }^{* *} p<0.05 ;{ }^{* * *} p<0.01$

\subsubsection{Structural Model}

To assess our research model, we follow the approach of Hair et al. (2014): coefficient of determination $\left(R^{2}\right), f^{2}$ effect-size, predictive relevance $Q^{2}$, and structural model path coefficients.

(1) $R^{2}$ is a measure of the model's predictive power. For this study we follow the suggested rule of thumb in marketing research for the interpretation of $\mathrm{R}^{2}$ values (Hair et al., 2014; Henseler et al., 2009), according to which, 0.75, 0.50, and 0.25, can be described as substantial, moderate, and weak, respectively. Both, intention to use (0.442) and intention to recommend (0.458), obtained moderate $R^{2}$ values.

(2) From the constructs that were significant, most of the values in $f^{2}$ yield small effects: age on recommendation (0.028), psychological empowerment on intention to use (0.062), facilitating conditions on intention to use (0.044), gender on intention to use $(0.028)$, intention to use on intention to recommend (0.034), and performance expectancy on intention to use (0.060). The only exception is psychological empowerment on intention to recommend (0.329), considered as a medium effect (Hair et al., 2014). The path coefficient of education level on recommendation was also found to be statistically significant. However, since its effect size $f^{2}$ is less than 0.02 , level of education has no meaningful effect on recommendation $\left(f^{2}=0.013\right.$ ).

(3) The blindfolding technique was used to calculate $Q^{2}$, with omission distance set to 7 . All three of the $Q^{2}$ values of endogenous latent variables are above zero, with the smallest $Q^{2}=$ 0.338. This means that all exogenous variables have predictive relevance for the endogenous constructs in the model (Hair et al., 2014). 
(4) Significance of the path coefficients indicates whether our hypotheses are supported or not, and was assessed using the bootstrapping technique (Hair et al., 2014) with 5000 iterations. Results are compared with the critical values for two-tailed tests. Amongst the seven hypotheses posited in our study, five are confirmed by the results. The model explains $44.0 \%$ of variation in the intention to use and $46.1 \%$ of variation in the intention to recommend. Figure 3.2 illustrates the values for path coefficients, their significance, $R^{2}$, and predictive relevance $Q^{2}$.

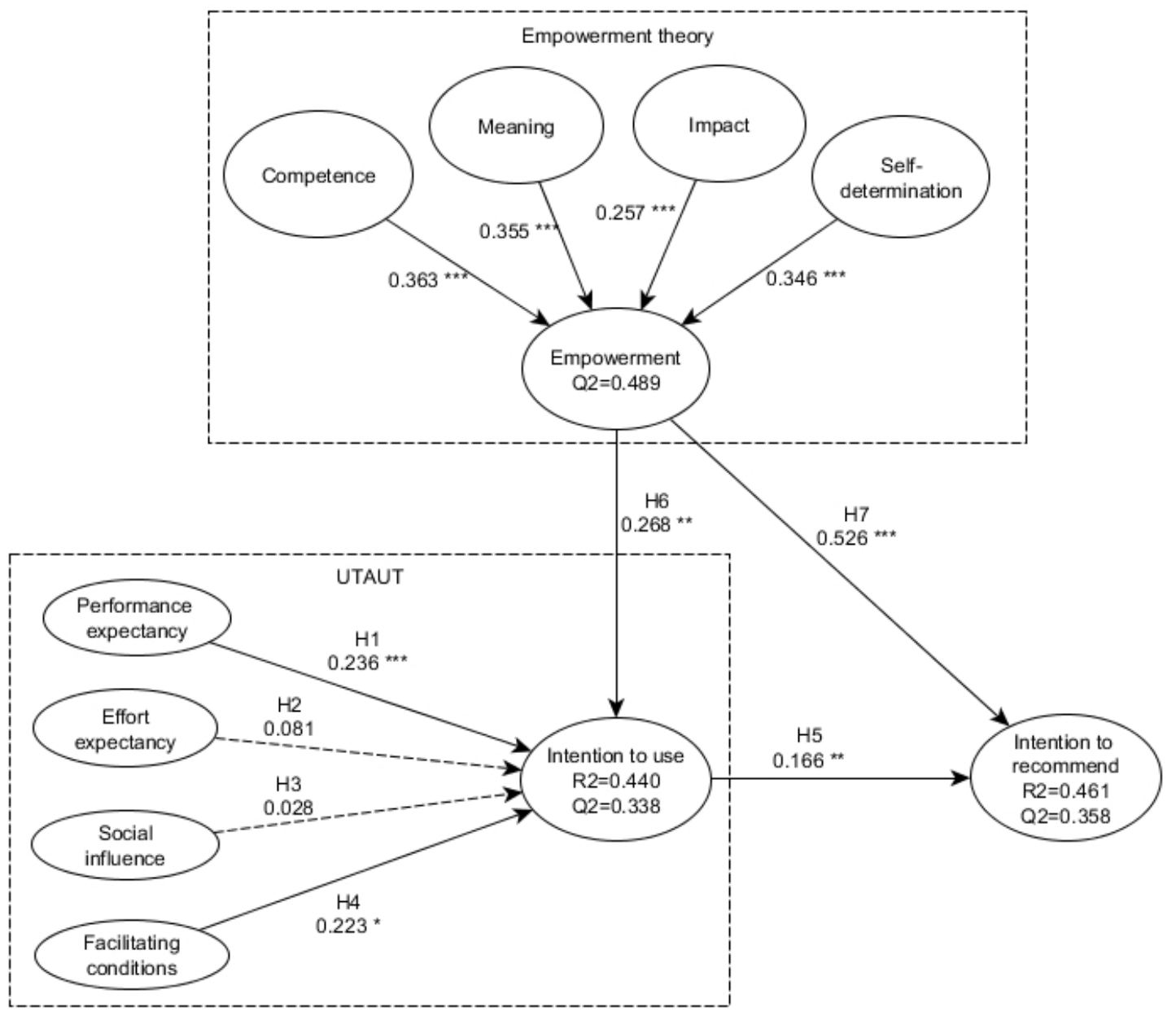

Figure 3.2. Structural model results

Notes: significant at ${ }^{*} 10 \% ; * * 5 \% ;{ }^{* *} 1 \%$. Non-significant paths are in dotted arrows.

Evidence shows that psychological empowerment improves the predictive power of UTAUT. We evaluated two structural models: (i) UTAUT alone and (ii) UTAUT with psychological empowerment. Hair et al. (2014) caution that problems emerge when comparing the $R^{2}$ of different models, since adding constructs slightly correlated with the endogenous variable will 
increase its $R^{2}$ value. Instead, they suggest the adjusted coefficient of determination $\left(R^{2}{ }_{\text {adj }}\right)$, which allows avoiding bias in complex models. We compare the path coefficients, significance, and $\mathrm{R}_{\text {adj }}$ for the two models. Based on $\mathrm{R}^{2}$ adj we can conclude that the full research model (UTAUT + empowerment) performs better than UTAUT alone in the e-participation context. The increment of $\mathrm{R}^{2}$ adj in the full model in comparison to the UTAUT alone model is more substantial for intention to recommend. The increment for intention to use is rather modest. Table 3.5 compares the results of the two models.

Table 3.5. Comparison of results

\begin{tabular}{|c|c|c|c|c|c|}
\hline \multirow[b]{2}{*}{ Independent variable } & \multirow[b]{2}{*}{ Dependent variable } & \multicolumn{2}{|c|}{ UTAUT Only } & \multicolumn{2}{|c|}{ UTAUT + Empowerment } \\
\hline & & Path coefficient & $R^{2} a d j$ & Path coefficient & $R^{2}$ adj \\
\hline Performance expectancy & & $0.287^{* * *}$ & & $0.236 * * *$ & \\
\hline Effort Expectancy & & 0.130 & & 0.081 & \\
\hline Social influence & & 0.056 & & 0.028 & \\
\hline Facilitating conditions & Intention to use & $0.339 * * *$ & 0.385 & $0.223^{*}$ & 0.417 \\
\hline Empowerment & & - & & $0.268^{* *}$ & \\
\hline Age & & 0.001 & & 0.022 & \\
\hline Gender & & $-0.131 * *$ & & $-0.128 * *$ & \\
\hline Level of education & & -0.043 & & -0.029 & \\
\hline Intention to use & & $0.462 * * *$ & & $0.166^{* *}$ & \\
\hline Empowerment & Intention to & - & בר20 & $0.526 * * *$ & 0447 \\
\hline Age & recommend & $-0.212 * * *$ & 0.272 & $-0.127^{*}$ & 0.441 \\
\hline Gender & & 0.025 & & -0.028 & \\
\hline Level of education & & -0.086 & & $-0.086^{*}$ & \\
\hline
\end{tabular}

Notes: Significant at $* 10 \% ; * * 5 \% ; * * * 1 \%$. Hypotheses are derived from the full model (UTAUT + empowerment).

As can be seen in Table 3.6 and Figure 3.2, of the seven hypotheses five are confirmed. Hypotheses $\mathrm{H} 1, \mathrm{H} 2, \mathrm{H} 3$, and $\mathrm{H} 4$ are about the constructs of UTAUT theory. Performance expectancy $(\mathrm{H} 1)$ and facilitating conditions $(\mathrm{H} 4)$ are significant in explaining intention to use eparticipation ( $\beta=0.236, p<0.01$ and $\beta=0.223, p<0.1$ respectively). Effort expectancy $(H 2)$ and social influence $(\mathrm{H} 3)$ have no significant effect on intention to use. Hypothesis $\mathrm{H} 5$ concerns the relationship between intention to use and intention to recommend e-participation, which is significant $(\beta=0.166, p<0.05)$, and thus $\mathrm{H} 5$ is confirmed. Hypotheses $\mathrm{H} 6$ and $\mathrm{H} 7$ are about the effect of empowerment theory of intention to use $(\beta=0.268, p<0.05)$ and intention to recommend $(\beta=0.526, p<0.01)$, respectively. Both are supported. The results show that the relationship between empowerment and intention to recommend is the strongest of the model. 
Table 3.6. Summary of hypotheses testing

\begin{tabular}{lc}
\hline \multicolumn{1}{c}{ Hypotheses } & Supported? \\
\hline H1: Performance expectancy --> Intention to use & Yes \\
H2: Effort expectancy --> Intention to use & No \\
H3: Social influence --> Intention to use & No \\
H4: Facilitating conditions --> Intention to use & Yes \\
H5: Intention to use --> Intention to recommend & Yes \\
H6: Empowerment --> Intention to use & Yes \\
H7: Empowerment --> Intention to recommend & Yes \\
\hline
\end{tabular}

\subsection{Discussion}

The current study builds and evaluates a model to understand the drivers of the intention to use and recommend e-participation. This model is based on UTAUT and psychological empowerment. We found that in addition to two of the UTAUT constructs, namely performance expectancy and facilitating conditions, psychological empowerment also influences the intention to use e-participation. Our results also reveal that women are more willing to use eparticipation than men, and younger citizens are more willing to recommend e-participation than older citizens (see Table 3.5). Our model explains $44.0 \%$ of the variance in the intention to use, and $46.1 \%$ of the variance in the intention to recommend e-participation (see Figure 3.2).

Regarding the UTAUT constructs, performance expectancy was found to be significant and the strongest predictor of intention to use e-participation. This finding is consistent with earlier research (Luo et al., 2010; Zuiderwijk et al., 2015), implying that when a citizen perceives that her/his productivity increases by participating in e-participation, she/he is more willing to adopt e-participation. The results also show that effort expectancy and social influence have no significant effect on the prediction of intention to use. This finding differs from findings in previous studies (Kollmann \& Kayser, 2010; Wang \& Shih, 2009), reporting those constructs as significant. Facilitating conditions is significant on intention to use, which is in line with other studies (Rodrigues et al., 2016; Wang \& Lo, 2012). This indicates that the extent to which the citizen has the ICT resources to use e-participation significantly influences the intention to use e-participation.

The finding of effort expectancy as not significant on intention to use coincides with studies in other contexts of information technology adoption, such as mobile banking (Gonçalo Baptista \& Oliveira, 2015; T. Oliveira, Faria, Thomas, \& Popovič, 2014), which suggest that when users are already familiar and find it easy to use e-participation tools, the influence of effort 
expectancy on behavioural intention decreases (Alharbi et al., 2017). Regarding the nonsignificance of social influence, this factor was introduced in UTAUT for the organizational context as the next version of subjective norms (Venkatesh et al., 2003). In the case of eparticipation, different from the organizational settings, the usage is completely voluntary, which may explain the non-significance of social influence. This finding goes in line with previous literature suggesting that when the use is perceived as voluntary, social influence is less important (Hartwick \& Barki, 1994; Venkatesh et al., 2003). Moreover, as e-participation is not yet widely used in the city where the data were collected, its usage cannot yet be considered the norm. The actual users of e-participation do not receive a direct influence from the other citizens who are so far not yet involved in e-participation projects. The initial influence to use eparticipation tools may well be the result of the marketing promotion and advertisement done by the local government that hosts the system.

Psychological empowerment is defined as a higher-order construct. We found its firstorder formative components, namely competence, meaning, impact, and self-determination to be significant and positive on the construct empowerment. This positively influences intention to use e-participation. This result is consistent with another study in the e-participation context (E. A. Abu-Shanab, 2015), in which empowerment was evaluated as a first-order construct in the context of open government. This implies that if citizens perceive a feeling of empowerment with e-participation, it will positively affect their intention to use e-participation. Furthermore, we found that intention to use and psychological empowerment positively influence intention to recommend. This finding is consistent with other studies that found intention to use to impact significantly over intention to recommend; for instance, Miltgen et al. (2013) in the context of biometrics, and Oliveira et al. (2016) in the context of mobile payment.

\subsubsection{Theoretical Implications}

The first theoretical implication is derived from the proposed integrated research model to analyse the behavioural intention and the action to recommend e-participation technologies. We explore the inner motivations of the individual by integrating psychological empowerment theory with UTAUT. The positive values in each of the dimensions of psychological empowerment may contribute, in some degree, to the perception of empowerment in the citizen regarding the intention to use and recommend e-participation. Thus, (a) competence may imply that the more skills the user has to use e-participation, the greater her/his intention to use e-participation; (b) meaning may indicate that when the purpose of using e-participation 
has a value for the citizen, she/he will be more willing to use and recommend e-participation to others; (c) impact may suggest that if the citizen has the perception that his usage of eparticipation will have a final positive outcome for the community, she/he may be more motivated to use and recommend the technology; and finally, (d) self-determination could indicate that when citizens have a perception of responsibility for an outcome of e-participation, they will also have a greater intention to use and recommend the system.

Secondly, our results confirm an acceptable explanatory power in predicting intention to use and recommendation of e-participation. The results indicate that when psychological empowerment is integrated with UTAUT the level of variance on intention to use and intention to recommend e-participation is increased. The $\mathrm{R}^{2}$ adj increases from $38.5 \%$ (UTAUT only) to $41.7 \%$ (full model) for intention to use, and from $27.2 \%$ (UTAUT only) to $44.7 \%$ (full model) for intention to recommend (Table 3.5). The stronger impact of empowerment on intention to recommend than on intention to use may imply that once the citizens have a perception of empowerment, they will be much more willing to recommend the usage to others, as for instance sharing the e-participation ideas in social networks and inviting others to join.

Thirdly, we contribute to the construct clarity of higher-order multidimensional constructs (Johnson, Rosen, Chang, Djurdjevic, \& Taing, 2012) in the context of e-participation. We provide a model in which psychological empowerment is used as a higher-order construct to explain intention to use and recommend e-participation. And finally, when the context of technology usage is completely voluntary and easy to use, which is the case for e-participation, the effect of effort expectancy and social influence, as they are defined in UTAUT, become little or non-significant over the behavioural intention to use the technology.

\subsubsection{Practical Implications}

Understanding the behavioural intention to use and intention to recommend of e-participation tools and platforms is critical for entities that implement and promote the use of those technologies (usually local government institutions). The hypotheses tested from both theories integrated in the model provide interesting insights for practitioners.

Regarding the empowerment-related hypotheses: positive effect of empowerment on intention to use and recommend e-participation implies, for the public sector, that the strategies for promotion and diffusion of e-participation should focus on citizens' positive perception of the four components of psychological empowerment: competence, meaning, impact, and self- 
determination. For instance, in the case of impact, the e-participation platform should keep the citizens informed about the effects produced by their participations through the platform (Royo \& Yetano, 2015). This may contribute to the perception of empowerment in the citizens, thereby creating a positive attitude toward intention to use and recommend the technology.

Regarding the UTAUT-related hypotheses: (i) the positive and significant effect of performance expectancy over intention to use suggests that citizens may perceive that their use of e-participation is producing a positive outcome in the community. Local governments should not only promote the use of e-participation tools, but also the positive final effects of that usage on the community. (ii) The positive effects of facilitating conditions on intention to use may indicate that local governments should keep a facilitating environment around e-participation, as for instance support chat rooms or call centres. (iii) The non-significant effect of effort expectancy and social influence suggest that local governments should keep the e-participation simple and easy to use, oriented to all citizens without conditions or restrictions for using it.

\subsubsection{Limitations and Future Research}

The first limitation of our work concerns the location of participants in the questionnaire, which was conducted in Portugal. Caution is needed when generalizing our findings toward the adoption of e-participation in different locations or with different participants. This study offers researchers a basis for future research by refining the model and testing it in different countries, age groups, and identifying new constructs that may help to increase the predictive power of the model. Secondly, we found effort expectancy and social influence to have no significant effect on intention to use. Future research can investigate these constructs in different scenarios in which they may become significant over the intention to use. Thirdly, the measurement and use of psychological empowerment as a higher-order multidimensional construct is still under research (Johnson et al., 2012; Peterson, 2014). Future research may explore each of the dimensions of psychological empowerment on e-participation adoption separately and combine psychological empowerment with other theories of technology adoption to compare the predictive power compared to our model. And finally, the data were collected from 210 citizens who are users of e-participation, which implies that they are probably more digitally savvy than the rest of the population in the city. This may have created a limitation regarding the random sample selection and may have influenced the result of non-significance of effort expectancy on intention to use, since the users may find e-participation easy to use and expect few or no problems when using it. Future research may address this limitation by collecting data from a 
broader sample of citizens, thereby allowing a comparison between the more and less experienced participants with e-participation.

Beyond citizen empowerment and the UTAUT constructs, a myriad of other factors can influence the adoption of e-participation. Future research may create new models based on UTAUT and integrate constructs such as sense of community (Talò et al., 2014), sense of place (Acedo, Painho, \& Casteleyn, 2017), and place identity (Cuba \& Hummon, 1993), which have been shown to potentially influence citizens' willingness to engage in participation activities. However, very little literature reports having measured the relationship between the degree of identification with the community and the adoption of e-participation, which would be a fruitful path forward.

\subsection{Conclusions}

This article provides insights on how citizens' perceptions of empowerment can influence the intention to use and intention to recommend e-participation systems, using a novel theoretical model. The model integrates UTAUT and psychological empowerment theory. It was evaluated based on data from 210 citizens in Portugal. Performance expectancy, facilitating conditions, and empowerment were found to be significant on the intention to use e-participation. Psychological empowerment significantly impacts intention to use and recommend eparticipation. These findings can help the public sector to design strategies to promote and diffuse e-participation amongst the citizenry for a long-term use; for instance, keeping and reinforcing the perception of empowerment in citizens who use e-participation tools. The model offers researchers a basis for future examination of inner motivations of citizens to adopt eparticipation. 


\section{Chaper 4 - Continuous usage of e-participation in the long term: The role of the sense of virtual community}

\subsection{Introduction}

In recent years local governments around the globe have made considerable endeavours to implement different forms of online public participation, the so-called e-participation, which is considered a branch of e-government oriented for consultation and decision-making (Welch, 2012). For instance, tools to provide public opinion for deliberation, such as online discussion forums (Jooho Lee \& Kim, 2012; Mou et al., 2013) were found in 32 countries by 2010 (United Nations, 2010) and increased to 72 countries by 2012 (United Nations, 2012). Active use of eparticipation in the long term can facilitate the engagement of citizens in consultation and decision-making processes along with governments. E-participation can produce positive effects in the community only if the members of that community use the systems in the long-term scenario. Since e-participation is oriented to the general public, its adoption and diffusion process is still a challenge for the local governments with a risk of discontinuity (Sun, 2013). Understanding these drivers is crucial for the local governments to implement strategies for the diffusion, active use, and engagement of citizens with e-participation in the long term.

Most local governments already integrated the use of online social networks in their egovernment platforms as means of improving a two-ways communication with citizens (Mossberger, Wu, \& Crawford, 2013) and increasing the public trustworthiness (Porumbescu, 2016). Nonetheless, only a small number of those implementation had an impact at policymaking or decision-making level (United Nations, 2016). A growing body of literature has devoted efforts to understand the factors that influence the online citizen participation (Naranjo Zolotov, Oliveira, \& Casteleyn, 2018; Rana, Dwivedi, Williams, \& Weerakkody, 2016; Schmidthuber, Hilgers, \& Gegenhuber, 2017), and how the usage of e-participation can lead to full partnership with the government (Abu-Shanab, 2015). However, the active involvement of members of small or medium-sized communities, such as neighbourhoods, parishes, or cities, in online consultation and decision-making processes in the long term is still a challenge.

The sense of community (Newbrough \& Chavis, 1986) is considered a key factor for the active involvement of citizens in public participation. The sense of virtual community (SOVC) is the degree of affective attachment to a given community mediated by an information technology (Koh \& Kim, 2003), in this case, e-participation technologies. Little is known about the factors that drive the intention to continue using e-participation in the post-adoption stage 
from a perspective of SOVC. This article makes two contributions to fill the existing gap. First, the article explores the effect of sense of virtual community on the usage and on the continuous intention to use e-participation. Second, we propose a research model that integrates two theories: (i) SOVC and (ii) the extended unified theory of acceptance and use of technology (UTAUT) (Venkatesh et al., 2012). Since our focus is on the post-adoption stage, we consider only the UTAUT constructs that have a direct influence on the use behaviour of e-participation: facilitation conditions and habit.

The research model is tested using partial least squares structural equation modelling (PLS-SEM) to analyse the data collected from 370 respondents through an electronic questionnaire that was applied to the users of the participatory budgeting platform, an eparticipation platform managed by the municipality of a Portuguese city from 2008.

The rest of the paper is organized as follows: Section 2 presents a literature review of eparticipation and post-adoption behaviour. Section 3 explains the research model development and hypotheses. Section 4 describes the methodology, including the description of research context, measurements, and data collection. Section 5 presents the results of measurement and structural model evaluations. Section 6 provides a discussion of results, and finally, conclusions and directions for future research are presented in Sections 7 and 8, respectively.

\subsection{An overview of e-participation in the post-adoption stage}

E-participation is the use of Information and Communication Technologies (ICTs) to support "top-down" engagement and empower citizens and civil society organizations (Macintosh \& Whyte, 2008). E-participation is seen as a type of e-government service (Jooho Lee \& Kim, 2014) with special focus on citizen engagement for deliberation and decision orientation (Welch, 2012). In this study e-participation is considered to be of a citizen-initiated nature, which implies that although the e-platform can be sponsored by the government, the initiatives, namely proposals, petitions, online voting, or suggestions, originate from the citizens toward the government. The long-term use of e-participation has the potential to promote citizen engagement in collaborative governance (Pereira, Cunha, Lampoltshammer, Parycek, \& Testa, 2017).

Rodríguez-Bolívar, Alcaide-Muñoz, \& López-Hernández (2016) suggest that eparticipation is a leading research topic in e-government literature for both developing and developed countries, although studies in developed countries focus more on the latter stages of 
e-government initiatives, whereas the developing-country focus is more on the early stages. The implementation of e-participation platforms like the online participatory budgeting (Allegretti \& Antunes, 2014) in some cities in Portugal already crossed the barrier of acceptance a number of years ago. Nevertheless, acceptance is not the ultimate indicator of success in e-participation implementations. The challenge after acceptance is to assure its diffusion and continuous usage in the long-term scenario.

Jasperson, Carter, and Zmud (2005) define post-adoption behaviour as "the myriad feature adoption decisions, feature use behaviours, and feature extension behaviours" performed by an individual after the use of a system. In our case, the system is e-participation. Most of the earlier studies that contributed to the understanding of the factors that affect postadoption behaviour in different contexts of technology adoption focus primarily on the analysis of satisfaction (Cho, 2016; Li \& Liu, 2014; Liao, Palvia, \& Chen, 2009; Tojib \& Tsarenko, 2012). However, more recent studies have found the existence of other factors with stronger predictive power for specific contexts of technology adoption. For instance, Ong and Lin (2016) found that well-being was the strongest predictor of continuance intention in the context of online social networks. They suggest exploring new constructs that may contribute to the understanding of the continuous intention to use the technology. Sun (2013) found that technology adoption motivated mainly by herd behaviour leads to not meeting the initial expectations in the postadoption stage, thereby increasing the risk of discontinuation or abandonment of the previously adopted e-participation.

\subsection{Research model}

The outcomes of using e-participation technologies, such as the creation of policies or the implementation of projects proposed by citizens, imply an impact on the community and not only on the individual. These outcomes are materialized only when the e-participation systems are used in the long term. Traditional theories in the realm of information systems are robust on the study of intention to use and usage of the technology (Davis, 1989; Venkatesh et al., 2003). However, the factors that may lead to the acceptance of e-participation in an initial stage, may not be the same in the continuous usage over time. As e-participation produces benefits for the community in the long term, the sense of virtual community in the individuals that have already accepted e-participation technologies may play a critical role as motivator of the continuous use of e-participation. In this regard, the main objective of this article is to explore the effects of SOVC on the usage and continuous intention to use e-participation. 
The research model integrates constructs from UTAUT and sense of virtual community to study the use behaviour and continued intention to use e-participation. SOVC is defined as the individual perception of belonging, identity, and attachment to a given community with a communication mediated by ICT (Cheng, Tsai, Cheng, \& Chen, 2012). When this perception is positive, it can act as a facilitator of active online participation in the community. The exploratory study of SOVC may help to explain the inner motivations of the citizens to engage and continuously use e-participation in the post-adoption stage. Since our focus is on the postadoption stage, SOVC constructs are combined with UTAUT constructs that have a direct impact on the use and continuous intention to use of e-participation: facilitation conditions and habit. UTAUT has been widely used in the study of technology adoption (Dwivedi et al., 2011; T. Oliveira et al., 2014), focusing on the drivers that influence intention to use and use of technology. However, one single theory may provide only a limited explanation about specific characteristics in the e-participation context. In this regard, Venkatesh, Thong, Chan, and Hu (2016) suggest drawing on additional theoretical perspectives. The integration of UTAUT constructs on usage and SOVC may contribute interesting insights regarding the drivers of the continuance intention to use e-participation in the post-adoption stage. The research model is presented in Figure 4.1.

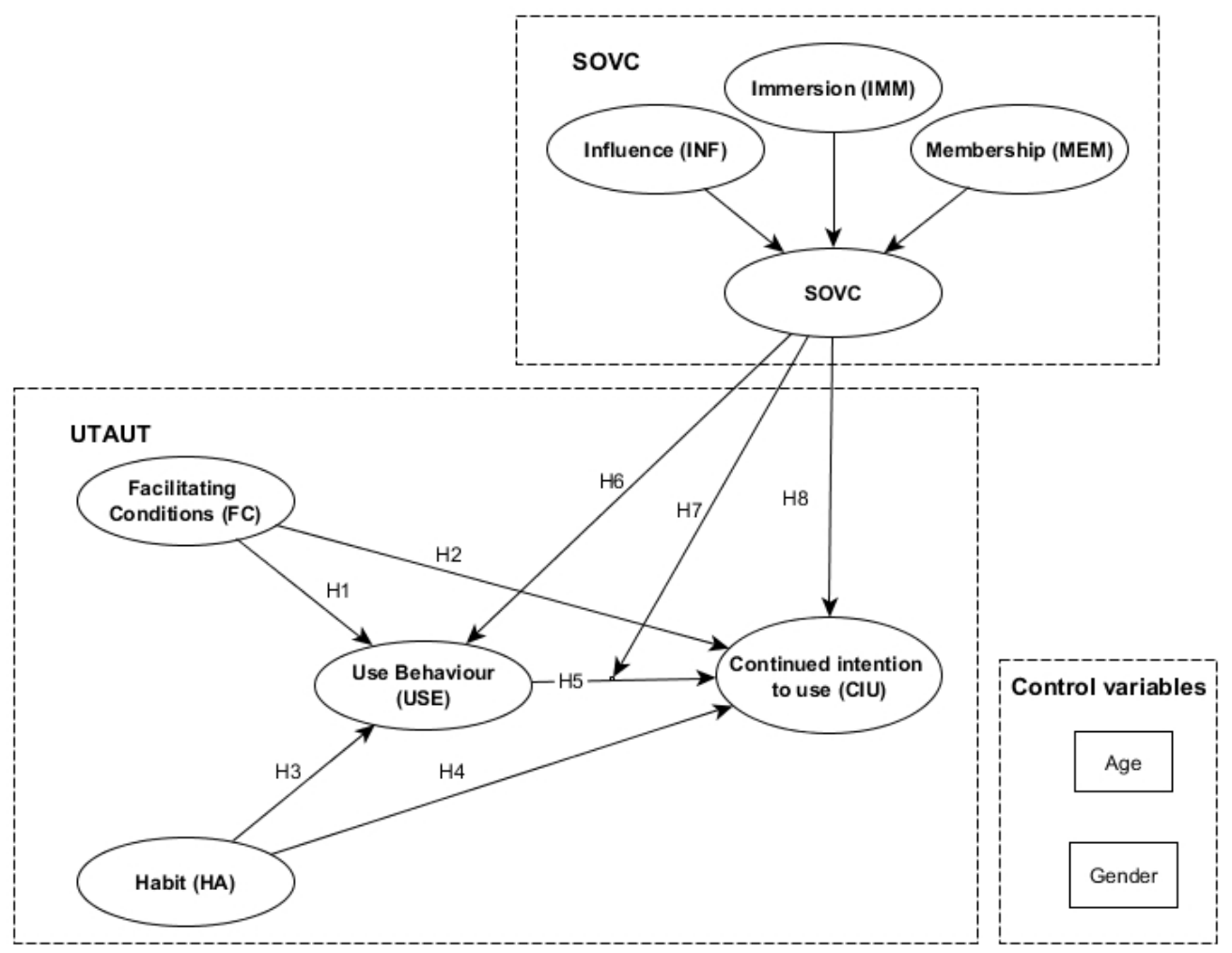

Figure 4.1. Research model and hypotheses 


\subsubsection{Hypotheses development}

\subsubsection{Facilitating conditions}

External factors related to e-participation, such as the availability of support and resources from the government that hosts and promotes the use of the system, may have an influence on citizen's behaviour regarding the use of e-participation. These external factors are captured in the variable facilitating conditions (Venkatesh, Brown, Maruping, \& Bala, 2008). Facilitating conditions refers to the individual perception of existence of resources and support to use the technology (Venkatesh et al., 2003, 2012). Earlier literature emphasized the importance of facilitating conditions in different contexts of the information systems use. For instance, the adoption of technology in households (S. A. Brown \& Venkatesh, 2005), or the behavioural intention to use biometric technologies (Miltgen et al., 2013).

The rationale for the effect of facilitating conditions on use behaviour and continued intention to use in the e-participation context is that the whole participatory process requires the support from the local government for the citizen contributions to be materialized. This process is mostly external to the e-participation technology and can therefore be considered as a facilitating condition. For instance, when reporting potholes through a mobile e-participation app, there is an internal process in the government that finally will solve the problem of the pothole. As the contributions on e-participation will have an impact on the community in the long term, facilitating conditions will affect the use behaviour and the continued intention to use e-participation technologies.

H1. Facilitating conditions positively influence the use behaviour of e-participation.

H2. Facilitating conditions positively influence the continuous intention to use e-participation.

\subsubsection{Habit}

E-participation systems are usually planned to be used for several years. For instance, online participatory budgeting (Mkude, Pérez-Espés, \& Wimmer, 2014), has a cyclical process that repeats every year, whereby citizens are able to submit proposals to be implemented by the local government. Once e-participation is adopted and the use of the system is stable, users may experience the formation of habit as a result of favourable confirmation of expectations, which may lead to increase the likeliness of repeating the behaviour ( $\mathrm{Hu}$, Stafford, Kettinger, Zhang, \& Dai, 2017). 
Habit is defined as the extent to which the individual performs a behaviour automatically (Venkatesh et al., 2012). Previous studies report evidence that once the habit is formed, it can have a direct effect on the future usage behaviour (Hu et al., 2017; Verplanken, 2006). Other studies have also evaluated the effect of habit on the continuance intention to use. For instance, Veeramootoo, Nunkoo, and Dwivedi (2018) showed evidence that habit has a positive effect on the continued intention to use e-government services.

H3. Habit positively impacts the use behaviour of e-participation.

H4. Habit positively impacts the continuous intention to use e-participation.

\subsubsection{Actual use and continued intention to use}

Rather than measure intention to use, which is usually measured in technology adoption research (Goncalo Baptista \& Oliveira, 2016; C. Martins, Oliveira, \& Popovič, 2014), continuous intention to use is considered a more appropriate variable when users already have experienced the e-participation technologies (Bhattacherjee, 2001; Hoehle \& Venkatesh, 2015a). Continuous intention to use is defined as the degree to which a citizen perceives that (s)he will continue using e-participation in the future (Hoehle \& Venkatesh, 2015a). The rationale is that a citizen who uses e-participation to contribute to her/his community over time will keep the intention to continuously use the system in the long term.

H5. Usage positively impacts the continuous intention to use e-participation.

\subsubsection{Sense of virtual community (SOVC)}

One of the goals of using e-participation is to involve citizens in consultation and decisionmaking process that have an impact on the community they belong to or to which they have some affective ties. Existing literature provides evidence to support the belief that citizens who are involved in different forms of civic engagement and community activities also show high levels of sense of community (Peterson et al., 2008; Talò et al., 2014). When citizens who are involved in community activities use e-participation technologies, the levels of sense of community may still be present in them, and this feeling may play a role as motivator to keep using e-participation technologies over time.

Sense of virtual community is a multidimensional construct (Koh \& Kim, 2003; Peterson et al., 2008). Koh and Kim (2003) define three dimensions to measure SOVC: immersion, influence, and membership. These dimensions are measured as second-order structure because 
earlier studies have demonstrated that the dimensions of SOVC can be considered as representing one SOVC construct (Peterson et al., 2008). In our research model SOVC is hypothesised as a second-order construct of a reflective-formative type (Becker et al., 2012).

In the context of e-participation, (i) immersion is defined as the state of flow the citizens may experience when using the system (Koh \& Kim, 2003). For instance, in the case of online participatory budgeting (Sintomer et al., 2013) citizens may find interesting the diversity of project proposals available on the platform and keep exploring them, thereby reaching some level of immersion, or in the case of a discussion forum, citizens may become immersed in a discussion of a policy. (ii) Influence is the degree to which a citizen perceives that (s)he can influence the other members in the e-participation community to share her/his view or goals (Hsiao \& Chuang, 2009; Koh \& Kim, 2003). For instance, by sharing on the online social networks the contributions made on e-participation, citizens may experience the feeling of influencing the decision(s) of others, and therefore keep the interest in using e-participation. (iii) Membership, or sense of belonging, is defined as the feeling of belonging to a community (Koh \& Kim, 2003). A group of citizens who use e-participation toward a common goal may experience the feeling of membership even without knowing each other in person, for instance, e-voting for a project of common interest for the members to be implemented in the community. Sense of belonging was found to have the strongest impact on electronic word of mouth intention (Cheung \& Lee, 2012).

Previous studies have confirmed a significant and positive effect of the SOVC to boost social support in a virtual community (Y.-H. Tsai, Joe, Lin, Wang, \& Chang, 2012). Chen, Yang, Wang, and Farn (2008) found that SOVC has a positive and significant effect on behavioural loyalty in the consumer context when the individuals are part of a virtual community. We posit that the levels of SOVC in citizens can positively influence the continuous use of e-participation. H6. SOVC positively impacts the use behaviour of e-participation.

Mesch and Talmud (2010) claimed that civic participation and sense of attachment to the local communities can be increased by the participation in different forms of e-participation (e.g. local electronic forums). SOVC not only may have a direct effect on the behavioural intention to continuously use e-participation, but may also have an augmenting effect on that behaviour when there are ties between the members of that community (Bansal \& Voyer, 2012). Previous studies found that SOVC has a significant positive effect as moderator of the intention to engage in word of mouth in the context of disseminating word of mouth (Hsiao \& Chuang, 
2009). Moreover, SOVC has been also been found to have a positive effect on the purchase intention in the context of online group buying (M.T. Tsai, Cheng, \& Chen, 2011).

H7. The stronger the SOVC is in the citizen, the stronger will be the relationship between the citizen's use behaviour and the continuous intention to use e-participation.

H8. SOVC positively impacts the continuous intention to use e-participation.

\subsection{Methodology}

\subsubsection{Research context}

In the last decade several local governments in Portuguese cities and around the world have implemented the so called online participatory budgeting (Allegretti \& Antunes, 2014), which are decision-oriented e-participation platforms. This implementation process can be summarized in five steps that take place cyclically throughout the year: (i) online submission of proposals from the citizens, (ii) technical feasibility analysis of the proposals submitted, (iii) promotion of the final list of projects for public voting, (iv) citizens participating in the voting process, mostly by SMS, and finally, $(v)$ announcement of the winning projects to be funded and implemented by the local government. For the evaluation of our research model, we use data collected from the users who experienced an online participatory budgeting platform. Online participatory platforms promote the direct involvement of citizens in consultation and the decision making-process. The main activities that citizens are able to do regarding the online participatory budgeting are: the submission of project initiatives, the search for information about the initiatives submitted by other citizens and the progress status of the winning ones from previous years, SMS vote for a candidate project, and the promotion on social networks of the projects submitted.

\subsubsection{Measurement and data collection}

All measurement items were adapted from the literature and adjusted to the context of eparticipation. The items for the constructs facilitating conditions, habit, and technology use, were adjusted from Venkatesh et al. (2012), continuous intention to use from Hsu, Yen, Chiu, and Chang (2006). The items pertaining to SOVC, namely immersion, influence, and membership, were adapted from Koh and Kim (2003). The variables were measured by multipletype close-ended questions on a seven-point scale from 1 (totally disagree) to 7 (totally agree). 
In the case of frequency of use the scale was from 1 (never) to 7 (whenever I have the chance). Please see the Appendix 4.1.

The data were collected through an electronic questionnaire from 1 December to 18 December 2016. An email containing a hyperlink to the questionnaire was sent to all of the citizens registered on the online participative budgeting platform. The hyperlink in the email could be used only once. The participation in the survey was voluntary, and the participants were offered prizes as incentives. We obtained 370 valid responses from citizens who had experienced the online participatory budgeting platform. See Table 4.1 for the demographic profile of the respondents.

Table 4.1. Demographic profile

\begin{tabular}{|c|c|c|}
\hline Characteristics & Freq. & $\%$ \\
\hline \multicolumn{3}{|l|}{ Gender } \\
\hline Feminine & 187 & 50.54 \\
\hline Masculine & 183 & 49.46 \\
\hline \multicolumn{3}{|l|}{ Age groups (years) } \\
\hline 40 to 55 & 167 & 45.14 \\
\hline 26 to 39 & 131 & 35.41 \\
\hline more than 56 & 64 & 17.30 \\
\hline 25 or less & 8 & 2.16 \\
\hline \multicolumn{3}{|l|}{ Education } \\
\hline Undergraduate degree & 110 & 29.73 \\
\hline Master's degree & 100 & 27.03 \\
\hline Post-graduation & 60 & 16.22 \\
\hline High school & 57 & 15.41 \\
\hline Doctorate & 39 & 10.54 \\
\hline Primary school & 3 & 0.81 \\
\hline N/A & 1 & 0.27 \\
\hline \multicolumn{3}{|l|}{ Profession } \\
\hline Employed & 229 & 61.89 \\
\hline Self-employed & 39 & 10.54 \\
\hline Retired & 27 & 7.30 \\
\hline Freelancer & 26 & 7.03 \\
\hline Unemployed & 19 & 5.14 \\
\hline Other & 17 & 4.59 \\
\hline Student & 13 & 3.51 \\
\hline
\end{tabular}




\subsection{Results}

\subsubsection{Measurement model}

All the constructs in our model have reflective indicators. SOVC is of a second-order construct that has first-order components of the formative type: influence, immersion, and membership. Following the guidelines of Hair, Hult, Ringle, and Sarstedt (2014), this study assesses the internal consistency, convergent validity, and discriminant validity of the measurement model (see Table 4.2). Internal consistency is assessed by Cronbach's alfa (CA) and composite reliability (CR). Both values are above 0.7 for all latent variables. Convergent validity is assessed by the average variance extracted (AVE) and the loadings (see Appendix 4.1), which are above 0.5 and 0.7 respectively in almost all cases. Only the loading FC4 obtained a lower value (0.65), but we decided to keep it due to the proximity to 0.7 . Finally, discriminant validity was tested using three criteria, (i) the cross-loadings, in which the loading of each indicator is greater than any of the cross-loadings, (ii) the Fornell \& Larcker (1981), which requires that the square root of AVE should be greater than its correlation with any other construct, and (iii) Heterotrait-Monotrait Ratio (HTMT) (Henseler, Ringle, et al., 2015), which requires HTMT values below 0.9 (Table 4.3) for good discriminant validity. We assess multicollinearity for formative constructs. SOVC is modelled as a higher-order reflective-formative type (Becker et al., 2012). Multicollinearity is evaluated by the variance inflation factor (VIF). The VIF values range from 2.09 to 3.42 , which are below 5, indicating no collinearity issues (Table 4.4). Consequently, we conclude that our measurement model is reliable and valid.

Table 4.2. Assessment of measurement model

\begin{tabular}{|c|c|c|c|c|c|c|c|c|c|c|c|c|}
\hline Construct & $\begin{array}{l}\text { Mea } \\
\mathrm{n}\end{array}$ & SD & $\mathrm{CA}$ & $\mathrm{CR}$ & AVE & 1 & 2 & 3 & 4 & 5 & 6 & 7 \\
\hline 1. Facilitating conditions (FC) & 6.17 & 1.20 & 0.82 & 0.88 & 0.66 & 0.81 & & & & & & \\
\hline 2. Habit (HA) & 4.36 & 2.00 & 0.71 & 0.83 & 0.63 & 0.35 & 0.79 & & & & & \\
\hline 3. Technology use (USE) & 4.59 & 2.21 & 0.78 & 0.86 & 0.60 & 0.27 & 0.50 & 0.78 & & & & \\
\hline 4. Continuous Intention to Use (CIU) & 6.11 & 1.21 & 0.95 & 0.97 & 0.91 & 0.52 & 0.54 & 0.50 & 0.95 & & & \\
\hline 5. Influence (INF) & 2.63 & 1.75 & 0.92 & 0.95 & 0.86 & 0.05 & 0.35 & 0.37 & 0.14 & 0.93 & & \\
\hline 6. Immersion (INV) & 2.40 & 1.68 & 0.90 & 0.94 & 0.83 & 0.00 & 0.37 & 0.32 & 0.12 & 0.75 & 0.91 & \\
\hline 7. Membership (MEM) & 3.87 & 1.93 & 0.80 & 0.88 & 0.72 & 0.20 & 0.46 & 0.39 & 0.33 & 0.72 & 0.54 & 0.85 \\
\hline
\end{tabular}

Notes: SD = Standard Deviation, CA = Cronbach's Alfa, CR = Composite Reliability, AVE = Average

Variance Extracted. Square root of AVE in bold. 
Table 4.3. Heterotrait-Monotrait Ratio (HTMT)

\begin{tabular}{lccccccc}
\hline Construct & 1 & 2 & 3 & 4 & 5 & 6 & 7 \\
\hline 1. Facilitating conditions (FC) & & & & & & & \\
2. Habit (HA) & 0.43 & & & & & & \\
3. Use behaviour (USE) & 0.31 & 0.64 & & & & & \\
4. Continuous Intention to Use (CIU) & 0.59 & 0.63 & 0.55 & & & & \\
5. Influence (INF) & 0.06 & 0.47 & 0.46 & 0.16 & & & \\
6. Immersion (IMM) & 0.06 & 0.51 & 0.40 & 0.13 & 0.82 & & \\
7. Membership (MEM) & 0.27 & 0.66 & 0.52 & 0.42 & 0.82 & 0.62 & \\
\hline
\end{tabular}

Table 4.4. Multicollinearity valuation for higher-order formative constructs

\begin{tabular}{llcc}
\hline $\begin{array}{l}\text { Higher-order formative } \\
\text { constructs }\end{array}$ & $\begin{array}{l}\text { First-order reflective } \\
\text { constructs }\end{array}$ & VIF & Weight \\
\hline \multirow{3}{*}{ SOVC } & Influence & 3.42 & $0.417^{* * *}$ \\
& Immersion & 2.32 & $0.367^{* * *}$ \\
& Membership & 2.09 & $0.342^{* * *}$ \\
\hline
\end{tabular}

Note: ${ }^{*} p<0.10 ;{ }^{* *} p<0.05 ;{ }^{* * *} p<0.01$

\subsubsection{Structural model}

The structural model is assessed following the approach of Hair et al. (2014). First, we examine for collinearity issues using the variance inflation factor (VIF) criterion, which states that VIF values above 5 indicate collinearity problems (Henseler et al., 2009). All the VIF values in our study are below 1.59 . Therefore, the model has no collinearity issues. Second, the $\mathrm{R}^{2}$ determines the predictive power of the model. Our model explains $31.5 \%$ of the variation in use, and $49.7 \%$ of the variation for continuous intention to use e-participation. Third, the significance of path coefficients was estimated using the bootstrapping technique (Hair et al., 2014) with 5000 iterations. Significant paths indicate that the hypotheses are supported. We evaluate eight hypotheses in this study. Six hypotheses were confirmed $(\mathrm{H} 1, \mathrm{H} 2, \mathrm{H} 3, \mathrm{H} 4, \mathrm{H} 5$, and $\mathrm{H6}$ ), $\mathrm{H} 7$ is negative and $\mathrm{H} 8$ not significant, so not confirmed (see Figure 4.2). We found no effect of individual differences such as age and gender on the dependent variables. 


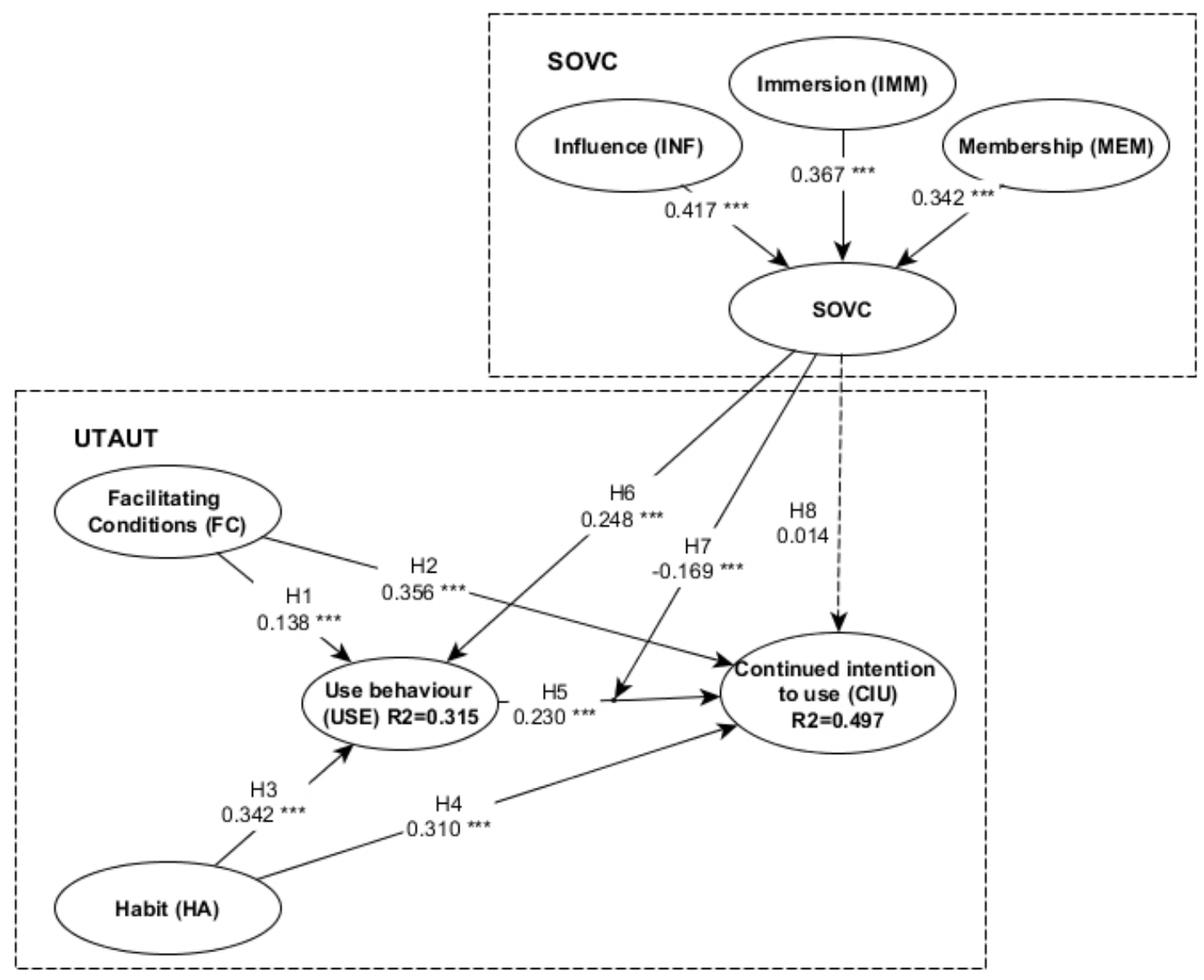

Figure 4.2. Structural model results

Notes: significant at $* 10 \% ; * * 5 \% ; * * 1 \%$. Non-significant paths are in dotted arrows.

\subsection{Findings}

This study explores the effect of the sense of virtual community (SOVC) on the usage and continuous intention to use e-participation technologies in the post-adoption stage. Specifically, we evaluate a research model that integrates facilitating conditions, habit, technology use, and continuous intention to use, from UTAUT, with SOVC as a second-order construct measured by its three first-order dimensions (immersion, influence, and membership) to analyse the drivers of the e-participation use and continuous intention to use in the post-adoption stage. Regarding the hypotheses from UTAUT constructs, all were accepted. Habit was found to be the strongest predictor to explain the use, and facilitating conditions was the strongest to predict the continuous intention to use.

Habit is the strongest predictor over use, surpassing the predictive power of all other constructs in the model, and the second-strongest predictor over the continuous intention to 
use. This finding was expected in a post-adoption stage of e-participation, which aligns with the claim of Kim and Malhotra (2005), that habit may drive the repeated behavioural patterns in the use of information technology. The strong effect of habit could be explained by the cyclical process of the online participatory budgeting process every year. Citizens who have already participated in previous editions of the e-participation platform are likely to participate again in the next editions. Most citizens contribute to e-participation by means of SMS voting for a candidate project every year, and this behaviour can be considered to be a habit.

Facilitating conditions was the strongest predictor for the continuance intention to use (and to a lesser extent, use), indicating that when a citizen has access to certain resources related to e-participation (namely ICT resources, knowledge on how to use e-participation, support from the local government for the whole participatory process, and information about the public participatory process) she/he is more likely to increase the frequency of use and continuous intention to use e-participation over time.

Sense of virtual community was found to have a positive influence over the frequency of use of e-participation. However, SOVC was not significant for the continuous intention to use and its moderating effect between technology use and continuous intention to use was significant and negative. The positive values provide evidence that citizens have a level of sense of community when using the online participatory budgeting platform to pursue a common goal. Even though the citizens using e-participation do not know the other citizens that use the platform, they share a common goal of contributing to the community. This feeling is probably motivated by the e-voting process and the information about the progress in the implementation of the winning projects that is available on the online participatory budgeting platform. The perception that others are supporting the same projects, or different projects in the same categories, may influence other citizens to participate for a common goal. This influence may trigger the e-participation usage in the short term. However, the non-significant effect of SOVC on continuous intention to use may imply that the feeling of community is either not strong enough to drive the continuous intention over time, probably because the participatory process involves a large urban area (the whole city), or SOVC is not a determinant factor to keep the continuous intention to use e-participation over time. The negative moderating effect of SOVC between e-participation use and continuous intention may imply that citizens may not be interested in influencing other citizens' decisions, but rather just provide their individual contribution to impact the final decision of the participative process. Results also show that in low SOVC, greater use of e-participation will increase the continuance intention to 
use in the citizen. On the other hand, in high SOVC, the low or high levels of e-participation usages will not have an impact on the continuance intention to use (Figure 4.3).

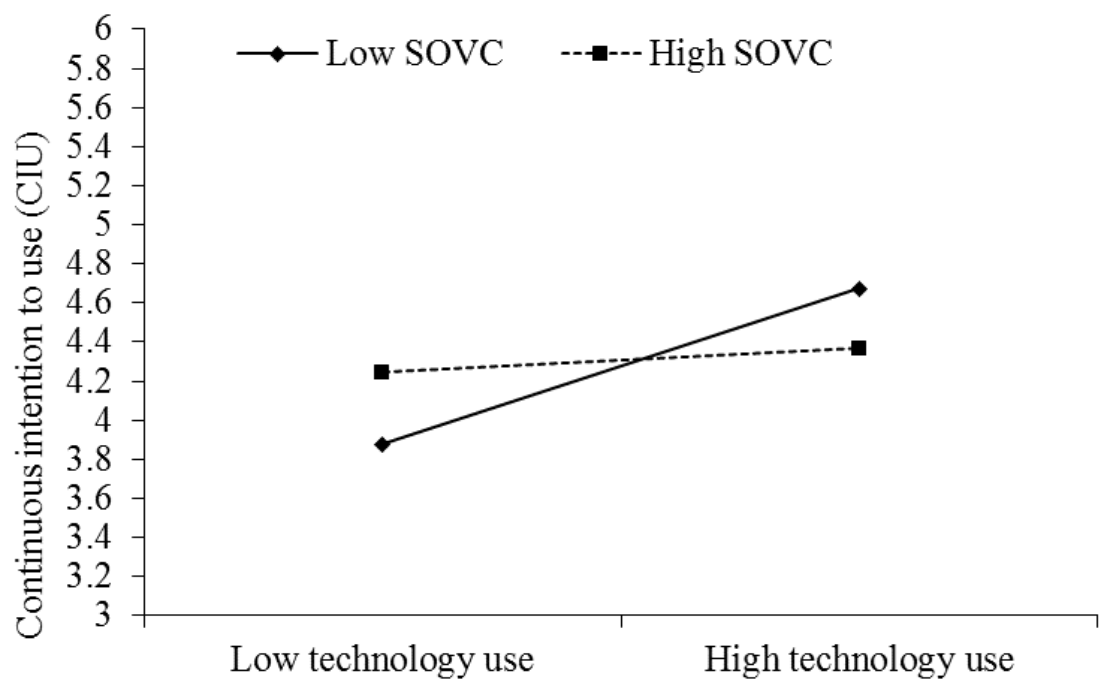

Figure 4.3. Moderating effect of SOVC between technology use and continuous intention to use

\subsection{Implications for practice}

The significant effect of habit over the usage and continued intention to use e-participation may imply (for public agencies and local governments that implement e-participation) that citizens who have already developed the habit of contributing through e-participation may be willing to engage in new and more advanced forms of e-participation. This could represent an opportunity for local governments that are seeking to increase the levels of public trust and higher levels of citizen involvement (Abu-Shanab, 2014; Lee \& Kim, 2018).

Hypotheses related to facilitating conditions were also confirmed. Local governments that implement e-participation should pay special attention to two resources related to the use of e-participation: (1) the clarity, accessibility, and availability online of the information about the participatory process. As e-participation is strictly voluntary, citizens may be demotivated from using the e-participation platform if they cannot find information in an effortless manner. And (2) the usage of e-participation platforms is only a small portion of the participatory process, which also involves background processes (Shareef, Kumar, Kumar, \& Dwivedi, 2011). Local governments that implement e-participation projects should ensure that the participants 
involved in consultation and decision-making process have support throughout the entire participatory process.

SOVC showed a partial effect on the continuous use of e-participation in the postadoption stage. This could be an indication that when e-participation is implemented in larger urban areas, for instance at the level of the city of Lisbon, the influence of sense of community decreases as a driver of continued intention to use e-participation. Consequently, local governments may consider different strategies to promote the use of e-participation when addressing a city level as when addressing at a neighbourhood level (Acedo, Painho, et al., 2017).

\subsection{Conclusions}

Local governments are making endeavours to engage citizens in consultation and decisionmaking processes through their e-government platforms. In the case of traditional (physical) forms of citizen participation, the literature review suggests that the level of sense of community is positively associated with civic engagement and involvement in active participation. However, our evidence shows that when the sense of community is mediated by an information technology, such e-participation, the sense of virtual community has a positive effect only on the usage of e-participation tools but is not enough to keep the motivation to use the system over time.

- In an online environment, the sense of community plays a less important role to engage citizens than in traditional participation.

Since e-participation is place and time independent, it allows the inclusion of more citizens in the participatory process in a much wider geographical area, which at the same time will diminish the effect of sense of community as driver of citizen engagement in e-participation.

- Local governments that aim to engage citizens in online participation should take into consideration the size of the community to design their diffusion and promotion strategies.

In the post-adoption stage, habit and facilitating conditions have a significant effect on the use and continuous intention to use e-participation. The implementation of e-participation systems that achieve the adoption and continuous usage over time is still challenging for local governments. The positive effect of habit on e-participation usage may represent an indicator 
of success in the e-participation usage over time.

- In the post-adoption stage, habit plays a stronger role than sense of community as driver of e-participation adoption.

\subsection{Limitations and future research}

This study has two limitations. First, the data for the study were collected in Portugal. Therefore, caution is suggested regarding generalization of the findings. Factors such as cultural differences (Hofstede et al., 2010), or a different research context may affect the final results. Future research may include cultural dimensions or test different e-participation contexts. Second, only one hypothesis from SOVC was accepted. Future research is needed to evaluate different scenarios and different e-participation platforms that may confirm or contradict the findings of this study regarding the effect of SOVC over use and continuous intention to use e-participation in the post-adoption stage. Moreover, since habit was found to be the strongest predictor of use, we suggest including the construct habit for future research on e-participation and investigate whether the sense of community may have an influence on the development of habit over time. 


\section{Chaper 5 - Continued intention to use online participatory budgeting: The effect of empowerment and habit}

\subsection{Introduction}

Participatory budgeting started in Porto Alegre (Brazil) in 1989 (Matheus, Ribeiro, Vaz, \& Souza, 2010) and since then rapidly gained popularity all around the world. Participatory budgeting is considered a public participatory instrument, which in most cases is managed by the local governments. It allows regular or non-elected citizens to participate in the allocation process of part of the public finances (Sintomer, Herzberg, \& Röcke, 2008) either providing suggestions on where or how to spend the budget, or by voting for available proposals to be implemented by the local governments. By 2013, participative budgeting has been implemented in around 1500 cities worldwide (Baiocchi \& Ganuza, 2014). Participatory budgeting is implemented in the form of (i) offline versions (public assemblies between local governments and citizens), (ii) online versions using ICT (Information and communication technologies) tools to interact with citizens, for instance receiving project proposals through a web portal or balloting via SMS votes, and (iii) hybrid versions (Miori \& Russo, 2011), when the citizens can participate both online and in public assemblies. The present article focuses on the motivations of continuous intention to use the online version of the participatory budgeting.

The online participatory budgeting implementations can be considered a form of eparticipation, a broader concept defined as "the process of engaging citizens through ICTs in policy and decision-making in order to make public administration participatory, inclusive, collaborative and deliberative for intrinsic and instrumental ends (p. 61)" (United Nations, 2014). Online participatory budgeting is seen as an example of co-governance (Ackerman, 2004), the involvement of social actors in the activities of the state. Moreover, Matheus et al. (2010) suggest that the use of online participatory budgeting is a way to promote citizens' rights and the legitimacy of the democratic system. Despite the potential advantages of using digital participatory budgeting, its diffusion and long-lasting adoption still represent a significant challenge for local governments. For instance, in many German cities, online participative budgeting is considered as an online suggestion box and $40 \%$ of citizens have rated it as a bad participatory instrument (Kersting, 2016). Omar et al. (2017) caution that given the failure of past e-participation platforms due to low adoption, the online participatory budgeting is also at risk. Alves \& Allegretti (2012) discuss the fragility and volatility of participative budgeting implementations in various cases in Portugal. 
Several implementations of digital participatory budgeting around the globe have been examined from the qualitative perspective. For instance, Matheus et al. (2010) analysed case studies of digital participatory budgeting in Latin American cities, whereas Mkude et al. (2014) contributed to case studies of participatory budgeting in European cities. Nevertheless, quantitative studies on the factors that may motivate the usage of online participatory budgeting in the long-term scenario are scarce. Peixoto (2009) highlights that the lack of data at individual level concerning the motivations of the citizens who participated in online participatory budgeting represents a limitation to evaluate each motivational factor or which are more important. This study contributes filling the gap by assessing the influence of the psychological empowerment (Miguel, Ornelas, \& Maroco, 2015) and habit (Venkatesh et al., 2012) as inner motivators for the continued intention to use online participatory budgeting. The implementation of online participatory budgeting in Lisbon is an ideal case of research due to its increasing success in the number of votes year after year. The authors build and evaluate a research model that is evaluated using structural equation modelling (Hair et al., 2014) based on the data collected from the users of the online participative budgeting in the city of Lisbon. Besides the evaluation of empowerment and habit, the article also provides a multigroup analysis to find individual differences in terms of age and gender.

The rest of the paper is organized as follows, in section 2 the authors describe the online participatory budgeting in the city of Lisbon. Section 3 provides the theoretical background for the research model and hypothesis development. Section 4 describes the methodology used. Section 5 shows the calculations for the measurement and structural models. Section 6 discusses the results. And lastly, section 7 presents the conclusions.

\subsection{Online participatory budgeting in the city of Lisbon}

Participatory budgeting is an e-participation instrument implemented by the local governments to involve regular citizens in the process of suggesting, debating and/or deciding on the allocation of a portion of public budget managed by the local government (Sintomer et al., 2008). Some implementations of online participatory budgeting have been described as a form of online suggestion box (Kersting, 2016), whereas the Lisbon case, was described as providing "effective decision-making power to the citizens" (Allegretti \& Antunes, 2014).

By 2017, according to negocios.pt (2017), one of the best local business newspapers, Portugal accounted for 118 participatory budgeting implementations, making it one of the 
leading countries in Europe in the implementation of participatory budgeting. The city of Lisbon was the first capital city in Europe to implement the online participatory budgeting in 2008 (Allegretti \& Antunes, 2014). The participatory budgeting in Lisbon (https://www.lisboaparticipa.pt/) has a hybrid approach, offering online and on-site space for participation. For instance, in the edition 2016, the participatory budgeting in Lisbon received 362 proposals online and 205 proposals in the participatory assemblies (Allegretti \& Antunes, 2014), a total of 567 proposals. The case of participatory budgeting in Lisbon can be considered successful, due to the increasing rate of citizen participation on the voting process from 2008 (see Figure 5.1). In 2016 overpassed the fifty thousand votes for a city of approximately 550000 inhabitants, each citizen can vote one or two times. As such, the city of Lisbon provides an ideal scenario to investigate the motivational factors that drive the success in similar online participatory budgeting projects.

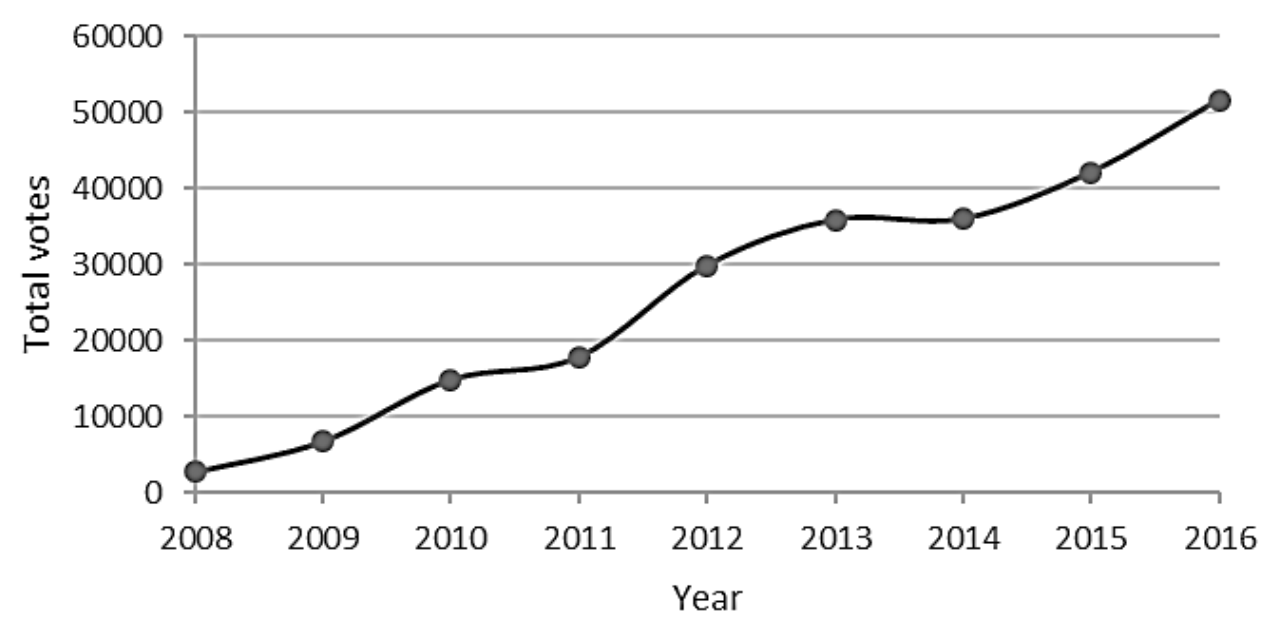

Figure 5.1. Voting in the Lisbon participatory budgeting. (Data from: www.lisboaparticipa.pt)

The yearly cycle of the participatory budgeting in Lisbon can be summarized in 5 stages: (1) from April to June the submission of proposals either online or through public assemblies; (2) from June to mid-September technical analysis of the proposals, merging of similar proposals, and transformation of proposals into projects; (3) from late-September to earlyOctober publication of the preliminary projects list and reception of possible complaints; (4) from mid-October to mid-November the voting process takes place, mostly by SMS, but also, on a lesser extent, through the web portal and on paper; and finally, (5) the announcement of the winners. The web portal of the Lisbon participatory budgeting allows to follow up the status of implementation of the winner projects. 


\subsection{Research model development}

Empowerment is considered as a key motivator for public participation and engagement (Kang, 2014). In the context of online participatory budgeting, Omar et al. (2017) suggest that the use of these systems promotes citizens' empowerment. Empowerment is defined as a set of individual components: competence, impact, meaning, and self-determination. This article assesses the effect of each dimension on the continued intention to use (CIU).

The four empowerment dimensions can be described as follows: (1) Competence (COM) can be defined as the extent to which a citizen can use the online participatory budgeting system with enough skills and ability. For instance, be able to search and obtain information about the candidate projects and send an SMS to vote for a project. (2) Impact (IMP) is defined as the degree of perception that an action on the online participatory budgeting will produce the desired effect (Sjoberg et al., 2017) by the citizen who performs the action. For instance, a citizen that provides a vote for a project that later is implemented may perceive that she/he influenced the implementation of that project. (3) Meaning (MEA) refers to which degree each citizen perceives the value of an action in the online participatory budgeting. For instance, if the citizen perceives that a candidate project in the system will bring some benefit to the community, is more likely that the citizen vote to support the project. Finally, (4) self-determination (SDET) refers to the perception of the degree of autonomy and freedom to interact with the online participatory budgeting. For instance, if a citizen can vote for a candidate project without restrictions regarding location or schedule, that citizen may be more likely use the system.

Habit (Venkatesh et al., 2012) refers to which extent a citizen performs a use behaviour of the online participatory budgeting automatically. For the Lisbon case study, every year a new edition of the online participatory budgeting in Lisbon is opened to call for new project proposals and, a few months later for electronic voting to select the winning projects. This yearly cyclical workflow may influence to develop a habit in the citizens that use the system. Habit has been evaluated in different contexts of the information systems adoption. For instance, in mobile banking (Gonçalo Baptista \& Oliveira, 2015), online social networks (Hu et al., 2017), and egovernment services (Alharbi et al., 2017). In all those studies, the results show a statistically significant and positive impact of habit on the intention to use the technology.

According to Venkatesh et al. (2000), individual differences such as age and gender can affect the way citizens perceive technology, in this case online participatory budgeting. For instance, Vicente \& Novo (2014) found that men are more likely than women to express political 
opinions or sign petitions online. Venkatesh et al. (2016) found that age has significant impact on intention to use e-government; Moores \& Chang (2006), found that moral judgement in ethical decision-making process was significant only for the older age group.

This article evaluates the impact of the four dimensions of psychological empowerment theory (Peterson, 2014; Spreitzer, 1995), i.e., competence, impact, meaning and selfdetermination, on the continued intention to use of online participatory budgeting $(\mathrm{H} 1-\mathrm{H} 4$ respectively). Additionally, in line with Venkatesh et al. (2012), and since the online participatory budgeting in Lisbon yearly opens a new edition since 2008 , we posit that habit may play a role on the citizens' continued intention to use (H5). Finally, consistent with Venkatesh et al. (2000) age and gender are used to carry out a multi-group analysis ( $\mathrm{H} 6$ and $\mathrm{H} 7$ respectively). Figure 5.2 depicts the research model.

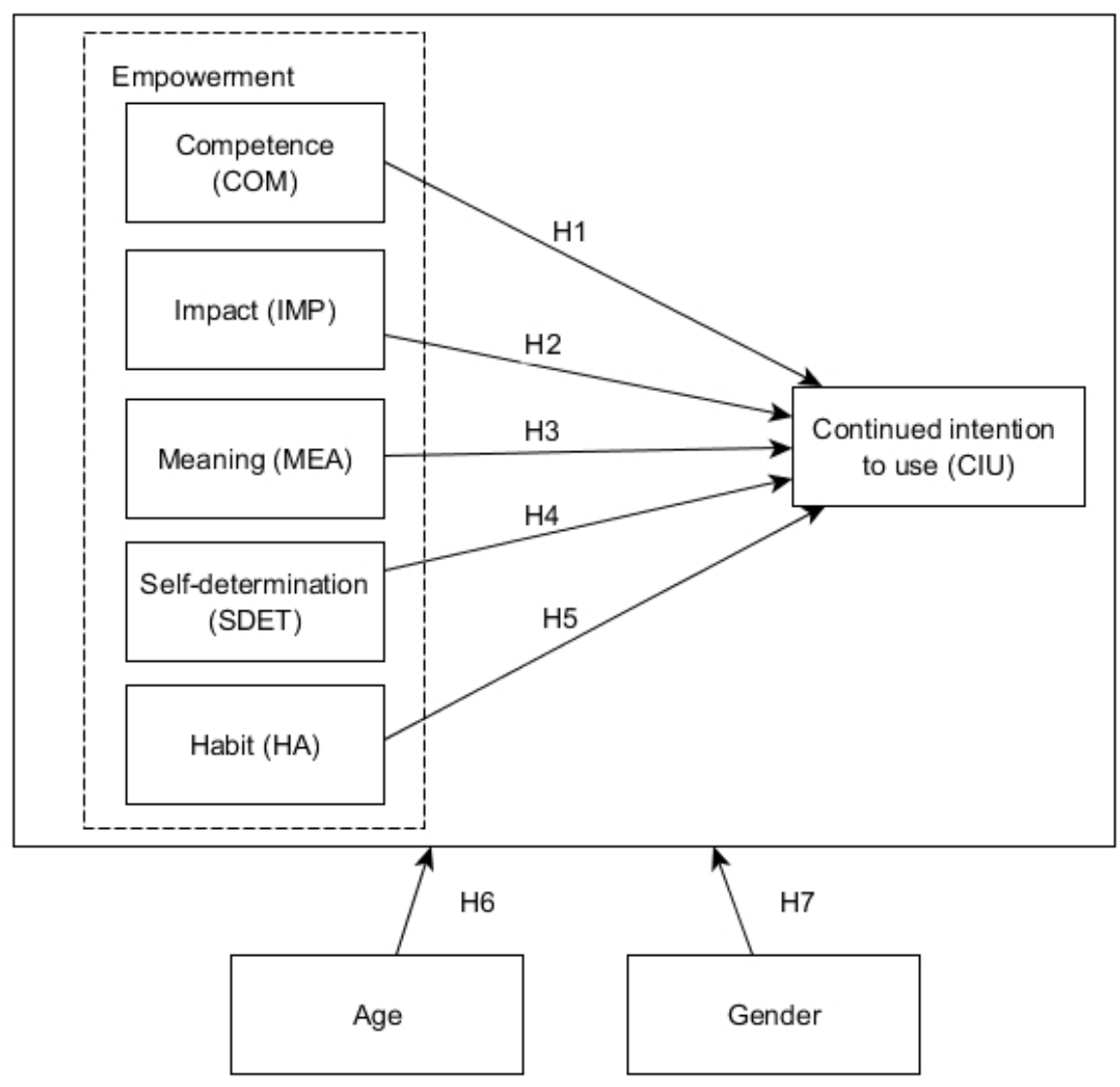

Figure 5.2. Research model and hypotheses

H1. Competence positively influences the continued intention to use online participatory budgeting. 
H2. Impact positively influences the continued intention to use online participatory budgeting.

H3. Meaning positively influences the continued intention to use online participatory budgeting.

H4. Self-determination positively influences the continued intention to use online participatory budgeting.

H5. Habit positively influences the continued intention to use online participatory budgeting.

H6. Age moderates the effect of empowerment and habit variables on the continued intention to use online participatory budgeting.

H7. Gender moderates the effect of empowerment and habit variables on the continued intention to use online participatory budgeting.

\subsection{Methodology}

The research model is evaluated using the partial least squares structural equation modelling (PLS-SEM) method (Hair et al., 2014). For all constructs, the measurement items were adapted from previously validated scales to the context of e-participation. We used reflective measures for all constructs. Age and gender are used to create separate groups of observations to detect whether the differences in the path coefficient estimates are statistically significant between those separate groups. The questions were multiple-type close ended on a seven-point range scale from 1 (totally disagree) to 7 (totally agree). The questions for empowerment were adapted from Kim \& Gupta (2014), the questions for habit from Venkatesh et al. (2012), and the questions for continued intention to use from Hsu et al. (2006). Please see the appendix 5.1.

An invitation email containing a hyperlink to the questionnaire was sent to the users registered in the municipality e-participation systems. The hyperlink could be used only once. We obtained 370 valid responses from December 1 to December 18, 2016, after the ninth edition of the online participatory budgeting in Lisbon. All responses corresponded to citizens that have experienced the online participatory budget in the past. Table 5.1 provides detail about the demographic profile of the respondents. 
Table 5.1. Demographic profile

\begin{tabular}{lll}
\hline Characteristics & Freq. & $\%$ \\
\hline Gender & & \\
Feminine & 187 & 50.54 \\
Masculine & 183 & 49.46 \\
Age groups (years) & & \\
40 or less & 164 & 45.14 \\
41 and more & 206 & 54.86 \\
Education & & \\
Bachelor & 110 & 29.73 \\
Master's degree & 100 & 27.03 \\
Post-graduation & 60 & 16.22 \\
High school & 57 & 15.41 \\
Doctorate & 39 & 10.54 \\
Primary school & 3 & 0.81 \\
NS/NR & 1 & 0.27 \\
Profession & & \\
Employed & 229 & 61.89 \\
Self-employed & 39 & 10.54 \\
Retired & 27 & 7.3 \\
Freelancer & 26 & 7.03 \\
Unemployed & 19 & 5.14 \\
Other & 17 & 4.59 \\
Student & 13 & 3.51 \\
\hline
\end{tabular}

\subsection{Results}

\subsubsection{Measurement Model}

We follow the guidelines of Hair et al. (2014) to evaluate the measurement model. Internal consistency, convergent validity, and discriminant validity are analysed for the measurement items. We used SmartPLS 3.0 software (Ringle et al., 2015) for the model estimation. The criteria to assess for internal consistency are Cronbach's alfa (CA) and composite reliability (CR), which are both above 0.7 for all latent variables. Average variance extracted (AVE) and the loadings are used to assess the convergent validity, both results above 0.5 and 0.7 respectively in almost all cases, except for HA2 (0.68). Although, due to its proximity to 0.7 we decided to keep the item (see Table 5.2). Finally, we tested discriminant validity by two criteria: the cross-loadings, where the loading of each indicator must be greater that the cross-loadings (Table 5.2), and using Fornell \& Larcker (1981), which states that the square root of AVE should be greater than its correlation with any other construct (see Table 5.3). 
Table 5.2. Loadings and cross-loadings

\begin{tabular}{llllllll}
\hline Construct & Item & COM & IMP & MEA & SDET & HA & CIU \\
\hline Competence & COM1 & 0.96 & 0.25 & 0.47 & 0.45 & 0.30 & 0.49 \\
CA=0.97 CR=0.98 AVE=0.94 & COM2 & 0.98 & 0.27 & 0.48 & 0.48 & 0.29 & 0.48 \\
& COM3 & 0.97 & 0.24 & 0.46 & 0.46 & 0.31 & 0.49 \\
Impact & IMP1 & 0.25 & 0.94 & 0.55 & 0.31 & 0.34 & 0.42 \\
CA=0.92 CR=0.95 AVE=0.86 & IMP2 & 0.27 & 0.96 & 0.51 & 0.28 & 0.36 & 0.40 \\
& IMP3 & 0.19 & 0.87 & 0.47 & 0.27 & 0.40 & 0.31 \\
Meaning & MEA1 & 0.46 & 0.52 & 0.93 & 0.40 & 0.56 & 0.59 \\
CA=0.94 CR=0.96 AVE=0.9 & MEA2 & 0.47 & 0.54 & 0.96 & 0.48 & 0.52 & 0.61 \\
& MEA3 & 0.44 & 0.51 & 0.95 & 0.46 & 0.48 & 0.56 \\
Self-Determination & SD1 & 0.48 & 0.32 & 0.45 & 0.95 & 0.30 & 0.40 \\
CA=0.95 CR=0.97 AVE=0.92 & SD2 & 0.44 & 0.30 & 0.46 & 0.97 & 0.32 & 0.40 \\
Habit & SD3 & 0.45 & 0.28 & 0.45 & 0.95 & 0.31 & 0.39 \\
CA=0.71 CR=0.83 AVE=0.62 & HA1 & 0.30 & 0.33 & 0.50 & 0.28 & 0.86 & 0.50 \\
& HA2 & 0.08 & 0.42 & 0.37 & 0.08 & 0.68 & 0.25 \\
Continued intention to use (CIU) & HA3 & 0.28 & 0.25 & 0.42 & 0.34 & 0.81 & 0.49 \\
CA=0.95 CR=0.97 AVE=0.91 & CIU1 & 0.48 & 0.37 & 0.57 & 0.41 & 0.53 & 0.96 \\
& CIU2 & 0.49 & 0.37 & 0.58 & 0.41 & 0.52 & 0.97 \\
\hline
\end{tabular}

Note: $\mathrm{CA}=$ Cronbach's Alfa, $\mathrm{CR}=$ Composite Reliability, AVE = Average Variance Extracted.

Table 5.3. Correlation matrix and the square root of AVE (in bold)

\begin{tabular}{lllllll}
\hline Construct & COM & IMP & MEA & SDET & HA & CIU \\
\hline Competence (COM) & $\mathbf{0 . 9 7}$ & & & & & \\
Impact (IMP) & 0.26 & $\mathbf{0 . 9 2}$ & & & & \\
Meaning (MEA) & 0.48 & 0.55 & $\mathbf{0 . 9 5}$ & & & \\
Self-determination (SDET) & 0.48 & 0.31 & 0.47 & $\mathbf{0 . 9 6}$ & & \\
Habit (HA) & 0.31 & 0.39 & 0.55 & 0.32 & $\mathbf{0 . 7 9}$ & \\
Continued intention to use (CIU) & 0.50 & 0.41 & 0.62 & 0.41 & 0.55 & $\mathbf{0 . 9 5}$ \\
\hline
\end{tabular}

\subsubsection{Structural Model and Multi-Group Analysis}

The model is evaluated with the full set of data (370 observations). The research model explains $50.1 \%$ (see Figure 5.3 - Full sample) of the variation in the continued intention to use online participatory budgeting, considered as moderate predictive power (Henseler et al., 2009). The statistical significance of the path coefficients was assessed using the bootstrapping technique (Hair et al., 2014) with 5000 iterations. The significance of the path coefficients indicates whether the hypotheses are supported or not. Five hypotheses are evaluated in this study. Three were supported ( $\mathrm{H} 1, \mathrm{H} 3$, and $\mathrm{H} 5$ resulted statistically significant). Unexpectedly, $\mathrm{H} 2$ and $\mathrm{H} 4$ were found not significant, thus not supported (Figure 5.3). Individuals are different in their intention and use behaviour of information technology (Hair et al., 2014). For this reason, we assess the observable heterogeneity in the data, namely the characteristics of age and gender. We use 
these characteristics to partition the dataset into four separate groups: A1 group - 41 years and older (206 observations); A2 group - 40 years and younger (164 observations); G1 group women (187 observations); And, G2 group - men (183 observations). The sub-group models are consistent with the full-sample model, except for $\mathrm{A} 2$ group, where the effect of meaning over continued intention is not significant (see Figure 5.3-A2 group).
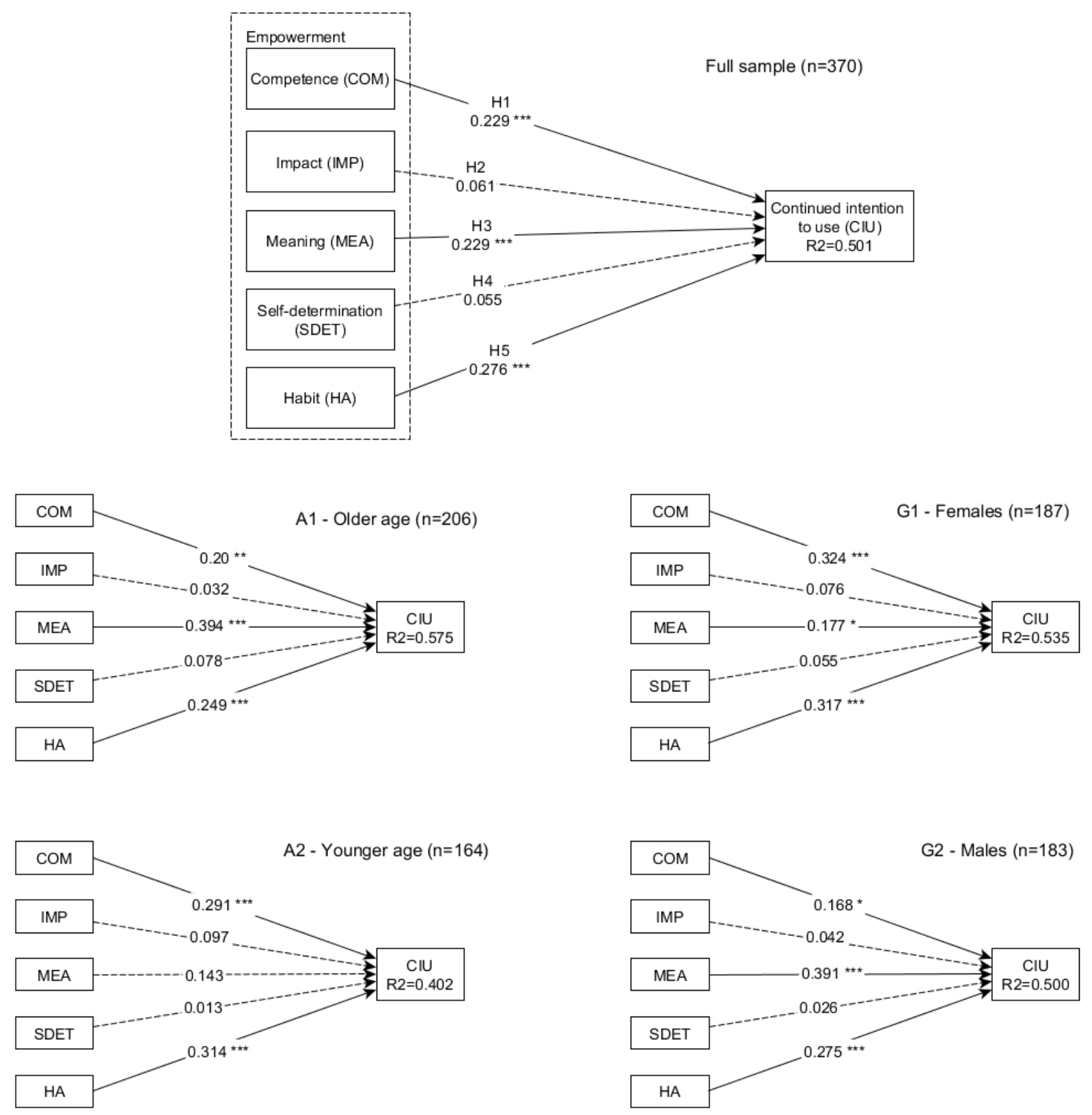

Figure 5.3. Structural model results by groups Notes: significant at $* 10 \% ;{ }^{* *} 5 \% ; * * * 1 \%$. Non-significant paths are in dotted arrows. 
The path coefficients for the separate groups resulted numerically different. We calculate the t-value to determine whether the differences of path coefficients by age and gender are statistically significant. The hypotheses on the individual differences by age $(\mathrm{H} 6)$ and gender (H7) were supported only for meaning. Differences between age and gender groups for other constructs were found not statistically significant, where the differences were statistically significant in both groups: age and gender. Please see Table 5.4.

Table 5.4. Multi-group analysis

\begin{tabular}{lllllllll}
\hline Construct & \multicolumn{3}{l}{ Age groups (A) } & \multicolumn{5}{l}{ Gender groups (G) } \\
\cline { 2 - 10 } & Beta & t-value & Beta & t-value \\
\cline { 2 - 10 } COM & 0.20 & 0.29 & 0.09 & 0.70 & 0.32 & 0.17 & 0.16 & 1.28 \\
IMP & 0.03 & 0.10 & 0.07 & 0.70 & 0.08 & 0.04 & 0.03 & 0.38 \\
MEA & 0.39 & 0.14 & 0.25 & 2.03 & 0.18 & 0.39 & 0.21 & 1.71 \\
SDET & 0.08 & 0.01 & 0.07 & 0.53 & 0.06 & 0.03 & 0.03 & 0.23 \\
HA & 0.25 & 0.31 & 0.06 & 0.53 & 0.32 & 0.28 & 0.04 & 0.35 \\
\hline
\end{tabular}

Notes: $\mathrm{A} 1=41$ years or more; $\mathrm{A} 2=40$ years or less; $\mathrm{G} 1=$ Females; $\mathrm{G} 2=$ Males

\subsection{Discussion}

This study evaluates the effect of the four dimensions of the psychological empowerment theory and habit on the continued intention to use online participatory budgeting. The influence of competence, meaning, and habit of the continued intention resulted positively significant, being habit the strongest predictor. On the contrary, impact and self-determination both were found not significant on continued intention to use. Regarding the individual differences, results show significant differences only for meaning. The effect of meaning over the continued intention is stronger for older men than for younger women.

The positive influence of competence on the continued intention to use, this is, the perception of having enough capabilities and skills to use the online participatory budgeting, may be an indicator that most of the citizens are able to complete seamlessly the intended actions in the system. For instance, search for information about projects or vote electronically, which gives them confidence to continue to use the system. The system design and the workflow process implementation and management of the participatory budgeting depend on the local government. Consequently, the main implication for local government that implement online participatory budgeting is to follow the best practices of system usability and keep the workflow 
as simple as possible. This will preserve the feeling of competence in the citizens and they will be more willing to continue using the system over time.

The significant and positive effect of meaning as a motivator of the continued intention to use online participatory budgeting implies that citizens indeed perceive that there is a value derived from the utilization of the system, a meaningful participation (The World Bank, 2007). This perception of value could be attributable to the implementation of the winning projects in benefit of the community. Different from competence, the perception of meaning does not only rely solely on the actions of local governments but also on the proposals submitted by the citizens to the online participatory budgeting. If voters do not perceive value in the proposals, the motivation to keep using the system in the upcoming editions may decrease. Nevertheless, local governments may play a critical role to attract meaningful proposals. For instance, defining the areas of interest in which the proposals should be framed. The results from the multi-group analysis show that differences between separate groups by age and gender are significant only for the effect of meaning over continued intention, being stronger for older men than younger women. This finding may suggest for local governments to devote more efforts and define strategies to promote the online participatory budgeting among younger citizens, especially young women. The strategies should focus on increasing the perception of value derived from using the online participatory budgeting.

Habit was found as the stronger predictor of the continued intention to use. Since the online participatory budgeting in Lisbon started in 2008 and is still ongoing, this result is not a surprise. The online participatory budgeting has a yearly general cyclical workflow, where most of the citizens participate using electronic voting every year, this behaviour may be considered a habit to a certain extent. Former studies demonstrated that habit is able to drive repeated behavioural patterns regarding the use of information technology (Kim \& Malhotra, 2005). This finding could have positive implications for local governments. The citizens that already perceive the use online participatory budgeting as a habit may be more willing to try and engage in new forms of e-participation.

The effect of impact and self-determination was found not significant over continued intention to use. In the case of impact, this may imply that the citizens do not perceive their individual votes as a strong influence on the result of the selected projects for implementation given the large number of votes (51591 votes in 2016). The degree of autonomy (selfdetermination) to interact with online participatory budgeting seems to play a minor role over 
continued intention, this may be due to the limited interaction in terms of tasks that citizens perform in the system, which in the most of cases is limited to the search of information and electronic voting.

\subsection{Conclusion}

The existence of a perception of empowerment in the citizens that may motivate the continued intention to use online participatory budgeting is not confirmed by this study. Although, two out of four dimensions of empowerment showed a significant and positive effect on continued intention to use. The strongest predictor of the continued intention to use was habit, which probably has been developed due to participation in previous editions of online participatory budgeting. Individual differences of age and gender had no effect on the variables analysed in this study, except on meaning, suggesting that older males perceive a higher value than young females in the participatory budgeting. Local governments should keep the citizen perceptions of competence and meaning high to ensure the use of online participatory budgeting over time. Additionally, local governments should design strategies to increase the perception of meaning regarding participatory budgeting among the young population, especially the younger women. 


\section{Chaper 6 - Satisfaction with e-participation: A model from the citizen's perspective, expectations, and affective ties to the place}

\subsection{Introduction}

The United Nations e-government survey 2014 (United Nations, 2014, p. 61) defines eparticipation as "the process of engaging citizens through ICTs [information and communication technologies] in policy and decision-making in order to make public administration participatory, inclusive, collaborative and deliberative for intrinsic and instrumental ends". The successful implementation of e-participation can bring prominent benefits for the society (Royo \& Yetano, 2015), as for instance, transparency, efficiency, and better quality of public services, even reducing costs in democratic and decision-making processes (Vragov \& Kumar, 2013). These benefits are possible if a substantial number of citizens of a community or city adopt and use eparticipation in the long-term. Therefore, the level of citizen satisfaction regarding the usage of e-participation is a crucial factor in the adoption of these technologies over time.

Citizen satisfaction with the use of e-participation and e-government systems has been proven to improve the trust in government (Bélanger \& Carter, 2008; United Nations, 2012), and to have a direct influence in citizens' adoption and use behaviour of the system. For instance, in the context of e-government, a study by Foresee (2016) found that highly satisfied citizens, compared to dissatisfied ones, are: $54 \%$ more likely to participate in democratic processes and express their opinions, $52 \%$ more likely to return to the system, $100 \%$ more likely to recommend the website to family and friends, and $63 \%$ more likely to trust the government agency. The United Nations e-government survey report (2012) suggests that measuring citizens experience and satisfaction is still a challenge, highlighting the crucial importance for governments to improve the measurement methods and build assessment frameworks for citizens satisfaction. However, scant literature has assessed the citizen satisfaction of e-participation (Kipenis \& Askounis, 2016; Naranjo Zolotov et al., 2018). This study proposes a conceptual model to fill this gap.

The main contribution of this study is the development of a conceptual model to evaluate citizens satisfaction with the use of e-participation systems, and the influence that the level of satisfaction plays for the continued intention to use e-participation. To achieve our goal, we propose integrating three well-known theories: The DeLone \& McLean (2003) success model, which measures satisfaction based on the perception of the e-participation system quality; the 
expectation-confirmation model (ECM) (Bhattacherjee, 2001), which measures satisfaction based on the perception of confirmation that citizens have in the post adoption stage of eparticipation; and finally, the dimensions of sense of place (SOP), which refer to the affective or meaning ties that a citizen may have for a place, which may strengthen the level of satisfaction when using e-participation systems.

The rest of the paper is organized as follows, Section 2 summarizes the insights from earlier studies and the potential effects of citizen satisfaction over e-participation and egovernment initiatives. Section 3 develops the conceptual model and hypotheses proposed in this study. Section 4 provides a conclusion and suggestions for future research.

\subsection{Citizen Satisfaction}

Most earlier studies have measured citizen satisfaction regarding government services performance (Van Ryzin, 2005, 2007), finding that citizen satisfaction mainly depends on their performance perception, which may also be influenced by external factors. The overall citizen satisfaction may be an important factor in the prediction of behavioural responses, such as trusting the government (Venkatesh et al., 2016) or influencing the adoption of e-government (Al Hujran, Aloudat, \& Altarawneh, 2013). However, in the case of e-participation platforms, where the citizens may be directly involved in the decision-making process, it is not yet clear what the main drivers of citizen satisfaction are.

In the context of the e-government mandatory services, Chan et al. (2010) evaluated the four main determinants of the unified theory of acceptance and use of technology (UTAUT) (Venkatesh et al., 2003) (performance expectancy, effort expectancy, social influence, and facilitating conditions) as predictors of satisfaction. They found that all those determinants, except social influence, positively influenced the level of citizen satisfaction. Other studies have measured citizen satisfaction with e-government services using three dimensions of services quality: responsiveness, reliability, and empathy (Al Hujran et al., 2013). Nevertheless, in the case of e-participation, which is used voluntarily (Medaglia, 2012), the perception of satisfaction may differ from other systems because the final perceived outcomes and benefits for the community are influenced directly by the interactions of the citizens with the e-participation.

Satisfaction is a variable that has been widely measured in different fields of information and communication technology. A variety of research models and variables have been employed across the literature to measure and understand satisfaction. Two of the most used theoretical 
models for this purpose are D\&M (DeLone \& McLean, 2003) and ECM (Bhattacherjee, 2001). For instance, D\&M model was used by Tam \& Oliveira (2017) to study user satisfaction in the context of mobile banking; and by Akter, D'Ambra, \& Ray (2010) to assess the service quality of mobile health applications. In the case of ECM, it was employed to evaluate the continuance intention to use the smartphone banking services, having user satisfaction as one of the dependent variables (Susanto, Chang, \& Ha, 2016); and also, for the study of satisfaction and continuous intention to use mobile instant messaging (Oghuma, Libaque-Saenz, Wong, \& Chang, 2016).

The implementation of e-participation systems by local governments has been proven to increase the level of citizen satisfaction (Ahn \& Bretschneider, 2011), and in turn, citizen satisfaction positively impacts the level of trust in government (Christensen \& Lægreid, 2005; Welch et al., 2005). Furthermore, citizen satisfaction has been found to be the strongest predictor of the intention to use electronic services from the government, even stronger than perceived usefulness and perceived ease of use (Al Hujran et al., 2013). A study across 32 European countries found evidence of a positive association between e-participation performance and citizen satisfaction (Ma \& Zheng, 2017).

\subsection{Conceptual Model and Hypotheses}

Our study adopts the updated version of the DeLone \& McLean (2003) success model (D\&M), the objective of which is to assess citizen satisfaction and e-participation usage. Six constructs define the D\&M model: information quality, system quality, service quality, use, citizen satisfaction, and net benefits. The net benefits refer to the benefits obtained by the organization that adopts the information system (IS). However, in the e-participation context the final beneficiary is a community of citizens. Consequently, we have dropped this construct from our model.

The ECM analyses citizen satisfaction as the result of the confirmation from prior use of an ICT and the perceived usefulness. The final goal of the expectation-confirmation model is to explain the continuance intention of an ICT, in our case, e-participation. We adopt the model of information system continuance proposed by Bhattacherjee (2001), which is composed of four constructs: perceived usefulness, confirmation, satisfaction, and e-participation continuance intention. The ECM sequence of e-participation adoption can be summarized as: (i) the citizen makes an initial acceptance decision, (ii) the citizen has an initial experience with e-participation, 
(iii) the citizen makes an ex-post decision regarding whether to continue using e-participation or reverse the initial decision.

In the context of public services, Van Ryzin (2013) suggests that citizens judge public services not only on the perceived quality of the information system, but also on an implicit comparison with prior expectations. E-participation systems can be considered public services provided by local or national governments, in this sense, the integration of D\&M model with ECM may provide a bigger picture of the factors that may explain citizen satisfaction and continuous intention to use e-participation. Moreover, since e-participation is voluntary and with the goal to bring benefits to a community, SOP (Jorgensen \& Stedman, 2001) may have roles to play as moderators between use and citizen satisfaction. Figure 6.1 presents the conceptual model.

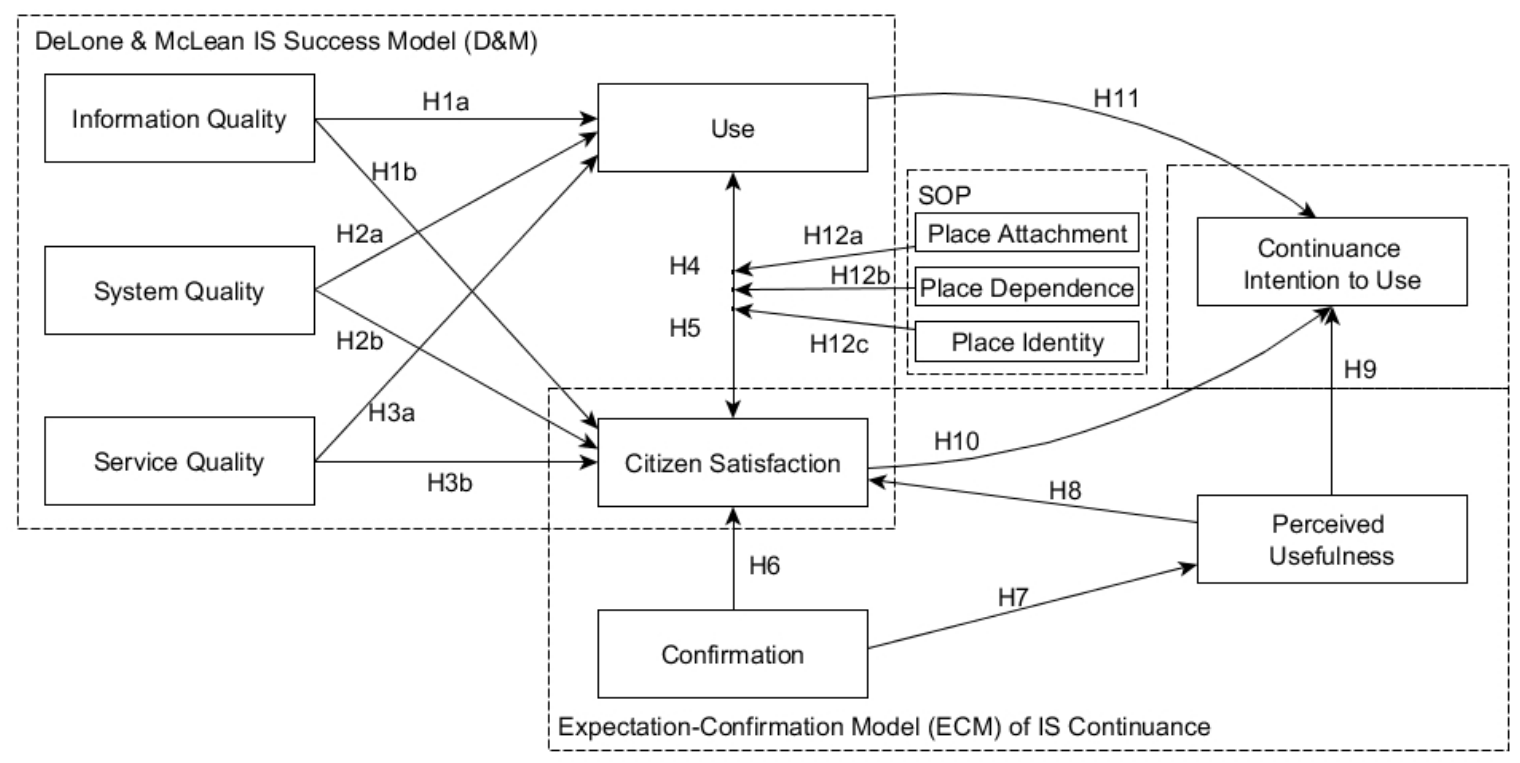

Figure 6.1. Conceptual model

\subsubsection{DeLone and McLean Variables}

Teo et al. (2009) define information quality as each citizen's assessment of whether the information on the e-participation website is accurate, valid, and timely. DeLone \& McLean (2003) identify five success metrics for information quality: completeness, ease of understanding, personalization, relevance, and security. In the e-participation context the information presented on the website is generated by both the government and the citizens. The government presents information about the objectives, process description, and feedback, which is essential to engage the citizens on e-participation and keep them using the system in 
the long term. At the same time, because the interaction of citizens on e-participation also generates information (e.g. discussion forums, project proposals), the improper presentation design of this information on the website may create barriers for the citizen interaction on eparticipation. For instance, in online participatory budgeting processes (Allegretti \& Antunes, 2014 ) it is expected that the information available on each project proposal is complete and can be easily found on the website in order for the citizens to have a clear idea about which project to vote for. Lack of clarity and consistency may cause citizen frustration and consequently increase absenteeism in the voting process and stop or decrease the use of the e-participation platform. Therefore, we hypothesize:

H1a. Information quality has a positive influence on the use of e-participation.

H1b. Information quality has a positive influence on the citizen satisfaction of e-participation.

System quality is defined as the individual perception of the system's overall performance (DeLone \& McLean, 2003), which in turn may lead to greater user satisfaction and use of the information system. In the e-participation context the overall system quality may be judged by the degree to which a citizen is able to contribute to an online participatory process (e.g. electronic voting, proposal submission, opinion giving). A citizen perception about the eparticipation overall quality may be initially linked to the trust in the local government that manages the system (Teo et al., 2009). As e-participation is made available to all the citizens in a given community, the system quality can be measured in terms of usability, ease of use, accessibility, reliability, feedback, transparency, and so on. For instance, using the same eparticipation example used for information quality (the online participatory budgeting), citizens who provided an electronic vote for a project may be interested in having access to a detailed report of the voting results shortly after the voting period is over. Failing to provide the final voting results in a reasonable time may affect the perception of transparency and trust in the eparticipation system, and thus, negatively impact the citizens perception of overall system quality. We hypothesize:

H2a. System quality has a positive influence on the use of e-participation.

$\mathrm{H} 2 \mathrm{~b}$. System quality has a positive influence on the citizen satisfaction of e-participation.

DeLone \& McLean (2003) define "service quality is the overall support delivered by the service provider". According to Teo et al. (2009), in the context of e-government, service quality is perceived as interaction between citizens and government officials. However, in e- 
participation the existing interactions are both between citizens and governments and between citizens and citizens. Government officials behind the online participatory platforms are expected to keep the information updated, provide feedback, and/or regulate inappropriate content generated by citizens. In turn, citizens are the core-content generators in eparticipation, for instance, providing opinions in online forums or submitting proposals for the online participatory budgeting. Poor service quality from the government side may lead to poor citizen participation, and consequently, poor content generated by citizens may lead to demotivate other citizens from using e-participation.

H3a. Service quality has a positive influence on the use of e-participation.

H3b. Service quality has a positive influence on the citizen satisfaction of e-participation.

DeLone \& McLean (2003) suggest that citizen satisfaction and usage of e-participation are closely interrelated, in which a positive experience in use may lead to a positive citizen satisfaction. Wang \& Liao (2008) note that the use of e-participation systems is completely voluntary and suggest that actual use has a closer meaning to success than intention to use. We follow the approach of Wang \& Liao (2008) and adopted use as a success measure in the context of e-participation for our conceptual model. On the opposite direction, greater citizen satisfaction has also being found to positively affect use of e-participation (Tam \& Oliveira, 2017). Therefore, we hypothesize:

H4. The use affects the citizen satisfaction on e-participation.

H5. The citizen satisfaction affects the use of e-participation.

\subsubsection{Expectation-Confirmation Variables}

Bhattacherjee (2001) refers to confirmation as the "realization of the expected benefits of IS use". In the EMC for continuous use, expectation is represented by perceived usefulness, which also suggests that perceived usefulness can be adjusted according to the citizen confirmation experience. Earlier studies have found a positive influence of confirmation over satisfaction and perceived usefulness (Hong, Thong, \& Tam, 2006; Oghuma et al., 2016; Susanto et al., 2016). Since e-participation platforms are oriented to the citizenry and managed by the governments, they are planned to last for several years (e.g., online participatory budgeting and incident reporting applications) before being changed or replaced. Therefore, it is expected that citizens who experience e-participation can adjust their perception of usefulness over time based on the confirmation experience. 
H6. Confirmation positively influences the citizen satisfaction with e-participation.

H7. Confirmation positively influences the perceived usefulness of e-participation.

In the job context, perceived usefulness is defined as the individual belief that using the ICT will help to increase one's job performance (Bhattacherjee \& Premkumar, 2004). For the context of e-participation, perceived usefulness can be interpreted as the perception of the citizen that using e-participation will help to make a better or more effective contribution to the community. According to Bhattacherjee (2001), perceived usefulness may affect citizen satisfaction in both phases: acceptance and post-acceptance. Due to the long-term vision of eparticipation, perceived usefulness becomes an especially suitable factor to analyse citizen satisfaction in this context. Earlier studies report that perceived usefulness positively affects citizens satisfaction and continuance intention to use (Oghuma et al., 2016; Susanto et al., 2016). Continuance intention to use is defined as the degree to which citizens perceive that they will continue using e-participation in the future (Hoehle \& Venkatesh, 2015a).

H8. Perceived usefulness positively influences the citizen satisfaction with e- participation.

H9. Perceived usefulness positively influences the citizen continuance intention to use eparticipation.

Citizen satisfaction with prior use of e-participation has been found to be one of the strongest predictors of continuance intention to use in several fields of ICT adoption; for instance, on university information systems (Liao et al., 2009), mobile internet (Hong et al., 2006), mobile banking (Susanto et al., 2016), and mobile instant messaging (Oghuma et al., 2016). As eparticipation systems are intended to be used in the long term, their frequent use over time may also positively influence the continuance intention to use. Therefore, we hypothesize:

H10. The level of citizen satisfaction positively influences the continuance intention to use eparticipation.

H11. The use of e-participation positively affects the continuance intention to use eparticipation.

\subsubsection{Moderator Role of Sense of Place (SOP)}

SOP has been defined as "the meaning attached to a spatial setting by a person or group" (Jorgensen \& Stedman, 2001). Considering that the most e-participation projects implemented by government are at city or parish level (e.g., participatory budgeting, incident reporting 
applications), the ties that a citizen has to a place may significantly affect her/his behaviour regarding the use of e-participation when that place is involved. Acedo et al. (2017) suggest that geographical areas containing a higher level of SOP may create better conditions for "cooperation and collaborative synergies between people who share more than just a space". SOP is encompassed and measured in three dimensions (Jorgensen \& Stedman, 2006): place attachment, place dependence, and place identity. Place attachment is defined as an emotional bond that citizens develop with some geographical place (Lewicka, 2011). Earlier literature has found that place attachment positively affects the neighbourhood ties of a citizen (Lewicka, 2005). Place dependence refers to the useful values that a place may have to satisfy the citizens' goals and desires in comparison to other places (Stedman, 2002). Place identity is conceived as the reflection of the citizen regarding a place (Jorgensen \& Stedman, 2006), also defined as an expression of "at homeness"(Cuba \& Hummon, 1993). We include the three components of SOP in our conceptual model as moderatos of the relationship between the use of e-participation and citizen satisfaction. We posit that the stronger the feeling of SOP to a certain area, the higher the level of satisfaction when the interaction on e-participation involves that area.

H12a. Place attachment moderates the effect of use of e-participation over citizen satisfaction, in which the citizen satisfaction is greater when the feeling of place attachment is stronger.

H12b. Place dependence moderates the effect of use of e-participation over citizen satisfaction, in which the citizen satisfaction is greater when the feeling of place dependence is stronger.

H12c. Place identity moderates the effect of use of e-participation over citizen satisfaction, in which the citizen satisfaction is greater when the feeling of place identity is stronger.

\subsection{Implications and Future Research}

On e-participation context, citizen satisfaction is a complex variable, challenging to measure from the citizen's perspective. Van Ryzin (2007) points out that exogenous variables to the information systems (IS) itself may impact on the performance perception and satisfaction of the citizens. Our model presents a wholistic approach that not only measures the perception of quality of the online information system (e.g., navigability or functionality of the e-participation website (Foresee, 2016)). But also attempts to provide a better understanding of the citizen satisfaction from the perspective of perceived usefulness.

Governments that implement e-participation, may use our model to evaluate citizen satisfaction and design policies of continuous improvement and evolution of e-participation 
tools, considering not only the improvement of the system quality, but also addressing the effect of external factors and citizens' perceived usefulness. Thus, achieving higher levels of citizen satisfaction in the long-term scenario. The continuous evaluation of citizen satisfaction may be crucial to prevent the risk, for governments, that citizens may generalize a non-satisfactory experience using e-participation to a feeling of distrust on the governmental institution (Petrovsky, Mok, \& León-Cázares, 2017). Governments may use the model to monitor the level of citizens satisfaction periodically and adjust the policies on time before the citizens loose interest on the e-participation platforms.

Measuring sense of place and its effect on citizen satisfaction may facilitate to refine eparticipation tools to create a bigger impact at local community level as neighbourhoods or parishes. For instance, to promote the use of participative budgeting platforms, the diffusion campaigns may be tailored to the local communities depending of the levels of sense of place.

Satisfied citizens with the continued use of e-participation may also be more willing to engage in democratic processes and try new e-participation initiatives proposed by the local governments. Consequently, by identifying high levels of citizen satisfaction, governments may identify the most appropriate period to promote new e-participation tools.

Future research may evaluate the proposed model by collecting data from citizens that have experienced e-participation systems, and either are still using the system or have discontinued the usage of e-participation. Using evaluation methods like structural equation modelling (Hair et al., 2014), we can obtain results about the strength of the conceptual factors as drivers of citizen satisfaction, use, and continued intention to use e-participation.

\subsection{Conclusion}

Citizen satisfaction is a critical factor that influences the e-participation adoption in the long term. Once the citizens reach a high level of satisfaction with e-participation use, additional side benefits come along with satisfaction, such as trust in government and increased willingness to participate in democratic processes. The assessment of citizen satisfaction on e-participation use is still a challenge for research and for governments that want to implement successful eparticipation projects. E-participation is of a voluntary use, accessible and inclusive to all citizens, is managed and sponsored by the government, and the information on the system is mainly generated by the citizens for the citizens. The assessment of the level of citizen satisfaction should consider all these characteristics. We propose a conceptual model to evaluate citizen 
satisfaction with e-participation. The model integrates the DeLone \& McLean success model, which measures the satisfaction in terms of perception of quality, the expectation-confirmation model, which measures satisfaction based on the confirmation and perceived usefulness, and finally, the sense of place, which refers to emotional and meaning ties that the citizen has to a specific area, which may moderate the effect of satisfaction over e-participation use. 


\section{Chaper 7 - Place and City: Towards a geography of engagement}

\subsection{Introduction}

The importance of encouraging people to act as participative citizens in issues of public concern is essential for a functioning democracy, particularly when researchers are observing that civic engagement (CE) is diminishing in developed countries (Aricat \& Ling, 2016). In turn, the relationship that individuals have toward a certain geographical area (i.e., sense of place (SoP)) or their significant social relationships (i.e., social capital (SC)) embedded within an area can play a crucial role on the engagement of a citizen (Perkins, Brown, \& Taylor, 1996). Researchers have revised the connection between individuals' place attachment and many forms of $C E$, such as civic activity (Lewicka, 2005), community participation and planning (Manzo \& Perkins, 2006) or pro-environmental behaviour (Buta, Holland, \& Kaplanidou, 2014). All these studies register the importance of relationships among citizens and their meaningful places in which they have significant relationships are central to citizens' engagement. However, the relation between participation, place and space has received little attention (Pain \& Kindon, 2007), leaving aside a further understanding of human-environment interactions in participatory processes. We already know that most of participation processes are grounded in specific sites and socioecological contexts (Haywood, 2014). Hence, the study of individuals' spatialities (individuals or collectives practices related to their geographical location) (Lussault, 2007) regarding SoP and SC in the city context can offer an alternative vision to better understand and foster participatory processes (i.e., CE). Our approach has its roots in the understanding of cities as place networks (Acedo, Painho, Casteleyn, \& Roche, 2018; Doreen Massey, 1994; Roche, 2016) and how we can comprehend a relational space based on networks of actions and actors (Duff, 2011; Latour, 2005; Murdoch, 1998). Our study aims to exalt the spatial dimension of individuals' spatialities (i.e., individuals' SoP and SC) as the pivotal aspect to fully appreciate the social-spatial practices of CE in the urban context.

This study performs a theoretical literature review to confirm the strong relationship between SoP, SC and CE and their dimensions from a non-spatial perspective to justify their revision from a spatial point-of-view. In this research, a spatial perspective means to study the spatial imprint of a concept defined by its location and their relative location versus other concepts (i.e., proximity, density). Then, we attempt the study and validation of the importance of their (i.e., SoP, SC and CE) spatial relationship. We gather the spatial dimension of SoP, SC and 
CE from a web map-based survey. We merge a web map-based approach with traditional questionnaires based on soft-GIS methodology (Kahila \& Kyttä, 2009; Kyttä \& Kahila, 2011). We analyse the answers using partial least squares structural equation modelling (PLS-SEM) techniques (Hair et al., 2014) to illustrate their quantitative relationship and assess the potential of considering the spatial dimension of the social concepts (i.e., SoP and SC) to better understand $\mathrm{CE}$ in the city context. Our methodology is eminently based on citizens' spatialities associated with the SoP, SC, and $\mathrm{CE}$; i.e., the entire methodology is revolving around a geographic perspective with a practical focus on studying the social-spatial practices of CE such as participatory processes in local or community affairs in the city context.

We assume that there is a difficulty to switch current participatory geographies (i.e., the spaces where the governments are setting up participatory processes) based on administrative boundaries to one based on common citizens' spatialities. The underlying reason to use those administrative boundaries is to find out the percentage of the participatory results upon census and socioeconomic data in those specific areas. However, the understanding of the spatial relationship between SoP, SC and CE establishes novel spatial scenes based on human-city interactions. These possible geographies can embrace a commitment to place (SoP), meaningful social groups (SC) and spaces of participation (CE) for a citizen. Therefore, those new spatial contexts can operate shared geographies of engagement that can underpin collaboration, cooperation and interaction between citizens engaged with these specific geographic areas in, for instance, local affairs, social issues or planning decision-making processes. This paper materializes the first step towards these new "geographies of engagement" in 1) performing a theoretical literature review between SoP, SC and CE and their dimensions, and 2) studying and assessing the influence of SoP on SC and the latter on CE with special focus on when it occurs their spatial relationship in a proposed model. This article starts with a review of the SoP, SC, and CE conceptualizations and dimensions as well as the suitability to understand them from a spatial point-of-view that end in a number of hypotheses. The article then presents the methods and the results of an experiment conducted in Lisbon (Portugal) to clarify the importance of the spatial dimensions of SoP, SC, and CE to explain their relationship. This explanation is followed by a discussion of the results, the remaining gaps, the limitations, and finally the conclusions of this research. 


\subsection{Theoretical background and hypotheses}

A city can be understood under a relational nature between actions and actors (e.g. humans, objects) (see actor-network theory (Latour, 2005; Law, 2008). Murdoch (1998) specified the characteristics of that city-space arguing a folded and striated geography in which all action is relational and reflects both the diversity of materials used in construction and the relations between elements. Drawing in the same line, Duff (2011) mentioned three needed resources (i.e., social, affective and material) to enable and define places. The inherent relation between the three resources forms networks and flows that configure the city environment (Duff, 2011). The same author defines the social resource as social capital, the affective resources mean feeling states and action-potential and the material one covers the materiality of place as well as services and information. Recently, Acedo et al. (2018) also put in value the understanding of a city throughout spatial urban dynamics, arguing the potentiality to conceptualize SoP and SC as inhibitors of place notion based on Agnew $(2002,2011)$. Those mentioned conceptualizations can apply to any city, the challenge resides on how to operationalize those arrangements in the city context to better understand the urban synergies.

SoP refers to the feelings, beliefs and behaviours that humans associate with a place (Jorgensen \& Stedman, 2001). The same authors argue explicitly for the positivistic research in the SoP notion and propose three dimensions (place attachment, place identity and place dependence). Place attachment is usually defined as an emotional bond that connects people to places (Altman \& Low, 1992; Lewicka, 2013; Manzo, 2005), while place identity refers to the relation between a place and one's personal identity (Proshansky, Fabian, \& Kaminoff, 1983; Trentelman, 2009). Finally, place dependence is the potential of a place to meet the necessities of an individual or group with respect to other places (Jorgensen \& Stedman, 2001).

SC analyses the value of social relationships and networks to societies and individuals (Holt, 2008), and it can be analysed by four dimensions: sense of community, collective efficacy or empowerment, neighbouring and citizen participation (Perkins, Hughey, \& Speer, 2002; Perkins \& Long, 2002). Sense of community is the feeling of membership to a group (Perkins \& Long, 2002), while collective efficacy/empowerment is the belief and thought of the potentiality of acting together. Neighbouring encloses the informal actions and behaviours of citizens to a group or society (Acedo, Painho, et al., 2017) that essentially occurs in localities (Mahmoudi Farahani, 2016), and citizen participation describes the change from passive to active involvement in the local activities and decisions (Adler \& Goggin, 2005) and electronic 
participation (Naranjo Zolotov et al., 2018).

CE explains associations or ways in which citizens have a common purpose to preserve and promote public goods (Son \& Lin, 2008), to improve conditions for others (Cegarra-Navarro et al., 2014), community (Putnam, 2000) or collective benefit (Moro, 2010). Many times CE is conceptualized as a process rather than an event (UNDP Evaluation Office, 2002), as a measurement of the right of citizens to have a say in the decisions that affect their lives (Sheedy, Mackinnon, Pitre, \& Watling, 2008, p. 4).

\subsubsection{Relating sense of place, social capital, and civic engagement}

A commitment to place motivates SC (Jorgensen, 2010) and neighbourhood ties (Lewicka, 2005). Processes of collective action (dimension of SC) perform better when there are emotional ties to places (Manzo \& Perkins, 2006). In the same line, emotional and behavioural attachment is related to a sense of community (Pretty, Chipuer, \& Bramston, 2003). There are studies that systematically demonstrate the existence of a relationship between SoP and SC (Jorgensen, 2010; Mesch \& Manor, 1998; Raymond, Brown, \& Weber, 2010). For instance, Acedo, Painho, et al. (2017) performed a systematic literature review with more than 20 references showing the strong relationships between SoP and SC and their dimensions (based on attitude theory (Ajzen \& Fishbein, 1977; Fishbein \& Ajzen, 1975; Rosenberg, 1960)). Figure 7.1 depicts the connections found between the dimensions of SC and SOP towards CE after to perform a theoretical literature review. 


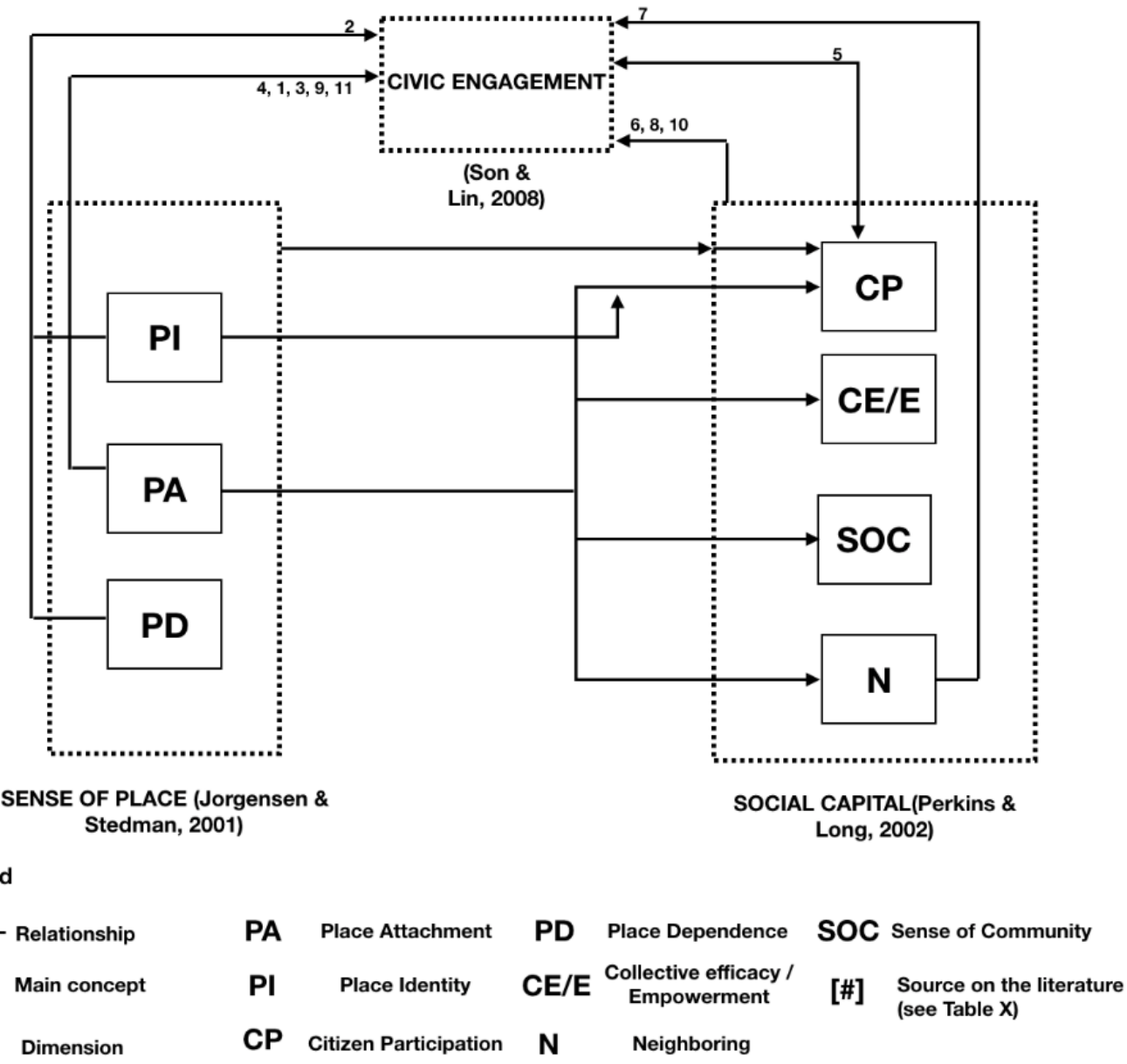

Figure 7.1. Relationships between sense of place and social capital dimensions toward civic engagement

Note: Figure adapted from Acedo, Painho, et al. (2017). Numbers in the arrows are references listed in Appendix 7.1.

Figure 7.1 summarizes the relationship between SoP and SC toward CE as extracted from the theoretical literature review. The analysis of Figure 7.1 shows the relationships between the main concepts and their dimensions of this research and depicts literature-based evidence that SoP and SC are strongly related to CE. Overall, the PA dimension of SoP is the dimension most related with $\mathrm{CE}$, while when is about main concepts $\mathrm{SC}$ is the most related to $\mathrm{CE}$. Therefore, based on the literature reviewed, in the non-spatial perspective both concepts (SoP and SC) and their dimensions show a plausible connection with CE.

CE can encompass place-based activities (Adler \& Goggin, 2005) and involve more direct forms of citizens' participation (Zlatareva, 2008). Chen (2016) distinguishes different forms of CE such as civic, electoral or political activities. In the same line, Son and Lin (2008) understand CE as a conceptual framework that contains a multitude of elements and measurements. For 
instance, membership in voluntary organizations, religious participation or membership in civic associations. Both CE and SC incorporate mutual obligation and responsibility for action (Putnam, 2000). In turn, a precondition for CE is the existence of SC (Zlatareva, 2008), since highly attached people are more willing to work collectively to reach a desired goal (G.G. Brown, Reed, \& Harris, 2002). Interestingly, Haywood (2014) positioned sense of place scholarship as a crucial resource to the better understanding of public participation in scientific research. Whereas Lewicka (2005) proves that it is neighbourhood ties (SC dimension) and not place attachment (SoP dimension) that predicts civic involvement. Later, the same author (Lewicka, 2011) underlines the inconsistent pattern of relationships between affective bonds with places and place-focused actions such as participation or planning, claiming that social aspects (e.g., SC) are more decisive. Research hypotheses are shown in Table 7.1.

Table 7.1. Research hypotheses

\begin{tabular}{|l|l|}
\hline $\mathrm{H}_{1}$ & Citizens' sense of place (SoP) has a positive effect on social capital (SC). \\
\hline $\mathrm{H}_{2}$ & Citizens' social capital (SC) has a positive effect on their civic engagement (CE). \\
\hline
\end{tabular}

\subsubsection{Relating sense of place, social capital, and civic engagement spatial dimensions}

A recurrent issue studied in the literature is the integration of GIS in the humanities scholarship (Bodenhamer, Corrigan, \& Harris, 2010). This synergy is allowing new concepts such as hybrid geographies that are forging creative connections within geographies (e.g., physical and human perspectives) (Sui \& DeLyser, 2012). Indeed, this merge highlights the epistemological and social/political meanings inherent in maps and mapping (DeLyser \& Sui, 2014) that reinforce the better understanding of how mapping emerge between geographers and social scientists (Kitchin, Gleeson, \& Dodge, 2013). Conversely, non-representational theorists (e.g., Dewsbury, 2003; Thrift, 2007) advocate to not represent as the primary step to extract knowledge (Cadman, 2009) and put the attention on what cannot be represented (Pile, 2010). In the same line, Massey (1991) highlights the problem of recurrently trying to draw boundaries to the conception of place and place-related concepts that, inherently, distinguishes between an inside (e.g., us) and an outside (e.g., them). She also supports that there is no need to conceptualize boundaries in order to define place, advocating that place is a process of social interactions. But she asserts that those boundaries may be necessary for certain studies. It is in this line that our study falls in: we attempt to spatially contextualize SoP, $\mathrm{SC}$ and $\mathrm{CE}$, to analyse the importance of their spatial relationship and their association. Thus, we don't deny the social dynamism of the 
studied concepts, but we need to spatially define individuals' spatial dimensions about significant places (i.e., SoP), meaningful social relationships (i.e., SC) and their spaces of engagement (i.e., $\mathrm{CE}$ ) in a given time to evaluate their relationship.

The studies attempting to connect CE with environmental psychology (e.g., SoP) and/or social concepts (e.g., SC) have underestimated the geographical perspective that these concepts own, i.e., the imprint that they (SoP and SC) acquire in the city context. Most of the studies that measure SoP (or related places concepts, e.g., place attachment (PA)) and SC are using preestablished administrative boundaries (i.e., neighbourhood, parish, city, region, country) or individual-vague boundaries (i.e., home) as continuous and homogeneous containers (Hidalgo \& Hernández, 2001; Mesch \& Manor, 1998; Westlund \& Adam, 2010). However, the citizens' perception of pre-established administrative boundaries can differ from the "real" one (Coulton, Korbin, Chan, \& Su, 2001; Montello, Goodchild, Gottsegen, \& Fohl, 2003) and, consequently, whole administrative boundaries might not cover the SoP, SC and CE of all its dwellers. Hence, although studies systematically demonstrate that the sense of community (SC's dimension (Perkins \& Long, 2002)) is significant, positive and moderately strong related to forms of participation (Talò \& Mannarini, 2015, p. 1) and some forms of SC are predictors of SoP (Mesch \& Manor, 1998; Raymond et al., 2010); the positive spatial dimension and relationship of the three concepts (SOP, SC, and CE) has been briefly studied in the literature. In part, it is because the gap of applications and methodologies to spatialize social concepts (Stedman, 2003). When we refer to spatialize a concept, we are meaning to transfer the non-spatial knowledge on SoP and $\mathrm{SC}$ to the geographical domain through GIS techniques.

The studied concepts (SoP, SC and CE) can be related to a human subjective meaning to a geographic area. Among the three concepts discussed in this study, SoP is the one in which the spatial dimension has been more thoroughly studied since its affective bonds are toward an area (Altman \& Low, 1992). The spatial dimension of social capital has also been analysed (Foster, Pitner, Freedman, Bell, \& Shaw, 2015; Rutten, Westlund, \& Boekema, 2010; Westlund, Rutten, \& Boekema, 2010), advocating for the potential of understanding and conceptualizing SC geographically (Holt, 2008; Putnam, 2000). However, some authors consider that geographical SC is 'almost dead' (see Radcliffe 2004). Finally, CE and participation are inherently spatial (Pain \& Kindon, 2007) and, consequently, influenced by social relations, time and space. The spatial dimension of CE (e.g., planning decisions or decision-making processes about communal spaces) has been established in administrative boundaries because of the availability of census and socioeconomic data in those areas (Dietz, 2002). However, this approach has probably hidden 
the spatial nature of CE associated with space, place and locality - essential characteristics to determine who is interested in the participatory processes and why (Carver, 2001). SoP and SC are strongly related in the non-spatial approach, as well as in the spatial one (Acedo, Painho, et al., 2017; Jorgensen, 2010; Jorgensen \& Stedman, 2011), and the combination of both in a geographical area may well be the most meaningful places for a citizen (Lewicka, 2011). On the other hand, CE occurs within a particular spatial environment where an individual has informal cooperation ties and strong horizontal linkages, that is, SC (Zlatareva, 2008). Therefore, the inclusion of the spatial dimension and relationship in our study can offer a better performance in the association between SoP-SC and SC-CE. Hence, we state the two spatial hypotheses in Table 7.2.

Table 7.2. Spatial hypotheses

\begin{tabular}{|l|l|}
\hline Hs1 & $\begin{array}{l}\text { A non-disjoint spatial relationship between SoP and SC spatial dimensions increases } \\
\text { the influence of SoP on SC. }\end{array}$ \\
\hline Hs2 & $\begin{array}{l}\text { A non-disjoint spatial relationship between SC and CE spatial dimensions increases } \\
\text { the influence of SC on CE. }\end{array}$ \\
\hline
\end{tabular}

\subsection{Methodology}

This methodology studies the effect of our individuals' spatialities (i.e., SoP and SC) on our CE behaviour when it occurs a spatial relationship between them. Thus, we stablish a twofold methodology; firstly, to gather the spatial dimension of the three aforementioned concepts and, secondly, to evaluate their association through a geographical perspective using SEM.

\subsubsection{Experimental design}

In spite of all the critical implications that are related to mapping through GIS methodologies (see Elwood (2006)) and the inherent digital divide that this kind of methodologies represent (Cruz-Jesus et al., 2012), we use a web map-based survey to gather all the (spatial) data of complex notions (SoP, SC and CE). Thus, studied concepts derived from environmental, social and participatory fields are artificially forced into geographic primitives (e.g., discrete points and/or polygons). Regarding this issue, Brown and Pullar (2012) compared studies with the two types of features, and recommended the use of points instead of polygons in participatory GIS applications. Conversely, our approach uses polygons due to (1) the ease of implementation of "standard" drawing tools to define polygons and users' familiarity with that type of approach 
respect fuzzy designs (Huck, Whyatt, \& Coulton, 2014); (2) the better encompass of high range of spatial scales, (from an armchair to the whole earth (Tuan, 1978, p. 149)) and; (3) the better performance of polygon features when there is a limited spatial dataset (Brown \& Pullar, 2012). Moreover, in the most recent and similar research to ours, Brown et al. (2015) use a PPGIS application to measure and mapping place attachment. They also define place attachment with polygon features from the minimum convex polygon of (at least) three points. However, the representation of vague concepts (i.e., SoP, SC and $\mathrm{CE}$ ) through geographic primitives in this research answer the need to classify the spatial relationship between them as positive or negative (i.e., there is an overlapping or not, respectively).

The data were collected by applying a web map-based survey (Acedo, Mendoza, Painho, \& Casteleyn, 2017)1. All the data gathered are referenced to a singular geographical geometry along the Lisbon city. The main goal of this web map-based survey is to catch the spatial dimension of SoP, SC and CE and measure their dimensions for a citizen in the city context. When we refer to the spatial dimension is the geographical definition on a map of the area that covers the feelings, thoughts and acts towards a place (i.e., SoP) a social group (i.e., SC) or engagement (i.e., $\mathrm{CE}$ ). We introduced the three concepts (SOP, SC and CE) and requested to the participants to think about their own places, social groups and spaces that comprise these three concepts, respectively. Each step of the survey has the same structure; some instructions to spatially define the constructor (SoP, SC or CE) on a base map centred in Lisbon city, and the questions, applied to the research model, pointing to that geometry. Participants first had to think of an 'area' and named since places need to be named (Gieryn, 2000). Then, they needed to draw this area on a map and rate it according different criteria and finally to choose the most important one and answer the respective questions (see Appendix 7.2). Each of the questions comprised in the tool were adapted from the literature. We tried to precisely guide the respondents throughout the application to improve the accuracy of the mapping activity (Brown \& Pullar, 2012). At the end of the entire process, we gathered a spatial data (i.e., polygon) with qualitative information that attempts to 'translate' participants' rich socio-spatial understandings of SoP/SC and socio-spatial practices of CE. Some of them (i.e., the chosen by the participant as the most important) had qualitative information analysed in an ordinal scale about the dimensions of SoP and SC, respectively. That ordinal information applies to measure the first-order dimensions of the model (see Figure 7.3). We represented each variable through three questions; thus, SoP

\footnotetext{
${ }^{1}$ https://placeandcity.com [accessed on 25th of August 2018]
} 
with three dimensions (i.e., PA, PI and PD) needed nine inquiries, and SC (i.e., SoC, CEE, N and $\mathrm{CP}$ ) required twelve. All these questions are crucial to build the first-order dimensions that nourish second-order reflective-formative constructs and, thus, the model. Figure 7.2 shows all the sequence of steps that encompass the survey. Participants were also requested to contribute their sociodemographic information (age, gender, profession, income and nationality). The survey was sent by the municipality of Lisbon to a database that contains a group of people engaged in the participatory processes in Lisbon; 373 people replied to the questionnaire in approximately two weeks period (i.e., 12 June to 2 July 2017 for this study).

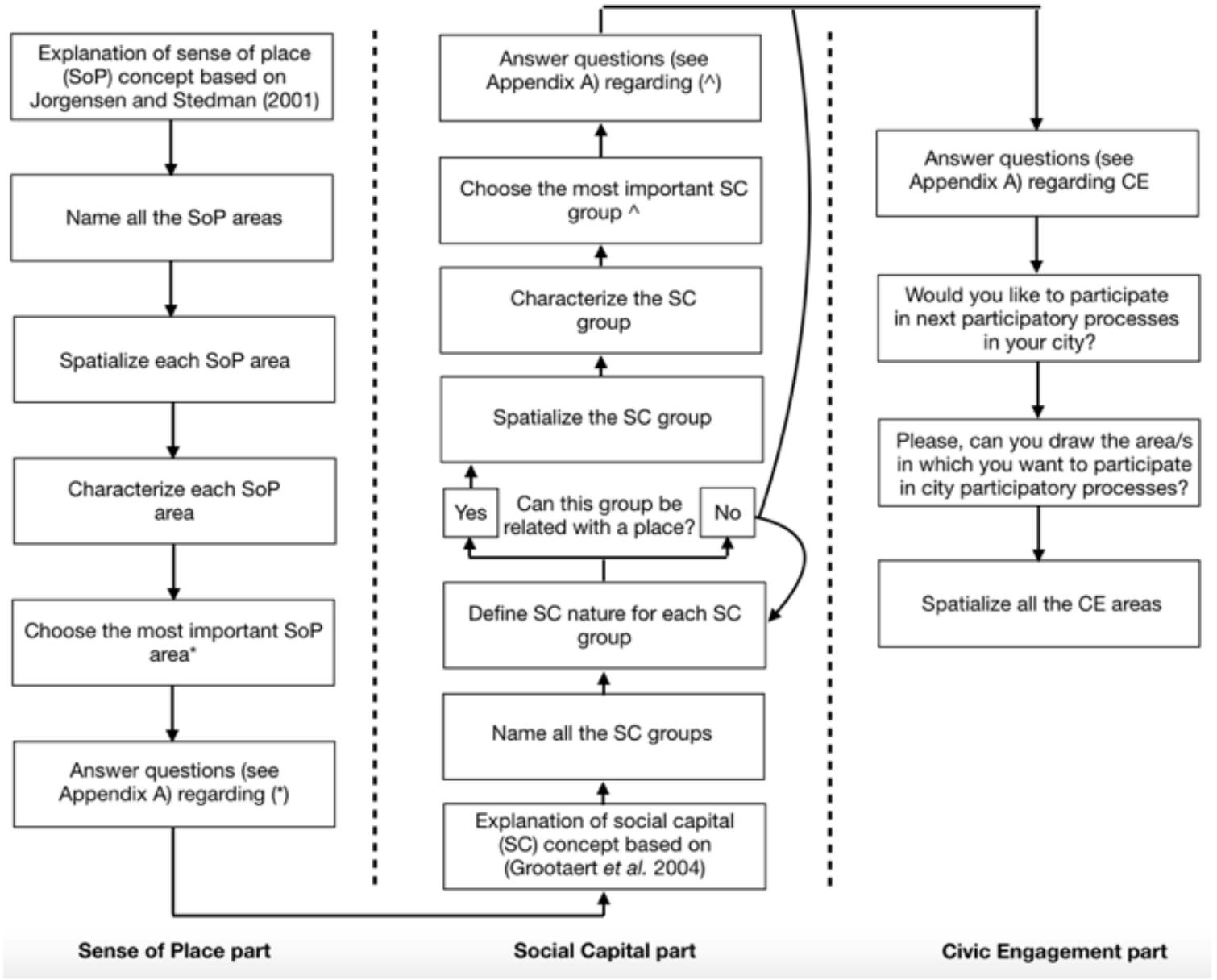

Figure 7.2. Schema of the application flow

\subsubsection{Research model}

This study integrates the SoP (Jorgensen \& Stedman, 2001) and SC (Perkins et al., 2002; Perkins \& Long, 2002) conceptualizations as predictors of CE (Son \& Lin, 2008). SoP is integrated in the 
research model as a second-order reflective-formative construct determined by its three firstorder dimensions: place attachment (PA), place identity (PI), and place dependence (PD). SC is another second-order reflective-formative construct determined by four first-order variables: sense of community $(\mathrm{SoC})$, collective efficacy (CEE), neighbouring $(\mathrm{N})$, and citizen participation (CP). CE is the dependent constructor of our model. Age and gender are included in the model as control variables on SC and CE. Figure 7.3 shows the research model.

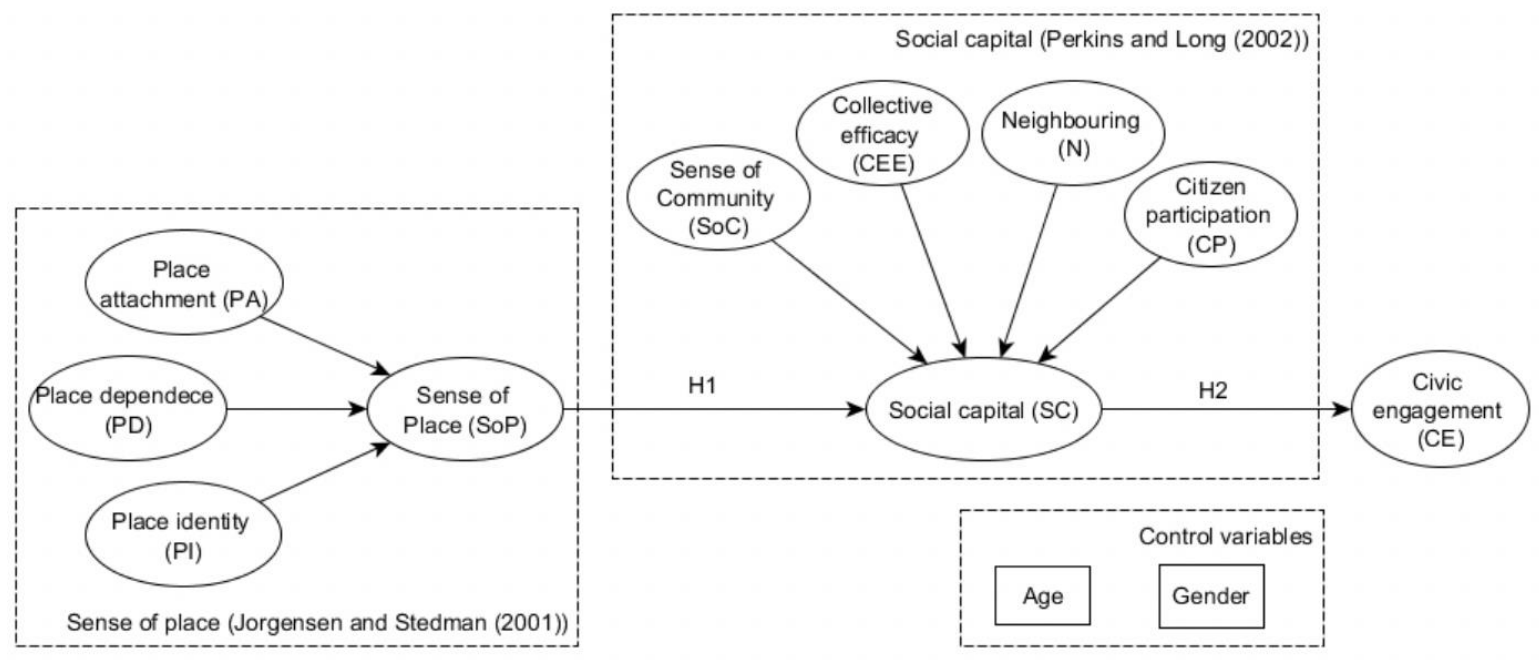

Figure 7.3. Research model

We use partial least squares structural equation modelling (PLS-SEM) (Hair et al., 2014) to evaluate the model since it is suitable for predictive analysis to test the hypotheses using empirical data (Hair et al., 2011). The measurement and structural model are estimated with SmartPLS 3.0 software (Ringle et al., 2015).

\subsubsection{Introducing the spatial perspective in the research model}

As mentioned above, SoP, SC, and CE exhibit spatial dimensions that can influence their mutual connections. Therefore, does the SoP, SC, and CE spatial relationship affect their association? Is there a spatial behaviour between those concepts that can better explain their non-spatial association? To answer these questions, this study analyses the proposed research model (Figure 7.3) for different subsets of respondents based on the diverse spatial relationship configurations that follow its constructors (SoP, SC and CE) for each citizen. This subsection wants to emphasize and operationalize the spatial dimension of the studied concepts (i.e., SoP, $\mathrm{SC}$ and $\mathrm{CE}$ ) to be able to validate in the research model (Figure 7.3). The spatial characterization of the participants' subsets is based on the research of Egenhofer, Clementini, \& Di Felice (1994), 
which defined eight topological relationship types between two regions (polygons in this study) with connected boundaries (i.e., disjoint, meet, contains, covers, equal, overlap, inside and covered by). Seven of these spatial relationships follow a non-disjoint spatial behaviour (coded as 1 for this study), that is assumed as the basis for classifying positive topological spatial relationships for SoP-SC, SC-CE and their own non-disjoint relationship. Figure 7.4 summarizes both the different spatial relationships between the different constructors (SoP, SC and CE) and the resulting spatial subsets according to our model for each citizen $\left(c_{i}\right)$ in the city context $(X)$. Subset A represents the positive spatial relationship between GSoP and GSC, and B between GSC and GCE. The overlapping between the three constructors is defined by the subset C. Finally, the last subset (D) is composed by those citizens without any positive spatial relationship between GSoP-GSC and GSC-GCE. In order to make the article easier to read, we will treat $G S o P_{i}$ as GSoP, $G S C_{i}$ as GSC and $G C E_{i}$ as GCE.

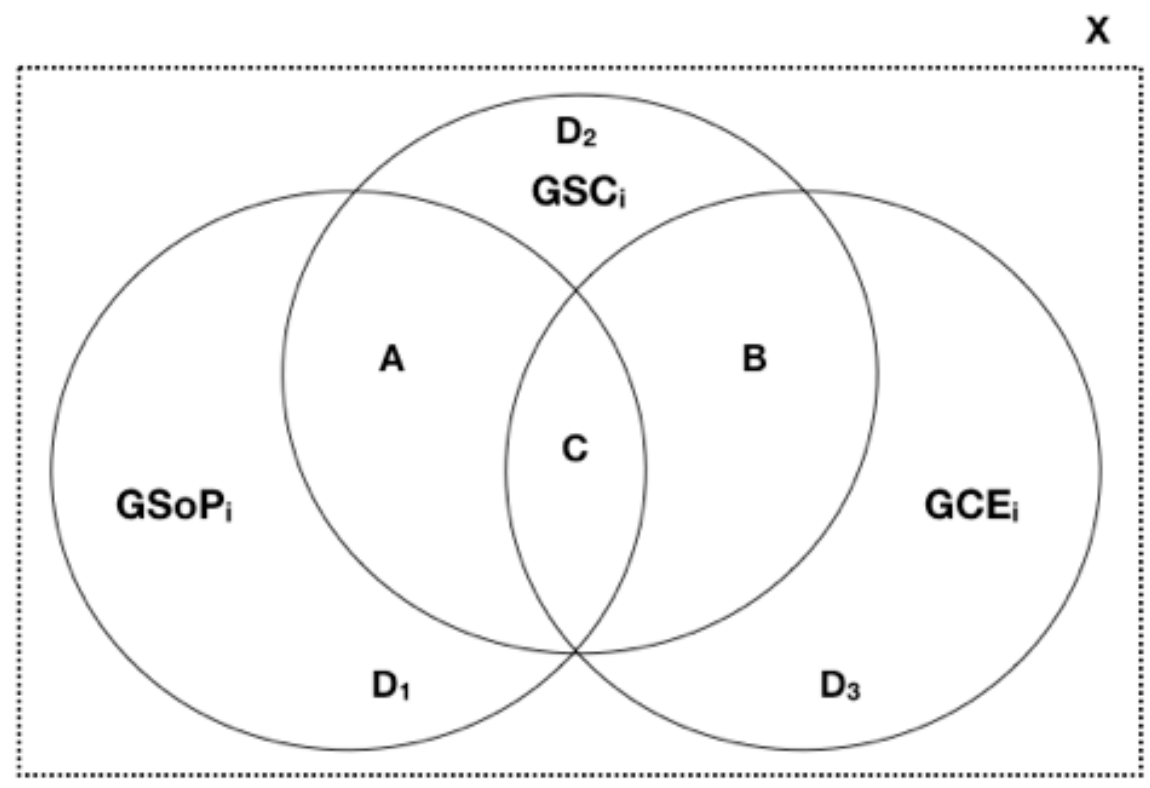

Figure 7.4. Spatial relationships between the three constructors: sense of place, social capital, and civic engagement.

- A: $G S o P_{i} \cap G S C_{i} \neq \varnothing$

- B: $G S C_{i} \cap G C E_{i} \neq \varnothing$

- $\mathrm{C}: G S o P_{i} \cap G S C_{i} \neq \varnothing \wedge G S C_{i} \cap G C E_{i} \neq \varnothing$

- D: $G S o P_{i} \cap G S C_{i}=\emptyset \wedge G S C_{i} \cap G C E_{i}=\varnothing$ 
where:

$$
G S o P_{i}=\bigcup_{j=1}^{N} G S O P_{i j} \quad G S C_{i}=\bigcup_{k=1}^{M} G S C_{i k} \quad G C E_{i}=\bigcup_{l=1}^{o} G C E_{i l}
$$

- $\mathrm{c}_{\mathrm{i}}$ is a citizen

- $\mathrm{i}$ is an integer number between 1 and $\mathrm{n}$, and $\mathrm{n}$ is the total number of citizens of a given city

- $\mathrm{N}, \mathrm{M}$ and $\mathrm{O}$ are positive integers, representing the total number of SoP, SC and CE areas, respectively, for a citizen $c_{i}$

- $\mathrm{GSoP}_{\mathrm{i}}$ is the union of all individual Geographical Sense of Place(s) $\left(\mathrm{GSoP}_{\mathrm{ij}}\right)$ for a citizen $\mathrm{c}_{\mathrm{i}}$

- $\mathrm{GSC}_{\mathrm{i}}$ is the union of all individual Geographical Social Capital(s) $\left(\mathrm{GSC}_{\mathrm{ik}}\right)$ for a citizen $\mathrm{c}_{\mathrm{i}}$

- $\mathrm{GCE}_{\mathrm{i}}$ is the union of all individual Geographical Civic Engagement(s) $\left(\mathrm{GCE}_{\mathrm{il}}\right)$ for a citizen $\mathrm{c}_{\mathrm{i}}$

- $X$ is the surface of a given city

We run the PLS-SEM using the four different datasets (i.e., A, B, C and D) based on the disjoint and non-disjoint spatial relation of the citizens' geometries regarding SoP-SC and SC-CE (see Figure 7.4).

\subsection{Results}

\subsubsection{Data collection and measurement model}

All 373 participants drew at least a GSoP, but only 119 participants defined (at least) one area of each SoP, SC and CE. Therefore, a total of 119 citizens offered valid responses to conduct this study. Table 7.3 shows their demographics. 
Table 7.3. Demographics of the sample for this study

\begin{tabular}{lcc}
\hline Demographic characteristics (N = 119) & Respondents & $\%$ \\
\hline Age (years) & 32 & \\
$\quad$ Less than 35 & 51 & 38.08 \\
Between 35 and 50 & 36 & 42.84 \\
$\quad$ More than 50 & & \\
Gender & 63 & 74.97 \\
$\quad$ Female & 56 & 66.64 \\
Male & & \\
Household monthly income (euros) & 23 & 27.37 \\
Less than 1000 & 17 & 20.23 \\
1000 - 1499 & 10 & 11.9 \\
1500 - 1999 & 30 & 35.7 \\
2000 - 2999 & 10 & 11.9 \\
3000 - 4999 & 12 & 14.28 \\
More than 5000 & 17 & 20.23 \\
N/A & & \\
Profession & 72 & 85.68 \\
Employed worker & 17 & 20.23 \\
Freelance & 11 & 13.09 \\
Retired & 11 & 13.09 \\
Student & 4 & 4.76 \\
Other & 4 & 4.76 \\
Unemployed & & \\
\hline
\end{tabular}

The measurement model is evaluated using the full sample size $(N=119)$. SoP and SC are second-order reflective-formative constructs. CE is a first-order construct and the dependent variable in the model. We assess the measurement model following the approach of Hair et al. (2014) to evaluate that our measurement model is reliable. Appendix 7.2 shows that all the loadings are above 0.7 . Table 7.4 presents the quality assessment of the measurement model. For formative constructs, SoP and SC, we assess multicollinearity (Table 7.5). Both tables show the goodness of fit of our model. 
Table 7.4. Quality assessment (square root of AVE in bold)

\begin{tabular}{lccccccccccc}
\hline Constructs & CA & CR & AVE & 1 & 2 & 3 & 4 & 5 & 6 & $\mathbf{7}$ & 8 \\
\hline 1. Place attachment & 0.88 & 0.93 & 0.81 & $\mathbf{0 . 9 0}$ & & & & & & & \\
2. Place dependence & 0.86 & 0.91 & 0.78 & 0.73 & $\mathbf{0 . 8 8}$ & & & & & & \\
3. Place identity & 0.86 & 0.91 & 0.78 & 0.78 & 0.66 & $\mathbf{0 . 8 8}$ & & & & & \\
4. Sense of community & 0.94 & 0.96 & 0.90 & 0.34 & 0.32 & 0.32 & $\mathbf{0 . 9 5}$ & & & & \\
5. Collective efficacy & 0.84 & 0.90 & 0.76 & 0.26 & 0.17 & 0.18 & 0.26 & $\mathbf{0 . 8 7}$ & & & \\
6. Neighbouring & 0.89 & 0.93 & 0.82 & 0.27 & 0.20 & 0.20 & 0.48 & 0.36 & $\mathbf{0 . 9 0}$ & & \\
7. Citizen participation & 0.88 & 0.92 & 0.80 & 0.12 & 0.04 & 0.13 & 0.35 & 0.27 & 0.46 & $\mathbf{0 . 9 0}$ & \\
8. Civic engagement & 0.92 & 0.95 & 0.86 & -0.08 & -0.19 & -0.11 & 0.01 & 0.39 & 0.11 & 0.21 & $\mathbf{0 . 9 3}$ \\
\hline
\end{tabular}

Note: $\mathrm{CA}=$ Cronbach's Alpha, $\mathrm{CR}=$ Composite Reliability, AVE = Average Variance Extracted

Table 7.5. Higher-order formative constructs. Inner VIF values ( $N=119)$

\begin{tabular}{llcc}
\hline Second-order formative constructs & $\begin{array}{l}\text { First-order reflective } \\
\text { constructs }\end{array}$ & VIF & Weights \\
\hline & Sense of community & 1.460 & $0.367 * * *$ \\
Social capital (SC) & Collective efficacy & 1.200 & $0.292 * * *$ \\
& Neighbouring & 1.589 & $0.377^{* * *}$ \\
& Citizen participation & 1.332 & $0.336^{* * *}$ \\
& Place attachment & 3.177 & $0.398^{* * *}$ \\
Sense of place (SOP) & Place dependence & 2.210 & $0.348 * * *$ \\
& Place identity & 2.646 & $0.361^{* * *}$ \\
\hline
\end{tabular}

\subsubsection{Structural Model}

The structural model is evaluated for the coefficient of determination (R2) and the path coefficients ( $\beta$ ). R2 is a measure of the model's predictive power. Both SC and CE obtained R2 values below the threshold of 0.25 (Figure 7.5), which is described as weak predictive power (Hair et al., 2014; Henseler et al., 2009). The model path coefficients ( $\beta$ ), its sign, and the statistical significance was assessed using the bootstrapping technique (Hair et al., 2014) with 5000 iterations. Age and gender were found not statistically significant on SC and CE. 


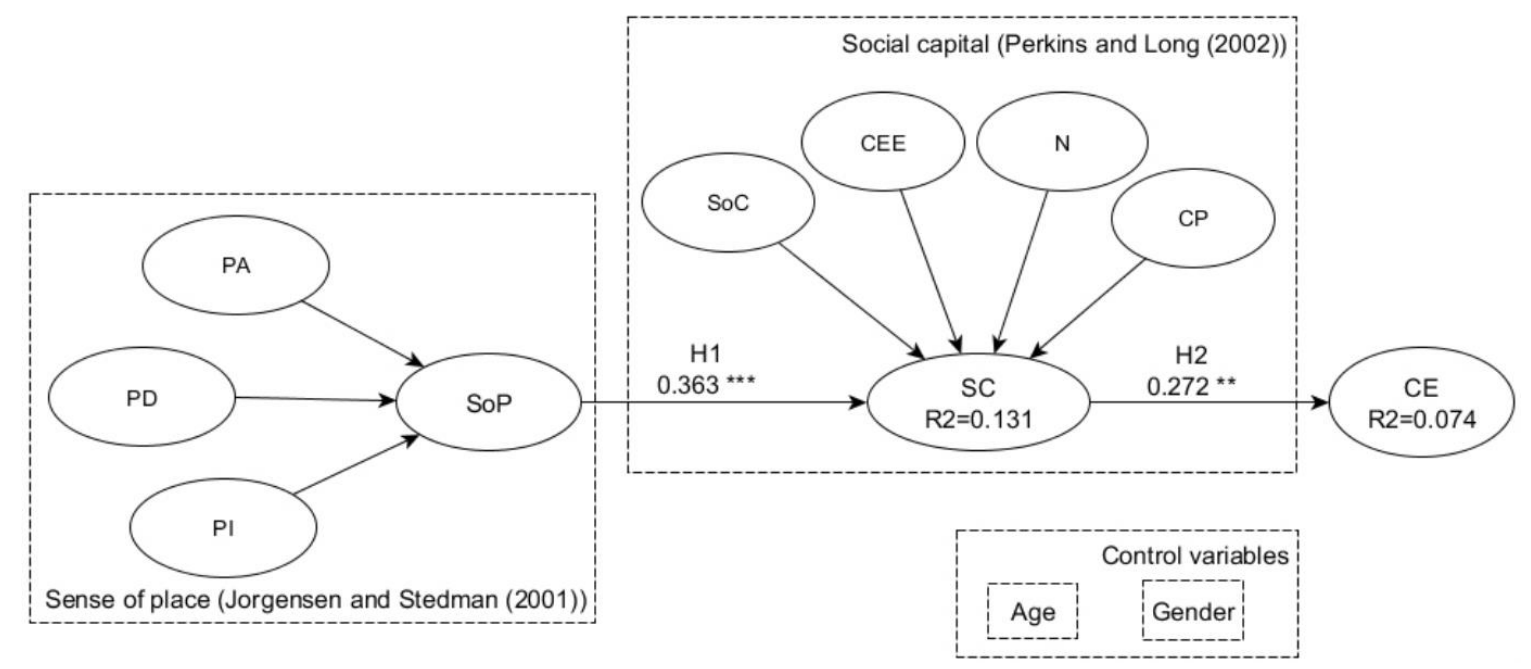

Figure 7.5. Structural model results

Results of the structural model evaluation with the full sample size $(N=119)$ provide evidence to support the model design (see Figure 7.5). The results reveal that all the three variables (i.e., place attachment $(P A)$, dependence $(P D)$ and identity $(P I))$ significantly explain SoP. Hence, this study validates the conceptualization of SoP by Jorgensen \& Stedman (2001) as it was performed by Pretty et al. (2003). The computed model also provides evidence that the four first-order variables (i.e., sense of community (SoC), collective efficacy (CEE) neighbouring (N) and citizen participation (CP)) significantly explain SC, supporting Perkins and his colleagues' conceptualization of SC (Perkins et al., 2002; Perkins \& Long, 2002). Finally, the results from the structural model (Figure 7.5) disclose that SoP has a positive effect on SC (H1) and, in turn, SC has a positive effect on CE (H2). The next subsection will analyse the acceptance of hypotheses $\mathrm{Hs} 1$ and $\mathrm{Hs} 2$ based on $\mathrm{H} 1$ and $\mathrm{H} 2$, respectively, for the subsets derived from the spatial relationship between SoP, SC, and CE.

\subsubsection{A geographical evaluation of the structural model}

As mentioned in previous discussions, one of the main goals of this study is the inclusion and analysis of the spatial relationship between GSoP, GSC and GCE in our model to prove the importance of the spatial dimension of studied concepts in the urban processes and dynamics. Based on the data and methodology followed we obtained the following spatial subsets: 
- $\mathrm{A}: \mathrm{GSoP}_{i} \cap \mathrm{GSC}_{i} \neq \varnothing(\mathrm{N}=57)$

- B: $G S C_{i} \cap G C E_{i} \neq \varnothing(\mathrm{N}=76)$

- $\mathrm{C}: G S o P_{i} \cap G S C_{i} \neq \varnothing \wedge G S C_{i} \cap G C E_{i} \neq \varnothing(\mathrm{N}=44)$

- the disjoint one D: $G S o P_{i} \cap G S C_{i}=\varnothing \wedge G S C_{i} \cap G C E_{i}=\varnothing(\mathrm{N}=34)$.

Figure 7.6 illustrates the schema of the resulting datasets derived from our model (Figure 7.3) and the different structural model results for the non-disjoint and disjoint subsets (A, B, C and D). Table 7.6 and Table 7.7 provide $\beta$ and $R 2$ results, respectively, for the four spatial datasets.
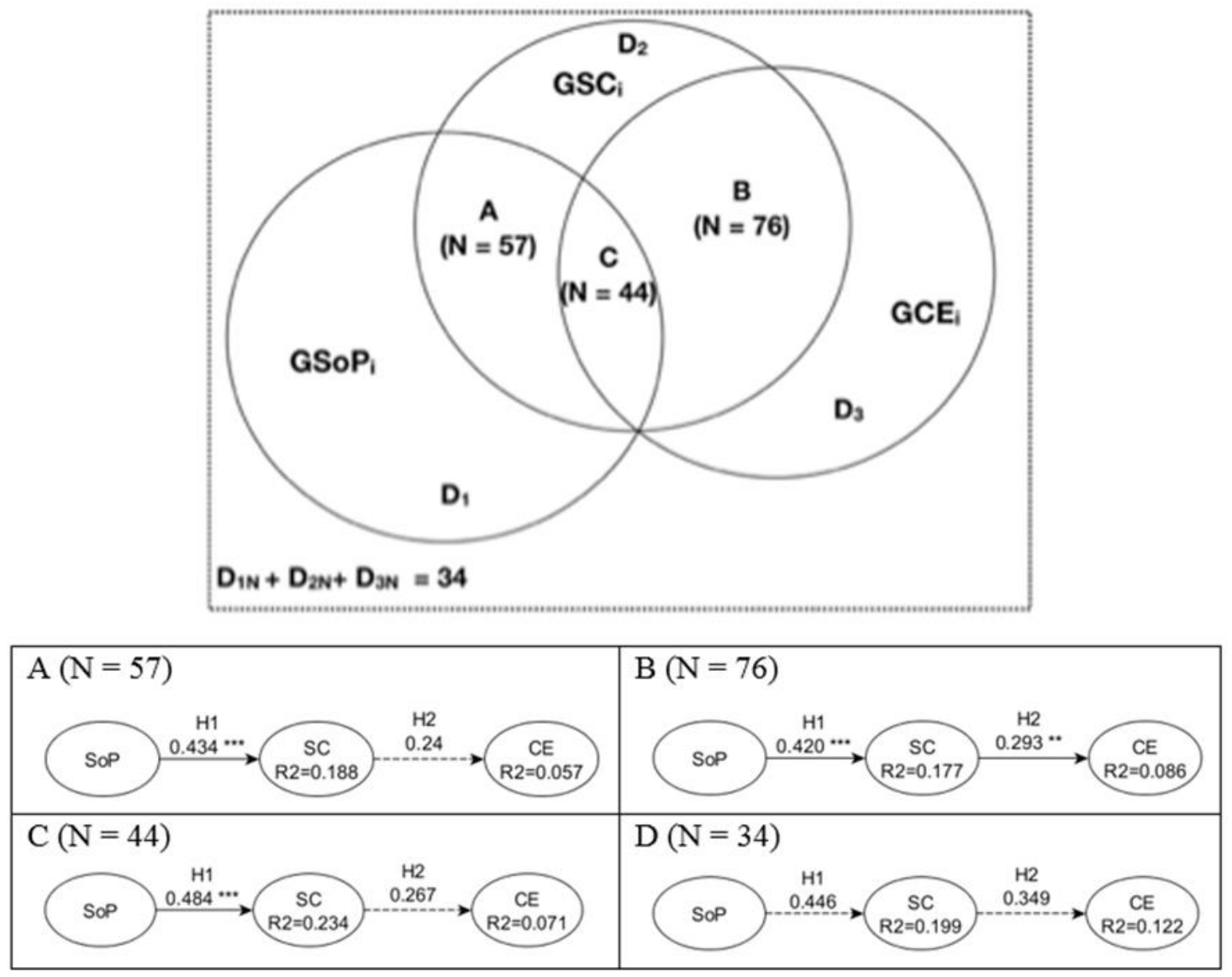

Figure 7.6. Spatial relationships results. Discontinuous lines mean statistically not significant. Notes: Significant at $* 10 \% ; * * 5 \% ; * * * 1 \%$ 
Table 7.6. Structural model evaluation ( $\beta$ values) for the sample and related subsets

\begin{tabular}{llcccc}
\hline & & \multicolumn{3}{c}{ Spatial related subsets (\# observations) } \\
\cline { 3 - 6 } Path & All obs. (119) & $\mathrm{A}-(57)$ & $\mathrm{B}-(76)$ & $\mathrm{C}-(44)$ & $\mathrm{D}-(34)$ \\
\hline $\mathrm{SoP} \rightarrow \mathrm{SC}(\mathrm{H} 1)$ & $0.363^{* * *}$ & $0.434^{* * *}$ & $0.42 * * *$ & $0.484^{* * *}$ & 0.446 \\
$\mathrm{SC} \rightarrow \mathrm{CE}(\mathrm{H} 2)$ & $0.272 * *$ & 0.24 & $0.293 * *$ & 0.267 & 0.349 \\
$\begin{array}{l}\text { Indirect effect } \\
(\mathrm{SOP} \rightarrow \mathrm{CE})\end{array}$ & $0.099^{*}$ & 0.104 & $0.123 * *$ & 0.129 & 0.156 \\
\hline Notes: Significant at $* 10 \% ; * * 5 \% ; * * 1 \%$ & & &
\end{tabular}

Table 7.7. R2 values for the sample and related subsets

\begin{tabular}{lll}
\hline Dataset & $\mathrm{R}^{2}(\mathrm{SC})$ & $\mathrm{R}^{2}(\mathrm{CE})$ \\
\hline All obs. (119) & 0.131 & 0.074 \\
A (57) & 0.188 & 0.057 \\
B (76) & 0.177 & 0.086 \\
C (44) & 0.234 & 0.071 \\
D (34) & 0.199 & 0.122 \\
\hline
\end{tabular}

Hypothesis $\mathrm{H} 1$ is fully supported for all the three datasets where a non-disjoint relationship exists (i.e., A, B and C) but is not statistically significant for the disjoint subset (i.e., D) (see Table 7.6). $\mathrm{H} 2$ is just supported for one of the three datasets with non-disjoint spatial behaviour (i.e., B). For the $\mathrm{A}$ and $\mathrm{C}$ datasets, $\mathrm{H} 2$ is not statistically significant, therefore not supported. In the cases where $\mathrm{H} 1$ and $\mathrm{H} 2$ are statistically significant, the influence of SoP on SC and SC on CE is stronger than the dataset with all the observations (see Table 7.6). The indirect effect of SoP on CE is also statistically significant for one of the three geographical related datasets (i.e., B). Subset D represents the citizens who defined their geometries regarding SoPSC and SC-CE as being disjoint. For this group (i.e., D), none of the path coefficients were statistically significant. Table 7.8 shows a summary about the supported and rejected hypotheses of the study.

Table 7.8. Summary about supported $(\mathrm{y})$ and rejected $(\mathrm{n})$ hypothesis

\begin{tabular}{lcllll}
\hline \multicolumn{5}{c|}{} & \multicolumn{4}{|l|}{ Non-disjoint subsets } & Disjoint subset \\
\hline Hypothesis & observations & A & B & C & D \\
\hline H1 & y & y & y & y & $n$ \\
H2 & y & n & y & n & $n$ \\
\hline
\end{tabular}


Therefore, the better results for the $\mathrm{H} 1$ and $\mathrm{H} 2$ path coefficients values (Table 7.6) and associated R2 (Table 7.7) in relation to the subsets A (GSOP and GSC non-disjoint relationship) and B (GSC and GCE non-disjoint relationship), respectively (see bold results in Table 7.7), allow us to support Hs1 and Hs2. This finding provides evidence that the geographical component plays a critical role for the statistical significance of the path coefficients in the prediction of $C E$, i.e., the influence on SoP to SC and SC on CE are statistically better explained when there is a non-disjoint spatial relationship between them.

\subsection{Discussion}

This research attempts to validate the importance of SoP and SC spatial relationships to explain $\mathrm{CE}$ at the individual level. These spatial interactions define new approaches to better understanding the city's social realm from the geographic study of social concepts. We highlight the suitability of these social concepts to encapsulate human notions that can be rendered on the map and elucidate connections with already understanding of cities as place networks (Acedo et al., 2018; Doreen Massey, 1994; Roche, 2016). Bridging (spatial) scholarship within social theory, environmental psychology through a participatory methodology using GIS techniques in a continually shifting city network environment (Duff, 2011; Latour, 2005; Murdoch, 1998), expands the participatory research agenda and embraces two general areas (i.e., GIS and humanities) that, unfortunately, has been rarely analysed together in deep (Bodenhamer et al., 2010). Surely, this carelessness has been mainly due to the dynamism and vague nature of those rich socio-spatial concepts (i.e., SoP, SC and CE) and the considerable difficulty of GIS techniques to embed their fuzzy perseverance (Coulton et al., 2001; Huck et al., 2014).

The results of our model shows low R2 values for both SC and CE in all models (Table 7.7) are in line with other studies that have reported similar R2 values; for instance, in the study of civic activity (Lewicka, 2005) and pro-environmental CE (Buta et al., 2014), the R2 values found were smaller than 0.16 and less than 0.33 , respectively. Thus, this study introduces the spatial component as part of the analysis to try to overcome this issue and to obtain better explanatory models. Our findings show that when there is a non-disjoint spatial relationship between the studied concepts (SOP, SC, and $\mathrm{CE}$ ), the corresponding model performs a better statistical description of their associations. 
SoP and SC display the most consistent relationship of the model. This relationship is statistically significant for all the subsets except for subset $\mathrm{D}$. Furthermore, SC is better explained by SoP when there is a non-disjoint relationship between both concepts' spatial dimensions (i.e., GSoP and GSC). The results of this study are in line with the conceptualizations of Acedo, et al. (2017), advocating for the strong spatial relationship of these two concepts, and Jorgensen (2010), who assures the mutual spatial behaviour between the two concepts. Independently of their spatial nature, it is clear from the findings of our study that the non-disjoint relationship between SoP and SC strengthens the explanation of SC by SoP. Surprisingly, the other positive geographical related spatial subsets (i.e., B and C) also show significant and better values than the entire dataset, showing that $\mathrm{H} 1$ performs better when a positive (non-disjoint) spatial interaction occurs in the model. Only for the subset $D$ (disjoint subset) is the relationship from SoP to SC not statistically significant. The method to statistically evaluate the different subsets is (i.e., PLS-SEM), it is worthy to say that, to the best of our knowledge, this is the first study to add the spatial relationship between constructs into a model. Jorgensen \& Stedman (2011) integrate the spatial and physical features of places with attitude and behavioural variables in this type of models, but the specific study of the spatial dimension of model' constructs has been never investigated to date.

Overall, the relationship between SC and CE is not as strong as that between SoP and SC. Interestingly, the only geographical subset that has statistical significance is B (i.e., when there is a positive spatial relationship between SC and CE for a citizen). Thus, to explain how SC influences $\mathrm{CE}$, it is interesting to highlight that its association is stronger when there is a nondisjoint relationship between their geographical areas. This finding is in consonance, in part, with studies assuring that participation is likely to occur in small-group situations (Rydin \& Pennington, 2011), where the citizen has a higher identification and satisfaction with the group (Bernardo \& Palma-Oliveira, 2016). In this line, this research contributes by highlighting the importance of these group's relationships (SC) being located in the same place where for instance, the participatory or planning process is taking place to have better CE's performance. The other two subsets (i.e., $A$ and $C$ ) and the subset $D$ do not show statistical significance in the relationship between $\mathrm{SC}$ and $\mathrm{CE}$.

The sample size to perform this study $(\mathrm{N}=119)$ and the derived smaller subsets based on the constructs' geographical behaviour could represent a limitation to conduct the study. Ideally, larger sample sizes lead to more accurate results. Other approaches to gather SoP (Jenkins, Croitoru, Crooks, \& Stefanidis, 2016) and SC (Antoci, Sabatini, \& Sodini, 2015) data 
through social network analysis are appearing in the last years. Unlike our approach, perhaps, these techniques can provide a quick approach to the concept as well as to gather a massive related dataset. However, it remains unclear how these techniques can infer the specific spatial area (polygon) for citizens' SoP or to measure the dimensions of SC from social network analysis to relate both pieces of information for a single citizen. Conversely, our approach goes straight to the point with the spatial representation and measurement of SoP, SC and CE at the individual level. Some non-representational theorists have defended the necessity of not emphasizing representation as the primary step to extract knowledge (Dewsbury, 2003; Thrift, 2008), especially in social theory attending to the constantly relational nature of actors' interaction. We do not deny this nature, but our study needs of a "spatial photo" of the individuals' spatialities in a given time (e.g., 12 June to 2 July 2017 for this study) in order to evaluate their spatial relationship in city socio-spatial processes such as participatory processes in a given time. In turn, the authors of this study acknowledge the dynamism, time-dependent, and scale variable of studied concepts (i.e., SoP, SC and CE) as a limitation of this kind of study and methodology, highlighting the requisite for longitudinal time-series studies and a dynamic collection of social data for a better comprehension. In the same line, the mapping activity using polygons can also exhibit either spatial and/or scalar ambiguity (Huck et al., 2014). Moreover, we already argued about the relative accuracy in defining the spatial dimension through polygons for concepts such as SoP, SC and CE. Thereby, our approach can be understood as an attempt to study the spatial dimension of those concepts and their spatial relationships. However, based on the results of this paper, the mapping activity through polygons performs better goodness of fit in the model (Figure 7.3) when there is a positive spatial relationship. Therefore, our approach to mapping the spatial dimension of those concepts (i.e., SoP, SC and CE) substantially cover their spatial association and trace a possible valid path to operationalize their spatial imprint, and possibly other social concepts, in the city context.

\subsection{Conclusions}

This paper is connecting citizens' areas of significant interaction (i.e., SC), environmental positive attitude towards places (i.e., SoP) and engagement to participate in community, society, planning and governmental issues (i.e., CE). The spatial data gathered from the web map-based application allows us to attempt the spatialization of citizens' SoP, SC and CE, psychological, social and participatory concepts that are critical in citizens' daily tasks and interactions. The findings of this study demonstrate, combining spatial and non-spatial data, the relationships 
among SoP, SC and CE, based on a GIS analysis of data collected through an electronic survey. The knowledge and management of these interactions, and where their spatial relationships occur, creates an occasion that provides fruitful social-spatial data for other areas of knowledge such as planning or citizen's participation. To some extent, we are setting up the foundations of new geographies of engagement for all the stakeholders of a city. Furthermore, the rainbow of applications that may profit from such understanding of space is wide, from location-based services to community detection and even citizen science processes (Haywood, 2014; Newman et al., 2016). This article highlights the role of the geographical perspective in taking another step forward to better understand citizens' social synergies in the urban context. Specifically, how GIS techniques can be used to attempt the operationalization of rich-complex human based concepts such as SoP, SC and CE. On the other hand, the use of PLS-SEM to explore the impact of spatial components in combination with non-spatial variables has been rarely used in the literature (Jorgensen \& Stedman, 2011). The method used in this research discloses the potential of introducing spatial perspectives in PLS-SEM models. Future work can be in line to add the relevant features enclosed in the spatial dimension of studied concepts into the research model to investigate how and what physical space is valued and influence the studied concepts (i.e., SoC, SC and CE).

\subsubsection{Notes to advance in the acquisition of the socio-spatial concepts}

We foresee a big potential to truly appreciate the spatial dimension of social concepts as spatial (forgive the repetition), i.e., to make a step further, recognizing and operationalizing the crucial matter of the spatial domain in social theory. This is not just to discuss or embed results in administrative boundaries, but to really assign the spatial dimension of social concepts in the studies' methodology section. Unfortunately, this research is one of the few studies of a long way to go in the meaningful operationalization of the social concepts spatial dimension in the urban context. Once this process is normalized and dynamically updated we will be able to disclose the suitability of including the geographical perspective in social, planning and participatory studies. There is a dearth of empirical research on the interactions between people and places and how their spatial understanding highlights a promising area of future scholarship. Therefore, this study calls for efforts that bridge multiple academic communities to open innovative avenues for understanding social-spatial behaviours, the outcomes of such encounters, and their addition in city' procedures such as participatory processes. 


\section{Chaper 8 - Conclusions}

\subsection{Summary of findings}

The main goal of this dissertation is to contribute to answer the research question "what are the main determinants factors of information and communication technologies (ICT) of the $e$ participation adoption?". In this regard, we conducted four quantitative studies (chapters 2 to 5 and chapter 7) and one theoretical study (chapter 6) that analyse the effect of different variables and theoretical approaches over the intention to use, intention to recommend, usage, and continued intention to use e-participation technologies. Table 8.1 summarizes the statistically significant and non-significant relationships found through the four quantitative studies.

Table 8.1. Relationships analysed in the quantitative studies

\begin{tabular}{|c|c|c|c|c|c|c|}
\hline \multicolumn{2}{|c|}{ E-participation variables } & \multirow{2}{*}{$\begin{array}{c}\begin{array}{c}\text { Literature } \\
\text { review }\end{array} \\
\text { Chapter } 2\end{array}$} & \multicolumn{4}{|c|}{ Cross-sectional } \\
\hline Independent & Dependent & & Chapter 3 & Chapter 4 & Chapter 5 & Chapter 7* \\
\hline Attitude & & 0.38 & & & & \\
\hline Effort expectancy & & 0.16 & $0.081(\mathrm{~ns})$ & & & \\
\hline $\begin{array}{l}\text { Empowerment (second } \\
\text { order) }\end{array}$ & & & 0.27 & & & \\
\hline Facilitating conditions & & & 0.22 & & & \\
\hline Perceived ease of use & Intention to & 0.16 & & & & \\
\hline Perceived usefulness & & 0.32 & & & & \\
\hline Performance expectancy & & 0.39 & 0.24 & & & \\
\hline Social influence & & 0.19 & 0.028 (ns) & & & \\
\hline Trust & & 0.33 & & & & \\
\hline Trust in government & & 0.22 & & & & \\
\hline $\begin{array}{l}\text { Empowerment (second } \\
\text { order) }\end{array}$ & Intention to & & 0.53 & & & \\
\hline Intention to use & recommend & & 0.17 & & & \\
\hline Facilitating conditions & & 0.29 & & 0.14 & & \\
\hline Habit & & & & 0.34 & & \\
\hline Intention to use & Usage & 0.25 & & & & \\
\hline $\begin{array}{l}\text { Sense of virtual community } \\
\text { (second order) }\end{array}$ & & & & 0.25 & & \\
\hline Competence & & & & & 0.23 & \\
\hline Facilitating conditions & & & & 0.36 & & \\
\hline Habit & & & & 0.31 & 0.28 & \\
\hline Impact & Continued & & & & 0.061 (ns) & \\
\hline Meaning & intention to & & & & 0.23 & \\
\hline Self-determination & use & & & & 0.055 (ns) & \\
\hline $\begin{array}{l}\text { Sense of virtual community } \\
\text { (second order) }\end{array}$ & & & & 0.014 (ns) & & \\
\hline Usage & & & & 0.23 & & \\
\hline Sense of place (SoP) & $\begin{array}{l}\text { Social capital } \\
\text { Civic }\end{array}$ & & & & & 0.36 \\
\hline Social capital (second order) & engagement & & & & & 0.27 \\
\hline
\end{tabular}


The literature review revealed that: (1) the most quantitatively evaluated constructs in the e-participation context are from TAM and UTAUT or are adapted from them. Although, not all constructs from these well-known theories resulted always significant or demonstrated to be strong predictors of e-participation (see Figure 2.3). (2) E-participation adoption research is highly heterogeneous due to the use of different research models, different variables, different populations, and different study protocols to evaluate the drivers of e-participation adoption. And, (3) the 'best' predictors identified in the existing literature include perceived usefulness, attitude, social influence, trust, effort expectancy, and trust in government on intention to use, perceived ease of use on perceived usefulness, perceived usefulness on attitude, and intention to use on use.

The cross-sectional studies evaluated three different research models. The first study evaluated psychological empowerment as second order construct. As expected, the inner motivations of the individual, represented in the psychological empowerment, were found to have a positive effect on the intention to use and intention to recommend e-participation. UTAUT showed a partial effect on the intention to use e-participation, only performance expectancy and facilitating conditions were significant and positive. The results also indicate that when psychological empowerment is integrated with UTAUT the level of variance on intention to use and intention to recommend e-participation is increased in comparison to the variance resulting from the UTAUT solely.

The second cross-sectional study, which was focused on the post-acceptance stage of the e-participation adoption, was carried out using a different sample and context than the study one. As expected for the post-acceptance stage (Kim \& Malhotra, 2005), habit was found as the strongest predictor over e-participation usage. Findings suggest that Sense of virtual community (SOVC) has a positive effect on triggering e-participation usage in the short term. However, SOVC was not significant for the continuous intention to use, which may imply that the feeling of community is either not strong enough to drive the continuous intention over time in large urban area (e.g. city), or SOVC is not a determinant factor to keep the continuous intention to use e-participation over time.

The third cross-sectional study, also focused on the post-acceptance stage, evaluated the dimensions of empowerment and habit over the continuance intention to use eparticipation. The existence of a perception of empowerment in the citizens was only partially confirmed by this study. Only two out of four dimensions of empowerment, namely competence 
and meaning, showed a significant and positive effect on continued intention to use. The significant and positive effect of meaning as a motivator of the continued intention to use online participatory budgeting implies that citizens indeed perceive that there is a value derived from the utilization of the system, a meaningful participation. The strongest predictor of the continued intention to use was habit, which was expected probably due to previous editions of online participatory budgeting.

Regarding the individual differences as age and gender, our results showed that in the e-participation context these differences are more tangible at the acceptance stage, later in the post-acceptance stage the differences tend to diminish or disappear. In the first cross-sectional study we found that younger citizens are more willing to recommend e-participation than older citizens and that women are more likely to use e-participation than men. In the second crosssectional study we found no effect of individual differences such as age and gender on the dependent variables for e-participation usage and continuous intention to use. In the third crosssectional study we performed a multi-group analysis, the individual differences of age and gender had no effect on the variables analysed in this study, except on meaning, suggesting that older males perceive a higher value than young females in the online participatory budgeting (an e-participation platform).

The forth cross-sectional study presented in Chapter seven complements the main line of research in this dissertation. Chapter seven was developed as a co-authorship of another doctoral study of the GEO-C program (see Table 1.2 in Chapter 1). The author of this dissertation contributed mainly with the methodological approach and the results section. This crosssectional study introduces the use of PLS-SEM to explore the impact of spatial components in combination with non-spatial variables, which highlights the role of the geographical perspective in taking another step forward to better understand citizens' social synergies in the urban context. The use of spatial and non-spatial data show evidence of the relationships existing among sense of place, social capital, and civic engagement.

\subsection{Contributions}

\subsubsection{Implications for theory}

The quantitative approach of the literature review presented in this dissertation contributes to research by providing a more concise, clearer, and extensive vision of the predictors of e- 
participation evaluated from years 2000 to 2017, serving as the foundation for future research and providing additional criteria for researchers to accurately select the constructs to be included in research models to analyse e-participation adoption.

The findings of the three cross-sectional studies presented in chapter three to five provide important contributions for the theoretical body of knowledge. All the cross-sectional studies combined different theories to investigate the drivers of e-participation adoption. In chapter three, previous literature suggests that when citizens are involved in consultation and decision-making processes they develop a perception of empowerment, however, scarce literature have evaluated the citizen empowerment as driver of e-participation adoption. We developed a research model that integrates UTAUT (Venkatesh et al., 2012) and empowerment theory to explain intention to use and recommend e-participation. The research model allows us to identify that the feeling of empowerment in citizens is indeed a strong motivator of intention to use and intention to recommend e-participation. Empowerment is evaluated as higher-order multidimensional constructs (Johnson et al., 2012), thus we contribute to the construct clarity of in the context of e-participation.

In chapter four, we present a research model that integrates the sense of virtual community theory (SOVC) (Koh \& Kim, 2003) which is the degree of affective attachment to a given community mediated by an information technology, as second-order construct, and UTAUT to examine the use and continuous intention to use e-participation. Moreover, we also evaluated the moderating effect of SOVC between the use and continuous use. And finally, in chapter five we contribute by evaluating a research model that integrates the four dimensions of psychological empowerment with habit as motivators for the continued intention to use eparticipation.

The use of PLS-SEM to explore the impact of spatial components in combination with non-spatial variables has been rarely used in the literature. In chapter seven we contribute to fill the existing gap using PLS-SEM to evaluate whether the spatial component has an effect on the operationalization of rich-complex human based concepts such as sense of place, social capital, and civic engagement.

\subsubsection{Implications for practice}

Local governments around the world still find challenging the implementation of e-participation tools that may achieve the involvement of citizens in consulting and decision-making process in 
the long-term scenario. Since the use of e-participation is completely voluntary and oriented to have an effect on a community and not only on the individual, the risk of low adoption and even abandonment of e-participation projects still exists. The findings of this dissertation provide interesting insights for the public sector that implements e-participation projects.

First, the literature review revealed several constructs that resulted significant and positive for the adoption of e-participation, namely perceived usefulness, attitude, social influence, trust, effort expectancy, and trust in government on intention to use; perceived ease of use on perceived usefulness; perceived usefulness on attitude; and intention to use on use. This suggests for local governments that have implemented e-participation platforms that should keep the positive attitude, perception of usefulness, and trust of citizens during the participative process.

Second, the findings from the examination of empowerment are valuable for the design of strategies for promotion and diffusion of e-participation. Those strategies should focus on preserve citizens' positive perception of the four components of psychological empowerment: competence, meaning, impact, and self-determination, focused mainly on competence and meaning. The e-participation platform should keep the citizens informed about the final outcomes derived from the contributions of the citizens through the platform (Royo \& Yetano, 2015). Local governments should not only promote the use of e-participation tools, but also the positive final benefits of that usage on the community. Furthermore, the positive effects of facilitating conditions on intention to use may indicate that local governments should keep a facilitating environment around e-participation, as for instance support chat rooms or call centres.

Third, the usage of e-participation platforms is only a small portion of the participatory process, which also involves background processes (Shareef et al., 2011). Local governments that implement e-participation projects should ensure that the participants involved in consultation and decision-making process have support throughout the entire participatory process.

Forth, the findings regarding the sense of virtual community as driver of e-participation adoption indicate that the local governments should consider the size of the community where the e-participation is promoted. When the size of the community is bigger, for instance a city, the ties between the participants tend to disappear. Consequently, the strategies to promote 
the use of e-participation when addressing a city level may be different as when addressing at a neighbourhood level (Acedo, Painho, et al., 2017).

And finally, the findings form the complementary study (co-authored), which uses geospatial data for the evaluation of the research model, showed evidence that introducing the spatial component has an impact on the predictors of civic engagement. The analysis of the spatial component in the study of civic engagement may help the local governments to implement participatory processes that combine online and offline citizen participation.

\subsection{Limitations and future research}

This dissertation examined in detail, using cross-sectional studies, the drivers of e-participation adoption that are grounded on three main theories, psychological empowerment, sense of virtual community, and UTAUT. The first logical limitation derived from this approach is the number of theories and constructs evaluated. Large models are difficult to test. Consequently, the inclusion of more and new drivers to evaluate using cross-sectional studies that collect data from users of e-participation can be a fruitful path forward. For instance, cultural moderators. Hoftede, Hofstede, \& Minkov (2010) have stated that culture is for humans what software is for computers. Culture varies from country to country. The inclusion of new or barely explored variables such as cultural dimensions in primary studies is suggested for future research on eparticipation adoption.

Regarding the limitations of the literature review study, the 60 articles analysed are a small portion of the existing literature on e-participation adoption. The language of the articles is limited to English, which excludes all the significant research conducted in other languages; and the type of selected articles was of quantitative type, excluding all the qualitative articles that are the majority retrieved from the database search. Due to the relatively limited sample size, conclusions regarding the trends and patterns should be interpreted with caution.

The cross-sectional studies were carried out in two Portuguese cities; therefore, caution should be taken when generalizing the results. In order to confirm or contract the results presented in this dissertation, the research models should be replicated to examine results and findings across different datasets of individuals in different samples, contexts, countries, and with different e-participation technologies. Moreover, cross-sectional studies capture a single point in time regarding the perception of the respondents using e-participation. These 
perceptions change over the time and a longitudinal evaluation could provide more interesting insights on how user perceptions and behaviour changes over time.

We note that e-participation has several levels of citizen involvement, from simply being informed to consultation and decision-making. Therefore, a comparative approach regarding the factors that drive the different levels of e-participation is recommended. This may provide interesting insights about whether the factors that influence e-participation have the same impact across the different levels.

The respondents who participated in the electronic survey were previously registered in the database of the municipalities that collaborated with our study. This may have created a limitation regarding the random sample selection and may have influenced the result of nonsignificance of effort expectancy on intention to use, since the users may find e-participation easy to use and expect few or no problems when using it. Future research may address this limitation by collecting data from a broader sample of citizens, thereby allowing a comparison between the more and less experienced participants with e-participation.

Regarding the analysis of sense of virtual community (SOVC), only one hypothesis was accepted, which was not in line with what is stated in previous studies. Future research is needed to evaluate different scenarios and different e-participation platforms that may confirm or contradict the findings of this study regarding the effect of SOVC over use and continuous intention to use e-participation in the post-adoption stage.

Future research may evaluate the proposed theoretical model in chapter six, which focuses on the evaluation of the citizen satisfaction considering the quality of e-participation system and the confirmation of expectations with the usage of e-participation tools. This model also takes into account the geographical ties of the individual, known as sense of place. For the evaluation, data should be collected from citizens that have experienced e-participation systems, and either are still using the system or have discontinued the usage of e-participation. Using evaluation methods like structural equation modelling (Hair et al., 2014) we can obtain results about the strength of the conceptual factors as drivers of citizen satisfaction, use, and continued intention to use e-participation.

Regarding the use of spatial data in the research of e-participation context, future work may add new relevant features enclosed in the spatial dimension of studied concepts into the research model to investigate how and what geographical space influence the studied concepts 
of sense of place, social capital, and civic engagement. And how the introduction of spatial dimensions can shed more light on the study of e-participation adoption.

Mixed-method and mixed-data approaches are scarce on e-participation research. The combination of two methodological approaches may significantly contribute to unveil new undetected factors that affect, positively or negatively, the adoption of e-participation. In our plan for future research, we want to follow the approach used by Zhang \& Venkatesh (2017) in the field of knowledge management systems, built a research model based on a qualitative approach and then conducted a quantitative study to evaluate the model. This line of future research is already ongoing and has the collaboration of Prof. Dr. Christy Cheung and Prof. Dr. Viswanath Venkatesh, two worldwide prominent researchers. 


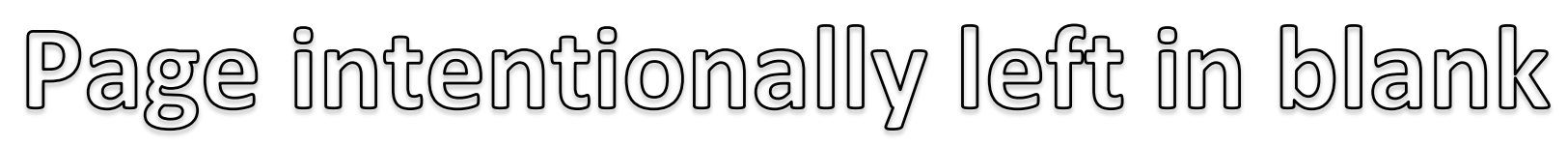




\section{References}

Abu-Shanab, E. (2014). Antecedents of trust in e-government services: an empirical test in Jordan. Transforming Government: People, Process and Policy, 8(4), 480-499. http://doi.org/10.1108/TG-08-2013-0027

Abu-Shanab, E. A. (2015). Reengineering the open government concept: An empirical support for a proposed model. Government Information Quarterly, 32(4), 453-463. http://doi.org/10.1016/j.giq.2015.07.002

Acedo, A., Mendoza, G., Painho, M., \& Casteleyn, S. (2017). One tool to spatialize all : sense of place, social capital and civic engagement. In A. Bregt, T. Sarjakoski, R. Lammeren, \& F. Rip (Eds.), Societal Geo-Innovation : short papers, posters and poster abstracts of the 20th AGILE Conference on Geographic Information Science. Wageningen: Wageningen University \& Research.

Acedo, A., Painho, M., \& Casteleyn, S. (2017). Place and city: Operationalizing sense of place and social capital in the urban context. Transactions in GIS, 21(3), 503-520. http://doi.org/10.1111/tgis.12282

Acedo, A., Painho, M., Casteleyn, S., \& Roche, S. (2018). Place and City : Toward Urban Intelligence. International Journal of Geo-Information, 7(9), 1-21. http://doi.org/10.3390/ijgi7090346

Ackerman, J. (2004). Co-governance for accountability: Beyond "exit" and "voice." World Development, 32(3), 447-463. http://doi.org/10.1016/j.worlddev.2003.06.015

Adler, R. P., \& Goggin, J. (2005). What Do We Mean By “Civic Engagement"? Journal of Transformative Education, 3(3), 236-253. http://doi.org/10.1177/1541344605276792

Agnew, J. A. (2002). Place and politics in modern Italy. University of Chicago Press.

Agnew, J. A. (2011). Space and place. In J. A. and D. Livingstone (Ed.), Handbook of geographical knowledge (Vol. 2011, pp. 316-330). London: SAGE Publications. http://doi.org/http://dx.doi.org/10.4135/9781446201091.n24

Ahn, M. J., \& Bretschneider, S. (2011). Politics of e-government: E-government and the political control of bureaucracy. Public Administration Review, 71(3), 414-424. http://doi.org/10.1111/j.1540-6210.2011.02225.x

Ajzen, I., \& Fishbein, M. (1977). Attitude-behavior relations: A theoretical analysis and review 
of empirical research. Psychological Bulletin, 84(5), 888-918.

http://doi.org/10.1037/0033-2909.84.5.888

Akter, S., D'Ambra, J., \& Ray, P. (2010). Service quality of mHealth platforms: Development and validation of a hierarchical model using PLS. Electronic Markets, 20(3-4), 209-227. http://doi.org/10.1007/s12525-010-0043-x

Al-Hujran, O., Al-dalahmeh, M., \& Aloudat, A. (2011). The role of national culture on citizen adoption of eGovernment services: An empirical study. Electronic Journal of EGovernment, 9(2), 93-106.

Al-Hujran, O., Al-Debei, M., \& Al-Lozi, E. (2014). Examining eDemocracy adoption intention for digital society: An integrative model. In The Eighth International Conference on Digital Society (pp. 39-47).

Al-Quraan, H., \& Abu-Shanab, E. (2015). Predictors of e-participation levels: The case of Jordan. In The 7th International Conference on Information Technology (pp. 325-331). Amman, Jordan. http://doi.org/10.15849/icit.2015.0064

Al-Sobhi, F., Weerakkody, V., \& El-Haddadeh, R. (2011). The relative importance of intermediaries in egovernment adoption: A study of Saudi Arabia. In International Conference on Electronic Government (pp. 62-74). Springer Berlin Heidelberg.

Al-Somali, S. A., Gholami, R., \& Clegg, B. (2009). An investigation into the acceptance of online banking in Saudi Arabia. Technovation, 29(2), 130-141. http://doi.org/10.1016/j.technovation.2008.07.004

Al Hujran, O., Aloudat, A., \& Altarawneh, I. (2013). Factors influencing citizen adoption of egovernment in developing countries. International Journal of Technology and Human Interaction, 9(2), 1-19. http://doi.org/10.4018/jthi.2013040101

Alathur, S., Ilavarasan, P. V., \& Gupta, M. P. (2011). Citizen empowerment and participation in e-democracy. In Proceedings of the 5th International Conference on Theory and Practice of Electronic Governance - ICEGOV'11 (p. 11). New York, New York, USA: ACM Press. http://doi.org/10.1145/2072069.2072072

Alawneh, A., Al-Refai, H., \& Batiha, K. (2013). Measuring user satisfaction from e-government services: Lessons from Jordan. Government Information Quarterly, 30(3), 277-288. http://doi.org/10.1016/j.giq.2013.03.001 
Alharbi, A., Kang, K., \& Hawryszkiewycz, I. (2015). The influence of trust and subjective norms on citizens' intentions to engage in e-participation on e-government websites. In Australasian Conference on Information Systems.

Alharbi, N., Papadaki, M., \& Dowland, P. (2017). The impact of security and its antecedents in behaviour intention of using e-government services. Behaviour \& Information Technology, 36(6), 620-636. http://doi.org/10.1080/0144929X.2016.1269198

Allegretti, G., \& Antunes, S. (2014). The Lisbon Participatory Budget: results and perspectives on an experience in slow but continuous transformation. Field Actions Science Reports [Online], (Special Issue 11), 1-10.

Alomari, M., Woods, P., \& Kuldeep, S. (2012). Predictors for e-government adoption in Jordan: Deployment of an empirical evaluation based on a citizen-centric approach. Information Technology \& People, 25(2), 207-234. http://doi.org/10.1108/09593841211232712

Aloudat, A., Michael, K., Chen, X., \& Al-Debei, M. M. (2014). Social acceptance of locationbased mobile government services for emergency management. Telematics and Informatics, 31(1), 153-171. http://doi.org/10.1016/j.tele.2013.02.002

Alrashedi, R., Persaud, A., \& Kindra, G. (2015). Drivers of eParticipation: Case of Saudi Arabia. The Journal of Business Inquiry, 14(1), 1-22.

Alshehri, M., Drew, S., Alhussain, T., \& Alghamdi, R. (2012). The effects of website quality on adoption of e-government service: An empirical study applying UTAUT model using SEM. In Australasian Conference On Information Systems. Greelong.

Altman, I., \& Low, S. M. (1992). Place Attachment. (I. Altman \& S. M. Low, Eds.). New York, USA: Plenum Press. http://doi.org/10.1007/978-1-4684-8753-4

Alves, M. L., \& Allegretti, G. (2012). (In)Stability, a key element to understand participatory budgeting: Discussing Portuguese cases. Journal of Public Deliberation, 8(2), Article 3.

Andersen, K. V., Henriksen, H. Z., Secher, C., \& Medaglia, R. (2007). Costs of e-participation: the management challenges. Transforming Government: People, Process and Policy, 1(1), 2943. http://doi.org/10.1108/17506160710733689

Antoci, A., Sabatini, F., \& Sodini, M. (2015). Online and Offline Social Participation and Social Poverty Traps: Can Social Networks Save Human Relations? The Journal of Mathematical Sociology, 39(4), 229-256. http://doi.org/10.1080/0022250X.2015.1022278 
Anton, C. E., \& Lawrence, C. (2016). The relationship between place attachment, the theory of planned behaviour and residents' response to place change. Journal of Environmental Psychology, 47, 145-154. http://doi.org/10.1016/j.jenvp.2016.05.010

Aricat, R. G., \& Ling, R. (2016). Civic Engagement in Myanmar: The Promise and Threat of Mobile Communication and the Internet. In R. Wei (Ed.), Mobile Communication in Asia: Local Insights, Global Implications (pp. 123-142). Springer Science \& Business Media. http://doi.org/10.1007/978-94-024-0917-8_7

Baiocchi, G., \& Ganuza, E. (2014). Participatory budgeting as if emancipation mattered. Politics \& Society, 42(1), 29-50. http://doi.org/10.1177/0032329213512978

Bandura, A. (1986). Social foundations of thought and action: A social cognitive theory: A Social Cognitive Theory. Englewood Cliffs, NJ: Prentice Hall.

Bansal, H. S., \& Voyer, P. A. (2012). World-of-mouth processes within a services purchase decision context. Journal of Service Research, 3(2), 166-177.

Baptista, G., \& Oliveira, T. (2015). Understanding mobile banking: The unified theory of acceptance and use of technology combined with cultural moderators. Computers in Human Behavior, 50, 418-430. http://doi.org/10.1016/j.chb.2015.04.024

Baptista, G., \& Oliveira, T. (2016). A weight and a meta-analysis on mobile banking acceptance. Computers in Human Behavior, 63, 480-489. http://doi.org/10.1016/j.chb.2016.05.074

Bataineh, L., \& Abu-Shanab, E. (2016). How perceptions of e-participation levels influence the intention to use e-government websites. Transforming Government: People, Process and Policy, 10(2), 315-334. http://doi.org/10.1108/TG-12-2015-0058

Becker, J. M., Klein, K., \& Wetzels, M. (2012). Hierarchical Latent Variable Models in PLS-SEM: Guidelines for Using Reflective-Formative Type Models. Long Range Planning, 45(5-6), 359-394. http://doi.org/10.1016/j.Irp.2012.10.001

Belanche, D., Casaló, L., \& Flavián, C. (2012). Integrating trust and personal values into the technology acceptance model: The case of e-government services adoption. Cuadernos de Economía y Dirección de La Empresa, 15(4), 192-204. http://doi.org/10.1016/j.cede.2012.04.004

Bélanger, F., \& Carter, L. (2008). Trust and risk in e-government adoption. The Journal of Strategic Information Systems, 17(2), 165-176. http://doi.org/10.1016/j.jsis.2007.12.002 
Bernardo, F., \& Palma-Oliveira, J. M. (2016). Identification with the neighborhood:

Discrimination and neighborhood size. Self and Identity, 15(5), 579-598.

http://doi.org/10.1080/15298868.2016.1178665

Bhattacherjee \& Premkumar. (2004). Understanding changes in belief and attitude toward information technology usage: A theoretical model and longitudinal test. MIS Quarterly, 28(2), 229-254.

Bhattacherjee, A. (2001). Understanding Information Systems Continuance: An ExpectationConfirmation Model. MIS Quarterly, 25(3), 351-370. http://doi.org/10.2307/3250921

Bodenhamer, D. J., Corrigan, J., \& Harris, T. M. (2010). The Spatial Humanities.

Borenstein, M., Hedges, L. V., Higgins, J. P. T., \& Rothstein, H. R. (2009). Publication bias. In Introduction to Meta-Analysis. John Wiley \& Sons, Ltd.

http://doi.org/10.1002/9780470743386.ch30

Bowman, N. A. (2012). Effect sizes and statistical methods for meta-analysis in higher education. Research in Higher Education, 53(3), 375-382. http://doi.org/10.1007/s11162011-9232-5

Brito Vieira, M., Carreira da Silva, F., \& Pereira, C. R. (2017). Waiting for Godot? Welfare Attitudes in Portugal before and after the Financial Crisis. Political Studies, 65(3), 535558. http://doi.org/10.1177/0032321716651653

Brown, G. G., \& Pullar, D. V. (2012). An evaluation of the use of points versus polygons in public participation geographic information systems using quasi-experimental design and Monte Carlo simulation. International Journal of Geographical Information Science, 26(2), 231-246. http://doi.org/10.1080/13658816.2011.585139

Brown, G. G., Reed, P., \& Harris, C. C. (2002). Testing a place-based theory for environmental evaluation: an Alaska case study. Applied Geography, 22(1), 49-76. http://doi.org/10.1016/S0143-6228(01)00019-4

Brown, G., Raymond, C. M., \& Corcoran, J. (2015). Mapping and measuring place attachment. Applied Geography, 57, 42-53. http://doi.org/10.1016/j.apgeog.2014.12.011

Brown, S. A., \& Venkatesh, V. (2005). Model of adoption of technology in households: A baseline model test and extension incorporating household life cycle. MIS Quarterly, 29(3), 399-426. http://doi.org/10.1080/01972240600791333 
Buta, N., Holland, S. M., \& Kaplanidou, K. (2014). Local communities and protected areas: The mediating role of place attachment for pro-environmental civic engagement. Journal of Outdoor Recreation and Tourism, 5-6, 1-10. http://doi.org/10.1016/j.jort.2014.01.001

Cadman, L. (2009). Nonrepresentational theory/nonrepresentational geographies. International Encyclopaedia of Human Geography, 1-8. http://doi.org/10.1016/B978008044910-4.00717-3

Cai Shuqin, B. H. M., Mastoi, A. G., Gul, N., \& Gul, H. (2016). Evaluating citizen e-satisfaction from e-government services: A case of Pakistan. European Scientific Journal, 12(5), 346370. http://doi.org/10.19044/esj.2016.v12n5p346

Carter, L., \& Bélanger, F. (2004). Citizen adoption of electronic government initiatives. In 37th Annual Hawaii International Conference on System Sciences.

Carter, L., \& Bélanger, F. (2005). The utilization of e-government services: citizen trust, innovation and acceptance factors. Information Systems Journal, 15. http://doi.org/10.1111/j.1365-2575.2005.00183.x

Carter, L., \& Bélanger, F. (2012). Internet voting and political participation: an empirical comparison of technological and political factors. ACM SIGMIS Database, 43. http://doi.org/10.1145/2351848.2351851

Carver, S. (2001). Participation and Geographical Information : a position paper. In ESFNSF Workshop on Access to Geographic Information and Participatory Approaches Using Geographic Information (pp. 6-8).

Cegarra-Navarro, J.-G., Garcia-Perez, A., \& Moreno-Cegarra, J. L. (2014). Technology knowledge and governance: Empowering citizen engagement and participation. Government Information Quarterly, 31(4), 660-668. http://doi.org/10.1016/j.giq.2014.07.001

Chan, F. K. Y., Thong, J. Y. L., Venkatesh, V., Brown, S. A., Hu, P. J., \& Tam, K. Y. (2010). Modeling citizen satisfaction with mandatory adoption of an e-government technology. Journal of the Association for Information Systems, 11(10), 519-549.

Chavis, D., \& Wandersman, A. (1990). Sense of community in the urban environment: A catalyst for participation and community development. American Journal of Community Psychology, 18(1), 55-81. http://doi.org/10.1007/BF00922689 
Chen, C.-D., Yang, S.-C., Wang, K., \& Farn, C.-K. (2008). Antecedents and consequences of sense of virtual community: The customer value perspective. Proc. 7th Workshop on e-Business (WeB 2008).

Chen, J. (2016). Can online social networks foster young adults' civic engagement? Telematics and Informatics. http://doi.org/10.1016/j.tele.2016.09.013

Chen, P.-Y., Wu, S., \& Yoon, J. (2004). The Impact of online recommendation and consumer feedback on sales. Proceedings of the International Conference on Information Systems, Paper 58, 711-724. http://doi.org/http://aisel.aisnet.org/icis2004/58

Chen, Z., Zhang, G., \& Li, J. (2015). Goodness-of-fit test for meta-analysis. Scientific Reports, 5(1), 1-8. http://doi.org/10.1038/srep16983

Cheng, S.-Y., Tsai, M.-T., Cheng, N.-C., \& Chen, K.-S. (2012). Predicting intention to purchase on group buying website in Taiwan: Virtual community, critical mass and risk. Online Information Review, 36(5), 698-712. http://doi.org/10.1108/14684521211275984

Cheung, C. M. K., \& Lee, M. K. O. (2012). What drives consumers to spread electronic word of mouth in online consumer-opinion platforms. Decision Support Systems, 53(1), 218-225. http://doi.org/10.1016/j.dss.2012.01.015

Chiang, L. (2009). Trust and security in the e-voting system. Electronic Government, an International Journal, 6(4), 343-360. http://doi.org/10.1504/EG.2009.027782

Cho, J. (2016). The impact of post-adoption beliefs on the continued use of health apps. International Journal of Medical Informatics, 87, 75-83.

http://doi.org/10.1016/j.ijmedinf.2015.12.016

Choi, J., \& Kim, Y. (2014). The moderating effects of gender and number of friends on the relationship between self-presentation and brand-related word-of-mouth on Facebook. Personality and Individual Differences, 68(October 2014), 1-5. http://doi.org/10.1016/j.paid.2014.03.040

Choi, S. O., \& Kim, B. C. (2012). Voter intention to use e-voting technologies: security, technology acceptance, election type, and political ideology. Journal of Information Technology \& Politics, 9(4), 433-452. http://doi.org/10.1080/19331681.2012.710042

Christensen, T., \& Lægreid, P. (2005). Trust in Government: The Relative Importance of Service Satisfaction, Political Factors, and Demography. Public Performance \& Management 
Review, 28(4), 487-511. http://doi.org/10.1080/15309576.2005.11051848

Colesca, S. E., \& Dobrica, L. (2008). Adoption and use of e-government services : The case of Romania. Journal of Applied Research and Technology, 6(3), 204-217.

Cooper, H. (2010). Research synthesis and meta-analysis: A step-by-step approach (4th ed.). Sage Publications, Inc.

Costello, A. B., \& Osborne, J. W. (2005). Best practices in exploratory factor analysis: Four recommendations for getting the most from your analysis. Practical Assessment, Research \& Evaluation, 10, 1-9. http://doi.org/10.1.1.110.9154

Coulton, C. J., Korbin, J., Chan, T., \& Su, M. (2001). Mapping residents' perceptions of neighborhood boundaries: a methodological note. American Journal of Community Psychology, 29(2), 371-383. http://doi.org/10.1023/A:1010303419034

Cruz-Jesus, F., Oliveira, T., \& Bacao, F. (2012). Digital divide across the European Union. Information and Management, 49(6), 278-291. http://doi.org/10.1016/j.im.2012.09.003

Cuba, L., \& Hummon, D. M. (1993). A place to call home: Identification with dwelling, community and region. The Sociological Quarterly, 34(1), 111-131. http://doi.org/10.1111/j.1533-8525.1993.tb00133.x

Dahi, M., \& Ezziane, Z. (2015). Measuring e-government adoption in Abu Dhabi with technology acceptance model (TAM). International Journal of Electronic Governance, 7(3), 206-231. http://doi.org/10.1504/IJEG.2015.071564

Davis, F. (1989). Perceived usefulness, perceived ease of use, and user acceptance of information technology. MIS Quarterly, 13(3), 319-340.

Deci, E. L., \& Ryan, R. M. (1985). The general causality orientations scale: Self-determination in personality. Journal of Research in Personality, 19(2), 109-134. http://doi.org/10.1016/0092-6566(85)90023-6

DeLone, W. H., \& McLean, E. R. (1992). Information systems success: The quest for the dependent variable. Information Systems Research, 3(1), 60-95. http://doi.org/10.1287/isre.3.1.60

DeLone, W. H., \& McLean, E. R. (2003). The DeLone and McLean model of information system success: A Ten-Year Update. Journal of Management Information Systems / Spring, 19(4), 9-30. http://doi.org/10.1073/pnas.0914199107 
Delyser, D., \& Sui, D. (2014). Crossing the qualitative-quantitative chasm III: Enduring methods, open geography, participatory research, and the fourth paradigm. Progress in Human Geography, 38(2), 294-307. http://doi.org/10.1177/0309132513479291

Dewsbury, J. D. (2003). Witnessing space: "Knowledge without contemplation." Environment and Planning A, 35(11), 1907-1932. http://doi.org/10.1068/a3582

Dietz, R. D. (2002). The estimation of neighborhood effects in the social sciences: An interdisciplinary approach. Social Science Research, 31(4), 539-575. http://doi.org/10.1016/S0049-089X(02)00005-4

Duff, C. (2011). Networks, resources and agencies: On the character and production of enabling places. Health and Place, 17(1), 149-156. http://doi.org/10.1016/j.healthplace.2010.09.012

Dwivedi, Y. K., Rana, N. P., Chen, H., \& Williams, M. D. (2011). A meta-analysis of the unified theory of acceptance and use of technology (UTAUT). In IFIP International Working Conference on Governance and Sustainability in Information Systems-Managing the Transfer and Diffusion of IT (pp. 155-170). Springer Berlin Heidelberg. http://doi.org/10.1007/978-3-642-24148-2

Egenhofer, M. J., Clementini, E., \& Di Felice, P. (1994). Topological relations between regions with holes. International Journal of Geographical Information Systems, 8(2), 129-142. http://doi.org/10.1080/02693799408901990

Egger, M., Smith, G. D., Schneider, M., \& Minder, C. (1997). Bias in meta-analysis detected by a simple, graphical test. BMJ, 315(7109), 629-634.

Elwood, S. (2006). Critical Issues in Participatory GIS: Deconstructions, Reconstructions, and New Research Directions. Transactions in GIS, 10(5), 693-708. http://doi.org/10.1111/j.1467-9671.2006.01023.x

Ergeneli, A., Ari, S. G., \& Metin, S. (2007). Psychological empowerment and its relationship to trust in immediate managers. Journal of Business Research, 60(1), 41-49. http://doi.org/10.1016/j.jbusres.2006.09.012

Fishbein, M., \& Ajzen, I. (1975). Belief, attitude, intention and behavior: An introduction to theory and research. Massachusetts: Addison-Wesley.

Foresee. (2016). Foresee e-government satisfaction index Q1 2016. 
Fornell, C., \& Larcker, D. F. D. (1981). Evaluating structural equation models with unobservable variables and measurement error. Journal of Marketing Research, 18(1), 39-50. http://doi.org/10.2307/3151312

Foster, K. A., Pitner, R., Freedman, D. A., Bell, B. A., \& Shaw, T. C. (2015). Spatial Dimensions of Social Capital. City \& Community, 14(4), 392-409. http://doi.org/10.1111/cico.12133

Gieryn, T. F. (2000). A Space for Place in Sociology. Annual Review of Sociology, 26(1), 463-496. http://doi.org/10.1146/annurev.soc.26.1.463

Gonçalves, J., Kostakos, V., Karapanos, E., Barreto, M., Camacho, T., Tomasic, A., \& Zimmerman, J. (2014). Citizen motivation on the go: The role of psychological empowerment. Interacting with Computers, 26(3), 196-207. http://doi.org/10.1093/iwc/iwt035

Goodhue, D. I., \& Thompson, R. L. (1995). Task-technology fit and individual performance. MIS Quarterly, 19(2), 213-236.

Grootaert, C., Narayan, D., Jones, V. N., \& Woolcock, M. (2004). Measuring social capital: An integrated Questionnaire. Washington, DC, USA.

Hair, J. F., Ringle, C. M., \& Sarstedt, M. (2011). PLS-SEM: Indeed a Silver Bullet. The Journal of Marketing Theory and Practice, 19(2), 139-152. http://doi.org/10.2753/MTP10696679190202

Hair, J., Hult, T., Ringle, C. M., \& Sarstedt, M. (2014). A primer on partial least squares structural equation modeling (PLS-SEM) (1st ed.). Thousand Oaks, CA: SAGE Publications.

Hair, J., Hult, T., Ringle, C. M., \& Sarstedt, M. (2017). A primer on partial least squares structural equation modeling (PLS-SEM) (2nd Editio). Thousand Oaks, CA: Sage Publications, Inc.

Hak, T., van Rhee, H., \& Suurmond, R. (2016). How to interpret results of meta-analysis. Rotterdam, The Netherlands.

Harrison, J. S., Banks, G. C., Pollack, J. M., O’Boyle, E. H., \& Short, J. (2017). Publication bias in strategic management research. Journal of Management, 43(2), 400-425. http://doi.org/10.1177/0149206314535438

Hartwick, J., \& Barki, H. (1994). Explaining the Role of User Participation in Information System Use. Management Science, 40(4), 440-465. http://doi.org/10.1287/mnsc.40.4.440 
Haywood, B. K. (2014). A "Sense of Place" in Public Participation in Scientific Research. Science Education, 98(1), 64-83. http://doi.org/10.1002/sce.21087

Heeks, R., \& Bailur, S. (2007). Analyzing e-government research: Perspectives, philosophies, theories, methods, and practice. Government Information Quarterly, 24(2), 243-265. http://doi.org/10.1016/j.giq.2006.06.005

Henseler, J., Hubona, G., \& Ash Ray, P. (2015). Using PLS path modeling in new technology research: updated guidelines. Industrial Management \& Data Systems, 116(1), 2-20. http://doi.org/10.1108/IMDS-09-2015-0382

Henseler, J., Ringle, C. M., \& Sarstedt, M. (2015). A new criterion for assessing discriminant validity in variance-based structural equation modeling. Journal of the Academy of Marketing Science, 43(1), 115-135. http://doi.org/10.1007/s11747-014-0403-8

Henseler, J., Ringle, C. M., \& Sinkovics, R. R. (2009). The Use of Partial Least Squares Path Modeling in International Marketing. Advances in International Marketing, 20(3), 277319. http://doi.org/10.1108/S1474-7979(2009)0000020014

Hibberts, M., Johnson, R. B., \& Hudson, K. (2012). Common survey sampling techniques. In Handbook of survey methodology for the social sciences (pp. 53-74). New York: Springer. http://doi.org/10.1007/978-1-4614-3876-2_5

Hidalgo, M. C., \& Hernández, B. (2001). Place Attachment: Conceptual and empirical questions. Journal of Environmental Psychology, 21(3), 273-281. http://doi.org/10.1006/jevp.2001.0221

Higgins, J. P. T., \& Thompson, S. G. (2002). Quantifying heterogeneity in a meta-analysis. Statistics in Medicine, 21(11), 1539-1558. http://doi.org/10.1002/sim.1186

Hochwälder, J., \& Brucefors, A. B. (2005). Psychological empowerment at the workplace as a predictor of ill health. Personality and Individual Differences, 39, 1237-1248. http://doi.org/10.1016/j.paid.2005.04.010

Hoehle, H., \& Venkatesh, V. (2015a). Mobile application usability: Conceptualization and instrument development. MIS Quarterly, 39(2), 435-472.

Hoehle, H., \& Venkatesh, V. (2015b). Mobile application usability: Conceptualization and instrument development - Annex, 39(2), 435-472.

Hofstede, G., Hofstede, J. G., \& Minkov, M. (2010). Cultures and organizations: software of the 
mind: intercultural cooperation and its importance for survival. McGraw-Hill.

Holt, L. (2008). Embodied social capital and geographic perspectives: performing the habitus. Progress in Human Geography, 32(2), 227-246.

http://doi.org/10.1177/0309132507087648

Hong, S., Thong, J. Y. L., \& Tam, K. Y. (2006). Understanding continued information technology usage behavior: A comparison of three models in the context of mobile internet. Decision Support Systems, 42(3), 1819-1834. http://doi.org/10.1016/j.dss.2006.03.009

Hong, S. Y., \& Yang, S. U. (2009). Effects of reputation, relational satisfaction, and customercompany identification on positive word-of-mouth intentions. Journal of Public Relations Research, 21(4), 381-403. http://doi.org/10.1080/10627260902966433

Hsiao, T.-T., \& Chuang, S.-T. (2009). The role of virtual community in disseminating electronic word of mouth. In 2009 Joint Conferences on Pervasive Computing (JCPC) (pp. 755-760). IEEE. http://doi.org/10.1109/JCPC.2009.5420083

Hsu, M.-H., Yen, C.-H., Chiu, C.-M., \& Chang, C.-M. (2006). A longitudinal investigation of continued online shopping behavior: An extension of the theory of planned behavior. International Journal of Human-Computer Studies, 64.

http://doi.org/10.1016/j.ijhcs.2006.04.004

Hu, T., Stafford, T. F., Kettinger, W. J., Zhang, X. "Paul," \& Dai, H. (2017). Formation and Effect of Social Media Usage Habit. Journal of Computer Information Systems, 1-10. http://doi.org/10.1080/08874417.2016.1261378

Huck, J. J., Whyatt, J. D., \& Coulton, P. (2014). Spraycan: A PPGIS for capturing imprecise notions of place. Applied Geography, 55, 229-237. http://doi.org/10.1016/j.apgeog.2014.09.007

Hung, S.-Y., Chang, C.-M., \& Kuo, S.-R. (2013). User acceptance of mobile e-government services: An empirical study. Government Information Quarterly, 30(1), 33-44. http://doi.org/10.1016/j.giq.2012.07.008

Hunter, B. (2016). Social Capital: Models and Efforts to Build and Restore among Marginalized Individuals and Communities. In T. P. Gullotta, H. J. Walberg, \& R. P. Weissberg (Eds.), Social Capital and Community Well-Being (pp. 199-212). London: Springer.

INE - Instituto Nacional de Estadística. (2016). A proporção de utilizadores de internet em 
mobilidade duplicou em 4 anos. Lisboa.

Ingrams, A. (2015). Mobile phones, smartphones, and the transformation of civic behavior through mobile information and connectivity. Government Information Quarterly, 32(4), 506-515. http://doi.org/10.1016/j.giq.2015.07.007

Janssen, M., Charalabidis, Y., \& Zuiderwijk, A. (2012). Benefits, Adoption Barriers and Myths of Open Data and Open Government. Information Systems Management, 29(4), 258-268. http://doi.org/10.1080/10580530.2012.716740

Jasperson, J., Carter, P. E., \& Zmud, R. W. (2005). A comprehensive conceptualization of postadoptive behaviors associated with information technology enabled work systems. Management Information Systems Quarterly, 29(3), 525-557. http://doi.org/10.2307/25148694

Jenkins, A., Croitoru, A., Crooks, A. T., \& Stefanidis, A. (2016). Crowdsourcing a Collective Sense of Place. Plos One, 11(4), 1-20. http://doi.org/10.1371/journal.pone.0152932

Jeyaraj, A., Rottman, J. W., \& Lacity, M. C. (2006). A review of the predictors, linkages, and biases in IT innovation adoption research. Journal of Information Technology, 21(1), 1-23. http://doi.org/10.1057/palgrave.jit.2000056

Johnson, R. E., Rosen, C. C., Chang, C.-H. (Daisy), Djurdjevic, E., \& Taing, M. U. (2012). Recommendations for improving the construct clarity of higher-order multidimensional constructs. Human Resource Management Review, 22(2), 62-72. http://doi.org/10.1016/j.hrmr.2011.11.006

Jorgensen, B. S. (2010). Subjective Mapping Methodologies for Incorporating Spatial Variation in Research on Social Capital and Sense of Place. Tijdschrift Voor Economische En Sociale Geografie, 101(5), 554-567. http://doi.org/10.1111/j.1467-9663.2010.00633.x

Jorgensen, B. S., \& Stedman, R. C. (2001). Sense of place as an attitude: Lakeshore owners attitudes toward their properties. Journal of Environmental Psychology, 21(3), 233-248. http://doi.org/10.1006/jevp.2001.0226

Jorgensen, B. S., \& Stedman, R. C. (2006). A comparative analysis of predictors of sense of place dimensions: Attachment to, dependence on, and identification with lakeshore properties. Journal of Environmental Management, 79(3), 316-327.

http://doi.org/10.1016/j.jenvman.2005.08.003 
Jorgensen, B. S., \& Stedman, R. C. (2011). Measuring the spatial component of sense of place: a methodology for research on the spatial dynamics of psychological experiences of places. Environment and Planning B: Planning and Design, 38(5), 795-813. http://doi.org/10.1068/b37054

Kahila, M., \& Kyttä, M. (2009). SoftGIS as a Bridge-Builder in Collaborative Urban Planning. In S. Geertman \& J. Stillwell2 (Eds.), Planning Support Systems Best Practice and New Methods (pp. 389-411). Springer, Dordrecht. http://doi.org/10.1007/978-1-4020-8951-0

Kang, M. (2014). Understanding Public Engagement: Conceptualizing and Measuring its Influence on Supportive Behavioral Intentions. Journal of Public Relations Research, 26(5), 399-416. http://doi.org/10.1080/1062726X.2014.956107

Kassen, M. (2017). Open data in Kazakhstan: Incentives, implementation and challenges. Information Technology \& People, 30(2), 301-323. http://doi.org/10.1108/ITP-10-20150243

Kersting, N. (2016). Participatory turn? Comparing citizens' and politicians' perspectives on online and offline local political participation. Lex Localis, 14(2), 251-263. http://doi.org/10.4335/14.2.249-263(2016)

Khan, G. F., Moon, J., Swar, B., Zo, H., \& Rho, J. J. (2012). E-government service use intentions in Afghanistan: Technology adoption and the digital divide in a war-torn country. Information Development, 28(4), 281-299. http://doi.org/10.1177/0266666912438879

Kil, N., Holland, S., \& Stein, T. (2014). Place meanings and participatory planning intentions. Society \& Natural Resources, 27(5), 475-491. http://doi.org/10.1080/08941920.2013.842274

Kim, H.-W., \& Gupta, S. (2014). A User Empowerment Approach to Information Systems Infusion. IEEE Transactions on Engineering Management, 61(4), 656-668. http://doi.org/10.1109/TEM.2014.2354693

Kim, S. S., \& Malhotra, N. K. (2005). A longitudinal model of continued IS use: An integrative view of four mechanisms underlying postadoption phenomena. Management Science, 51(5), 741-755. http://doi.org/10.1287/mnsc.1040.0326

King, W. R., \& He, J. (2006). A meta-analysis of the technology acceptance model. Information and Management, 43(6), 740-755. http://doi.org/10.1016/j.im.2006.05.003 
Kipenis, L., \& Askounis, D. (2016). Assessing e-participation via user's satisfaction measurement: the case of OurSpace platform. Annals of Operations Research, 247(2), 599-615. http://doi.org/10.1007/s10479-015-1911-8

Kitchin, R., Gleeson, J., \& Dodge, M. (2013). Unfolding mapping practices: A New epistemology for cartography. Transactions of the Institute of British Geographers, 38(3), 480-496. http://doi.org/10.1111/j.1475-5661.2012.00540.x

Koh, J., \& Kim, Y.-G. (2003). Sense of virtual community: A conceptual framework and empirical validation. International Journal of Electronic Commerce, 8(2), 75-94. http://doi.org/10.1080/10864415.2003.11044295

Kollmann, T., \& Kayser, I. (2010). A comprehensive approach to citizen engagement in edemocracy. In E. Ruhode (Ed.), 6th International Conference on e-Government - ICEG2006 (pp. 54-62). Cape Town: Academic Conferences and Publishing International.

Kubicek, H., \& Aichholzer, G. (2016). Closing the Evaluation Gap in e-participation Research and Practice. In Evaluating e-Participation Frameworks, Practice, Evidence (pp. 11-45). Springer. http://doi.org/10.1007/978-3-319-25403-6

Kyttä, M., \& Kahila, M. (2011). SoftGIS methodology-building bridges in urban planning. GIM International (The Global Magazine for Geomatics), 25(3).

Latour, B. (2005). Reassembling the Social.

Law, J. (2008). On sociology and STS. Sociological Review, 56(4), 623-649. http://doi.org/10.1111/j.1467-954X.2008.00808.x

Lean, O. K., Zailani, S., Ramayah, T., \& Fernando, Y. (2009). Factors influencing intention to use e-government services among citizens in Malaysia. International Journal of Information Management, 29(6), 458-475. http://doi.org/10.1016/j.ijinfomgt.2009.03.012

Lee, J.-K., Braynov, S., \& Rao, R. (2003). Effects of public emergency on citizens' usage intention toward e-government: a study in the context of war in Iraq. In International Conference on Information Systems - ICIS (pp. 896-902).

Lee, J., \& Kim, S. (2012). E-participation in the era of web 2.0: Factors affecting citizens' active e-participation in local governance. In Proceedings of the 6th International Conference on Theory and Practice of Electronic Governance - ICEGOV'12 (pp. 44-47). New York, New York, USA: ACM Press. http://doi.org/10.1145/2463728.2463739 
Lee, J., \& Kim, S. (2014). Active Citizen E-Participation in Local Governance: Do Individual Social Capital and E-Participation Management Matter? In System Sciences (HICSS) (47th Hawai, pp. 2044-2053). IEEE. http://doi.org/10.1109/HICSS.2014.259

Lee, J., \& Kim, S. (2018). Citizens' e-participation on agenda setting in local governance: Do individual social capital and e-participation management matter? Public Management Review, 20(6), 873-895. http://doi.org/10.1080/14719037.2017.1340507

Lee, J., \& Rao, H. R. (2009). Task complexity and different decision criteria for online service acceptance: A comparison of two e-government compliance service domains. Decision Support Systems, 47(4), 424-435. http://doi.org/10.1016/j.dss.2009.04.009

Lee, K., Yan, A., \& Joshi, K. (2011). Understanding the dynamics of users' belief in software application adoption. International Journal of Information Management, 31(2), 160-170. http://doi.org/10.1016/j.ijinfomgt.2010.07.009

Lewicka, M. (2005). Ways to make people active: The role of place attachment, cultural capital, and neighborhood ties. Journal of Environmental Psychology, 25(4), 381-395. http://doi.org/10.1016/j.jenvp.2005.10.004

Lewicka, M. (2011). Place attachment: How far have we come in the last 40 years? Journal of Environmental Psychology, 31(3), 207-230. http://doi.org/10.1016/j.jenvp.2010.10.001

Lewicka, M. (2013). Place inherited or place discovered? Agency and communion in peopleplace bonding. Estudios De Psicologia, 34(3), 261-274. http://doi.org/10.1174/021093913808295154

Li, H., \& Liu, Y. (2014). Understanding post-adoption behaviors of e-service users in the context of online travel services. Information and Management, 51(8), 1043-1052. http://doi.org/10.1016/j.im.2014.07.004

Liao, C., Palvia, P., \& Chen, J. L. (2009). Information technology adoption behavior life cycle: Toward a Technology Continuance Theory (TCT). International Journal of Information Management, 29(4), 309-320. http://doi.org/10.1016/j.ijinfomgt.2009.03.004

Lin, C.-C., \& Lockwood, M. (2014). Forms and sources of place attachment: Evidence from two protected areas. Geoforum, 53, 74-81. http://doi.org/10.1016/j.geoforum.2014.02.008

Lin, F., Fofanah, S. S., \& Liang, D. (2011). Assessing citizen adoption of e-government initiatives in Gambia: A validation of the technology acceptance model in information systems 
success. Government Information Quarterly, 28(2), 271-279.

http://doi.org/10.1016/j.giq.2010.09.004

Lindner, R., \& Riehm, U. (2011). Broadening participation through e-petitions? An empirical study of petitions to the German Parliament. Policy \& Internet, 3(1), 63-85. http://doi.org/10.2202/1944-2866.1083

Liu, Y., Li, H., Kostakos, V., Goncalves, J., Hosio, S., \& Hu, F. (2014). An empirical investigation of mobile government adoption in rural China: A case study in Zhejiang province. Government Information Quarterly, 31(3), 432-442. http://doi.org/10.1016/j.giq.2014.02.008

Luo, M. M., Chea, S., \& Bui, T. X. (2016). Post-adoption behavior of digital Media: The merge of U\&G theory and affect event theory. In Pacific Asia Conference on Information Systems (PACIS) 2016. Chia-Yi, Taiwan.

Luo, X., Li, H., Zhang, J., \& Shim, J. P. (2010). Examining multi-dimensional trust and multifaceted risk in initial acceptance of emerging technologies: An empirical study of mobile banking services. Decision Support Systems, 49(2), 222-234. http://doi.org/10.1016/j.dss.2010.02.008

Lussault, M. (2007). L'Homme spatial. La construction sociale de l'espace humain: La construction sociale de l'espace humain. Paris, France: Le Seuil.

Ma, L., \& Zheng, Y. (2017). National e-government performance and citizen satisfaction: A multilevel analysis across European countries. International Review of Administrative Sciences, 1-21. http://doi.org/10.1177/0020852317703691

Macintosh, A. (2004). Characterizing e-participation in policy-making. In 37th Hawaii International Conference on System Sciences (p. 10). Big Island, HI, USA: IEEE. http://doi.org/10.1109/HICSS.2004.1265300

Macintosh, A., Coleman, S., \& Schneeberger, A. (2009). eParticipation: The research gaps. In A. Macintosh \& E. Tambouris (Eds.), First International Conference of Electronic Participation (pp. 1-11). Linz - Austria: Springer-Verlag Berlin Heidelberg.

Macintosh, A., \& Whyte, A. (2008). Towards an evaluation framework for eParticipation. Transforming Government: People, Process and Policy, 2(1), 16-30. http://doi.org/10.1108/17506160810862928 
Mackenzie, S. B., Podsakoff, P. M., \& Podsakoff, N. P. (2011). Construct measurement and validation procedures in MIS and behavioral research: Integrating new and existing techniques. MIS Quarterly, 35(2), 293-334.

Magalhães, P. (2005). Disaffected democrats: Political attitudes and political action in Portugal. West European Politics, 28(5), 973-991. http://doi.org/10.1080/01402380500310626

Mahmoudi Farahani, L. (2016). The Value of the Sense of Community and Neighbouring. Housing, Theory and Society, 6096(April), 1-20. http://doi.org/10.1080/14036096.2016.1155480

Manzo, L. C. (2005). For better or worse: Exploring multiple dimensions of place meaning. Journal of Environmental Psychology, 25(1), 67-86. http://doi.org/10.1016/j.jenvp.2005.01.002

Manzo, L. C., \& Perkins, D. D. (2006). Finding Common Ground: The Importance of Place Attachment to Community Participation and Planning. Journal of Planning Literature, 20(4), 335-350. http://doi.org/10.1177/0885412205286160

Martins, C., Oliveira, T., \& Popovič, A. (2014). Understanding the Internet banking adoption: A unified theory of acceptance and use of technology and perceived risk application. International Journal of Information Management, 34(1), 1-13. http://doi.org/http://dx.doi.org/10.1016/j.ijinfomgt.2013.06.002

Martins, J., Gonçalves, R., \& Branco, F. (2017). A full scope web accessibility evaluation procedure proposal based on Iberian eHealth accessibility compliance. Computers in Human Behavior, 71, 676-684. http://doi.org/10.1016/j.chb.2016.12.010

Massey, D. (1991). A Global Sense of Place. Marxism Today, 35, 315-323. http://doi.org/10.1016/j.pecs.2007.10.001

Massey, D. (1994). Space, Place, and Gender. Minneapolis: University of Minnesota Press. http://doi.org/10.1049/el:19990302

Matheus, R., Ribeiro, M. M., Vaz, J. C., \& Souza, C. A. de. (2010). Case studies of digital participatory budgeting in Latin America - models for citizen engagement. In ICEGOV'10 4th International Conference on Theory and Practice of Electronic Governance (pp. 3136). http://doi.org/10.1145/1930321.1930328

Medaglia, R. (2012). eParticipation research: Moving characterization forward (2006-2011). 
Government Information Quarterly, 29(3), 346-360.

http://doi.org/10.1016/j.giq.2012.02.010

Mesch, G. S., \& Manor, O. (1998). Social Ties, Environmental Perception, And Local

Attachment. Environment and Behavior, 30(4), 504-519.

http://doi.org/10.1177/001391659803000405

Mesch, G. S., \& Talmud, I. (2010). Internet Connectivity, Community Participation, and Place Attachment: A Longitudinal Study. American Behavioral Scientist, 53(8), 1095-1110. http://doi.org/10.1177/0002764209356243

Miguel, C. M., Ornelas, H. J., \& Maroco, P. J. (2015). Defining Psychological Empowerment Construct: Analysis of three empowerment scales. Journal of Community Psychology, 43, 900-919.

Miltgen, C. L., Popovič, A., \& Oliveira, T. (2013). Determinants of end-user acceptance of biometrics: Integrating the "big 3" of technology acceptance with privacy context. Decision Support Systems, 56(1), 103-114. http://doi.org/10.1016/j.dss.2013.05.010

Miori, V., \& Russo, D. (2011). Integrating online and traditional involvement in participatory budgeting. Electronic Journal of E-Government, 9(1), 41-57.

Mkude, C. G., Pérez-Espés, C., \& Wimmer, M. A. (2014). Participatory budgeting: A framework to analyze the value-add of citizen participation. In Proceedings of the 47th Hawaii International Conference on System Sciences (pp. 2054-2062). http://doi.org/10.1109/HICSS.2014.260

Mohammadi, S. H., Norazizan, S., \& Shahvandi, A. R. (2011). Civic Engagement, Citizen Participation and Quality of Governance in Iran. Journal of Human Ecology, 36(3), 211216.

Montello, D. R., Goodchild, M. F., Gottsegen, J., \& Fohl, P. (2003). Where's downtown?: Behavioral methods for determining referents of vague spatial queries. Spatial Cognition and Computation, 3(2-3), 185-204. http://doi.org/10.1080/13875868.2003.9683761

Moores, T. T., \& Chang, J. C.-J. (2006). Ethical decision making in software piracy: Initial development and test of a four-component model. MIS Quarterly, 30(1), 167-180. http://doi.org/10.2307/4132321

Moro, G. (2010). Civic Action Key Issues. International Encyclopedia of Civil Society, 1-9. 
Mossberger, K., Wu, Y., \& Crawford, J. (2013). Connecting citizens and local governments? Social media and interactivity in major U.S. cities. Government Information Quarterly, 30(4), 351-358. http://doi.org/10.1016/j.giq.2013.05.016

Mou, Y., Atkin, D., Fu, H., Lin, C. A., \& Lau, T. Y. (2013). The influence of online forum and SNS use on online political discussion in China: Assessing "spirals of trust." Telematics and Informatics, 359-369. http://doi.org/10.1016/j.tele.2013.04.002

Murdoch, J. (1998). The spaces of actor-network theory. Geoforum, 29(4), 357-374. http://doi.org/10.1016/S0016-7185(98)00011-6

Naranjo Zolotov, M., Oliveira, T., \& Casteleyn, S. (2018). E-participation adoption models research in the last 17 years: A weight and meta-analytical review. Computers in Human Behavior, 81, 350-365. http://doi.org/10.1016/j.chb.2017.12.031

negocios.pt. (2017). 118 Orçamentos Participativos colocam Portugal no topo da Europa. Retrieved September 15, 2017, from http://www.jornaldenegocios.pt/economia/autarquias/detalhe/118-orcamentosparticipativos-colocam-portugal-no-topo-da-europa

Newbrough, J. R., \& Chavis, D. M. (1986). Psychological sense of community, I: Foreword. Journal of Community Psychology, 14(1), 6-23. http://doi.org/10.1002/15206629(198601)14:1<3::AID-JCOP2290140102>3.0.CO;2-U

Newman, G., Chandler, M., Clyde, M., McGreavy, B., Haklay, M., Ballard, H., ... Gallo, J. (2016). Leveraging the power of place in citizen science for effective conservation decision making. Biological Conservation, (August). http://doi.org/10.1016/j.biocon.2016.07.019

Oghuma, A. P., Libaque-Saenz, C. F., Wong, S. F., \& Chang, Y. (2016). An expectationconfirmation model of continuance intention to use mobile instant messaging. Telematics and Informatics, 33(1), 34-47. http://doi.org/10.1016/j.tele.2015.05.006

Oh, J.-C., \& Yoon, S.-J. (2014). Predicting the use of online information services based on a modified UTAUT model. Behaviour \& Information Technology, 33(7), 716-729. http://doi.org/10.1080/0144929X.2013.872187

Oliveira, G. H. M., \& Welch, E. W. (2013). Social media use in local government: Linkage of technology, task, and organizational context. Government Information Quarterly, 30(4), 397-405. http://doi.org/10.1016/j.giq.2013.05.019 
Oliveira, T., Faria, M., Thomas, M. A., \& Popovič, A. (2014). Extending the understanding of mobile banking adoption: When UTAUT meets TTF and ITM. International Journal of Information Management, 34(5), 689-703.

http://doi.org/10.1016/j.jijinfomgt.2014.06.004

Oliveira, T., Thomas, M., Baptista, G., \& Campos, F. (2016). Mobile payment: Understanding the determinants of customer adoption and intention to recommend the technology. Computers in Human Behavior, 61, 404-414. http://doi.org/10.1016/j.chb.2016.03.030

Omar, A., Weerakkody, V., \& Sivarajah, U. (2017). Developing criteria for evaluating a multichannel digitally enabled participatory budgeting platform. In International Conference on Electronic Participation (Vol. 7444, pp. 3-11). Springer. http://doi.org/10.1007/978-3642-33250-0

Ong, C.-S., \& Lin, M. Y.-C. (2016). Is being satisfied enough? Well-being and IT post-adoption behavior: An empirical study of Facebook. Information Development, 32(4), 1042-1054. http://doi.org/10.1177/0266666915587032

Oni, A. A., Oni, S., Mbarika, V., \& Ayo, C. K. (2017). Empirical study of user acceptance of online political participation: Integrating civic voluntarism model and theory of reasoned action. Government Information Quarterly, (1). http://doi.org/10.1016/j.giq.2017.02.003

Orlikowski, W., \& Baroudi, J. J. (1991). Studying information technology in organizations: Research approaches and assumptions. Information Systems Research, 2(1), 1-28. http://doi.org/10.1287/isre.2.1.1

Pain, R., \& Kindon, S. (2007). Participatory geographies. Environment and Planning A, 39(12), 2807-2812. http://doi.org/10.1068/a39347

Panopoulou, E., Tambouris, E., \& Tarabanis, K. (2014). Success factors in designing eParticipation initiatives. Information and Organization, 24(4), 195-213. http://doi.org/10.1016/j.infoandorg.2014.08.001

Park, M. J., Choi, H., \& Rho, J. J. (2014). Citizen patronage behavior of government social media services: Extended perspective of perceived value with the moderating effect of media synchronicity. Information Development. http://doi.org/10.1177/0266666914543959

Peixoto, T. (2009). Beyond theory : e-Participatory budgeting and its promises for eParticipation. European Journal of EPractice, 7(March), 1-9. 
Pereira, G. V., Cunha, M. A., Lampoltshammer, T. J., Parycek, P., \& Testa, M. G. (2017). Increasing collaboration and participation in smart city governance: a cross-case analysis of smart city initiatives. Information Technology for Development. http://doi.org/10.1080/02681102.2017.1353946

Perkins, D. D., Brown, B. B., \& Taylor, R. B. (1996). The ecology of empowerment: Predicting participation in community organizations. Journal of Social Issues, 52, 85-110. http://doi.org/10.1111/j.1540-4560.1996.tb01363.x

Perkins, D. D., Hughey, J., \& Speer, P. W. (2002). Community psychology perspectives on social capital theory and community development practice. Journal of the Community Development Society, 33(1), 33-52. http://doi.org/10.1080/15575330209490141

Perkins, D. D., \& Long, D. A. (2002). Neighborhood sense of community and social capital: A multi-level analysis. In A. Fischer, C. Sonn, \& B. Bishop (Eds.), Psychological sense of community: Research, applications and implications (pp. 291-318). New York: Plenum Press.

Persaud, A., \& Persaud, P. (2013). Rethinking E-Government Adoption: A user-focussed model abstract. International Journal of Electronic Government Research, 9(4), 56-74. http://doi.org/10.4018/ijegr.2013100104

Peterson, N. A. (2014). Empowerment Theory: Clarifying the Nature of Higher-Order Multidimensional Constructs. American Journal of Community Psychology, 53(1-2), 96108. http://doi.org/10.1007/s10464-013-9624-0

Peterson, N. A., Speer, P. W., \& McMillan, D. W. (2008). Validation of a brief sense of community scale: Confirmation of the principal theory of sense of community. Journal of Community Psychology, 36(1), 61-73. http://doi.org/10.1002/jcop.20217

Petrovsky, N., Mok, J. Y., \& León-Cázares, F. (2017). Citizen expectations and satisfaction in a young democracy: A test of the expectancy-disconfirmation model. Public Administration Review, 77(3), 395-407. http://doi.org/10.1111/puar.12623

Phang, C. W., \& Kankanhalli, A. (2006). Engaging youths via e-participation initiatives: An investigation into the context of online policy discussion forums. In Social inclusion: societal and organizational implications for information systems (Vol. 208, pp. 105-121). http://doi.org/10.1007/0-387-34588-4

Phang, C. W., \& Kankanhalli, A. (2008). A framework of ICT exploitation for e-participation 
initiatives. Communications of the ACM, 51(12), 128-132.

http://doi.org/10.1145/1409360.1409385

Piehler, R., Wirtz, B. W., \& Daiser, P. (2016). An analysis of continuity intentions of eGovernment portal users. Public Management Review, 18(2), 163-198. http://doi.org/10.1080/14719037.2014.965270

Pile, S. (2010). Emotions and effect in recent human geography. Transactions of the Institute of British Geographers, 35(1), 5-20. http://doi.org/10.1111/j.1475-5661.2009.00368.x

Porumbescu, G. A. (2016). Linking public sector social media and e-government website use to trust in government. Government Information Quarterly, 33(2), 291-304. http://doi.org/10.1016/j.giq.2016.04.006

Pretty, G. H., Chipuer, H. M., \& Bramston, P. (2003). Sense of place amongst adolescents and adults in two rural Australian towns: The discriminating features of place attachment, sense of community and place dependence in relation to place identity. Journal of Environmental Psychology, 23(3), 273-287. http://doi.org/10.1016/S02724944(02)00079-8

Proshansky, H. M., Fabian, A. K., \& Kaminoff, R. (1983). Place-identity: Physical world socialization of the self. Journal of Environmental Psychology, 3(1), 57-83. http://doi.org/10.1016/S0272-4944(83)80021-8

Putnam, R. D. (2000). Bowling alone: The collapse and revival of American community (Vol. 747). New York, USA: Simon and Schuster.

Rabaa'i, A. A. (2015). An empirical investigation on the adoption of e-Government in developing countries: The case of Jordan. Computer and Information Science, 8(3), 83102. http://doi.org/10.5539/cis.v8n3p83

Radcliffe, S. A. (2004). Geography of development: development, civil society and inequality social capital is (almost) dead? Progress in Human Geography, 28(4), 517-527. http://doi.org/10.1191/0309132504ph500pr

Rana, N. P., \& Dwivedi, Y. K. (2015). Citizen's adoption of an e-government system: Validating extended social cognitive theory (SCT). Government Information Quarterly, 32(2), 172181. http://doi.org/10.1016/j.giq.2015.02.002

Rana, N. P., Dwivedi, Y. K., \& Williams, M. D. (2015). A meta-analysis of existing research on 
citizen adoption of e-government. Information Systems Frontiers, 17(3), 547-563. http://doi.org/10.1007/s10796-013-9431-z

Rana, N. P., Dwivedi, Y. K., Williams, M. D., \& Weerakkody, V. (2016). Adoption of online public grievance redressal system in India: Toward developing a unified view. Computers in Human Behavior, 59, 265-282. http://doi.org/10.1016/j.chb.2016.02.019

Rappaport, J. (1987). Terms of empowerment/exemplars of prevention: toward a theory for community psychology. American Journal of Community Psychology, 15(2), 121-148. http://doi.org/10.1007/BF00919275

Raymond, C. M., Brown, G., \& Weber, D. (2010). The measurement of place attachment: Personal, community, and environmental connections. Journal of Environmental Psychology, 30(4), 422-434. http://doi.org/10.1016/j.jenvp.2010.08.002

Rehman, M., Esichaikul, V., \& Kamal, M. (2012). Factors influencing e-government adoption in Pakistan. Transforming Government: People, Process and Policy, 6(3), 258-282. http://doi.org/10.1108/17506161211251263

Ringle, C. M. (2012). A Critical Look at the Use of PLS-SEM in MIS Quarterly. MIS Quarterly, 36(1), iii-xiv.

Ringle, C. M., Wende, S., \& Becker, J.-M. (2015). SmartPLS 3. Bönningstedt: SmartPLS. Retrieved from http://www.smartpls.com

Roche, S. (2016). Geographic information science II. Progress in Human Geography, 40(4), 565573. http://doi.org/10.1177/0309132515586296

Rodrigues, G., Sarabdeen, J., \& Balasubramanian, S. (2016). Factors that influence consumer adoption of e-government services in the UAE: A UTAUT model perspective. Journal of Internet Commerce, 15(1), 18-39. http://doi.org/10.1080/15332861.2015.1121460

Rodríguez Bolívar, M. P., Alcaide Muñoz, L., \& López Hernández, A. M. (2016). Scientometric Study of the Progress and Development of e-Government Research During the Period 2000-2012. Information Technology for Development, 1102 (June 2015), 1-39. http://doi.org/10.1080/02681102.2014.927340

Rokhman, A. (2011). E-government adoption in developing countries; the case of Indonesia. Journal of Emerging Trends in Computing and Information Sciences, 2(5), 228-236.

Rosenberg, M. J. (1960). Cognitive, affective, and behavioral components of attitudes. Attitude 
Organization and Change.

Royo, S., \& Yetano, A. (2015). "Crowdsourcing" as a tool for e-participation: two experiences regarding $\mathrm{CO} 2$ emissions at municipal level. Electronic Commerce Research, 15(3), 323348. http://doi.org/10.1007/s10660-015-9183-6

Rutten, R., Westlund, H., \& Boekema, F. (2010). The Spatial Dimension of Social Capital. European Planning Studies, 18(6), 863-871. http://doi.org/10.1080/09654311003701381

Rydin, Y., \& Pennington, M. (2011). Public Participation and Local Environmental Planning : The collective action problem and the potential of social capital. Local Environment: The International Journal of Justice and Sustainability, 5(2), 153-169. http://doi.org/10.1080/13549830050009328

Sæbø, Ø., Rose, J., \& Skiftenes Flak, L. (2008). The shape of eParticipation: Characterizing an emerging research area. Government Information Quarterly, 25(3), 400-428. http://doi.org/10.1016/j.giq.2007.04.007

Sanford, C., \& Rose, J. (2007). Characterizing eParticipation. International Journal of Information Management, 27(6), 406-421. http://doi.org/10.1016/j.jijinfomgt.2007.08.002

Schaupp, L. C., \& Carter, L. (2005). E-voting: From apathy to adoption. Journal of Enterprise Information Management, 18(5), 586-601. http://doi.org/10.1108/17410390510624025

Schaupp, L. C., Carter, L., \& McBride, M. E. (2010). E-file adoption: A study of U.S. taxpayers' intentions. Computers in Human Behavior, 26(4), 636-644. http://doi.org/10.1016/j.chb.2009.12.017

Schmidthuber, L., Hilgers, D., \& Gegenhuber, T. (2017). Shedding light on participation in open government arenas : Determinants of platform activity of web and app users. In Proceedings of the 50th Hawaii International Conference on System Sciences / 2017 (pp. 2761-2770).

Seo, D., \& Bernsen, M. (2016). Comparing attitudes toward e-government of non-users versus users in a rural and urban municipality. Government Information Quarterly. http://doi.org/10.1016/j.giq.2016.02.002

Shareef, M. A., Kumar, V., Kumar, U., \& Dwivedi, Y. K. (2011). E-Government Adoption Model (GAM): Differing service maturity levels. Government Information Quarterly, 28(1), 17- 
35. http://doi.org/10.1016/j.giq.2010.05.006

Sharma, S. (1996). Applied multivariate techniques. New York, New York, USA: John Wiley \& Sons, Inc.

Sheedy, A., Mackinnon, P., Pitre, S., \& Watling, J. (2008). Handbook on Citizen Engagement : Beyond Consultation. Canadian Policy Research Networks, (March), 59.

Shin, D.-H. (2010). The effects of trust, security and privacy in social networking: A securitybased approach to understand the pattern of adoption. Interacting with Computers, 22(5), 428-438. http://doi.org/10.1016/j.intcom.2010.05.001

Shin, D.-H., Lee, S., \& Hwang, Y. (2017). How do credibility and utility play in the user experience of health informatics services? Computers in Human Behavior, 67, 292-302. http://doi.org/10.1016/j.chb.2016.11.007

Shyu, S. H.-P., \& Huang, J.-H. (2011). Elucidating usage of e-government learning: A perspective of the extended technology acceptance model. Government Information Quarterly, 28(4), 491-502. http://doi.org/10.1016/j.giq.2011.04.002

Sintomer, Y., Herzberg, C., Allegretti, G., \& Röcke, A. (2010). Learning from the South: Participatory budgeting worldwide - an invitation to global cooperation. Bonn: InWEnt gGmbH - Capacity Building International, Germany/ Service Agency Communities in One World.

Sintomer, Y., Herzberg, C., Allegretti, G., Röcke, A., \& Alves, M. (2013). Participatory budgeting worldwide - Updated version. Bonn: GLOBAL CIVIC ENGAGEMENT - Service for Development Initiatives.

Sintomer, Y., Herzberg, C., \& Röcke, A. (2008). Participatory budgeting in Europe: Potentials and challenges. International Journal of Urban and Regional Research, 32(1), 164-178. http://doi.org/10.1111/j.1468-2427.2008.00777.x

Sjoberg, F. M., Mellon, J., \& Peixoto, T. (2017). The Effect of Bureaucratic Responsiveness on Citizen Participation. Public Administration Review, 77(3), 340-351. http://doi.org/10.1111/puar.12697

Son, J., \& Lin, N. (2008). Social capital and civic action: A network-based approach. Social Science Research, 37(1), 330-349. http://doi.org/10.1016/j.ssresearch.2006.12.004

Spreitzer, G. (1995). Psychological Empowerment in the Workplace: Dimensions, 
Measurement, and Validation. Academy of Management Journal, 38(5), 1442-1465.

Stedman, R. C. (2002). Toward a social psychology of place: Predicting behavior from placebased congnitions, attitude, and identity. Environment and Behavior, 34(5), 561-581. http://doi.org/10.1177/0013916502034005001

Stedman, R. C. (2003). Is It Really Just a Social Construction?: The Contribution of the Physical Environment to Sense of Place. Society \& Natural Resources, 16(8), 671-685. http://doi.org/10.1080/08941920309189

Sterne, J. A. C., Gavaghan, D., \& Egger, M. (2000). Publication and related bias in meta-analysis: Power of statistical tests and prevalence in the literature. Journal of Clinical Epidemiology, 53(11), 1119-1129. http://doi.org/10.1016/S0895-4356(00)00242-0

Sterne, J. A. C., Sutton, A. J., loannidis, J. P. A., Terrin, N., Jones, D. R., Lau, J., ... Higgins, J. P. T. (2011). Recommendations for examining and interpreting funnel plot asymmetry in meta-analyses of randomised controlled trials. BMJ (Clinical Research Ed.), 343(d4002), 1-8. http://doi.org/10.1136/bmj.d4002

Styvén, M., \& Wallström, Å. (2011). "IT's complicated": Influence of perceived sacrifice and trust on eService adoption. In International Conference on Electronic Government (pp. 112-121). Springer Berlin Heidelberg.

Sui, D., \& Delyser, D. (2012). Crossing the qualitative-quantitative chasm I: Hybrid geographies, the spatial turn, and volunteered geographic information (VGI). Progress in Human Geography, 36(1), 111-124. http://doi.org/10.1177/0309132510392164

Šumak, B., Heričko, M., \& Pušnik, M. (2011). A meta-analysis of e-learning technology acceptance: The role of user types and e-learning technology types. Computers in Human Behavior, 27(6), 2067-2077. http://doi.org/10.1016/j.chb.2011.08.005

Sun, H. (2013). A longitudinal study of herd behavior in the adoption and continued use of technology. MIS Quarterly, 37(4), 1013-1041.

Susanto, A., Chang, Y., \& Ha, Y. (2016). Determinants of continuance intention to use the smartphone banking services. Industrial Management \& Data Systems, 116(3), 508-525. http://doi.org/10.1108/IMDS-05-2015-0195

Susha, I., \& Grönlund, Å. (2012). eParticipation research: Systematizing the field. Government Information Quarterly, 29(3), 373-382. http://doi.org/10.1016/j.giq.2011.11.005 
Talò, C., \& Mannarini, T. (2015). Measuring Participation: Development and Validation the Participatory Behaviors Scale. Social Indicators Research, 123(3), 799-816. http://doi.org/10.1007/s11205-014-0761-0

Talò, C., Mannarini, T., \& Rochira, A. (2014). Sense of community and community participation: A meta-analytic review. Social Indicators Research, 117(1), 1-28. http://doi.org/10.1007/s11205-013-0347-2

Tam, C., \& Oliveira, T. (2017). Understanding mobile banking individual performance The DeLone \& McLean model and the moderating effects of individual culture. Internet Research, 27(3), 538-562. http://doi.org/10.1108/IntR-05-2016-0117

Tan, C.-W., Bembasat, I., \& Cenfetelli, R. T. (2008). Building citizen trust towards e-government services: Do high quality websites matter? In 41st Hawaii International Conference on System Sciences (p. 217). IEEE.

Tang, H. L., Chung, S. H., \& Se, C. W. (2009). Examining the impact of possible antecedents on service usage: An empirical study on Macao e-government. Electronic Government, an International Journal, 6(1), 97. http://doi.org/10.1504/EG.2009.022595

Tarhini, A., El-Masri, M., Ali, M., \& Serrano, A. (2016). Extending the UTAUT model to understand the customers' acceptance and use of internet banking in Lebanon. Information Technology \& People, 29(4), 830-849. http://doi.org/10.1108/ITP-02-20140034

Teo, T. S. H., Srivastava, S. C., \& Jiang, L. (2009). Trust and electronic government success: An empirical study. Journal of Management Information Systems, 25(3), 99-132. http://doi.org/10.2753/MIS0742-1222250303

Terrin, N., Schmid, C. H., \& Lau, J. (2005). In an empirical evaluation of the funnel plot, researchers could not visually identify publication bias. Journal of Clinical Epidemiology, 58(9), 894-901. http://doi.org/10.1016/j.jclinepi.2005.01.006

The World Bank. (2007). Participatory Budgeting. Public Sector Governance and Accountability Series. The World Bank. http://doi.org/10.1596/978-0-8213-6923-4

Thomas, K. W., \& Velthouse, B. A. (1990). Cognitive Elements of Empowerment: An "Interpretive" Model of Intrinsic Task Motivation. The Academy of Management Review, 15(4), 666. http://doi.org/10.2307/258687 
Thrift, N. (2008). Non-representational theory: Space, politics, affect. (J. Urry, Ed.). Routledge.

Tojib, D., \& Tsarenko, Y. (2012). Post-adoption modeling of advanced mobile service use. Journal of Business Research, 65(7), 922-928. http://doi.org/10.1016/j.jbusres.2011.05.006

Torcal, M. (2014). The Decline of Political Trust in Spain and Portugal: Economic Performance or Political Responsiveness? American Behavioral Scientist, 58(12), 1542-1567. http://doi.org/10.1177/0002764214534662

Torgerson, C. J. (2006). Publication bias: The achilles' heel of systematic reviews? British Journal of Educational Studies, 54(1), 89-102. http://doi.org/10.1111/j.14678527.2006.00332.x

Trentelman, C. K. (2009). Place Attachment and Community Attachment: A Primer Grounded in the Lived Experience of a Community Sociologist. Society \& Natural Resources, 22(3), 191-210. http://doi.org/10.1080/08941920802191712

Tsai, M.-T., Cheng, N.-C., \& Chen, K.-S. (2011). Understanding online group buying intention: the roles of sense of virtual community and technology acceptance factors. Total Quality Management \& Business Excellence, 22(10), 1091-1104.

http://doi.org/10.1080/14783363.2011.614870

Tsai, Y.-H., Joe, S.-W., Lin, C.-P., Wang, R.-T., \& Chang, Y.-H. (2012). Modeling the relationship between IT-mediated social capital and social support: Key mediating mechanisms of sense of group. Technological Forecasting \& Social Change, 79(9), 1592-1604. http://doi.org/10.1016/j.techfore.2012.05.013

Tuan, Y.-F. (1978). Space and Place: The Perspective of Experience. Contemporary Sociology (Vol. 7). Minneapolis, MN, USA: University of Minnesota Press. http://doi.org/10.2307/2064418

UNDP Evaluation Office. (2002). Civic Engagement, Essentials No. 8.

United Nations. (2010). E-Government Survey 2010 Leveraging e-government at a time of financial and economic crisis. New York, New York, USA.

United Nations. (2012). E-Government Survey 2012 E-government for the People.

United Nations. (2014). E-government survey 2014 E-government for the future we want. New York, New York, USA. 
United Nations. (2016). E-government survey 2016 E-government in support of sustainable development. New York, New York, USA.

United Nations. (2018). E-Government Survey 2018 Gearing e-government to support transformation towards sustainable and resililent societies. New York.

van der Meer, T., \& Hakhverdian, A. (2017). Political trust as the evaluation of process and performance: A cross-national study of 42 European countries. Political Studies, 65(1), 81-102. http://doi.org/10.1177/0032321715607514

van Deursen, A. J. A. M., \& van Dijk, J. A. G. M. (2009). Improving digital skills for the use of online public information and services. Government Information Quarterly, 26(2), 333340. http://doi.org/10.1016/j.giq.2008.11.002

Van Dijk, J. A. G. ., Peters, O., \& Ebbers, W. (2008). Explaining the acceptance and use of government internet services: A multivariate analysis of 2006 survey data in the Netherlands. Government Information Quarterly, 25(3), 379-399. http://doi.org/10.1016/j.giq.2007.09.006

Van Rhee, H. J., Suurmond, R., \& Hak, T. (2015). User manual for meta-essentials: Workbooks for meta-analysis. Rotterdam, The Netherlands: Erasmus Research Institute of Management. Retrieved from www.erim.eur.nl/research-support/meta-essentials

Van Ryzin, G. G. (2005). Testing the expectancy disconfirmation model of citizen satisfaction with local government. Journal of Public Administration Research and Theory, 16(4), 599611. http://doi.org/10.1093/jopart/mui058

Van Ryzin, G. G. (2007). Pieces of a puzzle: Linking government performance, citizen satisfaction, and trust. Public Performance \& Management Review, 30(4), 521-535. http://doi.org/10.2753/PMR1530-9576300403

Van Ryzin, G. G. (2013). An experimental test of the expectancy-disconfirmation theory of citizen satisfaction. Journal of Policy Analysis and Management, 32(3), 597-614. http://doi.org/10.1002/pam.21702

van Zomeren, M., Postmes, T., \& Spears, R. (2008). Toward an integrative social identity model of collective action: A quantitative research synthesis of three socio-psychological perspectives. Psychological Bulletin, 134(4), 504-535. http://doi.org/10.1037/00332909.134.4.504 
Veeramootoo, N., Nunkoo, R., \& Dwivedi, Y. K. (2018). What determines success of an egovernment service? Validation of an integrative model of e-filing continuance usage. Government Information Quarterly, 35(2), 161-174. http://doi.org/10.1016/j.giq.2018.03.004

Venkatesh, V., Brown, S. A., Maruping, L. M., \& Bala, H. (2008). Predicting different conceptualizations of system use: The competing roles of behavioral intention, facilitating conditions, and behavioral expectation. MIS Quarterly, 32(3), 483-502.

Venkatesh, V., Morris, M. G., \& Ackerman, P. L. (2000). A Longitudinal field investigation of gender differences in individual technology adoption decision-making processes. Organizational Behavior and Human Decision Processes, 83(1), 33-60. http://doi.org/10.1006/obhd.2000.2896

Venkatesh, V., Morris, M. G., Davis, G. B., \& Davis, F. D. (2003). User acceptance of information technology: Toward a unified view. MIS Quarterly, 27(3), 425-478. http://doi.org/10.2307/30036540

Venkatesh, V., Thong, J., \& Xu, X. (2012). Consumer acceptance and use of information technology: Extending the unified theory of acceptance and use of technology. MIS Quarterly, 36(1), 157-178.

Venkatesh, V., Thong, J. Y. L., Chan, F. K. Y., Hu, P. J.-H., \& Brown, S. A. (2011). Extending the two-stage information systems continuance model: incorporating UTAUT predictors and the role of context. Information Systems Journal, 21(6), 527-555. http://doi.org/10.1111/j.1365-2575.2011.00373.x

Venkatesh, V., Thong, J. Y. L., Chan, F. K. Y., \& Hu, P. J. H. (2016). Managing citizens' uncertainty in e-government services: The mediating and moderating roles of transparency and trust. Information Systems Research, 27(1), 87-111. http://doi.org/10.1287/isre.2015.0612

Verplanken, B. (2006). Beyond frequency: Habit as mental construct. British Journal of Social Psychology, 45(3), 639-656. http://doi.org/10.1348/014466605X49122

Vicente, M. R., \& Novo, A. (2014). An empirical analysis of e-participation. The role of social networks and e-government over citizens' online engagement. Government Information Quarterly, 31(3), 379-387. http://doi.org/10.1016/j.giq.2013.12.006

Vlachos, P. A., Tsamakos, A., Vrechopoulos, A. P., \& Avramidis, P. K. (2009). Corporate social responsibility: Attributions, loyalty, and the mediating role of trust. Journal of the 
Academy of Marketing Science, 37(2), 170-180. http://doi.org/10.1007/s11747-0080117-x

Vragov, R., \& Kumar, N. (2013). The impact of information and communication technologies on the costs of democracy. Electronic Commerce Research and Applications, 12(6), 440-448. http://doi.org/10.1016/j.elerap.2013.06.003

Wang, H.-J., \& Lo, J. (2012). Determinants of citizens' intent to use government websites in Taiwan. Information Development, 29(2), 123-137. http://doi.org/10.1177/0266666912453835

Wang, M. C., \& Bushman, B. J. (1998). Using the normal quantile plot to explore meta-analytic data sets. Psychological Methods, 3(1), 46-54. http://doi.org/10.1037/1082-989X.3.1.46

Wang, Y.-S., \& Shih, Y.-W. (2009). Why do people use information kiosks? A validation of the unified theory of acceptance and use of technology. Government Information Quarterly, 26(1), 158-165. http://doi.org/10.1016/j.giq.2008.07.001

Wang, Y., \& Liao, Y. (2008). Assessing eGovernment systems success: A validation of the DeLone and McLean model of information systems success. Government Information Quarterly, 25(4), 717-733. http://doi.org/10.1016/j.giq.2007.06.002

Wangpipatwong, S., Chutimaskul, W., \& Papasratorn, B. (2008). Understanding citizen's continuance intention to use e-government website: A composite view of technology acceptance model and computer self-efficacy. The Electronic Journal of E-Government, $6(1), 55-64$.

Webster, J., \& Watson, R. T. (2002). Analyzing the past to prepare for the future: Writing a review. MIS Quarterly, 26(2), xiii-xxiii.

Welch, E. W. (2012). The rise of participative technologies in government. In Transformational government through eGov practice: Socio-economic, cultural, and technological issues (pp. 347-367). Bingley, United Kingdom: Emerald Group Publishing Limited.

Welch, E. W., Hinnant, C. C., \& Moon, M. J. (2005). Linking Citizen Satisfaction with EGovernment and Trust in Government. Journal of Public Administration Research and Theory, 15(3), 371-391. http://doi.org/10.1093/jopart/mui021

Westlund, H., \& Adam, F. (2010). Social Capital and Economic Performance: A Meta-analysis of 65 Studies. European Planning Studies, 18(6), 893-919. 
http://doi.org/10.1080/09654311003701431

Westlund, H., Rutten, R., \& Boekema, F. (2010). Social Capital, Distance, Borders and Levels of Space: Conclusions and Further Issues. European Planning Studies, 18(6), 965-970. http://doi.org/10.1080/09654311003701506

White Baker, E., Al-Gahtani, S. S., \& Geoffrey S. Hubona. (2007). The effects of gender and age on new technology implementation in a developing country: Testing the theory of planned behavior (TPB). Information Technology \& People, 20(4), 352-375. http://doi.org/10.1108/09593841111182250

Winkler, T. J., Hirsch, H., Trouvilliez, G., \& Günther, O. (2012). Participatory urban sensing: Citizens' acceptance of a mobile reporting service. In European Conference on Information Systems (p. 106).

Wood, J. A. (2007). Methodology for dealing with duplicate study effects in a meta-analysis. Organizational Research Methods, 11(1), 79-95. http://doi.org/10.1177/1094428106296638

Yang, X., Li, Y., Tan, C.-H., \& Teo, H. H. (2007). Students' participation intention in an online discussion forum: Why is computer-mediated interaction attractive? Information \& Management, 44(5), 456-466. http://doi.org/10.1016/j.im.2007.04.003

Yao, Y., \& Murphy, L. (2007). Remote electronic voting systems: An exploration of voters' perceptions and intention to use. European Journal of Information Systems, 16(2), 106120. http://doi.org/10.1057/palgrave.ejis.3000672

Zhang, L., Zhu, J., \& Liu, Q. (2012). A meta-analysis of mobile commerce adoption and the moderating effect of culture. Computers in Human Behavior, 28(5), 1902-1911. http://doi.org/10.1016/j.chb.2012.05.008

Zhang, X., \& Venkatesh, V. (2017). A nomological network of knowledge management system use: Antecedents and consequences. MIS Quarterly, 41(4), 1275-1306.

Zhao, L., Lu, Y., Wang, B., Chau, P. Y. K., \& Zhang, L. (2012). Cultivating the sense of belonging and motivating user participation in virtual communities: A social capital perspective. International Journal of Information Management, 32(6), 574-588. http://doi.org/10.1016/j.ijinfomgt.2012.02.006

Ziggers, G. W., \& Henseler, J. (2016). The reinforcing effect of a firm's customer orientation 
and supply-base orientation on performance. Industrial Marketing Management, 52, 1826. http://doi.org/10.1016/j.indmarman.2015.07.011

Zimmerman, M. A. (1995). Psychological empowerment: issues and illustrations. American Journal of Community Psychology, 23(5), 581-599. http://doi.org/10.1007/BF02506983

Zimmerman, M. A., \& Rappaport, J. (1988). Citizen participation, perceived control, and psychological empowerment. American Journal of Community Psychology, 16(5), 725750.

Zlatareva, M. (2008). Promoting Civic Engagement in a Post- Totalitarian and EU Accession Context : A Case from Bulgaria. United Nations Development Program Oslo Governance Centre The Democratic Governance Fellowship Program.

Zuiderwijk, A., Janssen, M., \& Dwivedi, Y. K. (2015). Acceptance and use predictors of open data technologies: Drawing upon the unified theory of acceptance and use of technology. Government Information Quarterly, 32(4), 429-440.

http://doi.org/10.1016/j.giq.2015.09.005 


\section{Appendix}

Appendix 2.1. Merging variables

\begin{tabular}{|c|c|c|}
\hline Study & Original Variable Name & $\begin{array}{l}\text { Merged/Modified } \\
\text { Variable Name }\end{array}$ \\
\hline (Van Dijk et al., 2008) & Attitude towards use & \multirow{4}{*}{ Attitude } \\
\hline (Chiang, 2009) & Attitude towards using e-voting system & \\
\hline (Lin et al., 2011) & Attitude Towards Using & \\
\hline (Oni et al., 2017) & Attitude towards e-democracy & \\
\hline (Wangpipatwong et al., 2008) & Continuance Intention & \multirow{3}{*}{$\begin{array}{l}\text { Intention to continue } \\
\text { using }\end{array}$} \\
\hline (Tan et al., 2008) & Continuance usage intentions & \\
\hline (Piehler et al., 2016) & Continuance Intention & \\
\hline (Yang et al., 2007) & Intention towards Participation & \multirow{2}{*}{ Intention to participate } \\
\hline (Yao \& Murphy, 2007) & Participation Intention & \\
\hline (Tang et al., 2009) & Intention of usage & \multirow{15}{*}{ Intention to use } \\
\hline (Persaud \& Persaud, 2013) & Usage intentions e-government & \\
\hline (Alrashedi et al., 2015) & e-Participation Intention & \\
\hline (Choi \& Kim, 2012) & User Intention & \\
\hline (Lee et al., 2003) & Intention to use online function & \\
\hline (Wang \& Shih, 2009) & \multirow{6}{*}{ Behavioural Intention } & \\
\hline (Kollmann \& Kayser, 2010) & & \\
\hline (Shyu \& Huang, 2011) & & \\
\hline (Al-Sobhi et al., 2011) & & \\
\hline (Zuiderwijk et al., 2015) & & \\
\hline (Rana \& Dwivedi, 2015) & & \\
\hline (Lin et al., 2011) & \multirow[t]{2}{*}{ Behaviour Intention } & \\
\hline (Rehman et al., 2012) & & \\
\hline (Rabaa'i, 2015) & \multirow[t]{2}{*}{ Intention to adopt } & \\
\hline (Seo \& Bernsen, 2016) & & \\
\hline (Oni et al., 2017) & Perceived e-democracy outcome & Perceived outcome \\
\hline (Yao \& Murphy, 2007) & \multirow{5}{*}{ Ease of use } & \multirow{5}{*}{ Perceived ease of use } \\
\hline (Chiang, 2009) & & \\
\hline (Rokhman, 2011) & & \\
\hline (Choi \& Kim, 2012) & & \\
\hline (Al-Quraan \& Abu-Shanab, 2015) & & \\
\hline (F. Lin et al., 2011) & Information System Quality * & \multirow{5}{*}{ Perceived quality } \\
\hline (Wang \& Liao, 2008) & \multirow{2}{*}{ System Quality * } & \\
\hline (Teo et al., 2009) & & \\
\hline (Cai Shuqin et al., 2016) & Quality of E-services * & \\
\hline (Alshehri et al., 2012) & Website Quality * & \\
\hline (Choi \& Kim, 2012) & \multicolumn{2}{|l|}{ Usefulness } \\
\hline (Lee et al., 2003) & $\begin{array}{l}\text { Perceived Usefulness of e-Government } \\
\text { services }\end{array}$ & Perceived usefulness \\
\hline (Mou et al., 2013) & Political Internal efficacy & Political efficacy \\
\hline (Wang \& Liao, 2008) & User Satisfaction & \multirow{5}{*}{ Satisfaction } \\
\hline & Satisfaction with e-participation & \\
\hline (Choi \& Kim, 2012) & applications & \\
\hline (Cai Shuqin et al., 2016) & Citizen's Satisfaction & \\
\hline (Teo et al., 2009) & User Satisfaction & \\
\hline (Colesca \& Dobrica, 2008) & Perceived Trust & \multirow{2}{*}{ Trust } \\
\hline (Alharbi et al., 2015) & Trust in E-Participation & \\
\hline
\end{tabular}




\begin{tabular}{|c|c|c|}
\hline (Tan et al., 2008) & Consumer Trust & \\
\hline (Teo et al., 2009) & Trust in E-Government Web Site & \\
\hline (Chiang, 2009) & Trust in e-voting system & \\
\hline (Abu-Shanab, 2014) & Trust in E-Government & \\
\hline (Bélanger \& Carter, 2008) & Trust of the Government & \multirow{5}{*}{ Trust in government } \\
\hline (Lee et al., 2003) & Trust in the Government & \\
\hline (Carter \& Bélanger, 2004) & Trust of Government & \\
\hline (Rehman et al., 2012) & Trust in the government & \\
\hline (Piehler et al., 2016) & Trust in the Local Administration & \\
\hline (Carter \& Bélanger, 2004) & Trust of Internet & \multirow{8}{*}{ Trust in Internet } \\
\hline (Bélanger \& Carter, 2008) & Trust of the Internet & \\
\hline (Carter \& Bélanger, 2012) & Internet Trust & \\
\hline (Styvén \& Wallström, 2011) & \multirow{3}{*}{ Trust in the internet } & \\
\hline (Rehman et al., 2012) & & \\
\hline (Piehler et al., 2016) & & \\
\hline (Al-Sobhi et al., 2011) & Trust of the Internet & \\
\hline (Mou et al., 2013) & Internet Trust & \\
\hline (Oni et al., 2017) & Technological skill & \multirow{2}{*}{ Usage skill } \\
\hline (Carter \& Bélanger, 2012) & E-service usage skills & \\
\hline (Van Dijk et al., 2008) & Actual use & \multirow{9}{*}{ Use } \\
\hline (Kollmann \& Kayser, 2010) & \multirow{4}{*}{ Use Behaviour } & \\
\hline (Wang \& Shih, 2009) & & \\
\hline (Alshehri et al., 2012) & & \\
\hline (Al-Sobhi et al., 2011) & & \\
\hline (Mou et al., 2013) & \multirow[t]{2}{*}{ Online Forum Use } & \\
\hline (Shyu \& Huang, 2011) & & \\
\hline (Oni et al., 2017) & Actual usage & \\
\hline (Schmidthuber et al., 2017) & Platform activity & \\
\hline
\end{tabular}

*All these constructs are derivations from system quality construct from D\&M model (DeLone \& McLean, 1992, 2003), except website quality, which according to its author, includes multiple dimensions of that model. 


\section{Appendix 3.1. Measurement Items and Factor's Loadings}

\begin{tabular}{|c|c|c|c|}
\hline Construct & Item & Loading & Source \\
\hline Performance & I find e-participation useful in my daily life & 0.87 & (Venkatesh et \\
\hline \multirow[t]{2}{*}{ Expectancy } & Using e-participation helps me accomplish things more quickly & 0.88 & al., 2012) \\
\hline & Using e-participation increases my productivity & 0.89 & \\
\hline Effort & Learning how to use e-participation is easy for me & 0.83 & \\
\hline \multirow[t]{3}{*}{ Expectancy } & My interaction with e-participation is clear and understandable & 0.90 & \\
\hline & I find e-participation easy to use & 0.90 & \\
\hline & It is easy for me to become skilful at using e-participation. & 0.90 & \\
\hline \multirow[t]{3}{*}{$\begin{array}{l}\text { Social } \\
\text { Influence }\end{array}$} & $\begin{array}{l}\text { People who are important to me think that I should use e- } \\
\text { participation }\end{array}$ & 0.95 & \\
\hline & $\begin{array}{l}\text { People who influence my behaviour think that I should use e- } \\
\text { participation }\end{array}$ & 0.95 & \\
\hline & People whose opinions that I value prefer that I use e-participation & 0.95 & \\
\hline Facilitating & I have the resources necessary to use e-participation & 0.75 & \\
\hline \multirow[t]{2}{*}{ Conditions } & I have the knowledge necessary to use e-participation & 0.88 & \\
\hline & E-participation is compatible with other technologies I use & 0.90 & \\
\hline \multirow[t]{3}{*}{$\begin{array}{l}\text { Intention to } \\
\text { Use }\end{array}$} & I intend to continue using e-participation in the future & 0.91 & \\
\hline & I will always try to use e-participation in my daily life & 0.92 & \\
\hline & I plan to continue to use e-participation frequently & 0.94 & \\
\hline \multirow[t]{13}{*}{ Empowerment } & Competence & & (Kim \& Gupta, \\
\hline & I have mastered the skills necessary for using the e-participation. & 0.96 & 2014) \\
\hline & I am self-assured about my capabilities to use the e-participation. & 0.97 & \\
\hline & $\begin{array}{l}\text { I am confident about my ability to use the e-participation. } \\
\text { Meaning }\end{array}$ & 0.98 & \\
\hline & The e-participation I use is very important to me. & 0.97 & \\
\hline & The e-participation I use is meaningful to me. & 0.97 & \\
\hline & $\begin{array}{l}\text { My e-participation activities are personally meaningful to me. } \\
\text { Impact }\end{array}$ & 0.96 & \\
\hline & $\begin{array}{l}\text { Based on e-participation usage, my impact on what happens in the } \\
\text { community is large. }\end{array}$ & 0.96 & \\
\hline & $\begin{array}{l}\text { Based on e-participation usage, I have significant influence over what } \\
\text { happens in the community. }\end{array}$ & 0.97 & \\
\hline & $\begin{array}{l}\text { Based on e-participation usage, I have a great deal of control over } \\
\text { what happens in the community. } \\
\text { Self-Determination }\end{array}$ & 0.91 & \\
\hline & $\begin{array}{l}\text { I have significant autonomy in determining how I use the e- } \\
\text { participation }\end{array}$ & 0.96 & \\
\hline & $\begin{array}{l}\text { I have considerable opportunity for independence and freedom in } \\
\text { how I use the e-participation }\end{array}$ & 0.95 & \\
\hline & I can decide on my own how to go about using the e-participation & 0.94 & \\
\hline \multirow{3}{*}{$\begin{array}{l}\text { Intention to } \\
\text { recommend }\end{array}$} & I will recommend to my friends to subscribe to e-participation. & 0.92 & (Oliveira et \\
\hline & $\begin{array}{l}\text { If I have a good experience with e-participation I will recommend } \\
\text { friends to subscribe to the platform. }\end{array}$ & 0.89 & al., 2016) \\
\hline & $\begin{array}{l}\text { I would recommend the e-participation to someone who seeks my } \\
\text { advice. }\end{array}$ & 0.94 & $\begin{array}{l}\text { (Hoehle \& } \\
\text { Venkatesh, } \\
\text { 2015b) }\end{array}$ \\
\hline
\end{tabular}


Appendix 3.2. Exploratory factor analysis results

\begin{tabular}{|c|c|c|c|c|c|c|c|c|c|c|}
\hline & \multicolumn{10}{|c|}{ Factor } \\
\hline & 1 & 2 & 3 & 4 & 5 & 6 & 7 & 8 & 9 & 10 \\
\hline PE1 & 0.660 & 0.220 & 0.134 & 0.100 & 0.203 & 0.135 & 0.036 & 0.142 & 0.072 & 0.191 \\
\hline PE2 & 0.724 & 0.141 & 0.229 & 0.096 & 0.158 & 0.110 & 0.045 & 0.116 & 0.169 & 0.068 \\
\hline PE3 & 0.728 & 0.200 & 0.189 & 0.047 & 0.156 & 0.187 & 0.181 & 0.164 & 0.102 & 0.031 \\
\hline EE1 & 0.243 & 0.511 & 0.053 & 0.298 & 0.108 & 0.124 & 0.394 & 0.188 & -0.038 & 0.129 \\
\hline EE2 & 0.187 & 0.828 & 0.093 & 0.095 & 0.171 & 0.118 & 0.167 & -0.006 & 0.153 & 0.196 \\
\hline EE3 & 0.131 & 0.863 & 0.039 & 0.087 & 0.196 & 0.097 & 0.156 & -0.005 & 0.049 & 0.134 \\
\hline EE4 & 0.295 & 0.626 & 0.053 & 0.321 & 0.086 & 0.144 & 0.334 & 0.077 & -0.011 & 0.206 \\
\hline SI1 & 0.118 & 0.074 & 0.901 & 0.070 & 0.045 & 0.047 & 0.049 & 0.139 & 0.077 & 0.012 \\
\hline $\mathrm{SI} 2$ & 0.165 & 0.020 & 0.897 & 0.006 & 0.077 & 0.042 & 0.019 & 0.115 & 0.125 & 0.012 \\
\hline $\mathrm{SI} 3$ & 0.146 & 0.057 & 0.883 & 0.020 & 0.072 & 0.079 & 0.056 & 0.088 & 0.197 & -0.011 \\
\hline $\mathrm{FC} 1$ & 0.187 & 0.074 & 0.018 & 0.506 & 0.178 & 0.112 & 0.165 & 0.207 & -0.015 & 0.195 \\
\hline FC2 & 0.053 & 0.201 & 0.051 & 0.727 & 0.097 & 0.135 & 0.408 & 0.174 & 0.092 & 0.220 \\
\hline FC3 & 0.043 & 0.289 & 0.071 & 0.663 & 0.285 & 0.149 & 0.277 & 0.147 & -0.039 & 0.141 \\
\hline BIP1 & 0.235 & 0.233 & 0.045 & 0.169 & 0.708 & 0.187 & 0.121 & 0.104 & 0.089 & 0.159 \\
\hline BIP2 & 0.142 & 0.144 & 0.120 & 0.111 & 0.771 & 0.137 & 0.064 & 0.261 & 0.104 & 0.138 \\
\hline BIP3 & 0.180 & 0.139 & 0.081 & 0.167 & 0.806 & 0.114 & 0.115 & 0.250 & 0.060 & 0.195 \\
\hline REC1 & 0.128 & 0.144 & 0.062 & 0.121 & 0.189 & 0.734 & 0.104 & 0.191 & 0.275 & 0.142 \\
\hline REC2 & 0.194 & 0.070 & 0.056 & 0.133 & 0.088 & 0.691 & 0.247 & 0.199 & 0.098 & 0.212 \\
\hline REC3 & 0.172 & 0.192 & 0.117 & 0.116 & 0.201 & 0.772 & 0.098 & 0.134 & 0.271 & 0.211 \\
\hline COMP1 & 0.099 & 0.208 & 0.040 & 0.314 & 0.103 & 0.128 & 0.775 & 0.221 & 0.127 & 0.227 \\
\hline COMP2 & 0.088 & 0.244 & 0.068 & 0.186 & 0.106 & 0.158 & 0.807 & 0.221 & 0.123 & 0.242 \\
\hline COMP3 & 0.091 & 0.244 & 0.061 & 0.220 & 0.116 & 0.158 & 0.832 & 0.232 & 0.125 & 0.228 \\
\hline MEAN1 & 0.148 & 0.027 & 0.165 & 0.148 & 0.184 & 0.179 & 0.215 & 0.834 & 0.118 & 0.099 \\
\hline MEAN2 & 0.164 & 0.037 & 0.146 & 0.158 & 0.212 & 0.168 & 0.200 & 0.841 & 0.131 & 0.105 \\
\hline MEAN3 & 0.126 & 0.037 & 0.143 & 0.136 & 0.207 & 0.134 & 0.183 & 0.827 & 0.112 & 0.151 \\
\hline IMP1 & 0.111 & 0.025 & 0.129 & 0.034 & 0.102 & 0.163 & 0.085 & 0.119 & 0.888 & 0.126 \\
\hline IMP2 & 0.128 & 0.047 & 0.103 & 0.022 & 0.083 & 0.142 & 0.082 & 0.094 & 0.918 & 0.120 \\
\hline IMP3 & 0.045 & 0.072 & 0.174 & -0.024 & 0.016 & 0.131 & 0.073 & 0.070 & 0.805 & 0.099 \\
\hline SDET1 & 0.142 & 0.207 & 0.011 & 0.139 & 0.120 & 0.159 & 0.233 & 0.105 & 0.168 & 0.846 \\
\hline SDET2 & 0.131 & 0.116 & 0.010 & 0.168 & 0.179 & 0.169 & 0.202 & 0.149 & 0.167 & 0.790 \\
\hline SDET3 & 0.034 & 0.206 & -0.013 & 0.165 & 0.195 & 0.186 & 0.190 & 0.107 & 0.112 & 0.789 \\
\hline
\end{tabular}

Note: Factor analysis with varimax rotation. 


\section{Appendix 4.1. Measurement instrument}

\begin{tabular}{|c|c|c|c|c|}
\hline Construct & Question & Item & Loading & Source \\
\hline Facilitating & I have the resources necessary to use e-participation & FC1 & 0.81 & \multirow{11}{*}{$\begin{array}{c}\text { (Venkatesh } \\
\text { et al., } \\
\text { 2012) }\end{array}$} \\
\hline conditions & I have the knowledge necessary to use e-participation & FC2 & 0.90 & \\
\hline$(\mathrm{FC})$ & E-participation is compatible with other technology I use & FC3 & 0.86 & \\
\hline \multirow{4}{*}{ Habit (HA) } & $\begin{array}{l}\text { I can get help from others when I have difficulties using } \\
\text { e-participation }\end{array}$ & FC4 & 0.65 & \\
\hline & The use of e-participation has become a habit for me & HA1 & 0.88 & \\
\hline & I am addicted to using e-participation & HA2 & 0.72 & \\
\hline & I must use e-participation & HA3 & 0.77 & \\
\hline \multirow{4}{*}{$\begin{array}{l}\text { Technology } \\
\text { use (USE) }\end{array}$} & Search for information on the web portal & USE1 & 0.84 & \\
\hline & Proposal submission & USE2 & 0.73 & \\
\hline & Share or comment on the projects on the social networks & USE3 & 0.73 & \\
\hline & Electronic voting of the projects & USE4 & 0.80 & \\
\hline \multirow{8}{*}{$\begin{array}{l}\text { Continuous } \\
\text { intention to } \\
\text { use (CIU) }\end{array}$} & I intend to continue using e-participation in the future & CIU1 & 0.96 & \multirow{3}{*}{$\begin{array}{l}\text { (Hsu et al., } \\
\text { 2006) }\end{array}$} \\
\hline & I will continue using e-participation in the future & CIU2 & 0.97 & \\
\hline & I will regularly use e-participation in the future & CIU3 & 0.93 & \\
\hline & Immersion (IMM) & & & \multirow{12}{*}{$\begin{array}{c}\text { (Koh \& } \\
\text { Kim, 2003) }\end{array}$} \\
\hline & $\begin{array}{l}\text { I spend much time on-line in my e-participation } \\
\text { community. }\end{array}$ & IMM1 & 0.94 & \\
\hline & $\begin{array}{l}\text { I spend more time than I expected navigating my e- } \\
\text { participation community. }\end{array}$ & IMM2 & 0.93 & \\
\hline & $\begin{array}{l}\text { I feel as if I am addicted to my e-participation } \\
\text { community. }\end{array}$ & IMM3 & 0.90 & \\
\hline & Influence (INF) & & & \\
\hline \multirow[t]{7}{*}{ SOVC } & $\begin{array}{l}\text { I am well known as a member of my e-participation } \\
\text { community. }\end{array}$ & INF1 & 0.92 & \\
\hline & I feel that I control the e-participation community & INF2 & 0.92 & \\
\hline & $\begin{array}{l}\text { My activities on e-participation are often reviewed by } \\
\text { other members. }\end{array}$ & INF3 & 0.89 & \\
\hline & Membership (MEM) & & & \\
\hline & I feel as if I belong to my e-participation community & MEM1 & 0.71 & \\
\hline & $\begin{array}{l}\text { I feel as if my e-participation community members are } \\
\text { my close friends }\end{array}$ & MEM2 & 0.90 & \\
\hline & I like my e-participation community members. & MEM3 & 0.91 & \\
\hline
\end{tabular}




\section{Appendix 5.1. Measurement instrument}

\begin{tabular}{|c|c|c|}
\hline \multicolumn{2}{|l|}{ Construct } & $\begin{array}{l}\text { Item } \\
\text { I have mastered the skills necessary for using the e- } \\
\text { participation. }\end{array}$ \\
\hline \multirow[t]{5}{*}{ 2014) } & Competence (COM) & $\begin{array}{l}\text { I have mastered the skills necessary for using the e- } \\
\text { participation. } \\
\text { I am self-assured about my capabilities to use the e- } \\
\text { participation. } \\
\text { I am confident about my ability to use the e- } \\
\text { participation. }\end{array}$ \\
\hline & Impact (IMP) & $\begin{array}{l}\text { Based on e-participation usage, my impact on what } \\
\text { happens at community is large. } \\
\text { Based on e-participation usage, I have significant } \\
\text { influence over what happens at community. } \\
\text { Based on e-participation usage, I have a great deal of } \\
\text { control over what happens at community. }\end{array}$ \\
\hline & Meaning (MEA) & $\begin{array}{l}\text { The e-participation I use is very important to me. } \\
\text { The e-participation I use is meaningful to me. } \\
\text { My e-participation activities are personally } \\
\text { meaningful to me. }\end{array}$ \\
\hline & $\begin{array}{l}\text { Self-Determination } \\
\text { (SDET) }\end{array}$ & $\begin{array}{l}\text { I have significant autonomy in determining how I use } \\
\text { the e-participation }\end{array}$ \\
\hline & & $\begin{array}{l}\text { I have considerable opportunity for independence } \\
\text { and freedom in how I use the e-participation } \\
\text { I can decide on my own how to go about using the e- } \\
\text { participation }\end{array}$ \\
\hline \multicolumn{2}{|c|}{ Habit (HA) (Venkatesh et al., 2012) } & $\begin{array}{l}\text { The use of e-participation has become a habit for me } \\
\text { I am addicted to using e-participation } \\
\text { I must use e-participation }\end{array}$ \\
\hline \multicolumn{2}{|c|}{$\begin{array}{l}\text { Continued intention to use (CIU) (Hsu et al., } \\
\text { 2006) }\end{array}$} & $\begin{array}{l}\text { I intend to continue using e-participation in the } \\
\text { future } \\
\text { I will continue using e-participation in the future } \\
\text { I will regularly use e-participation in the future }\end{array}$ \\
\hline
\end{tabular}




\section{Appendix 7.1. Theoretical support for relationship between numbers in Figure \\ 7.1}

\begin{tabular}{|c|c|c|}
\hline Relationship & Statement & Source \\
\hline 1 & $\begin{array}{l}\text { "Such attachment (attachment to place) motivated interviewees } \\
\text { to participate in campaigns against developments that they } \\
\text { perceived would threaten these place-based values." }\end{array}$ & $\begin{array}{l}\text { (Lin \& Lockwood, } \\
2014, \text { p. } 80 \text { ) }\end{array}$ \\
\hline 2 & $\begin{array}{l}\text { "It was therefore predicted that people who protested would } \\
\text { have higher levels of place attachment; a prediction confirmed } \\
\text { by the significant correlations between protesting and both place } \\
\text { identity and place dependence in this study." }\end{array}$ & $\begin{array}{l}\text { (Anton \& } \\
\text { Lawrence, 2016, } \\
\text { p. 151) }\end{array}$ \\
\hline 3 & $\begin{array}{l}\text { "From this we can conclude that while people with strong place } \\
\text { attachment [...] it is those who also have positive attitudes about } \\
\text { the value and importance of pro-testing, who perceive civic } \\
\text { action as the norm amongst their friends and family, and who } \\
\text { perceive that they have control over their actions that may be } \\
\text { more likely to actively oppose place change." }\end{array}$ & $\begin{array}{l}\text { (Anton \& } \\
\text { Lawrence, 2016) }\end{array}$ \\
\hline 4 & $\begin{array}{l}\text { "Specifically, people who were more attached to a place were } \\
\text { more likely to express behavioral intentions to engage in place- } \\
\text { based planning actions". }\end{array}$ & $\begin{array}{l}\text { (Kil, Holland, \& } \\
\text { Stein, 2014, p. } \\
\text { 486) }\end{array}$ \\
\hline 5 & $\begin{array}{l}\text { "Although, people participation is affected by civic engagement, } \\
\text { but people participation also plays a crucial role in promoting } \\
\text { civic engagement, [...]" }\end{array}$ & $\begin{array}{l}\text { (Mohammadi, } \\
\text { Norazizan, \& } \\
\text { Shahvandi, 2011) }\end{array}$ \\
\hline 6 & $\begin{array}{l}\text { "individual social capital was the consistent and significant } \\
\text { predictor of both expressive and instrumental civic actions." }\end{array}$ & (Son \& Lin, 2008) \\
\hline 7 & $\begin{array}{l}\text { "As the model reported here shows, it is neighborhood ties and } \\
\text { not place attachment that predicted civic involvement." }\end{array}$ & (Lewicka, 2005) \\
\hline 8 & $\begin{array}{l}\text { "civic virtue is most powerful when embedded in a dense } \\
\text { network or reciprocal social relations" }\end{array}$ & (Putnam, 2000) \\
\hline 9 & $\begin{array}{l}\text { "Both community attachment and park related place } \\
\text { attachment played a role in predicting citizensO levels of pro- } \\
\text { environmental civic engagement beliefs." }\end{array}$ & (Buta et al., 2014) \\
\hline 10 & $\begin{array}{l}\text { "the connections among individuals such that, over time, a social } \\
\text { network is created in which people come to expect mutual } \\
\text { support and trust. This leads to: (a) potential increases in each } \\
\text { individual's physical health and social-emotional well-being, as } \\
\text { well as (b) potential increases in civic engagement and } \\
\text { employment in the community of which they are a part, both } \\
\text { contributing to a healthier and more effectively functioning } \\
\text { society." }\end{array}$ & $\begin{array}{l}\text { (Hunter, 2016, p. } \\
\text { 200) }\end{array}$ \\
\hline 11 & $\begin{array}{l}\text { "According to the structural model, the influence of place } \\
\text { meanings on participatory planning intentions was significant. } \\
\text { Specifically, people who were more attached to a place were } \\
\text { more likely to express behavioral intentions to engage in place- } \\
\text { based planning actions." }\end{array}$ & (Kil et al., 2014) \\
\hline
\end{tabular}




\section{Appendix 7.2. Questions from the web map-based application}

\begin{tabular}{|c|c|c|c|}
\hline Construct & Question & Loading & Adapted from \\
\hline \multirow{12}{*}{$\begin{array}{l}\text { Sense of } \\
\text { place (SoP) }\end{array}$} & Place attachment & & \multirow{12}{*}{$\begin{array}{l}\text { (Jorgensen \& } \\
\text { Stedman, 2001) }\end{array}$} \\
\hline & I feel relaxed when I'm at this area $(\mathrm{Y})$ & 0.90 & \\
\hline & I feel happiest when I'm at this area $(Y)$ & 0.93 & \\
\hline & This area $(\mathrm{Y})$ is my favourite place to be & 0.87 & \\
\hline & Place dependence & & \\
\hline & This area $(\mathrm{Y})$ is the best place for doing the things that I enjoy most & 0.93 & \\
\hline & $\begin{array}{l}\text { For doing the things that I enjoy most, no other place can compare } \\
\text { to this area }(\mathrm{Y}) \text {. }\end{array}$ & 0.82 & \\
\hline & This area $(\mathrm{Y})$ is a good place to do the things I most like to do & 0.89 & \\
\hline & Place identity & & \\
\hline & Everything about this area $(\mathrm{Y})$ is a reflection of me & 0.82 & \\
\hline & I feel that I can really be myself at this area $(\mathrm{Y})$ & 0.91 & \\
\hline & This area $(\mathrm{Y})$ reflects the type of person I am & 0.92 & \\
\hline \multirow{16}{*}{$\begin{array}{l}\text { Social capital } \\
\text { (SC) }\end{array}$} & $\underline{\text { Sense of community }}$ & & \multirow{4}{*}{$\begin{array}{l}\text { (Peterson et al., } \\
\text { 2008) }\end{array}$} \\
\hline & I feel like a member of the group $Y$ & 0.95 & \\
\hline & I belong to the group $Y$ & 0.96 & \\
\hline & I feel connected to the group Y & 0.93 & \\
\hline & Collective efficacy/Empowerment & & \multirow{5}{*}{$\begin{array}{c}\text { (van Zomeren, } \\
\text { Postmes, \& Spears, } \\
\text { 2008) } \\
\text { (Perkins \& Long, } \\
\text { 2002) }\end{array}$} \\
\hline & $\begin{array}{l}\text { I think that a collective action from this group }(\mathrm{Y}) \text { will increase } \\
\text { chances of the local government changing their plans }\end{array}$ & 0.91 & \\
\hline & I think that together (group $(\mathrm{Y})$ members) we can change an issue & 0.91 & \\
\hline & $\begin{array}{l}\text { I think that it is important to get people in the group }(\mathrm{Y}) \text { to help } \\
\text { each other more }\end{array}$ & 0.78 & \\
\hline & Citizen participation & & \\
\hline & Have you attended a group $(\mathrm{Y})$ meeting in the last 12 months? & 0.91 & \multirow{3}{*}{$\begin{array}{c}\text { (Grootaert, } \\
\text { Narayan, Jones, \& } \\
\text { Woolcock, 2004) }\end{array}$} \\
\hline & $\begin{array}{l}\text { How often do you participate in the activities of the group }(\mathrm{Y}) \text { in } \\
\text { the last } 12 \text { months? }\end{array}$ & 0.88 & \\
\hline & $\begin{array}{l}\text { To what extent did you participate in group }(\mathrm{Y}) \text { decision-making in } \\
\text { the last } 12 \text { months? }\end{array}$ & 0.89 & \\
\hline & Neighbouring & & \multirow{4}{*}{$\begin{array}{l}\text { (Perkins \& Long, } \\
\text { 2002) }\end{array}$} \\
\hline & Help a group $(\mathrm{Y})$ member in an emergency & 0.88 & \\
\hline & Offer an advice on a personal problem of a group $(\mathrm{Y})$ member & 0.91 & \\
\hline & Discuss a problem with a group $(\mathrm{Y})$ member & 0.92 & \\
\hline \multirow{5}{*}{$\begin{array}{l}\text { Civic } \\
\text { engagement } \\
\text { (CE) }\end{array}$} & In the last 12 months, have you joined together with other people & & \multirow{5}{*}{$\begin{array}{l}\text { (Grootaert et al., } \\
\text { 2004) }\end{array}$} \\
\hline & to address a community, local authority or governmental & 0.93 & \\
\hline & organization problems? & & \\
\hline & $\begin{array}{l}\text { In the last } 12 \text { months, have you talked with a community, local } \\
\text { authority, or governmental organization about common problems? }\end{array}$ & 0.93 & \\
\hline & $\begin{array}{l}\text { In the last } 12 \text { months, have you worked with a community, local } \\
\text { authority, or governmental organization about common problems? }\end{array}$ & 0.93 & \\
\hline
\end{tabular}





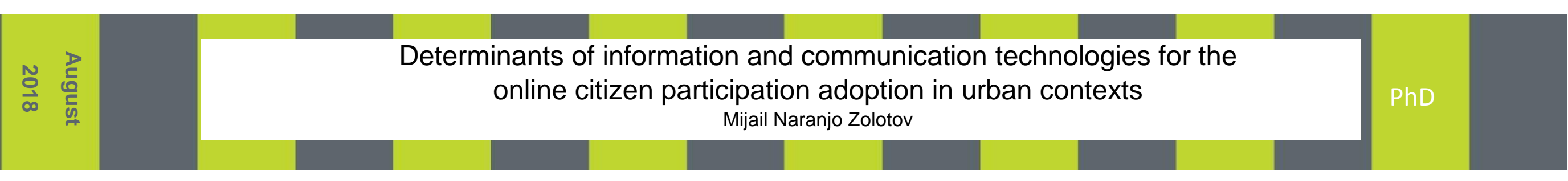

